\title{
IDENTIFICATION OF ACTIVE AGENTS FOR TETRACHLOROETHYLENE DEGRADATION IN PORTLAND CEMENT SLURRY CONTAINING FERROUS IRON
}

\author{
A Dissertation \\ by \\ SAE BOM KO

\begin{abstract}
Submitted to the Office of Graduate Studies of Texas A\&M University

in partial fulfillment of the requirements for the degree of

DOCTOR OF PHILOSOPHY
\end{abstract}

May 2005

Major Subject: Civil Engineering 


\title{
IDENTIFICATION OF ACTIVE AGENTS FOR TETRACHLOROETHYLENE DEGRADATION IN PORTLAND CEMENT SLURRY CONTAINING FERROUS IRON
}

\author{
A Dissertation \\ by \\ SAE BOM KO \\ Submitted to Texas A\&M University \\ in partial fulfillment of the requirements \\ for the degree of \\ DOCTOR OF PHILOSOPHY
}

Approved as to style and content by:

Bill Batchelor

(Chair of Committee)

Jennifer T. McGuire

(Member)
Timothy Kramer

(Member)

Bruce E. Herbert

(Member)

David V. Rosowsky

(Head of Department)

May 2005

Major Subject: Civil Engineering 


\begin{abstract}
Identification of Active Agents for Tetrachloroethylene Degradation in Portland Cement Slurry Containing Ferrous Iron. (May 2005)

Sae Bom Ko, B.S., Dongguk University; M.S., Texas A\&M University

Chair of Advisory Committee: Dr. Bill Batchelor
\end{abstract}

$\mathrm{Fe}(\mathrm{II})$-based degradative solidification/stabilization (Fe(II)-DS/S) technology is the modification of conventional solidification/stabilization $(\mathrm{S} / \mathrm{S})$. Inorganic pollutants are immobilized by $\mathrm{Fe}(\mathrm{II})-\mathrm{DS} / \mathrm{S}$ while organic pollutants are destroyed. Experimental studies were conducted to identify the active agents for Tetrachloroethylene (PCE) degradation as well as the conditions that enhance the formation of the active agents in the Fe(II)-DS/S system. PCE was chosen as a model chlorinated aliphatic hydrocarbon in this study.

First, the conditions that lead to maximizing production of the active agents were identified by measuring the ability of various chemical mixtures to degrade PCE. Results showed that $\mathrm{Fe}(\mathrm{II}), \mathrm{Fe}(\mathrm{III}), \mathrm{Ca}$, and $\mathrm{Cl}$ were the the important elements that affect degradation activity. Elemental compositions of the mixtures and the conditions affecting solid formation might be the important factors in determining how active solids are formed. 
Second, instrumental analyses (XRD, SEM, SEM-EDS) were used to identify minerals in chemical mixtures that have high activities. Results indicate that active agents for PCE degradation in Portland cement slurries and in cement extracts might be one of several AFm phases. However, systems without cement did not form the same solids as those with cement or cement extract. Ferrous hydroxide was identified as a major solid phase formed in systems without cement.

Finally, the effect of using different types of ordinary Portland cement (OPC) on PCE degradation rate during Fe(II)-DS/S was examined and the solids were examined by instrumental analyses (XRD, SEM, SEM-EDS). Four different OPC (Txi, Lehigh, Quikrete, and Capitol) showed different PCE degradation behaviors. Pseudo first-order kinetics was observed for Capitol and Txi OPC and second-order kinetics was observed for Quikrete. In the case of Lehigh cement, pseudo first-order kinetics was observed in cement slurry and second-order kinetics in cement extract. Calcium aluminum hydroxide hydrates dominated solids made with Txi, Quikrete, and Lehigh cements and Friedel's salt was the major phase found in solids made with Capitol cements. Fe tended to be associated with hexagonal thin plate particles, which were supposed to be a LDH. 
To the memory of my grandfather (1921-2002) 


\section{ACKNOWLEDGEMENTS}

I am deeply indebted to my committee chair, Dr. Batchelor, for his support and encouragement for the past 7 years. His ability to approach the problem and develop the solution is truly my inspiration. I can not imagine how I became myself today without him. He always showed me a much wider vision on research and guided me in the right direction whenever I struggled and was lost. I can explore the ideas and deepen the works because of him. He also led me to be a true scientist. Thanks also to Dr. Herbert who has been very kind and generous to me. He always opened the door and listened to all my questions, even stupid and nonsense ones. His advice helped me a lot from the beginning stage of this research. I want to give an appreciation to Dr. Kramer and Dr. McGuire from the bottom of my heart. They encouraged me all the time and provided constructive suggestions and guidance.

Thanks to the Texas Transportation Institute and Geology Department at Texas A\&M University for the use of the Rigu automatic X-ray diffract meter and Microscopy and Image center at Texas A\&M University for the use of JEOL 6400 Scanning Microscope.

Besides all my committee members, I also really appreciate my lab colleagues, Jungyeon Choi, Bangmi Jung, Jinkun Song, Sihyun Doh, Eunjung Kim, and Ahmed Abdel-Wahab, for their opinions on the research as well as for their friendship.

Special thanks go to my grandparents and parents for their endless prayers and love. I would be unable to finish the Ph.D program successfully unless they supported me. I 
won't forget their consistent devotion. Even though my grandfather can not share this pleasant moment right now, I believe that he would be proud of me and be happy in heaven. 


\section{TABLE OF CONTENTS}

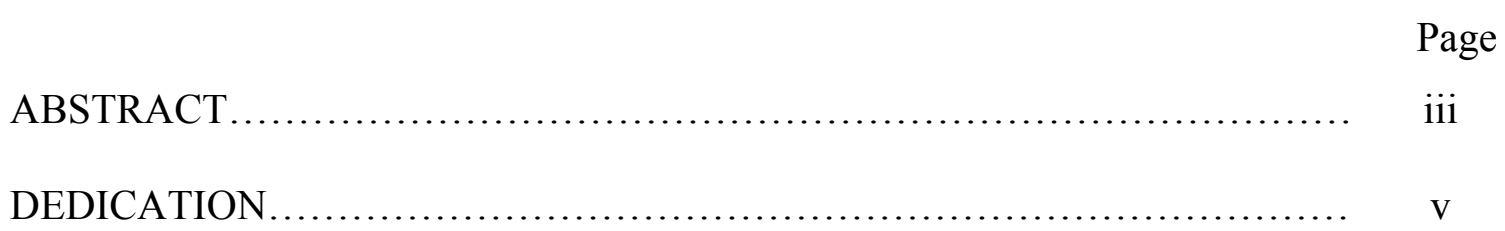

ACKNOWLEDGEMENTS........................................... vi

TABLE OF CONTENTS ............................................ viii

LIST OF FIGURES.............................................. xi

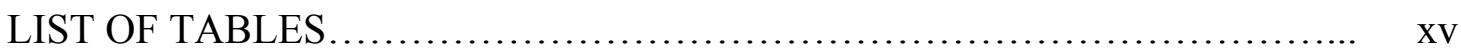

CHAPTER

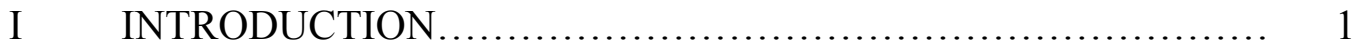

II $\quad$ BACKGROUND................................................... 5

2.1 Cement hydration products and layered double hydroxides

(LDHs)

2.1.1 Portland cement: General

2.1.2 Cement hydration products and layered double hydroxides.......................................... 6

2.1.3 Morphology of cement hydration products and LDHs...... 12

2.2 Reductive dechlorination...................................... 17

2.2.1 Biotic reductive dechlorination.......................... 17

2.2.2 Abiotic reductive dechlorination...................... 23

2.2.2.1 Fe(II)-based degradative solidification and stabilization.................................... 25

2.2.2.2 Iron and sulfide minerals....................... 28

2.2.2.3 Zero-valent metals and permeable reactive barriers..................................... 30

2.3 X-ray diffraction........................................... 34

2.4 Electron microscopy..................................... 37

III METHODOLOGY........................................ 42

3.1 Materials .................................................. 42

3.2 Analytical procedures................................... 43

3.3 Experiment procedures.................................. 44 
3.3.1 Reactor system....................................... 44

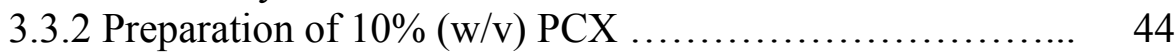

3.3.3 Identification of conditions that promote formation of the active agents......................................... 45

3.3.3.1 Ca effect.................................. 45

3.3.3.2 Effect of cement hydration product............... 47

3.3.3.3 Effect of synthetic cement extract (SCX)......... 48

3.3.3.4 Effect of major cement extract element........... 50

3.3.4 Identification of the active agents through instrumental analyses(XRD, SEM and SEM-EDS) .................. 53

3.3.5 Examination of variability of Ordinary Portland Cement

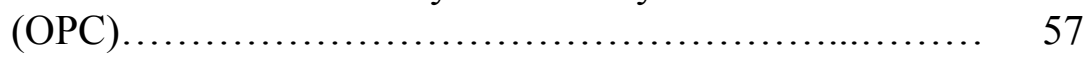

IV RESULTS AND DISCUSSION ............................... 58

4.1 Identification of conditions that promote formation of the active agents through solid activity tests............................. 58

4.1.1 Evaluation of kinetic constants.......................... 58

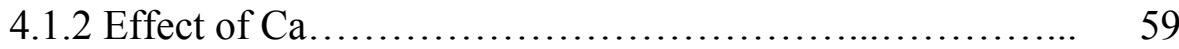

4.1.3 Effect of cement hydration products....................... 67

4.1.4 Effect of synthetic cement extract......................... 71

4.1.5 Effect of major element of cement extract.................. 73

4.1.5.1 Simple mixing method.......................... 73

4.1.5.2 Adaptation of GR synthesis method............... $\quad 79$

4.2 Identification of the active agents through instrumental analyses. $\quad 90$

4.2.1 10\% Portland cement slurry (10\% PCS) ..................... 90

4.2.2 10\% Portland cement extract (10\% PCX) .................. 99

4.2.3 Synthetic cement extract (SCX).......................... 106

4.2.3.1 Full synthetic cement extract (FSCX)............. 106

4.2.3.2 Minor synthetic cement extract (MSCX).......... 108

4.2.3.3 Fe(II)(III)Cl................................ 111

4.3 Examination of variability of ordinary Portland cement (OPC).. $\quad 120$

4.3.1 PCE degradation kinetic tests.......................... 120

4.3.1.1 10\% cement slurry solids with Fe(II)............. 120

4.3.1.2 $10 \%$ cement extract solids with Fe(II) ............. 125

4.3.2 Instrumental analyses: XRD, SEM, and EDS............. 131

4.3.2.1 10\% cement slurry solids......................... 131

4.3.2.2 10\% cement extract solids...................... 139

V SUMMARY AND CONCLUSION ............................. 151 


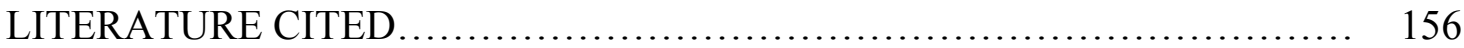

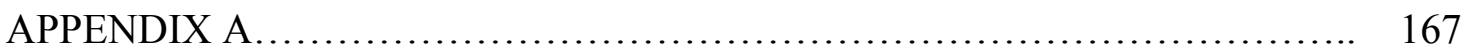

APPENDIX B..................................................... 179

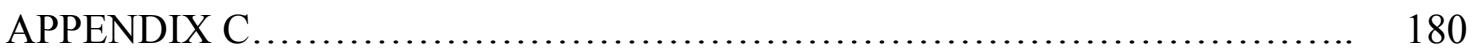

VITA............................................................ 181 


\section{LIST OF FIGURES}

Page

FIGURE 2-1 Schematic X-ray diffractogram of Portland cement paste........ 9

FIGURE 2-2 Schematic representation of a LDH structure................. 10

FIGURE 2-3 SEM image shows hexagonal shape of calcium hydroxide, needle-like Ettringite, and sheet-like calcium silicate hydrates....

FIGURE 2-4 SEM image of hexagonal Friedel's salt and Ettringite needles.................................................... 14

FIGURE 2-5 SEM images and EDS spectra of electrodeposited GR......... 15

FIGURE 2-6 SEM micrographs of CuLDH............................. 16

FIGURE 2-7 Reductive dechlorination pathway of PCE................... 17

FIGURE 2-8 Schematic sequential bioremediation processes................ 20

FIGURE 2-9 Schematic diagrams of (A) biobarrier and (B) the trench system 22

FIGURE 2-10 Hypothesized reaction pathways for the chlorinated ethylenes and other intermediates during reduction by $\mathrm{Fe}(0) \ldots \ldots \ldots \ldots \ldots .24$

FIGURE 2-11 Dependence of initial degradation rates on initial substrate concentration

FIGURE 2-12 The reaction and schematic diagrams of pyrite formation......... 28

FIGURE 2-13 Scheme showing proposed pathways for reductive dehalogenation in anoxic $\mathrm{Fe}^{0}-\mathrm{H}_{2} \mathrm{O}$ systems......................

FIGURE 2-14 X-ray spectra....................................... 36

FIGURE 2-15 Types of signals resulting from the interaction of an electron beam with a sample.

FIGURE 2-16 Schematic of SEM showing the electron column, the deflection system and the electron detectors. 
FIGURE 3-1 Schematic diagram of method of synthesizing solids to examine effect of calcium.

FIGURE 3-2 Two layers of solids after centrifugation of $\mathrm{Fe}(\mathrm{II})$ containing PCS solids

FIGURE 4-1 The variation of normalized pseudo first-order rate constants with respect to CPCX contents............................ 64

FIGURE 4-2 The variation of normalized pseudo first-order rate constants with respect to PCX contents................................ 65

FIGURE 4-3 The effect of $\mathrm{pH}$ on pseudo first-order rate constants normalized with $\mathrm{Fe}(\mathrm{II})$ concentration $\left(\mathrm{k}_{\mathrm{Fe}(\mathrm{II})}\right) \ldots \ldots \ldots \ldots \ldots \ldots \ldots .66$

FIGURE 4-4 X-ray patterns of 10\% Capitol cement slurry................. 92

FIGURE 4-5 The first SEM image and EDS of Capitol cement slurry without

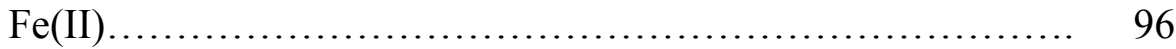

FIGURE 4-6 The second SEM image and EDS of Capitol cement slurry 97 without $\mathrm{Fe}(\mathrm{II}) \ldots$...

FIGURE 4-7 SEM image and EDS of Capitol cement slurry with Fe(II)........ 98

FIGURE 4-8 X-ray patterns of $10 \%$ Capitol cement extract................... 101

FIGURE 4-9 SEM image and EDS of Capitol cement extract without Fe(II)... 104

FIGURE 4-10 SEM image and EDS of Capitol cement extract with Fe(II).... 105

FIGURE 4-11 XRD patterns of FSCXFe solids ........................ 106

FIGURE 4-12 SEM image and EDS of full synthetic cement extract with

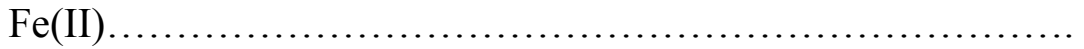

FIGURE 4-13 XRD pattern and mineral identification using software program, JADE, of MSCXFe solids

FIGURE 4-14 SEM image and EDS of minor elements synthetic cement extract with $\mathrm{Fe}$ (II). 
FIGURE 4-15 XRD pattern and mineral identification using software program, JADE, of $\mathrm{Fe}(\mathrm{II})(\mathrm{III}) \mathrm{Cl}$ solids

FIGURE 4-16 SEM image and EDS of Fe(II)(III)Cl_Simple Mixing............

FIGURE 4-17 SEM image and EDS of Fe(II)(III)Cl_GR12................ 118

FIGURE 4-18 SEM image and EDS of Fe(II)(III)Cl_GRN................. 119

FIGURE 4-19 Kinetics of PCE reduction by slurries prepared with Fe(II) and $10 \%$ Quikrete cement, QPCSFe.

FIGURE 4-20 Kinetics of PCE reduction by slurries prepared with Fe(II) and $10 \%$ Lehigh and Txi cement, LPCSFe and TPCSFe, respectively.

FIGURE 4-21 Kinetics of PCE reduction by extracts prepared with Fe(II) and $10 \%$ Txi cement, TPCXFe.

FIGURE 4-22 Kinetics of PCE reduction by extracts prepared with $\mathrm{Fe}(\mathrm{II})$ and 10\% Lehigh and Quikrete cement, LPCXFe and QPCXFe, respectively.

FIGURE 4-23 XRD patterns of solids prepared with Fe(II) and 10\% Portland cement

FIGURE 4-24 SEM image and EDS of solids prepared with Fe(II) and 10\% Txi cement.

FIGURE 4-25 SEM image and EDS of solids prepared with Fe(II) and 10\% Quikrete cement

FIGURE 4-26 SEM image and EDS of solids prepared with Fe(II) and 10\% Lehigh cement

FIGURE 4-27 X-ray diffractograms of solids prepared with 10\% Portland cement extracts without $\mathrm{Fe}(\mathrm{II})$.

FIGURE 4-28 X-ray diffractograms of solids prepared with $\mathrm{Fe}(\mathrm{II})$ and 10\% Portland cement extracts prepared from cements made by Txi (TPCXFe), Quikrete (QPCXFe), and Lehigh (LPCXFe) 
FIGURE 4-29 SEM image and EDS of solids prepared with Fe(II) and 10\% Txi cement extract............................................

FIGURE 4-30 The first SEM image and EDS of solids prepared with Fe(II) and $10 \%$ Quikrete cement extract.......................... 146

FIGURE 4-31 The second SEM image and EDS of solids prepared with Fe(II) and $10 \%$ Quikrete cement extract.............................

FIGURE 4-32 The first SEM image and EDS of solids prepared with Fe(II) and $10 \%$ Lehigh cement extract............................

FIGURE 4-33 The second SEM image and EDS of solids prepared with Fe(II) and $10 \%$ Lehigh cement extract............................ 


\section{LIST OF TABLES}

Page

TABLE 2-1 Hydration reactions for Portland cement mineral phases........ 8

TABLE 2-2 Catabolic $\mathrm{H}_{2}$-releasing reactions of biotic reductive

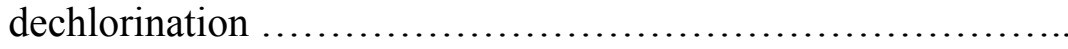

TABLE 2-3 X-ray wavelengths and suitable filters to give $\mathrm{K}_{\beta 1} / \mathrm{K}_{\alpha 1}=1 / 100 \ldots \quad 36$

TABLE 3-1 The procedure to examine the effect of cement hydration product...................................................

TABLE 3-2 Stock solution of each element consisting in SCX and element composition of SCX in each experiment.......................

TABLE 3-3 Different element compositions for the simple mixing method in which solids were synthesized from major element of PCX...

TABLE 3-4 Different element compositions and element addition orders for the GR synthesis method in which solids were synthesized from major element of PCX.....................................

TABLE 3-5 Solids to be analyzed by XRD and SEM with EDS............ 56

TABLE 4-1 Pseudo first-order rate constants for PCE reduction by Fe(II)-

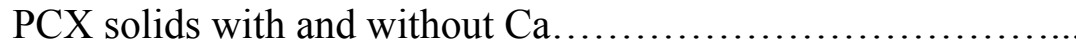

TABLE 4-2 Iron and solid concentrations in different cement extract contents of 24 hour-mixed CPCX solid II and Fe(II)-PCX solid

TABLE 4-3 Pseudo first-order rate constants for PCE reduction by cement hydration products (tetracalcium aluminate, Friedel's salt, and Kuzel's salt) by themselves, with Fe(II) and with both Fe(II) and $\mathrm{Fe}(\mathrm{III})$

TABLE 4-4 Pseudo first-order rate constants of PCE reduction by various kind of synthetic cement extracts

TABLE 4-5 Pseudo first-order rate constants of PCE reduction by solids composed of major elements of cement extract................. 
TABLE 4-6 Iron and solid concentrations of solids containing $\mathrm{Fe}(\mathrm{II})$, $\mathrm{Fe}(\mathrm{III})$, and $\mathrm{Cl}$ with different initial $\mathrm{Fe}(\mathrm{III})$ concentration.........

TABLE 4-7 Pseudo first-order rate constants of PCE reduction by solids $\mathrm{Fe}(\mathrm{II}), \mathrm{Fe}(\mathrm{III})$, and $\mathrm{Cl}$ with different initial $\mathrm{Fe}(\mathrm{III})$ concentrations............................................

TABLE 4-8 Pseudo first-order rate constants of PCE reduction by solids containing $\mathrm{Fe}(\mathrm{II}), \mathrm{Fe}(\mathrm{III})$, and $\mathrm{Cl}$ with different solid synthesis mixing time.

TABLE 4-9 Pseudo first-order rate constants of PCE reduction by solids containing $\mathrm{Fe}(\mathrm{II}), \mathrm{Fe}(\mathrm{III})$, and $\mathrm{Cl}$ synthesized by GR synthesis method

TABLE 4-10 Pseudo first-order rate constants of PCE reduction by solids containing $\mathrm{Fe}(\mathrm{II}), \mathrm{Fe}(\mathrm{III}), \mathrm{Cl}$, and $\mathrm{Mg}$ synthesized by GR synthesis method....

TABLE 4-11 Pseudo first-order rate constants of PCE reduction by solids containing $\mathrm{Fe}(\mathrm{II}), \mathrm{Fe}(\mathrm{III}), \mathrm{Cl}$, and $\mathrm{SO}_{4}$ synthesized by $\mathrm{GR}$ synthesis method.

TABLE 4-12 Pseudo first-order rate constants of PCE reduction by solids containing $\mathrm{Fe}(\mathrm{II}), \mathrm{Fe}(\mathrm{III}), \mathrm{Cl}$, and $\mathrm{SiO}_{3}$ synthesized by GR synthesis method.

TABLE 4-13 The Fe(II) concentration normalized first and second order rate constants for PCE degradation in various slurries made with $\mathrm{Fe}(\mathrm{II})$ and $10 \%$ cement.

TABLE 4-14 The Fe(II) concentration normalized first and second order rate constants for PCE degradation in various Fe(II) containing 10\% cement extracts

TABLE 4-15 The comparison of $d$-spacing values of $10 \%$ cement slurry solids, unit $=\AA$

TABLE 4-16 Corresponding d-spacing values of peaks in Figure 4-27 and comparison to CPCX, unit $=\AA$ 
TABLE 4-17 Corresponding d-spacing values of peaks in Figure 4-28 and

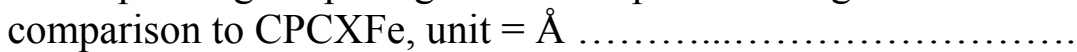




\section{CHAPTER I}

\section{INTRODUCTION}

In 1980, US Congress promulgated the Comprehensive Environmental Response, Compensation and Liabilities Act (CERCLA) to regulate hazardous waste at both active and properly closed facilities. The main purpose of CERCLA is to clean up hazardous waste sites and it establishes the term of "Superfund", which refers to both the law and the cleanup program mandated under the law. An essential element in CERCLA is the fund established with the tax revenue that can be used to fund cleanup when the responsible parties are unable to do so or are not able to be identified. The Superfund Amendments and Reauthorization Act (SARA) in 1986 was an extension and modification of CERCLA. Under CERCLA, EPA is authorized to take any necessary actions whenever any hazardous substance is actually or potentially released into the environment and wherever an imminent and substantial danger to public health by any actually or potentially released pollutant or contaminant. However, these actions by EPA may be implanted only at sites on the National Priority List (NPL), which identifies the most dangerous hazardous waste sites that are eligible for remedial cleanup under Superfund (1).

Among 1,430 former or current NPL sites, tetrachloroethylene (perchloroethene, PCE) has been found in at least 771 of them (2). According to EPA, the exact number of

This dissertation follows the style of Environmental Science and Technology. 
NPL sites contaminated by this substance is not known. PCE is a synthetic chemical that is widely used for dry cleaning of fabrics and for metal degreasing. It is also used to make other chemicals and is used in some consumer products, such as water repellents, silicone lubricants, fabric finishers, spot removers, adhesives, and wood cleaners. Exposure to very high concentrations of PCE can cause dizziness, headaches, sleepiness, nausea, unconsciousness, etc. Moreover, the International Agency for Research on Cancer (IARC) has determined that PCE is probably carcinogenic to humans (3).

Conventional remediation technologies, such as bioremediation, soil vapor extraction, incineration, passive/reactive treatment wells, advanced oxidation processes, or activated carbon sorption, have been applied to remediate sites contaminated by PCE and other chlorinated organic compounds (4). However, these technologies have not worked well in destroying it, because PCE is very resistant to both biotic and abiotic degradation under aerobic conditions (5-7).

PCE and other chlorinated aliphatic compounds are suspected to undergo reductive dechlorination under anoxic conditions $(8,9)$. These transformations are caused by both microbial activities and abiotic geochemical reactions that usually involve inorganic Fe(II) or sulfide (10-12). Reductive dechlorination of PCE and other chlorinated aliphatic compounds has been investigated by many researchers. Intensive research related to abiotic reductive dechlorination of chlorinated aliphatic compounds has included investigations of zero-valent metals (13-24), Fe(II) in combination with Portland cement (23-25), and iron and sulfide minerals (10,11,26-40). 
Fe(II)-based degradative solidification/stabilization (Fe(II)-DS/S) technology has been recently developed (23). DS/S is the modification of conventional solidification/stabilization $(\mathrm{S} / \mathrm{S})$, which has been an important part of environmental technology at superfund sites in the United States since the passage of hazardous waste control acts (23). The reductive degradation of PCE is enhanced in Fe(II)-DS/S at high $\mathrm{pH}$. Unfortunately, the active reductant for reductive degradation of PCE in Fe(II)-DS/S has not been identified.

The principal goal of this research was to identify the active agents for PCE degradation as well as the conditions that enhance the formation of the active agents in the $\mathrm{Fe}(\mathrm{II})-\mathrm{DS} / \mathrm{S}$ system.

Three objectives were pursued to achieve this research goal. First, conditions that lead to maximizing production of the active agents were identified by measuring the ability of various chemical mixtures to degrade PCE. To achieve this objective, various kinds of solids were synthesized including solids synthesized from Portland Cement Extract (PCX) that has been treated to remove calcium, cement hydration products, solids produced from synthesized cement extract (SCX), and solids prepared with addition of major cement extract elements. These activities were compared to ones for $\mathrm{Fe}(\mathrm{II})-\mathrm{DS} / \mathrm{S}$, i.e. mixtures of Fe(II) and Portland cement.

Second, instrumental analyses were used to identify compounds in chemical mixtures that have high activities. Analyses to be used include X-Ray Diffraction (XRD), Scanning Electron Microscopy (SEM), and SEM with Electron-Dispersive Spectrometry (SEM-EDS). Solids to be analyzed by these methods were chosen to be 
those with more rapid PCE degradation as measured in experiments associated with the first objectives.

Third, the variability of PCE degradation rate by Fe(II)-DS/S using different types of ordinary Portland cement (OPC) was examined and the solids produced were examined by instrumental analyses (XRD, SEM, SEM-EDS). 


\section{CHAPTER II}

\section{BACKGROUND}

\subsection{Cement hydration products and layered double hydroxides (LDHs)}

\subsubsection{Portland cement: General}

Anhydrous Portland cement is produced by heating mixtures of limestone and clay, or other materials (41). The initial product is called "clinker", and it is eventually made into cement by grinding to a fine powder and mixing with a small amount (about 5\%) of gypsum to slow down set (42). Gypsum regulates the rate of setting cement and affects the rate of cement strength during hardening processes (41).

Clinkers consist of about $67 \%$ of $\mathrm{CaO}, 22 \%$ of $\mathrm{SiO}_{2}, 5 \%$ of $\mathrm{Al}_{2} \mathrm{O}_{3}, 3 \%$ of $\mathrm{Fe}_{2} \mathrm{O}_{3}$, and 3\% of other constituents. These formulas do not imply the chemical form of these elements. Allite, belite, aluminate, and ferrite are the four major phases of these elements in clinkers (41).

Alite $\left(\mathrm{Ca}_{3} \mathrm{SiO}_{5}=\mathrm{C}_{3} \mathrm{~S}\right.$, tricalcium silicate $)$ is the major components of clinkers and represents 50 to $70 \%$ of the mass in clinkers. It is responsible for the early stage of development of strength in cement, which lasts up to 28 days. Belite $\left(\mathrm{Ca}_{2} \mathrm{SiO}_{4}=\mathrm{C}_{2} \mathrm{~S}\right.$, dicalcium silicate) is the second major component of clinkers and represents 15 to $30 \%$ of clinker mass. The later stage of cement strength is mostly influenced by belite. Clinkers contain 5 to $10 \%$ of their mass as aluminate $\left(\mathrm{Ca}_{3} \mathrm{Al}_{2} \mathrm{O}_{6}=\mathrm{C}_{3} \mathrm{~A}\right.$, tricalcium aluminate $)$ and 5 to $15 \%$ as ferrite $\left(2 \mathrm{Ca}_{2} \mathrm{AlFeO}_{5}=\mathrm{C}_{4} \mathrm{AF}\right.$, tetracalcium aluminoferrite $)$. The ratio of $\mathrm{Al}$ to $\mathrm{Fe}$ varies in cements (41) 
The modified chemical composition of Portland cement results in the variability of the properties, such as specific surface area, the rate of hardening, or the degree of compressive strength $(41,42)$.

\subsubsection{Cement hydration products and layered double hydroxides}

When Portland cement is mixed with water, its four major phases $\left(\mathrm{C}_{3} \mathrm{~S}, \mathrm{C}_{2} \mathrm{~S}, \mathrm{C}_{3} \mathrm{~A}\right.$ and $\mathrm{C}_{4} \mathrm{AF}$ ) are totally changed and it sets and hardens. The degree of cement hydration is very important in determining the strength of cement. If the cement to water ratio is very low, strength will be low. However, a ratio of cement to water that is too high creates a high volume of capillary pores, which damages strength and impermeability (42).

The hydration of the calcium silicate phases $\left(\mathrm{C}_{3} \mathrm{~S}\right.$ and $\left.\mathrm{C}_{2} \mathrm{~S}\right)$ forms calcium silicate hydrate $(\mathrm{C}-\mathrm{S}-\mathrm{H})$ and Portlandite $\left(\mathrm{Ca}(\mathrm{OH})_{2}\right)$. C-S-H represents any amorphous or semicrystalline calcium silicate hydrate. A large percentage (70\%) of $\mathrm{C}_{3} \mathrm{~S}$ turns into $\mathrm{C}-\mathrm{S}-\mathrm{H}$ in 28 days and all of it is converted within a year. A smaller percentage $(30 \%)$ of $\beta-\mathrm{C}_{2} \mathrm{~S}$ is converted into C-S-H in 28 days and 90\% is converted within a year (41). The structure of C-S-H is similar to that of 1.4-nm tobermorite $\left(\mathrm{C}_{5} \mathrm{~S}_{6} \mathrm{H}_{9}\right.$, approx.) and the ratio of $\mathrm{Ca} / \mathrm{Si}$ is between 0.88 and $1.45(43) . \mathrm{C}-\mathrm{S}-\mathrm{H}$ is the predominant cement hydration product and it controls the chemical properties of hydrated cement due to its high surface area (44).

The hydration of $\mathrm{C}_{3} \mathrm{~A}$ and $\mathrm{C}_{4} \mathrm{AF}$ forms mostly aluminite-ferrite-tri (AFt) and aluminate-ferrite-mono (AFm) phases. $\mathrm{C}_{3} \mathrm{~A}$ in the presence of water and calcium sulfate forms Ettringite $\left(\mathrm{AFt}, 3 \mathrm{CaO} \cdot \mathrm{Al}_{2} \mathrm{O}_{3} \cdot 3 \mathrm{CaSO}_{4} \cdot 32 \mathrm{H}_{2} \mathrm{O}\right)$ within 30 minutes and then 
Ettringite and unhydrated $\mathrm{C}_{3} \mathrm{~A}$ form monosulfate $\left(\mathrm{AFm}, 3 \mathrm{CaO} \cdot \mathrm{Al}_{2} \mathrm{O}_{3} \cdot \mathrm{CaSO}_{4} \cdot 12 \mathrm{H}_{2} \mathrm{O}\right)(41$, 42). Hydration of $\mathrm{C}_{3} \mathrm{~A}$ also forms tetracalcium aluminate hydrate (AFm, $4 \mathrm{CaO} \cdot \mathrm{Al}_{2} \mathrm{O}_{3} \cdot 13 \mathrm{H}_{2} \mathrm{O}$ ) in the presence of calcium hydroxide. It can also form hydrogarnet $\left(3 \mathrm{CaO} \cdot \mathrm{Al}_{2} \mathrm{O}_{3} \cdot 6 \mathrm{H}_{2} \mathrm{O}\right)$, which is subsequently converted from $2 \mathrm{CaO} \cdot \mathrm{Al}_{2} \mathrm{O}_{3} \cdot 8 \mathrm{H}_{2} \mathrm{O}$ and $4 \mathrm{CaO} \cdot \mathrm{Al}_{2} \mathrm{O}_{3} \cdot 19 \mathrm{H}_{2} \mathrm{O}$ (42). The hydration reaction of $\mathrm{C}_{4} \mathrm{AF}$ is very similar to that of $\mathrm{C}_{3} \mathrm{~A}$. In general, $\mathrm{C}_{4} \mathrm{AF}$ reacts much more slowly than $\mathrm{C}_{3} \mathrm{~A}(41)$. The hydration reaction rates of $\mathrm{C}_{4} \mathrm{AF}$ decrease with increasing $\mathrm{Fe}(\mathrm{II})$ contents (45).

In the presence of free-chloride, the hydration of $\mathrm{C}_{3} \mathrm{~A}$ forms $\mathrm{C}_{3} \mathrm{~A} \cdot \mathrm{CaCl}_{2} \cdot 10 \mathrm{H}_{2} \mathrm{O}$, called "Friedel's salt" (46). Friedel's salt is also an AFm phase. Friedel's salt is more stable than hydroxylaluminate AFm, which has variable water contents $\left(4 \mathrm{CaO} \cdot \mathrm{Al}_{2} \mathrm{O}_{3} \cdot x \mathrm{H}_{2} \mathrm{O}\right)$ and can be converted into hydrogarnet and gibbsite. When chloride ions diffuse into cement, AFm serves as a "sink" for chloride so that chloride ion diffusion further into the solid is delayed. The mixtures of Friedel's salt and hydroxylaluminate AFm keep $\mathrm{pH}$ above 12 through substitution of $\mathrm{Cl}^{-}$for $\mathrm{OH}^{-}$. Friedel's salt is very stable at $20^{\circ} \mathrm{C}$ over a wide range of $\mathrm{Cl}^{-}$concentration, from $14.5 \mathrm{mM}$ to about $8 \mathrm{M}$, in aqueous phases. Intrusion of $\mathrm{CO}_{2}$ is a main mechanism to destabilize $\mathrm{AFm}$, but other hydration products, such as Portlandite or C-S-H gel, are still able to buffer the system. Therefore, AFm phases are able to maintain their stability locally and keep reacting with adjacent $\mathrm{Cl}^{-}$ions. All aluminate hydrates will be converted to Friedel's salt in the same chloride concentration ranges, so that Friedel's salt formation is largely dependent on the Al content of cement (47) for a given $\mathrm{Cl}$ content. Table 2-1 summarizes some of the cement hydration reactions 
TABLE 2-1 Hydration reactions for Portland cement mineral phases (48)

\section{Tricalcium silicate:}

$$
2\left(3 \mathrm{CaO} \cdot \mathrm{SiO}_{2}\right)+6 \mathrm{H}_{2} \mathrm{O} \rightarrow 3 \mathrm{CaO} \cdot 2 \mathrm{SiO}_{2} \cdot 3 \mathrm{H}_{2} \mathrm{O}+3 \mathrm{Ca}(\mathrm{OH})_{2}
$$

\section{Dicalcium silicate:}

$$
2\left(2 \mathrm{CaO} \cdot \mathrm{SiO}_{2}\right)+4 \mathrm{H}_{2} \mathrm{O} \rightarrow 3 \mathrm{CaO} \cdot 2 \mathrm{SiO}_{2} \cdot 3 \mathrm{H}_{2} \mathrm{O}+\mathrm{Ca}(\mathrm{OH})_{2}
$$

\section{Tricalcium aluminate and Gypsum:}

then

$$
3 \mathrm{CaO} \cdot \mathrm{Al}_{2} \mathrm{O}_{3}+3\left(\mathrm{CaSO}_{4} \cdot 2 \mathrm{H}_{2} \mathrm{O}\right)+26 \mathrm{H}_{2} \mathrm{O} \rightarrow 3 \mathrm{CaO} \cdot \mathrm{Al}_{2} \mathrm{O}_{3} \cdot 3 \mathrm{CaSO}_{4} \cdot 32 \mathrm{H}_{2} \mathrm{O}
$$

$$
\begin{aligned}
2\left(3 \mathrm{CaO} \cdot \mathrm{Al}_{2} \mathrm{O}_{3}\right)+3 \mathrm{CaO} \cdot \mathrm{Al}_{2} \mathrm{O}_{3} \cdot 3 \mathrm{CaSO}_{4} \cdot & 32 \mathrm{H}_{2} \mathrm{O}+4 \mathrm{H}_{2} \mathrm{O} \\
\rightarrow & 3\left(3 \mathrm{CaO} \cdot \mathrm{Al}_{2} \mathrm{O}_{3} \cdot \mathrm{CaSO}_{4} \cdot 12 \mathrm{H}_{2} \mathrm{O}\right)
\end{aligned}
$$

then

$$
3 \mathrm{CaO} \cdot \mathrm{Al}_{2} \mathrm{O}_{3}+\mathrm{Ca}(\mathrm{OH}) 2+12 \mathrm{H} 2 \mathrm{O} \rightarrow 4 \mathrm{CaO} \cdot \mathrm{Al}_{2} \mathrm{O}_{3} \cdot 13 \mathrm{H}_{2} \mathrm{O}
$$

Tetracalcium aluminoferrite:

$$
4 \mathrm{CaO} \cdot \mathrm{Al}_{2} \mathrm{O}_{3} \cdot \mathrm{Fe}_{2} \mathrm{O}_{3}+4 \mathrm{Ca}(\mathrm{OH})_{2}+22 \mathrm{H}_{2} \mathrm{O} \rightarrow
$$

Hydrated Portland cement generally consists of 70\% C-S-H, 20\% Portlandite, 7\% Ettringite/monosulfate, and 3\% minor phases. Porous hydrated Portland cement has up to $200 \mathrm{~m}^{2} / \mathrm{g}$ of specific surface area (42). The XRD pattern of typical hydrated Portland cement is shown in figure 2-1. 


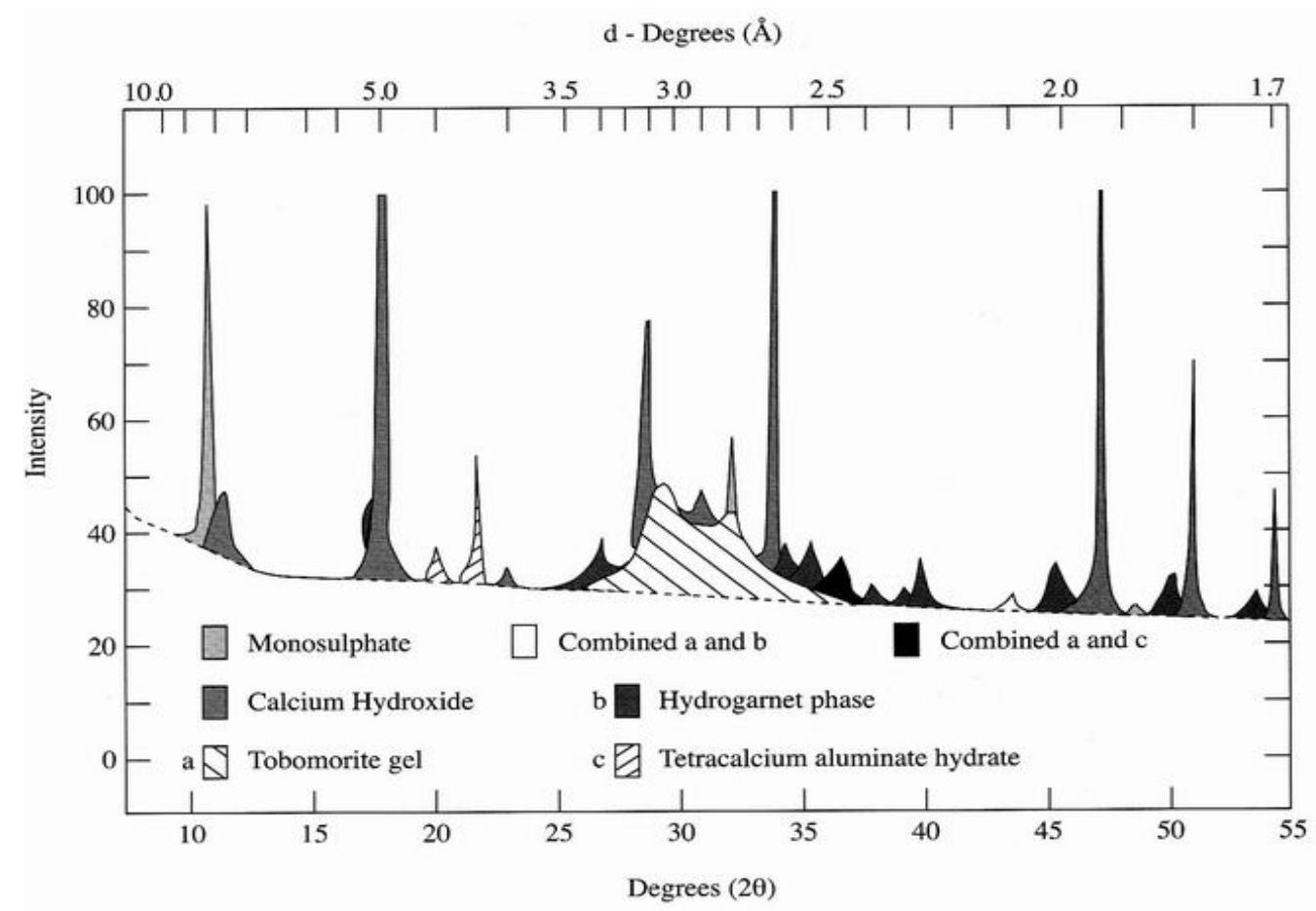

FIGURE 2-1 Schematic X-ray diffractogram of Portland cement paste (49).

AFm phases are examples of compounds called layered double hydroxides (LDHs) $(50,51)$. LDH are compounds that have sheets of metal hydroxides with anions in the interlayer. They are referred as hydrotalcite-like compounds or pyroaurite-like compounds. Divalent and trivalent metal cations are present in the sheet and to some degree, the divalent cations can substitute for trivalent cations. The divalent and trivalent cations are randomly distributed in an edge-sharing octahedral sheet, forming hydroxylated $\mathrm{M}(\mathrm{OH})_{2}$ sheets similar to those of brucite, $\mathrm{Mg}(\mathrm{OH})_{2}$. The excess positive charge created by isomorphous substitution is balanced by the presence of anions in the interlayers. General formula of an LDH is: 


$$
\left[\mathrm{M}_{1-\mathrm{x}}^{\mathrm{II}} \mathrm{M}_{\mathrm{x}}^{\mathrm{III}}(\mathrm{OH})_{2}\right]^{\mathrm{x}+}\left[\mathrm{X}_{\mathrm{x} / \mathrm{m}}^{\mathrm{m}-} \bullet \mathrm{nH}_{2} \mathrm{O}\right]^{\mathrm{x}-}
$$

where $\mathrm{M}^{\mathrm{II}}$ is a divalent cation, $\mathrm{M}^{\mathrm{III}}$ a trivalent cation, and $\mathrm{X}$ an anion $(52-55)$. The schematic structure of LDH is shown in figure 2-2.

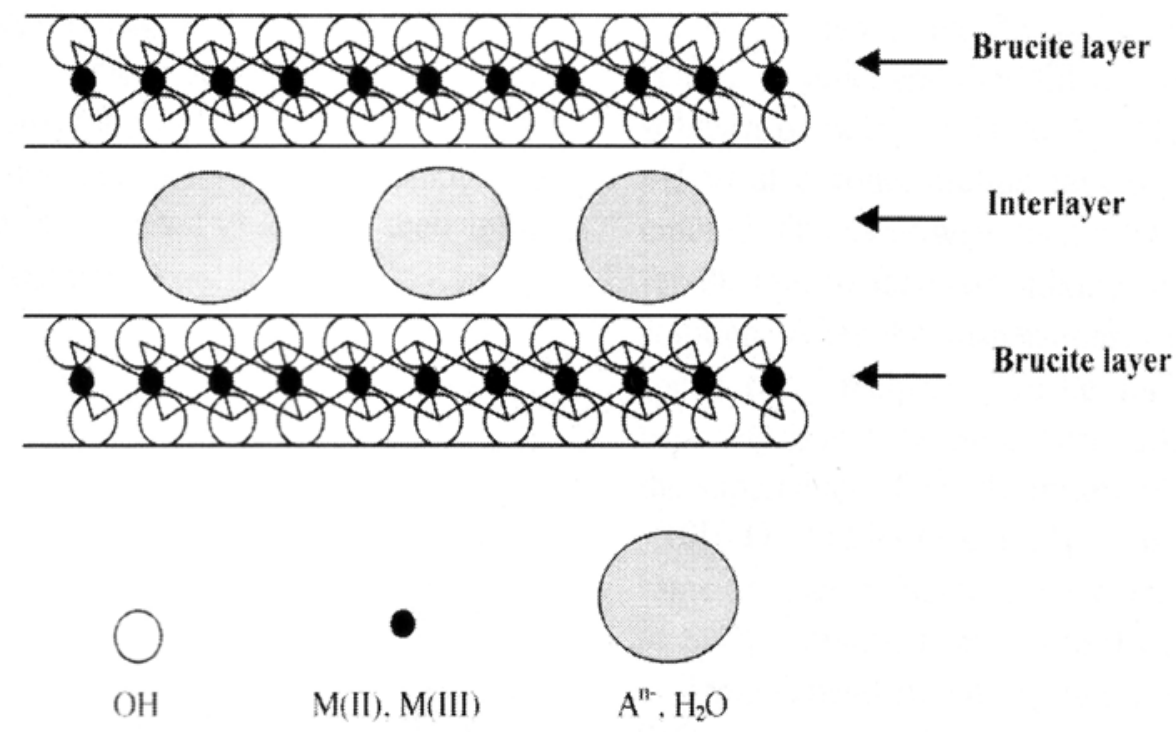

FIGURE 2-2 Schematic representation of a LDH structure (55).

Various cations are found in natural or synthetic LDH. Divalent cations include $\mathrm{Mg}, \mathrm{Mn}, \mathrm{Fe}, \mathrm{Co}, \mathrm{Ni}, \mathrm{Cu}, \mathrm{Zn}$, and $\mathrm{Ca}$. Trivalent cations include $\mathrm{Al}, \mathrm{Cr}, \mathrm{Mn}, \mathrm{Fe}, \mathrm{Co}$, and Ni. A diversity of interlayer anions is also reported in LDH and they include halides (F-, Cl-, Br-, I-), oxo-anions (nitrate, sulfate, chromate, selenate, selenite, carbonate), complex anions (ferrocyanide), and organic anions (alkyl-sulfate, carboxylic acid, porphyrins) (53-56) 
As we can see from the formula of AFm phases, $\left[\mathrm{Ca}_{2}(\mathrm{Al}, \mathrm{Fe})(\mathrm{OH})_{6}\right]^{+} \cdot \chi^{-} \cdot \mathrm{mH}_{2} \mathrm{O}$, a divalent cation for $\mathrm{AFm}$ phases is $\mathrm{Ca}^{2+}$ and a trivalent cation is $\mathrm{Al}^{3+}$ and/or $\mathrm{Fe}^{3+}$. Commonly found interlayer anions are $\mathrm{OH}^{-}, \mathrm{Cl}^{-}, \mathrm{SO}_{4}{ }^{2-}$, and $\mathrm{CO}_{3}{ }^{2-}(41)$.

The unique characteristic of LDHs is high anion exchange capacities. It is possible to exchange anions in the interlayer with various kinds of other anions $(52,53)$. The selectivity of $\mathrm{LDH}$ for monovalent anions is $\mathrm{OH}^{-}>\mathrm{F}^{-}>\mathrm{Cl}^{-}>\mathrm{Br}^{-}>\mathrm{NO}_{3}^{-}>\mathrm{I}^{-}$, and divalent anions are more highly selected than monovalent anions (57). Interlayer spacing of LDHs vary, depending on the size and structure of the anions. LDHs, thus, can have a large surface area, $20-120 \mathrm{~m}^{2} / \mathrm{g}$ to $800 \mathrm{~m}^{2} / \mathrm{g}$, and high anion exchange capacity, 2-5 $\mathrm{meq} / \mathrm{g}$, due to the characteristics of anions in the interlayers $(53,54)$. These properties of LDHs result in interesting applications including use as catalysts, electrochemical agents, separation media, and adsorbent $(54,55,58,59)$.

A naturally occurring LDH is Green Rust (GR), which is found as the product of steel corrosion at near neutral conditions and as precipitates in anaerobic soils and sediments (60). GRs formed during steel corrosion are stable up to $\sim \mathrm{pH} 13$ (61). Commonly found anions in the interlayers of $\mathrm{GR}$ are $\mathrm{Cl}^{-}, \mathrm{SO}_{4}{ }^{2-}$, and $\mathrm{CO}_{3}{ }^{2-}(60)$. There are two types of GR, rhombohedral GR1 and hexagonal GR2, based on features of X-ray diffraction. GR1 has planar anions, such as chloride and carbonate and GR2 has threedimensional anions such as sulfate (62). 


\subsubsection{Morphology of cement hydration products and LDHs}

The microscopic examination of minerals elucidates their microstructure on a scale of micrometers or below and can include characteristics such as composition, surface topography, crystallography, etc (63). Petrographic examination of cement identifies the type, composition, and nature of cement pastes, as well as aids the estimation of the life of concrete (64).

The predominant cement hydration product is the C-S-H gel. It can be amorphous so that it can be difficult to identify through X-ray diffraction alone. Scanning electron microscopic examination shows that it is often found as filaments or tubular structures (Type I) soon after mixing with water and then changes to honeycomb structures (Type II). At the late stage of cement hydration, the shape of the gel has a more massive appearance (Type III) and then it develops a featureless shape (Type IV). Features are not found after 28 days, even at the scale of $100 \mathrm{~nm}$ scale $(41,42)$.

The morphology of Portlandite and hydrated calcium aluminate is hexagonal. Friedel's salt and tetracalcium aluminate hydrate, which are LDHs, are difficult to distinguish due to a similar maximum intensity peak position as well as the same shape. However, they can be distinguished by their size. Crystals of Friedel's salt are typically 2 to $3 \mu \mathrm{m}$, while hydration products of $\mathrm{C}_{3} \mathrm{~A}$ are typically less than $1 \mu \mathrm{m}$. Portlandite is also hexagonal in shape, but it is much larger than Friedel's salt, with maximum lengths of about $100 \mu \mathrm{m}$. Ettringite and monosulfate form acicular crystals, with sizes generally below1 $\mu \mathrm{m}(42,65)$. 

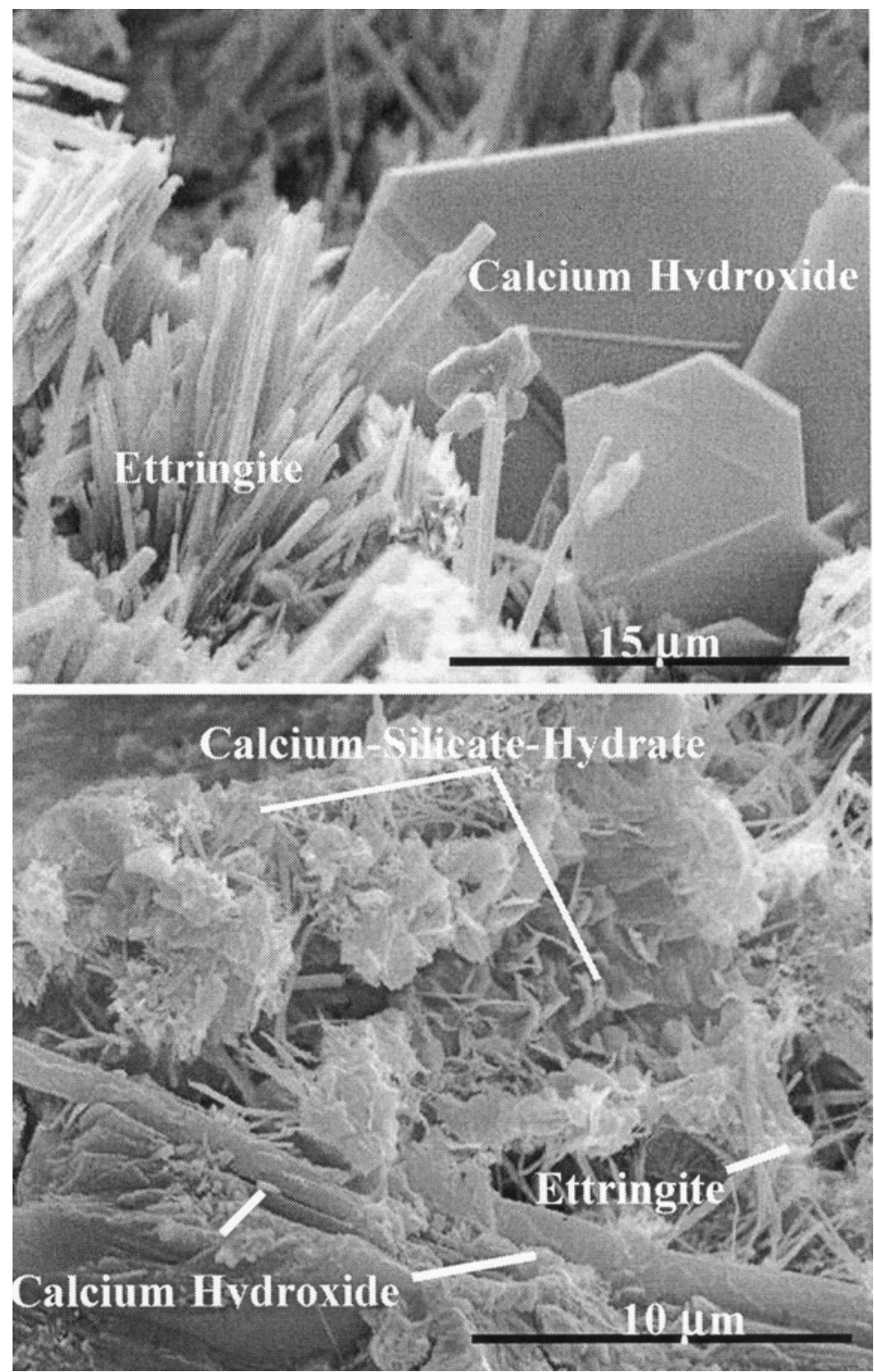

FIGURE 2-3 SEM image shows hexagonal shape of calcium hydroxide, needle-like Ettringite, and sheet-like calcium silicate hydrates (64). 


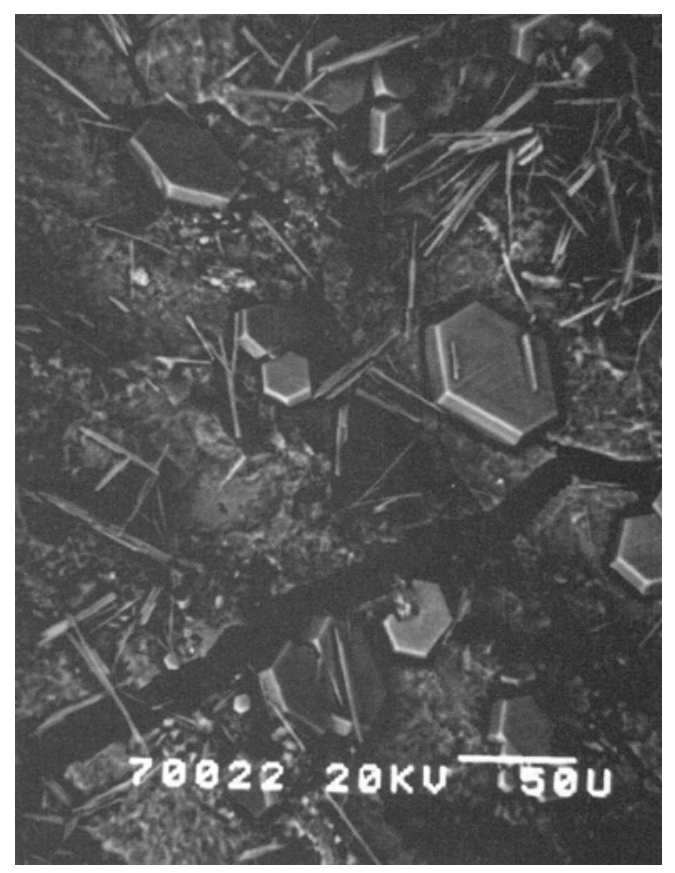

FIGURE 2-4 SEM image of hexagonal Friedel's salt and Ettringite needles (42).

The structure of LDHs is stacking edge sharing octahedral planes with divalent and isomorphously substituted trivalent cations in the center and hydroxyl groups in the vertices and charge balancing anions between octahedral planes (66). In general, crystals having thin flat plane shapes indicate LDHs (67).

For example, green rust sulfate, $\mathrm{GR}\left(\mathrm{SO}_{4}{ }^{2-}\right)$, has the shape of hexagonal thin plates with sizes of several micrometers (figure 2-5(a)) (68-70). Although green rust carbonate, $\mathrm{GR}\left(\mathrm{CO}_{3}{ }^{2-}\right)$ and green rust chloride, $\mathrm{GR}\left(\mathrm{Cl}^{-}\right)$do not show perfect hexagonal shapes in figure 2-5(b) and (c), they also have thin flat characteristics. $\mathrm{GR}\left(\mathrm{CO}_{3}{ }^{2-}\right)$ particles are very compact platy shapes and have very large thickness, about $0.7 \mu \mathrm{m}(68,70)$. Figure 2-6 shows synthesized $\mathrm{Cu}$ substituted MgAlLDH in laboratory. They also have thin plate shapes, similar with $\mathrm{GR}\left(\mathrm{Cl}^{-}\right)(71)$. 
(a) $\mathrm{GR}\left(\mathrm{SO}_{4}{ }^{2-}\right.$ )
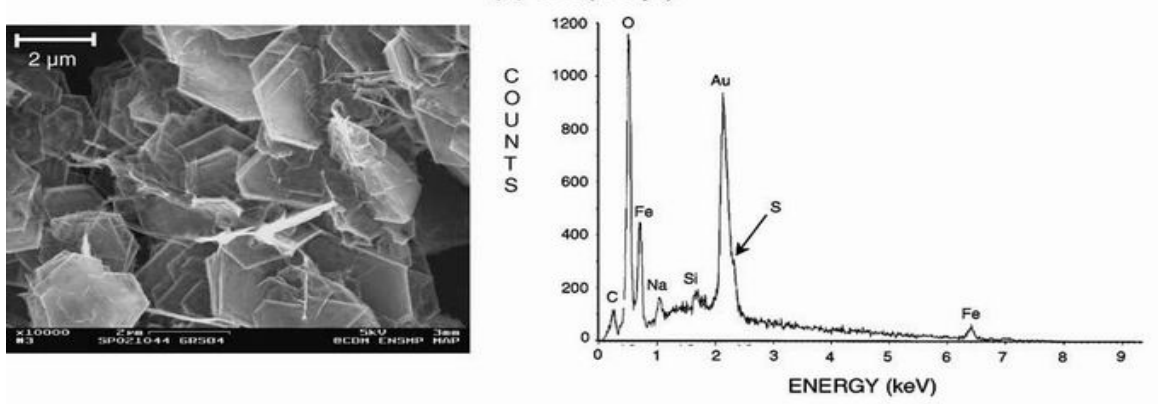

(b) $\mathrm{GR}\left(\mathrm{CO}_{3}{ }^{2-}\right)$
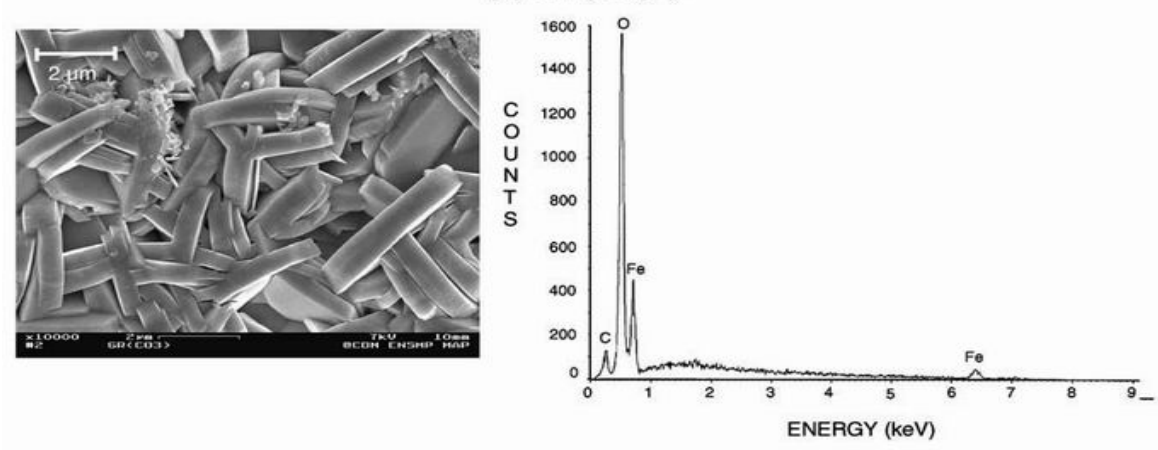

(c) $\mathrm{GR}\left(\mathrm{Cl}^{-}\right)$
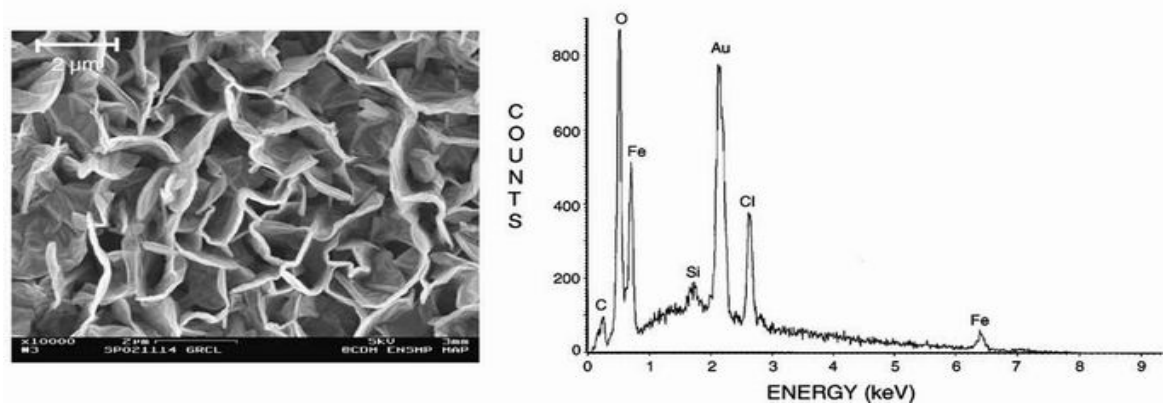

FIGURE 2-5 SEM images and EDS spectra of electrodeposited GR (69). 


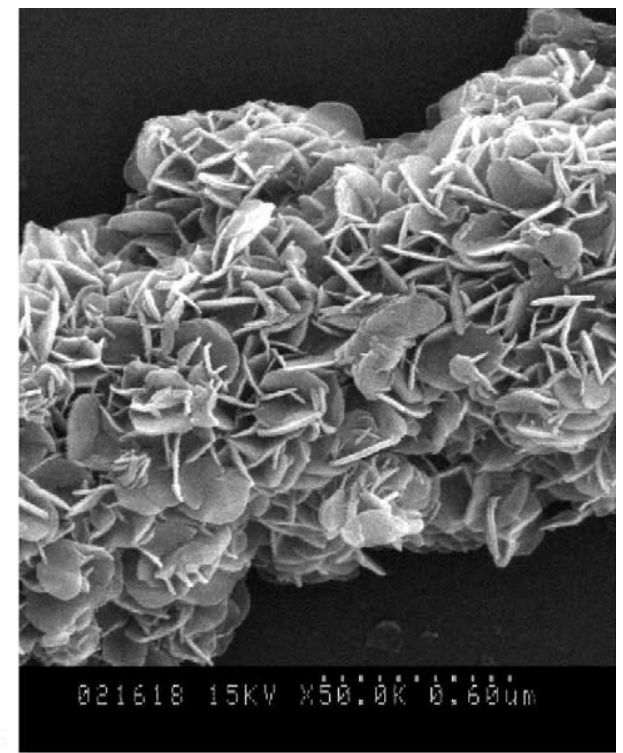

(a)

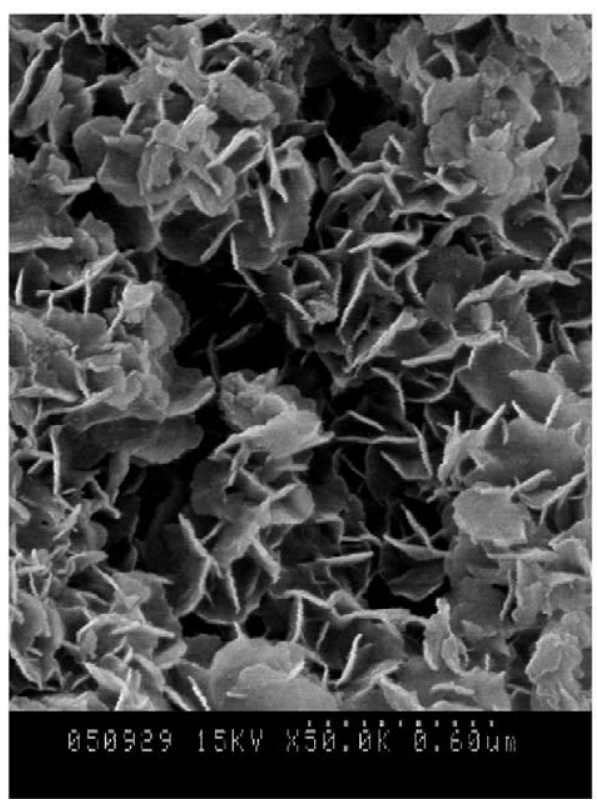

FIGURE 2-6 SEM micrographs of CuLDH (71). 


\subsection{Reductive dechlorination}

\subsubsection{Biotic reductive dechlorination}

Reductive dechlorination is a major mechanism under anaerobic conditions for biological removal of harmful, toxic chlorinated organic solvents from contaminated environments. Usually, chlorinated organic compounds are very recalcitrant under aerobic conditions, but sometimes they can be degraded to less substituted compounds. In reductive dechlorination, a hydrogen is substituted for a chorine atom.

$$
\boldsymbol{R C l}+\boldsymbol{H}^{+}+2 \boldsymbol{e}^{-} \rightarrow \boldsymbol{R H}+\mathrm{Cl}^{-}
$$

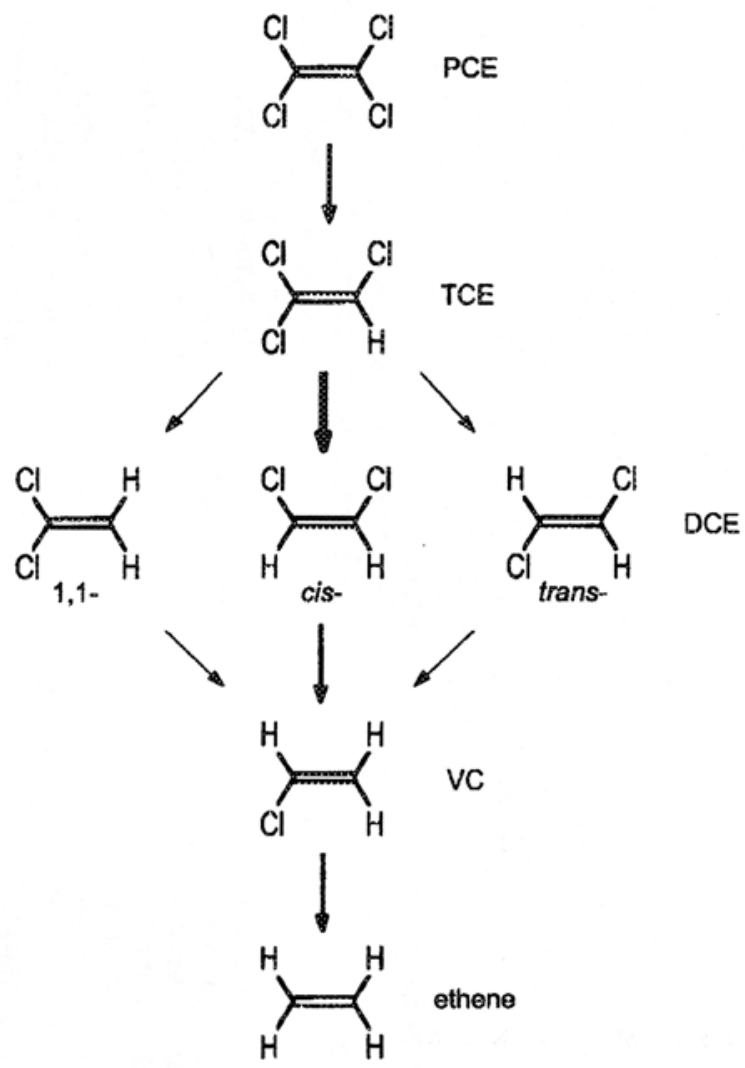

FIGURE 2-7 Reductive dechlorination pathway of PCE (72). 
There are two categories of biotic reductive dechlorination; cometabolic dechlorination, and metabolic dechlorination (72-74). In cometabolic processes, microbes do not directly use chlorinated organic compounds as their energy sources. Instead, they utilize other electron donors in their energy-producing reactions, and create enzymes or cofactors to degrade contaminants. For example, PCE was degraded to ethane by introducing acetate, glucose, formate, methanol, lactate, or sucrose as electron donors (75-78). A site that is contaminated by petroleum hydrocarbons and chlorinated solvents can be cleaned up through cometabolic processes. In this case, microbes gain energy through metabolizing petroleum hydrocarbons and synthesize enzymes that can degrade chlorinated organic contaminants in reactions that do not yield energy to the organism.

In metabolic dechlorination, a chlorinated organic compound serves as a terminal electron acceptor in reactions that provide for energy storage and growth (72). Dehalococcoides ethenogenes strain 195 is known as halorespiration bacteria, and it is able to dechlorinate PCE to ethane (79).

Microbial dechlorination occurs usually under methanogenic conditions $(72,80$, 81). However, polychlorinated methane and ethane are also able to undergo biotransformation under various redox zones, such as a sulfate-reducing conditions, or Fe(III) -reducing conditions $(80,82,83)$.

Even though various kinds of electron donors are being investigated, the actual electron donor in dechlorination is hydrogen, which is available directly or through fermentation of fed electron donors $(84,85)$. Ferguson $(85)$ demonstrated a hydrogen 
effect on anaerobic biotransformations of chlorinated compounds. He shows that PCE dechlorination does not occur when acetate is the only electron donor. However, PCE is converted to less chlorinated compounds after $\mathrm{H}_{2}$ is injected. PCE also starts to degrade soon after adding $\mathrm{H}_{2}$ in the case when cultures did not previously receive other electron donors. Table 2-2 shows reactions with various electron donors that produce $\mathrm{H}_{2}$.

TABLE 2-2 Catabolic $\mathrm{H}_{2}$-releasing reactions of biotic reductive dechlorination (78)

\begin{tabular}{l}
\hline $\mathrm{H}_{2}$-releasing reactions \\
\hline acetate $^{-}+4 \mathrm{H}_{2} \mathrm{O} \rightarrow 2 \mathrm{HCO}_{3}^{-}+4 \mathrm{H}_{2}+\mathrm{H}^{+}$ \\
propionate $+3 \mathrm{H}_{2} \mathrm{O} \rightarrow$ acetate $^{-}+\mathrm{HCO}_{3}^{-}+\mathrm{H}^{+}+3 \mathrm{H}_{2}$ \\
butyrate $+2 \mathrm{H}_{2} \mathrm{O} \rightarrow 2$ acetate $^{-}+\mathrm{H}^{+}+2 \mathrm{H}_{2}$ \\
ethanol $+\mathrm{H}_{2} \mathrm{O} \rightarrow$ acetate $^{-}+\mathrm{H}^{+}+3 \mathrm{H}_{2}$ \\
methanol $+2 \mathrm{H}_{2} \mathrm{O} \rightarrow \mathrm{HCO}_{3}^{-}+\mathrm{H}^{+}+3 \mathrm{H}_{2}$ \\
lactate $+2 \mathrm{H}_{2} \mathrm{O} \rightarrow$ acetate $^{-}+\mathrm{HCO}_{3}^{-}+\mathrm{H}^{+}+2 \mathrm{H}_{2}$ \\
\hline
\end{tabular}

In contrast to other halorespiring bacteria, Desulfuromonas chloroethenica uses acetate as an electron donor, instead of $\mathrm{H}_{2}$, and reduces PCE to cis-DEC $(86,87)$.

Along with electron donors, temperature is an important factor as well. Anaerobic reductive dechlorination occurs typically in the temperature range between $20{ }^{\circ} \mathrm{C}$ and $37{ }^{\circ} \mathrm{C}(72)$. The rate of degradation significantly decreases $(88)$ or is stopped $(89,90)$ below $10{ }^{\circ} \mathrm{C}$. However, microbial reductive dechlorination of PCE is observed even under thermophilic conditions (91).

Several remediation technologies apply biotic reductive dechlorination. First, natural attenuation is an economically favorable remediation process in which indigenous microorganisms use contaminants as their energy sources and degrade them to harmless products without any engineering modifications. When natural attenuation is 
applied as a remediation processes at contaminated sites with chlorinated solvents, important controlling factors are subsurface redox conditions and availability of soil organic carbons, which could serve as electron donors to indigenous microorganisms (92). Natural attenuation could be a feasible choice for a site contaminated by both petroleum hydrocarbons and chlorinated solvents.

Another application for bioremediation of chlorinated organics is sequential bioremediation. Figure 2-8 shows a schematic of a sequential bioremediation process. In an anaerobic zone, PCE is dechlorinated to cis-DCE, followed by an aerobic zone in which cis-DCE is biomineralized to $\mathrm{CO}_{2}$ by a cometabolic oxidation. An electron donor, such as methanol, is added to stimulate reductive dechlorination in the anaerobic zone, while oxygen and an additional substrate are added to the aerobic zone (93).

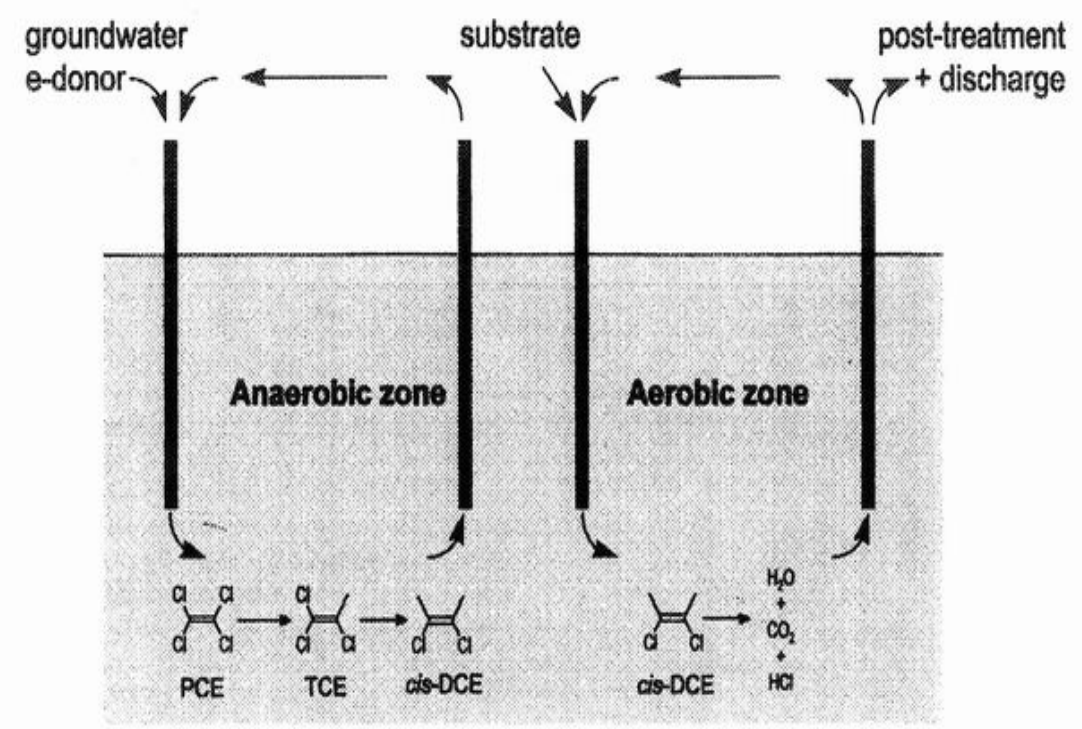

FIGURE 2-8 Schematic sequential bioremediation processes (72). 
A third approach to bioremediation of chlorinated organics is bioaugmentation, which is the process where suitable microorganisms are added to contaminated sites when indigenous microorganisms are unable to perform dechlorination. Both biological and chemical factors at contaminated sites are important to successfully conducting bioaugmentation (72). Gregory and co-workers (94) demonstrate that the anaerobes, such as those found in acetate-enriched or lactate-enriched methanogenic cultures, are able to degrade chlorinated aliphatic compounds in combination with $\mathrm{Fe}(0)$, which produces $\mathrm{H}_{2}$. Microbes use this hydrogen as their electron donor for energy production. $\mathrm{Fe}(0)$ by itself also reduces chlorinated aliphatic compounds.

$$
\begin{aligned}
& \mathbf{F e}(0)+2 \mathrm{H}_{2} \mathrm{O} \rightarrow \mathrm{Fe}^{2+}+2 \mathrm{OH}^{-}+\boldsymbol{H}_{2} \\
& \boldsymbol{F e}(0)+\boldsymbol{R} \boldsymbol{X}+\boldsymbol{H}^{+} \rightarrow \mathrm{Fe}^{2+}+\boldsymbol{R H}+\boldsymbol{X}^{-}
\end{aligned}
$$

Permeable reactive zones or barriers in aquifers are economical and promising remediation technologies. As contaminated groundwater passes through the zones, contaminants are chemically and biologically degraded, sorbed and/or precipitated (95). One type of reactive zone is produced by using biological sludge cake to fill remediation wells or trenches (95-97). Biological sludge cake is a good material for this purpose due to its abundance of carbon sources, sufficient carbon bioavailability for reductive dechlorination, and its low cost. PCE is degraded to less chlorinated products such as vinyl chloride (VC) in upstream anaerobic zones by methanogenic microorganisms and $\mathrm{VC}$ is aerobically co-metabolized in downstream zones (refer to figure 2-9).

Ex-situ bioremediation technologies applying biotic reductive dechlorination mechanisms such as the anaerobic filter (98) or biofilm (99) are also reported. 
A)
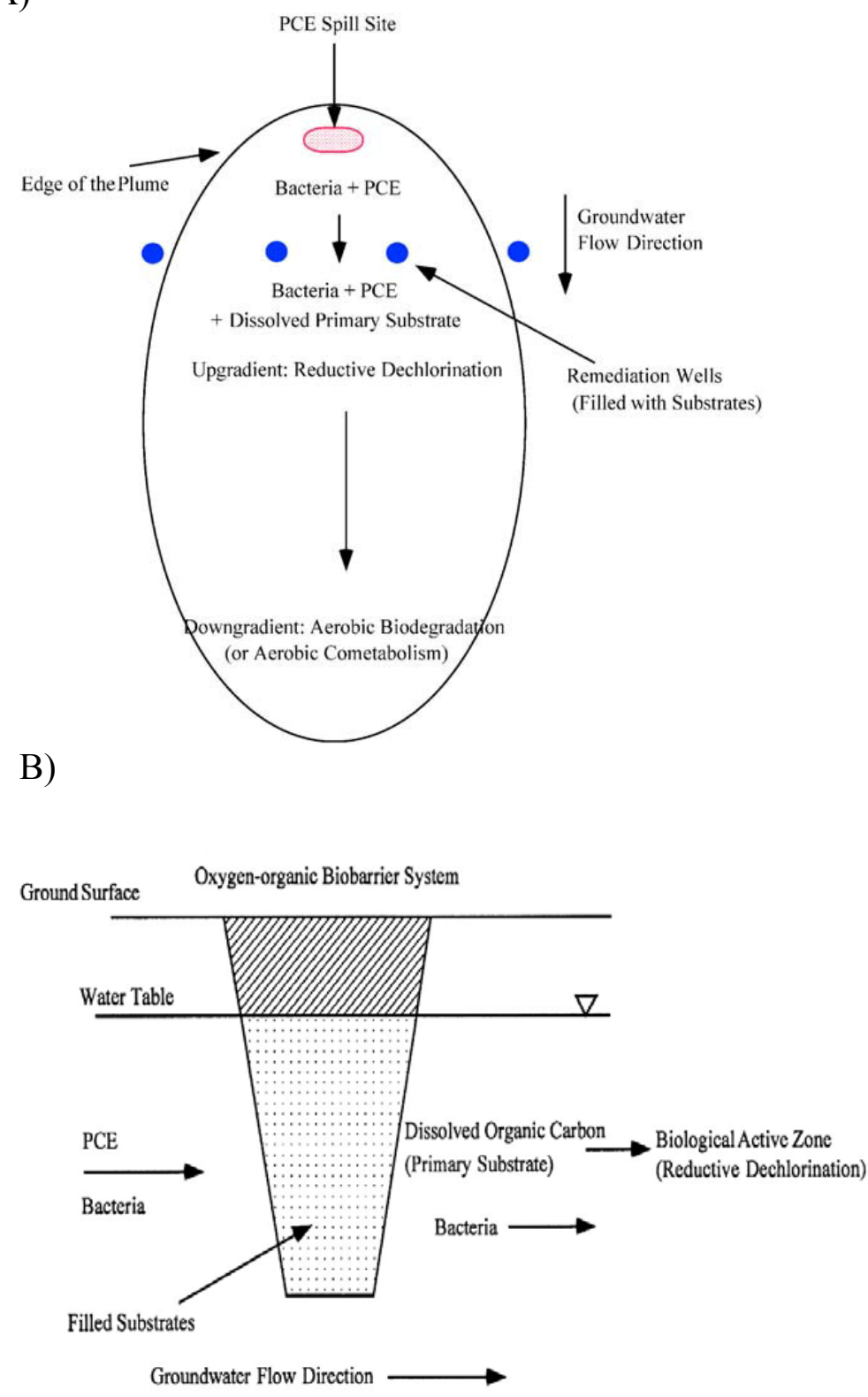

FIGURE 2-9 Schematic diagrams of (A) biobarrier and (B) the trench system (95). 


\subsubsection{Abiotic reductive dechlorination}

Biotic reductive dechlorination sometimes does not completely dechlorinate contaminants, so that more harmful daughter products accumulate, such as cis-DCE and VC, which are very toxic to microorganisms. The only microorganism known to completely degrade PCE to ethane is Dehalococcoides ethenogenes strain 195. Appropriate environments, such as temperature, nutrient, oxygen, moisture content, and substrate, are required for successful application of natural attenuation (72).

Due to several limitations of biotic reductive dechlorination, abiotic reductive dechlorination could be a promising alternative for remediation of chlorinated solvents. Abiotic reductive dechlorination could be achieved by addition of chemical reductants such as iron-bearing minerals, hydrogen sulfide, iron sulfides, and zero-valent metals, such as iron, zinc Abiotic reductive dechlorination occurs presumably through three reactions; hydrogenolysis (chloride substitution for hydrogen), reductive elimination (dichloroelimination), and hydrogenation (reduction of multiple bonds) (13) (refer to figure 2-9). The ratios of the rates of these different reactions determine the distribution of products (13).

The first step in abiotic reductive dechlorination is a one-electron transfer from the reductant that results in removal of chloride and the formation of an alkylchloride radical. This intermediate radical undergoes several reactions, such as hydrogenolysis, reductive elimination and dimerization. Hydrogen is attached to the intermediate alkyl radical from the surrounding environment during hydrogenolysis. Another chloride that is attached to an adjacent radical carbon could be lost and an alkene would be formed in a 
process called reductive elimination.. This would decrease the possibility of further reduction (7). If there is not a good proton donor, dimerization of the radical can be important. However, dimerization is not favored in dilute solution (100).

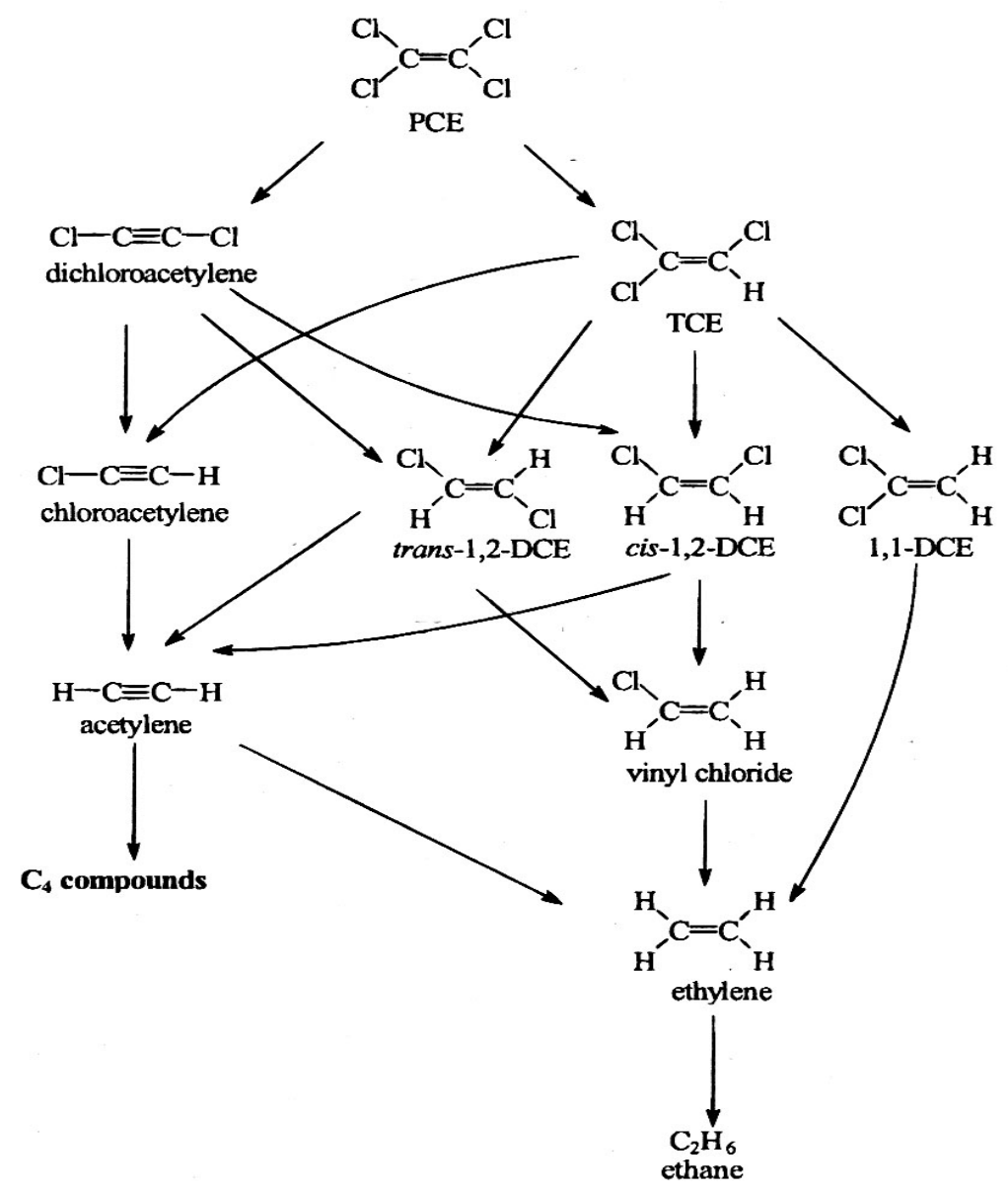

FIGURE 2-10 Hypothesized reaction pathways for the chlorinated ethylenes and other intermediates during reduction by $\mathrm{Fe}(0)$ (13).

Several reductants have been investigated for abiotic reductive dechlorination for decades, such as Fe(II) in cement slurry (19-25), iron and sulfide minerals $(10,11,26-$ 
40), and zero-valent metal (13-22). All of them have shown the ability to dechlorinate chlorinated organic compounds and their dechlorination pathways have been investigated.

\subsubsection{Fe(II)-based degradative solidification and stabilization}

Many hazardous materials, especially those that are recalcitrant to chemical, biological, and thermal processes, have been treated by solidification and stabilization (101). Wastes are stabilized and detoxified by binding to reagents, such as cement. They can also be solidified by changing the physical characteristic of wastes, such as strength, compressibility, permeability. The principle purpose of solidification and stabilization is not only reduction of toxicity and mobility of contaminants but also improvement in physical properties of stabilized wastes (1).

There are six possible physical and chemical mechanisms that affect the effectiveness of solidification and stabilization; macroencapsulation, microencapsulation, absorption, adsorption, precipitation, and detoxification. One or more of these mechanisms can be employed (1). The most widely used principle binder is Portland cement. Pozzolans, lime and soluble silicate are also used as binders (1).

Degradative solidification and stabilization (DS/S) is the modification of conventional solidification and stabilization. The advantage of DS/S is that wastes are contained as well as degraded, for example, inorganic pollutants are immobilized while chlorinated organic pollutants are degraded. Therefore, DS/Swill be a promising 
technology for sites that are contaminated by both inorganic and organic pollutants (e.g., chlorinated aliphatic compounds) (23).

Hwang $(23,24)$ developed the DS/S system that uses Fe(II) as a reductant for reductive dechlorination of PCE. He used Portland cement as a binder. He chose Fe(II) as a reductant because Fe(II) showed the highest removal efficiency for PCE of the five reductants tested (sulfide, polysulfide, dithionite, pyrite and $\mathrm{Fe}(\mathrm{II})$ ). It is popular reductants at $\mathrm{S} / \mathrm{S}$ sites, and it is inexpensive (23).

PCE is degraded by pseudo-first order kinetics in slurries of Portland cement that contain $\mathrm{Fe}(\mathrm{II})$. This combination is called Fe(II)-based DS/S (Fe(II)-DS/S). The reductive elimination pathway is the major one for PCE degradation in Fe(II)-DS/S and the optimum $\mathrm{pH}$ is 12.1 (23).

Reductive dechlorination of carbon tetrachloride (CT) (24), and 1,1,1trichloroethane (1,1,1-TCA) (25) by Fe(II)-DS/S also follows pseudo-first order kinetics. The optimum $\mathrm{pH}$ for degradation of $\mathrm{CT}$ is $\mathrm{pH} 13$ and the optimum for 1,1,1-TCA degradation is $\mathrm{pH} 12.5$. Reductive dechlorination of $\mathrm{CT}$ follows a hydrogenolysis pathway in which chloroform (CT) and methylene chloride (MC) are produced as daughter products (24).

The effect of initial concentration of target compounds has also been investigated $(24,25)$. The rate of degradation is described by a saturation model: 


$$
\boldsymbol{R}_{0}=\frac{\boldsymbol{v}_{\max }[\text { substrates }]_{0}}{\left(\boldsymbol{K}_{\boldsymbol{m}}+[\text { substrates }]_{0}\right)}
$$

where, $\mathrm{R}_{0}=$ initial degradation rate; $v_{\max }=$ maximum degradation rate; $\mathrm{K}_{\mathrm{m}}=$ the halfsaturation constant. The value of $v_{\max }$ and $\mathrm{K}_{\mathrm{m}}$ are obtained by nonlinear regression. Figure 2-11 shows the saturation behavior for reductive dechlorination of 1,1,1-TCA. The saturation behavior in $\mathrm{Fe}(\mathrm{II})-\mathrm{DS} / \mathrm{S}$ suggests that reductive dechlorination of target compounds might occur on the surface through their adsorption on reactive sites.

Hwang (23) assumed that the possible active reductant in Fe(II)-DS/S might be similar to GR, based on the observation that increased PCE degradation rates were obtained when Fe(III) was added along with Fe(II) to Portland cement slurries.

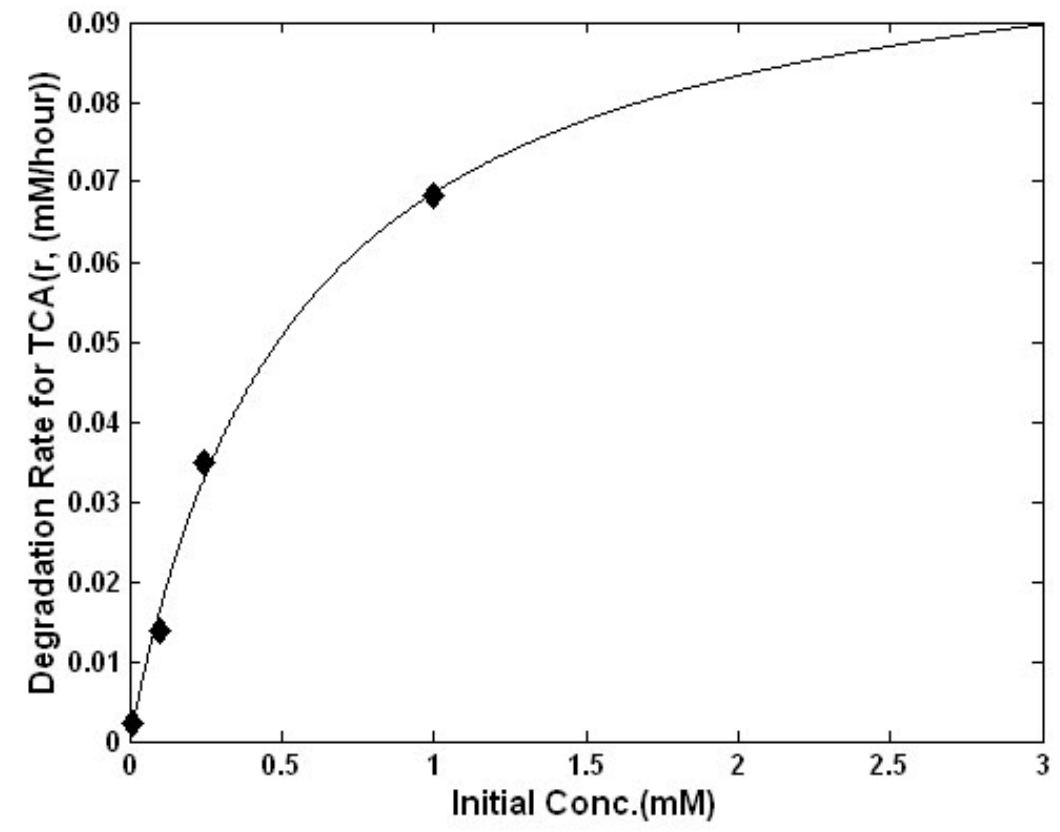

FIGURE 2-11 Dependence of initial degradation rates on initial substrate concentration (25). 


\subsubsection{Iron and sulfide minerals}

In anoxic subsurface environment, dissimilatory $\mathrm{Fe}(\mathrm{III})$-reducing bacteria (DIRB) and sulfate-reducing bacteria (SRB) plays an important role on the formation of reduced iron and sulfide minerals, such as pyrite (102) and magnetite $(103,104)$.

Sulfide minerals are very sensitive to oxidation so that they cannot be present in a great amount under aerobic conditions. The reduction of sulfate to sulfide requires a sulfate source, SRB (e.g., Disulfovibrio), a carbon source for microorganisms, and anaerobic environments (102).

$$
\begin{aligned}
& \mathrm{SO}_{4}^{2-}+2 \mathrm{CH}_{2} \mathrm{O} \stackrel{\text { SBR }}{\longrightarrow} \mathrm{H}_{2} \mathrm{~S}+2 \mathrm{HCO}_{3}^{-} \\
& \mathrm{Fe}^{2+}+\mathrm{S}^{2-} \rightarrow \mathrm{FeS} \\
& \mathrm{FeS}+\mathrm{S}^{0} \rightarrow \mathrm{FeS}_{2}
\end{aligned}
$$

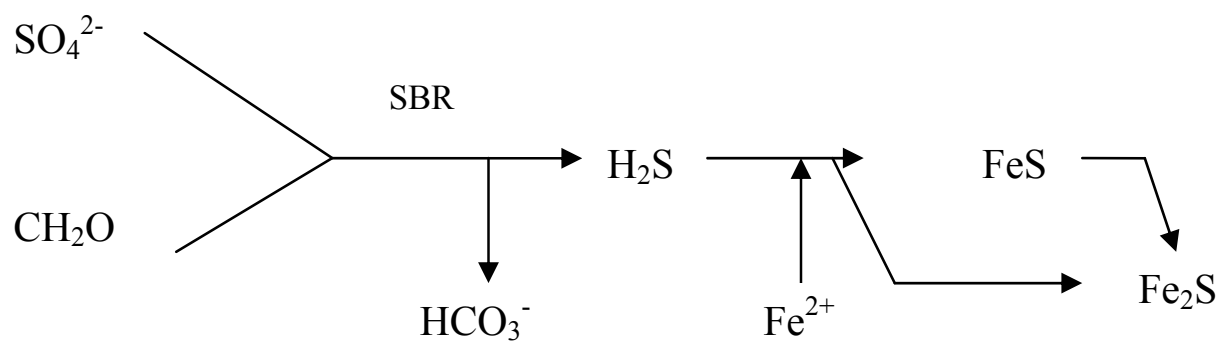

FIGURE 2-12 The reaction and schematic diagrams of pyrite formation (102). 
Fe(III)-(hydro)oxides (e.g., hydrous ferric oxide, goethite, hematite, magnetite) and structural Fe(III) in clay minerals can be reduced by DIRB (105). Even SRB, RS-1 (discovered by Sakaguchi and co-workers in 1993), is able to form magnetite (103). Bioavailability of Fe(III)-oxides to DIRB increases by the addition of Fe(III)-binding ligands, such as lactate or ethylenediaminetetraacetic acid (EDTA) (106).

The rate of $\mathrm{Fe}^{2+}$ release is very dependent on microbial physiological conditions so that high cell concentrations and the cultivation of cells in nutrient-rich media can increase $\mathrm{Fe}^{2+}$ releasing rate (105).

Magnetite is the most commonly formed mineral produced by dissimilatory $\mathrm{Fe}$ reduction $(37,104)$. It is mainly formed via reductive dissolution of ferrihydrite, which can be facilitated by the presence of $\mathrm{Cl}^{-}(104,107-109)$. The second major pathway of the formation of magnetite is the oxidation of GR, which is commonly found as an intermediate of corrosion processes (110).

Microbial reduction of $\mathrm{Fe}(\mathrm{III})$ and/or sulfate plays an important role in degradation of chlorinated solvents in the subsurface due to the reducing ability of iron or sulfide minerals. Those minerals have been intensively investigated $(10,11,26-40)$. Understanding the effect of minerals on reductive dechlorination of chlorinated solvents helps to predict the role of abiotic processes in natural attenuation (36).

Green rust is a LDH that has a large surface area due to its interlayer and can act as a reductant for $\mathrm{CT}$ (26), PCE, TCE, cis-DCE, and VC (27). Its ability as a reductant is dramatically improved when metals, such as $\mathrm{Ag}, \mathrm{Au}$, and $\mathrm{Cu}(28)$ for $\mathrm{CT}$ and $\mathrm{Ag}, \mathrm{Cu}, \mathrm{Pb}$, 
and Pt (29) for PCE, are added to GR. Reductive dechlorination with GR and modified GR follows either the hydrogenolysis or the reductive elimination pathway $(27,29)$.

Butler and Hayes demonstrate the reductive dechlorination of hexachloroethane (HCA), PCE, TCE, and chlorinated ethane by iron sulfide. Most of them were degraded with the half-lives of hours to days. The rate limiting steps were electron transfer and chloride bond cleavage (30-32). The reductive ability of iron sulfide for HCA also increases with addition of a soft transition metal, such as $\mathrm{Ni}(\mathrm{II}), \mathrm{Cu}(\mathrm{II}), \mathrm{Zn}(\mathrm{II}), \mathrm{Cd}(\mathrm{II})$, and $\mathrm{Hg}(\mathrm{II})$ (33). Methanogenic activities also improve the reducing power of $\mathrm{FeS}$ for transforming 1,1,1-TCA (34). Reductive dechlorination of CT, PCE, and TCE by pyrite is also observed $(10,35,36)$.

Iron oxides, such as magnetite and goethite, show the ability to degrade chlorinated aliphatic compounds (36-38). The additions of Fe(II) to magnetite (36) and $\mathrm{Cu}(\mathrm{II})$ to goethite (38) enhance degradation of chlorinated aliphatic compounds. The reactive surface bound $\mathrm{Fe}(\mathrm{II})$ species are able to be regenerated by transition metals, which are contaminants in aquifers, or, by Fe(II), which is produced by DIRB. This results in maintaining reductive ability over long periods $(36,38)$. Reductive dechlorination of chlorinated aliphatic compounds is observed by iron-bearing clay minerals, such as biotite and vermiculite $(11,39,40)$.

2.2.2.3 Zero-valent metals and Permeable reactive barriers

Reductive dechlorination of chlorinated solvents by zero-valent metal (ZVM) $(13,14,19-22)$ has been an active research area since Gillham and coworkers (111) 
proposed zero-valent iron (ZVI) as a reductant. Since then, permeable reactive barriers (PBR) employing ZVI are the most commonly applied technology for in-situ ground water remediation, because they are inexpensive (100). Degradation reactions occur at the metal surface $(111,112$,$) . There are three possible pathways for reductive$ degradation in PBR (figure 2-13). According to Matheson and Tratnyek (100), the direct electron transfer from metal to sorbed organic compounds (figure 2-13(A)) is a principal reductive dechlorination mechanism. The dissociation of water, resulting in the formation of hydrogen reaction, is also a possible reaction pathway, due to the observation of increasing $\mathrm{pH}$ (figure 2-13(B)) (111).

Rate constants are proportional to specific surface area (surface area of iron per solution volume) $(111,112)$. Therefore, first-order rate constants are normalized by a specific area concentration $\left(\mathrm{k}_{\mathrm{SA}}\right.$ in order to describe the kinetics of dechlorination by zero-valent iron more generally (14). The rate-determining step of reductive dechlorination in a PBR is mass transport of the target compounds to the metal surface. Other factors that affect the long-term operation of PBRs are the formation of precipitates on the metal surface (decreasing permeability), sulfide (affecting redox chemistry of iron), and bacterial activities (oxidizing and reducing Fe) (100).

Frequently found precipitates in PBRs are Fe (oxy)hydroxides, such as goethite, magnetite, and ferrihydrite, green rust, amorphous FeS, and calcium and Fe carbonate (113-115). They are formed as a result of Fe corrosion and deteriorate iron reactivity due to clogging pores $(114,115)$. Fe corrosion is developed either geochemically (114) or microbially (115). 
A)
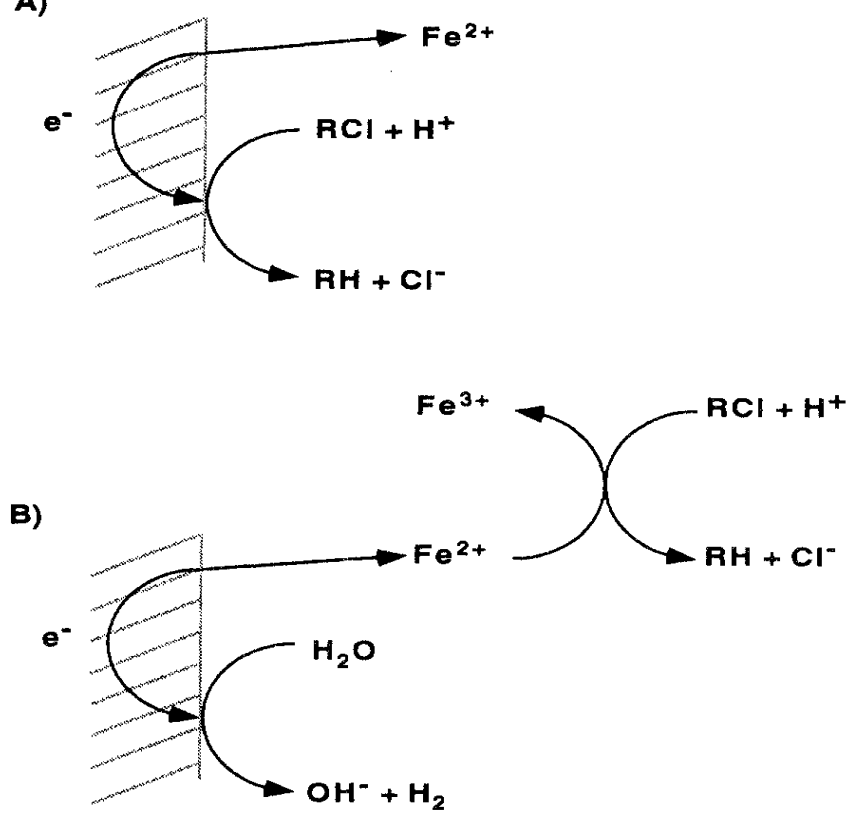

c)

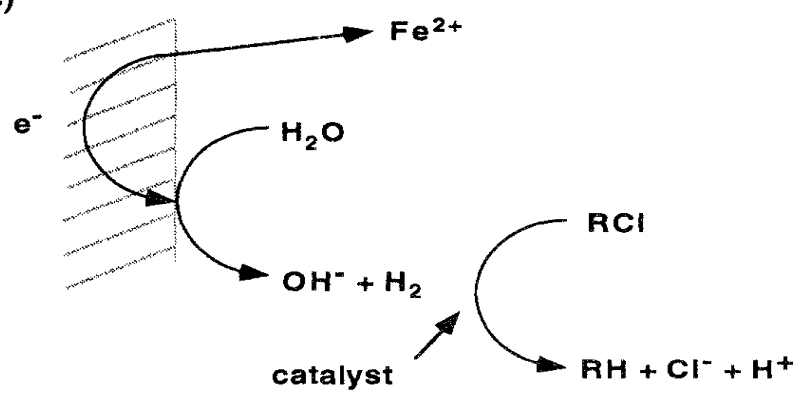

FIGURE 2-13 Scheme showing proposed pathways for reductive dehalogenation in anoxic $\mathrm{Fe}^{0}-\mathrm{H}_{2} \mathrm{O}$ systems. (A) direct electron transfer from iron metal at the metal surface; (B) reduction by $\mathrm{Fe}^{2+}$, which results from corrosion of the metal; (C) catalyzed hydrogenolysis by the $\mathrm{H}_{2}$ that is formed by reduction of $\mathrm{H}_{2} \mathrm{O}$ during anaerobic corrosion (100). 
Modified ZVMs can be produced by adding metals such as $\mathrm{Pd}, \mathrm{Cu}, \mathrm{Ni}$ and $\mathrm{Pt}$, which form a metallic coating on the ZVM surface. These bimetallic reductants can be applied to reductive dechlorination. (15-17). Metal catalysts might reduce the activation energy for reductive dechlorination, so that reaction rates increase (15).

Zero-valent silicon/iron $\left(\mathrm{Si}^{0} / \mathrm{Fe}^{0}\right)$ can also serve as a reductant for reductive dechlorination (18). Even though the oxidative dissolution of $\mathrm{Si}^{0}$ forms silicon dioxide $\left(\mathrm{SiO}_{2}\right)$ on the surface of silicon after a long exposure to humid air, the removal reaction of hydrogenated silicon and silicon oxide is catalyzed by hydroxide ion $\left(\mathrm{OH}^{-}\right)$.

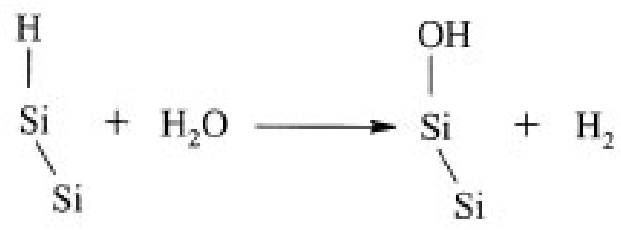

It might be a great advantage to operate a PBR with $\mathrm{Si}^{0} / \mathrm{Fe}^{0}$ because consumption of hydroxide ion by silicon keeps $\mathrm{pH}$ from increasing. Iron oxide precipitation on the zerovalent iron surface can be prevented through the $\mathrm{pH}$ buffering ability of $\mathrm{Si}^{0}$ thereby avoiding the problems of reduced permeability and reactivity found in $\mathrm{Fe}^{0}$-PBRs (18).

According to Arnold and Roberts (13), reductive $\beta$-elimination is a major reaction for dechlorination of PCE, TCE, cis- and trans-DCE and hydrogenolysis of cisand trans-DCE to acetylene. The rate of reductive dechlorination by ZVI increases with increasing degree of chlorination, that is, the degradation rate of PCE is about 5 times faster than that for TCE and 3 to 60 times faster than that for DCE isomers $(19,20)$. 


\subsection{X-ray diffraction}

$\mathrm{X}$-ray diffraction (XRD) is the most widely used method to identify unknown minerals and determine crystal structures. Each mineral has its own atomic arrangement and distances between crystal planes, thus, it shows its unique XRD pattern (116). Mineral samples with particle sizes less than $50 \mu \mathrm{m}$ in the diameter are scanned through diffraction angle and plots of x-ray intensity versus twice diffraction angle (20) are obtained. Bragg's law is used to relate the location of x-ray peaks in the plots with distances between diffracting crystal plans (117). Bragg's law (117) is

$$
\frac{d}{n}=\frac{\lambda}{2 \sin \theta}
$$

where, $d=$ perpendicular distance between diffracting planes to diffracting angle; $\theta=$ diffracting angle; $\mathrm{n}=$ order of diffraction, usually $\mathrm{n}$ is unknown, so it set as $1 ; \lambda=$ wavelength of $\mathrm{x}$-ray radiation; $\mathrm{d} / \mathrm{n}=\mathrm{d}$-value. These $\mathrm{d}$-values resulting from XRD are characteristics of each mineral and used to identify the minerals.

The wavelength of $\mathrm{x}$-ray is between 0.1 and $10 \AA$ and depends on the energy of the electron and the materials it hits. When x-rays hit the target materials, two kinds of x-ray beams are emitted. White radiation is a continuous spectrum of $\mathrm{x}$-ray (figure 2-14(A)) and characteristic x-ray (figure 2-14(B)) is characteristic of the target element that produces the $\mathrm{x}$-ray (118). The continuous spectrum of $\mathrm{x}$-ray is background noise and has to be removed by filtering. Along with the continuous spectrum, $\mathrm{K}_{\beta}$ must be also removed to have monochromatic $\mathrm{x}$-rays of $\mathrm{K} \alpha$, which has the greatest intensity. Table 23 present the wavelengths of characteristic x-ray commonly used as targets and suitable thickness. Copper is the most frequently used target. 
Fluorescent x-radiation, resulting from an exited element in the specimen by primary x-ray beams, increases background noise and, thus, reduces the clarity of x-ray diffraction. To avoid unwanted fluorescent effects, a proper target should be chosen. For example, if the sample contains high amounts of iron, copper would be not a good target. Cobalt or iron radiation would be better. However, copper radiation gives a higher intensity than cobalt and iron. Another way to reduce fluorescent effect while using copper as target is to put a crystal monochromator between the specimen and the counter (118).

XRD data are collected in a series of books called the Joint Committee on Power Diffraction Standards (JCPDS) X-ray Powder Data File (PDF). This book lists d-values with relative intensity along with crystallography, physical property and optical data of each mineral (119). Minerals can be identified by either Hanawalt or chemical index. Three strongest peaks are listed in the Hanawalt index. Under the assumption of possible chemical compositions of suspected minerals, search chemical index until the three strongest peaks get matched (120). 
TABLE 2-3 X-ray wavelengths and suitable filters to give $\mathrm{K}_{\beta 1} / \mathrm{K}_{\alpha 1}=1 / 100$ (118)

\begin{tabular}{|c|c|c|c|c|c|c|c|c|c|}
\hline \multirow{2}{*}{$\begin{array}{l}\text { Target } \\
\text { element }\end{array}$} & \multicolumn{4}{|c|}{ Wavelength $(\AA)$} & \multirow{2}{*}{$\begin{array}{l}\beta \\
\text { filter }\end{array}$} & \multirow{2}{*}{$\begin{array}{l}\text { Thickness } \\
\text { (mm) }\end{array}$} & \multirow{2}{*}{\multicolumn{3}{|c|}{$\begin{array}{l}\text { High fluorescence } \\
\text { from }\end{array}$}} \\
\hline & $\mathrm{K}_{\alpha 1,2}$ & $\mathrm{~K}_{\alpha 1}$ & $\mathrm{~K}_{\alpha 2}$ & $\mathrm{~K}_{\beta}$ & & & & & \\
\hline Mo & 0.7107 & 0.7093 & 0.7135 & 0.6323 & $\mathrm{Zr}$ & 0.08 & $\mathrm{Y}$ & $\mathrm{Sr}$ & $\mathrm{Ru}$ \\
\hline $\mathrm{Cu}$ & 1.5 & 1.5405 & 1.5443 & 1.3922 & $\mathrm{Ni}$ & 0.015 & Co & $\mathrm{F}$ & $\mathrm{Mn}$ \\
\hline Co & 1.7902 & 1.7889 & 1.7928 & 1.62 & $\mathrm{Fe}$ & 0.0 & $\mathrm{Mn}$ & $\mathrm{Cr}$ & V \\
\hline $\mathrm{Fe}$ & 1.9373 & 1.9360 & 1.9399 & 1.7565 & $\mathrm{Mn}$ & 0.011 & $\mathrm{Cr}$ & $\mathrm{V}$ & $\mathrm{Ti}$ \\
\hline
\end{tabular}
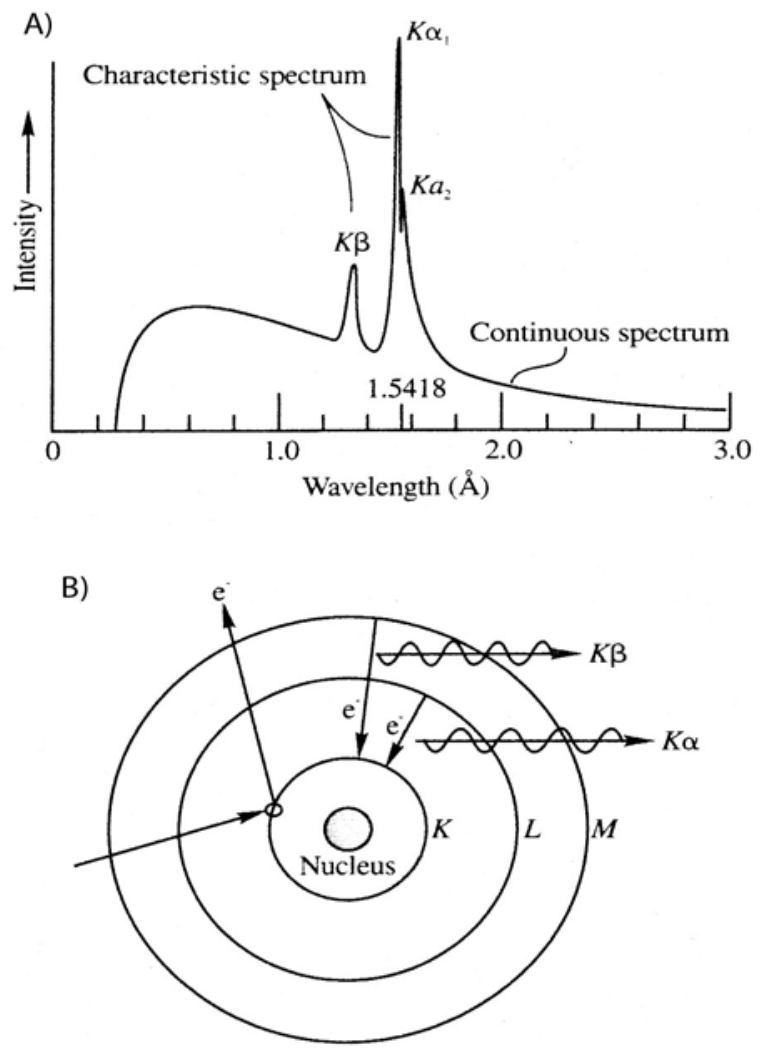

FIGURE 2-14 X-ray spectra. (A) Intensity of X-rays emitted by a copper target operated at $50 \mathrm{kV}$. The characteristic spectrums (peaks) are superimposed on the continuous spectrum. (B) The characteristic spectrum is produced when electrons are dislodged from the K shell and electrons from outer shell drop in to occupy the vacancy (119). 
The quantitative interpretation of diffraction patterns is possible because intensity of diffraction is related to the number of planes. The relative intensity can give an estimation of mineral concentrations. There are two methods to estimate the concentrations of a mineral. One is the internal standard method, which uses a calibration curve and the other is the standard addition method, where known amounts of material are added to the sample. The second method does not require a calibration curve to determine the concentration of minerals, but uses the ratio of the relative intensity (120). The relative intensity is also affected by other factors, such as particle size, crystal perfection, and chemical composition, variations in sample packing, crystal orientation, and presence of amorphous substances (121). Therefore, quantification of minerals by XRD is very difficult (120).

\subsection{Electron microscopy}

Scanning election microscopy (SEM) and electron probe microanalyzer (EPMA) can examine the surface of heterogeneous organic and inorganic materials at a micrometer $(\mu \mathrm{m})$ or submicrometer scale. Both instruments use very finely focused electron beams to examine specimens. The types of electron beams include secondary electrons, backscattered electrons, augur electrons, characteristic x-rays, and photons of various energies (figure 2-15). SEM often uses secondary electrons and backscattered electrons to produce images. EPMA uses mainly characteristic x-ray to yield both qualitative and quantitative compositional analyses of micrometer scale area of a specimen (63). 
The useful features of SEM yield high resolution and a three-dimensional image, while EPMA can gather compositional information nondestructively, as well as create compositional mapping. The energy-dispersive spectrometer (EDS) is the most commonly used x-ray analyzer (63).

The components of an SEM are the three lens systems, electron gun, electron collector, visual and recording cathode ray tubes (CRT), and the electronics associated them (figure 2-16). An electron gun produces an electron beam having the range of 1 to $40 \mathrm{KeV}$ of the energy and then three electron lenses generate a finely focused beam, which forms a spot less than about $10 \mathrm{~nm}$ on the specimen surface. Two pairs of scan coils control the magnification, which is defined as the ratio of the linear size of the viewing screen to the linear size of the rater on the specimen. This is done by controlling the deflection distance of the raster of the beam on the specimen. The electron detector collects the signal and the camera records the images (63).

Samples used in SEM are required to eliminate or reduce the electric charge and image distortion. The electric charge is generated when the high energy of the beam scans the surface of samples. Samples are usually coated with conductive materials, such as gold, platinum, palladium, or carbon, to reduce the electric charge on the surface of samples (63). 


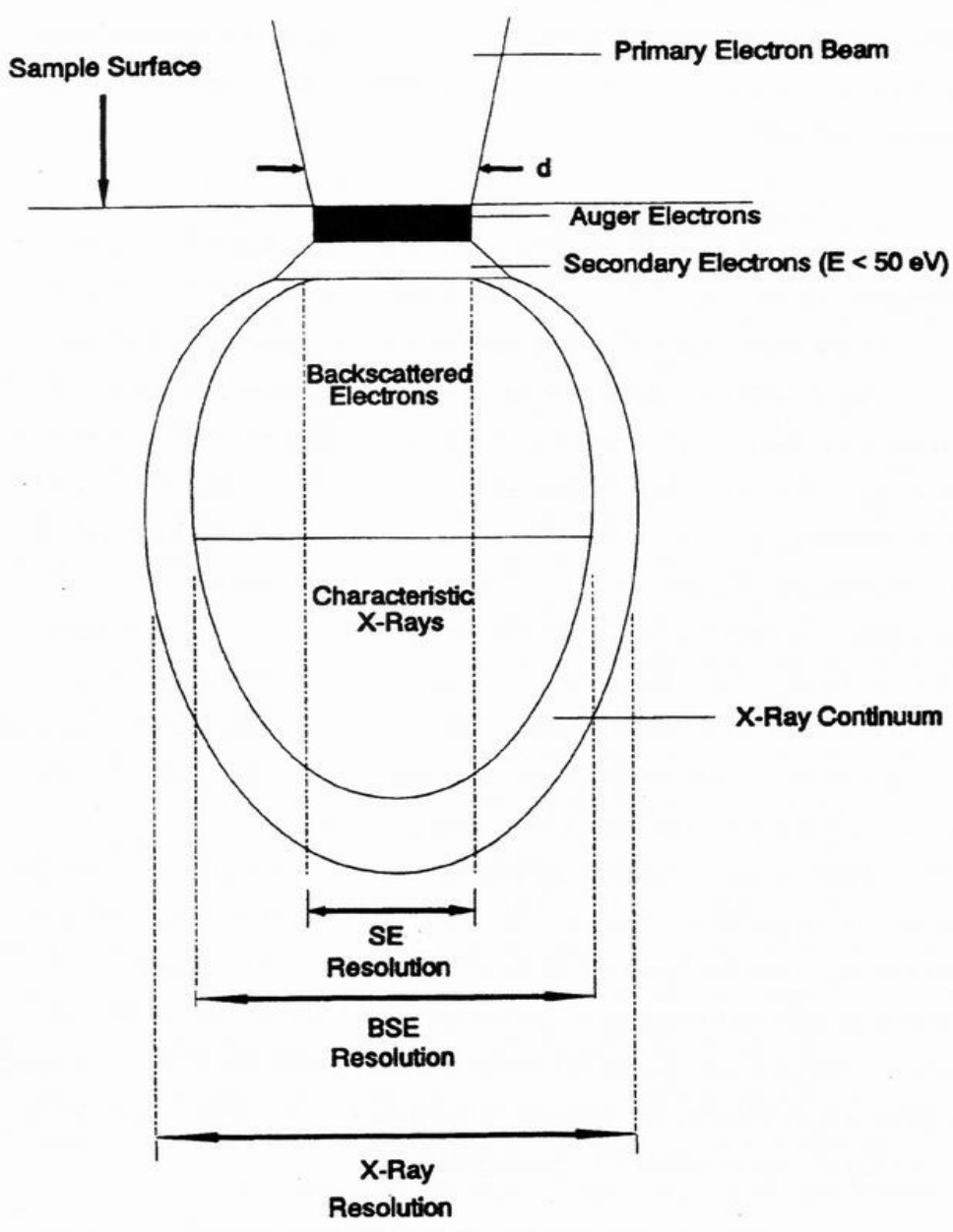

FIGURE 2-15 Types of signals resulting from the interaction of an electron beam with a sample (63). 


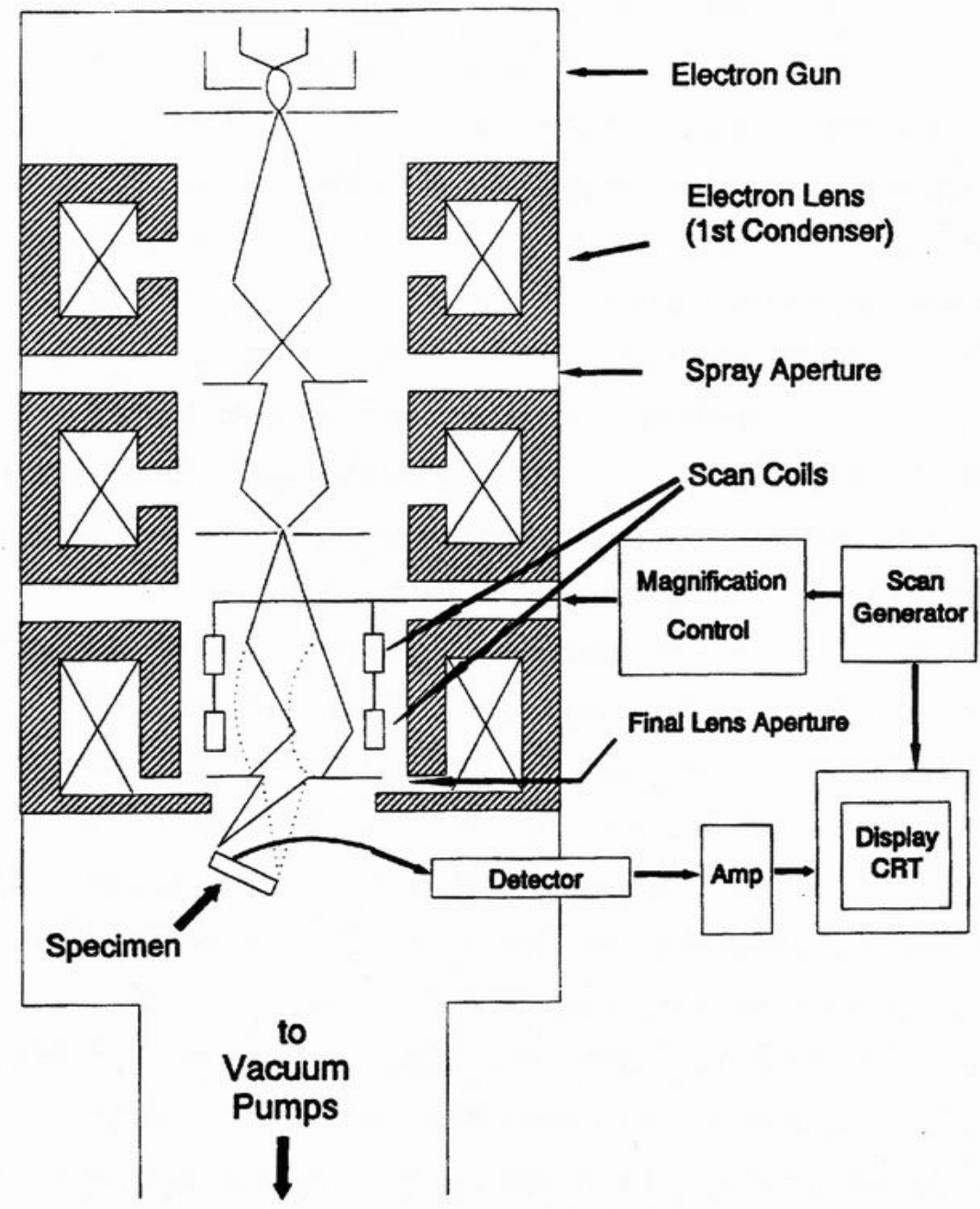

FIGURE 2-16 Schematic of SEM showing the electron column, the deflection system, and the electron detectors (63).

Relatively accurate quantitative analysis of elements above $\mathrm{Na}$ can be achieved, but this is more difficult for elements below Be in the periodic table. The detection limit of X-ray analysis is normally 50-100 part per millions (ppm) (122). The concentration of a given element in the analyzed region is proportional to x-ray intensities emitted by a 
specimen (63). In addition, each element has its own characteristic wavelength, so that differentiated quantum energy can be obtained using the following equation,

$$
\boldsymbol{E}(\boldsymbol{K e V})=\frac{12.396}{\lambda}
$$

where, $\lambda=$ wavelength of each photon, $\AA$. For example, $\mathrm{NiK}_{\alpha}$ is $1.659 \AA$ and quantum energy for $\mathrm{Ni}$ is $7.471(=12.396 / 1.659) \mathrm{KeV}$. Thus, typical $\mathrm{x}$-ray spectrum can be obtained by the plot of quantum energy (x-axis) versus intensity ( $\mathrm{y}$-axis), providing qualitative or semi-quantitative analyses of a selected region of a specimen (122). 


\section{CHAPTER III \\ METHODOLOGY}

\subsection{Materials}

Tetrachloroethylene (99.9+\%, HPLC grade, Aldrich) was used as a target organic compound. Portland cement (Capitol Cement, Lehigh, and Quikrete for type I and Txi for type I/II) and ferrous chloride (99+\%, tetrahydrate, Aldrich) were used as DS/S agents. Synthetic cement extract solutions were made using the following chemicals (ACS or higher grade): aluminum chloride (hexahydrate, 98+\%, Sigma), boric acid (Matheson), barium chloride (dehydrate, 100.3\%, Fisher Scientific), beryllium sulfate (tetrahydrate, 99+\%, Fluka), calcium chloride (dihyrate, 99.5\%-105.0\%, ACS grade, EM), ferric chloride (hexahydrate, 98+\%, Sigma), cupric chloride (dehydrate, 99+\%, Aldrich), magnesium chloride (hexahydrate, 99+\%, EM), magnesium sulfate (heptahydrate, 98+\%, EM), manganous sulfate (monohydrate, 98.6+\%, Fisher Scientific), nickel sulfate (hexahydrate, Aldrich), strontium chloride (hexahydrate, 99+\%, Fluka), zinc chloride (anhydrous, 98+\%, EM), sodium silicate (ACS grade, Fisher Scientific). The following chemicals were used to synthesize cement hydration products of monosulfate, Friedel's salt, Kuzel's salt and tetracalcium aluminate hydrate: calcium chloride (dihydrate, 99.5\%-105.0\%, ACS grade, EM), sodium aluminate (anhydrous, EM), calcium sulfate (dehydrate, 101.5\%, ACS grade, Sigma), aluminum chloride (hexahydrate, 98+\%, Sigma). Sodium chloride (100.8\%, ACS grade, Mallinckrodt) and sodium sulfate $(99.9 \%$, ACS grade, Sigma) were used to adjust chloride and sulfate 
concentrations in synthetic cement extract (SCX). Sodium carbonate $(99.0 \%$, ACS grade, Sigma) was used to remove calcium in Portland cement extract (PCX). De-aerated deionized water was prepared by purging water purified by the Barnstead Nanopure system with nitrogen for at least 12 hours in an anaerobic chamber (Coy Laboratory Product) that contained 5\% hydrogen and 95\% nitrogen. Ferrous chloride stock solutions were prepared daily in de-aerated deionized water in the anaerobic chamber. PCE stock solution was prepared daily in methanol (99.8\%, HPLC grade, EM). Calcium hydroxide (Fisher Scientific) and sodium hydroxide $(97+\%$, ACS grade, EM) were used to maintain $\mathrm{pH}$ around 12 . Hydrochloric acid (36.5\%-38\%, ACS grade, EM) was used to dissolve cement.

\subsection{Analytical procedures}

PCE was analyzed by gas chromatography (Hewlett-Packard 5890 GC with a combination of DB-5 column $(30 \mathrm{~m} \times 0.35 \mathrm{~mm}$ i.d. $\times 0.25 \mu \mathrm{m}$ film thickness, $\mathrm{J} \& \mathrm{~W}$ Scientific), and an electron capture detector (ECD)). Aqueous samples were separated from solid phases by centrifuging the reaction vials at $2000 \mathrm{rpm}(739 \mathrm{~g})$ for $3 \mathrm{~min}$ (International Equipment CO., model CS centrifuge). PCE in the liquid phase was extracted with hexane $(99.9 \%$, HPLC grade, EM) containing 1,2-dibromopropane (1,2DBP, 97\%, Aldrich) as an internal standard.

Solid phases containing potential active agents were characterized by X-ray Diffraction and Scanning Electron Microscope with Electron-Dispersive Spectrometer. Riga automated diffract meter using $\mathrm{Cu} \mathrm{K} \alpha$ radiation $(\lambda=1.5406 \AA)$ was used to obtain 
the powder X-ray patterns (Geology Department and Texas Transport Institute at Texas A\&M University). The sample was scanned between $5 \theta$ and $60 \theta$ with scan speed 30/minute for XRD analysis. JEOL 6400 Scanning Microscope (Microscopy and Image center at Texas A\&M University) was used to analyze morphology and chemical compositions of the sample.

Ferrozine method (123) was used for Fe(II) and total iron analysis (UV-VIS spectrophotometer, Hewlett Packard G1103A).

\subsection{Experiment procedures}

\subsubsection{Reactor system}

A completely mixed batch reactor was used for the PCE degradation test. The clear borosilicate glasses were used with screw caps lined with three layers: Teflon, lead foil, and Teflon-lined rubber septum $(23,27,36)$.

\subsubsection{Preparation of $10 \%(w / v)$ PCX}

Portland cement was dissolved by mixing it with strong acid $(2.2 \mathrm{~N} \mathrm{HCl})$ on the shaking table for at least 24 hours. After 24 hours, the mixture of Portland cement and acid were transferred to several 250-ml plastic centrifuge bottles and centrifuged at 6000 rpm (6650g) for 5 min (Beckman, model J-6M centrifuge, JS-7.5 rotor). Supernatant was filtered with filter paper $(2 \mu \mathrm{m}$ quantitative filter paper, VWR scientific products) to remove the visible suspension and solids at the bottom of bottle were discarded. The filtered solution was called a Portland cement extract (PCX) and was used to prepare the 
potential active agent. In order to remove oxygen, PCX was purged with nitrogen for at least 24 hours in an anaerobic chamber that contained 5\% hydrogen and 95\% nitrogen.

\subsubsection{Identification of conditions that promote formation of the active agents}

Activity tests of all synthesized solids were conducted as one-point kinetic experiments in an anaerobic chamber. Ferrous chloride was used as the ferrous iron source and the reaction $\mathrm{pH}$ was around 12. PCE controls were prepared in duplicate and all solid samples were prepared in triplicate. A control contained de-aerated deionized water and PCE. A volume $(10 \mu \mathrm{l})$ methanolic PCE stock solution was added to the suspension $(24.3 \mu \mathrm{l})$ of the potential active agent to achieve an initial concentration of $0.242 \mathrm{mM}$. As soon as PCE was spiked, three-layered closures capped the vials. Then the vials were placed on the tumbler that provides end-over-end rotation at $7 \mathrm{rpm}$ at room temperature. PCE concentration in the liquid phase was measured as a function of time.

\subsubsection{Ca effect}

PCX prepared from $100 \mathrm{~g} / \mathrm{L}$ Portland cement $(10 \% \mathrm{w} / \mathrm{v})$ was pretreated with sodium carbonate to remove calcium. The $\mathrm{pH}$ of the mixture of was adjusted to 10 and mixed for 2 hours. Supernatant of this carbonate-pretreated PCX (CPCX) was taken after centrifugation. Two types of solids were prepared using CPCX. One was a mixture of $\mathrm{Fe}(\mathrm{II})$, calcium chloride and CPCX and another was a mixture of Fe(II) and CPCX. The $\mathrm{pH}$ values of both were adjusted to 11.7 by adding $5 \mathrm{~N} \mathrm{NaOH}$ after putting all 
components together. The mixtures were allowed to react for 2 and 24 hours as shown in figure $3-1$.

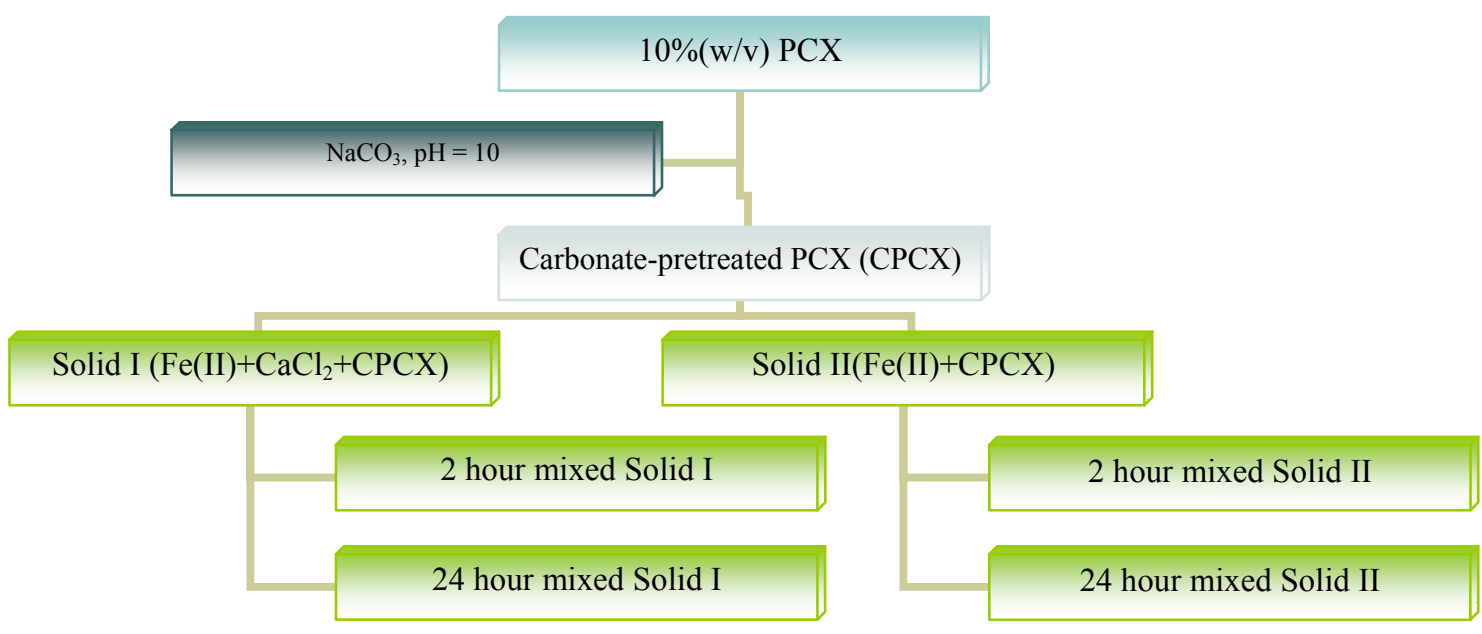

FIGURE 3-1 Schematic diagram of method of synthesizing solids to examine effect of calcium.

Abilities of solids produced from CPCX to degrade PCE were examined over a range of $\mathrm{pH}(10,10.5,11,11.5,11.7,12,12.5$, and 13), CPCX concentrations $(4.5 \%$, $8.6 \%, 17.3 \%$, and $34.5 \%$ of weight to volume) and PCX contents $(6 \%, 8 \%$, and $10 \%$ of weight to volume).

Experiments to evaluate the effect of $\mathrm{pH}$ on activity of solids produced from CPCX were conducted by first preparing 20\% (w/v) PCX by dissolving Portland Cement in $4.1 \mathrm{~N} \mathrm{HCl}$. Then, $20 \%(\mathrm{w} / \mathrm{v})$ PCX was evaporated passing dry air through the solution until its total volume was reduced by half. Air was dried by passing it through a column 
filled with desiccant. The resulting PCX content was $34 \%(\mathrm{w} / \mathrm{v})$ after evaporation. Sodium carbonate was added to $34 \%(\mathrm{w} / \mathrm{v}) \mathrm{PCX}$ to prepare CPCX. The $\mathrm{pH}$ was adjusted with $5 \mathrm{~N} \mathrm{HCl}$ and $5 \mathrm{~N} \mathrm{NaOH}$ to the desired values $(10,10.5,11,11.5,11.7,12,12.5,13)$. Experiments to examine the effects of concentration of PCX and CPCX were prepared by first preparing a 20\% (w/v) PCX solution by dissolving Portland Cement in 4.1 N HCl. Then, 20\% (w/v) PCX was evaporated by passing dry air through it until its total volume was reduced by half. The resulting PCX content was $34.5 \%(\mathrm{w} / \mathrm{v})$ after evaporation. Sodium carbonate was added to $34.5 \%$ (w/v) PCX to prepare CPCX. The concentrated CPCX $(34.5 \% \mathrm{w} / \mathrm{v})$ was diluted to make $4.3 \%, 8.6 \%$, and $17.3 \% \mathrm{CPCX}$. $\mathrm{Fe}(\mathrm{II})$ was added to each $\mathrm{CPCX}$ solution and $\mathrm{pH}$ was adjusted to 11.8 . The mixture was mixed for 24 hours in the anaerobic chamber. Two dilutions $(6 \%$ and $8 \% \mathrm{w} / \mathrm{v})$ of PCX were prepared from the concentrated solution $\left(10 \%\right.$ w/v). $\mathrm{Fe}(\mathrm{II})$ and $\mathrm{Ca}(\mathrm{OH})_{2}$ were added and mixed with PCX for 2 hours in the anaerobic chamber. After mixing, solid mixtures were centrifuged at $6000 \mathrm{rpm}$ for $5 \mathrm{~min}$ and solids from the upper were taken for the PCE degradation test.

\subsubsection{Effect of cement hydration product}

Monosulfate (124), Friedel's salt (125), tetracalcium aluminate hydrate (125) and Kuzel's salt (126) were synthesized in the lab to examine the effect of cement hydration products (CHPs) on solid activities. Each cement hydration product was mixed with ferrous or both ferrous and ferric iron to synthesize ferrous containing solid mixtures as indicated in Table 3-1. The suspensions were adjusted to the desired $\mathrm{pH}$ 
(11.7 or 12.1). Along with ferrous-containing solids, each cement hydration product without ferrous and/or ferric addition was examined to measure its activity in degrading PCE. In the case of Friedel's salt, two different mixing times, 10 days and 7 days, were used to synthesize the solid.

TABLE 3-1 The procedure to examine the effect of cement hydration product

\begin{tabular}{ccccc}
\hline CHPs & \multicolumn{2}{c}{$2 \mathrm{hr}$ mixing } & \multicolumn{2}{c}{$24 \mathrm{hr}$ mixing } \\
& $\mathrm{Fe}(\mathrm{II})$ & $\mathrm{Fe}(\mathrm{III})$ & $\mathrm{Fe}(\mathrm{II})$ & $\mathrm{Fe}(\mathrm{III})$ \\
\hline $\mathrm{C}_{4} \mathrm{AHx}$ & $39.2 \mathrm{mM}$ & & $39.2 \mathrm{mM}$ & \\
& $39.2 \mathrm{mM}$ & $47.8 \mathrm{mM}$ & $39.2 \mathrm{mM}$ & $47.8 \mathrm{mM}$ \\
10d mixed Friedel & $39.2 \mathrm{mM}$ & & $39.2 \mathrm{mM}$ & \\
& $39.2 \mathrm{mM}$ & $47.8 \mathrm{mM}$ & $39.2 \mathrm{mM}$ & $47.8 \mathrm{mM}$ \\
7d mixed Friedel & $39.2 \mathrm{mM}$ & & $39.2 \mathrm{mM}$ & \\
Kuzel & $39.2 \mathrm{mM} \mathrm{FeCl}_{2}$ & & $39.2 \mathrm{mM} \mathrm{FeCl}_{2}$ & \\
& $39.2 \mathrm{mM} \mathrm{FeSO}_{4}$ & & $39.2 \mathrm{mM} \mathrm{FeSO}_{4}$ & \\
\hline
\end{tabular}

\subsubsection{Effect of synthetic cement extract (SCX)}

Synthetic cement extract (SCX) was prepared with the composition described by Table 3-2. The concentrations of the elements in table 3-2 are the same as those measured in PCX (10\%) (127). Each stock solution was made in $0.01 \mathrm{~N} \mathrm{HCl}$. Ferrous iron was mixed with SCX for 3 days in the anaerobic chamber to produce reactive solids. Three different kinds of SCX were prepared. One contained all elements of PCX. The second excluded only one element of PCX, and the third excluded all major PCX elements $\left(\mathrm{Ca}, \mathrm{Mg}, \mathrm{Al}\right.$, and $\left.\mathrm{SO}_{4}\right)$. PCE degradation tests were conducted after a 3-day mixing period. The $\mathrm{pH}$ was adjusted to 12.0 with $1.25 \mathrm{M} \mathrm{Ca}(\mathrm{OH})_{2}$ for $\mathrm{SCX}$ containing full PCX elements and with $5 \mathrm{~N} \mathrm{NaOH}$ for SCX that excludes individual elements. 
TABLE 3-2 Stock solution of each element consisting in SCX and element compositions of SCX in each experiment

\begin{tabular}{lrrrrr}
\hline Chemical & $\begin{array}{c}\text { Conc } \\
\text { mM }\end{array}$ & MW & $\begin{array}{c}\text { stock } \\
\text { mM }\end{array}$ & g/100ml & $\begin{array}{c}\text { added } \\
\text { amt } \\
\text { mL }\end{array}$ \\
\hline $\mathrm{CaCl}_{2}$ & 1000 & 147.02 & & 14.70 & \\
$\mathrm{AlCl}_{3}$ & 47.8 & 241.4 & 477.8 & 11.53 & 10 \\
$\mathrm{MgSO}_{4}$ & 6.98 & 246.48 & 698 & 17.20 & 1 \\
$\mathrm{MgCl}_{2}$ & 15.25 & 203.3 & 152.5 & 3.10 & 10 \\
$\mathrm{MnSO}_{4}$ & 0.41 & 169.01 & 41 & 0.693 & 1 \\
$\mathrm{SrCl}_{2}$ & 1.07 & 266.62 & 107 & 2.85 & 1 \\
$\mathrm{Na}_{2} \mathrm{SiO}_{3}$ & 1.62 & 284.2 & 162 & 4.60 & 1 \\
$\mathrm{H}_{3} \mathrm{BO}_{3}$ & 0.35 & 61.83 & 35 & 0.216 & 1 \\
$\mathrm{BaCl}_{2}$ & 0.05 & 244.28 & 5 & 0.122 & 1 \\
$\mathrm{BeSO}_{4}$ & 0.005 & 177.14 & 5 & 0.0886 & 0.1 \\
$\mathrm{CuCl}_{2}$ & 0.02 & 170.48 & 20 & 0.341 & 0.1 \\
$\mathrm{FeCl}_{3}$ & 0.4 & 270.3 & 40 & 1.08 & 1 \\
$\mathrm{NiSO}_{4}$ & 0.04 & 262.86 & 4 & 0.105 & 1 \\
$\mathrm{ZnCl}_{2}$ & 0.24 & 136.28 & 24 & 0.327 & 1 \\
$\mathrm{Cl}_{\text {TotSCX }}$ & 2178 & & & & \\
$\mathrm{SO}_{440 t S C X}$ & 7.44 & & & & \\
$\left.\mathrm{Ca}_{4} \mathrm{OH}\right)_{2}$ & 1250 & 74.09 & & 9.26 & \\
$\mathrm{FeCl}_{2}$ & 39.2 & 198.8 & 196 & 3.896 & 20 \\
\hline
\end{tabular}

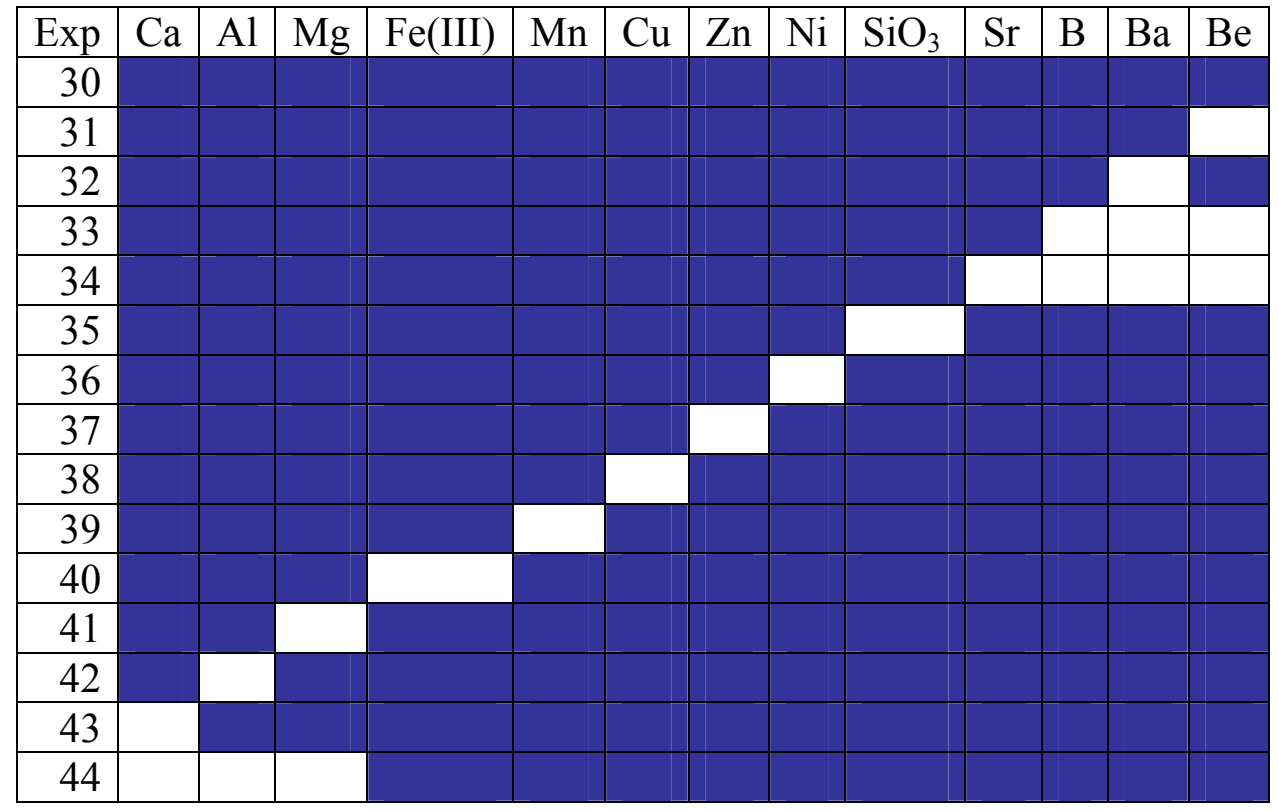

No filled box indicates the absence of an element in each experiment 


\subsubsection{Effect of major cement extract element}

$\mathrm{Fe}(\mathrm{III}), \mathrm{Mg}, \mathrm{Al}, \mathrm{SO}_{4}$, and/or $\mathrm{SiO}_{3}$ were used to synthesize another set of solids that potentially could contain high concentrations of the active agent. $\mathrm{Fe}(\mathrm{II})$ and $\mathrm{Cl}$ were always added to the mixtures because they were presumed to be the critical elements for the formation of the active agent (127) and PCE degradation tests were performed with the solids produced after mixing for 3 days in the anaerobic chamber. The concentrations of these elements other than $\mathrm{Fe}(\mathrm{III})$, presented in table 3-3, were chosen as the same as ones in section 3.3.3.3. The lower concentration of Fe(III) to be used $(0.4 \mathrm{mM})$ was the same as in table 3-2. The higher concentration of Fe(III) $(13.1 \mathrm{mM})$ was chosen to make the ratio of $\mathrm{Fe}(\mathrm{II})$ to $\mathrm{Fe}(\mathrm{III})$ equal to 3, which was the same ratio found in chloride green rust $(\mathrm{GR}(\mathrm{Cl}))$, which was a presumable active agent in Fe(II)-DS/S system. These solids were synthesized in two ways. One way simply mixed the necessary elements at once (table 3-3) and the other applied a method used to synthesize GR (128) (Table 3-4). The effect of the concentration of ferric iron $(0.4 \mathrm{mM}, 2 \mathrm{mM}, 4 \mathrm{mM}, 6 \mathrm{mM}, 8 \mathrm{mM}$, and $10 \mathrm{mM})$ and the effect of mixing time (2h, 12h, 1d, 2d, and 3d) on the activity of solids were examined for solids prepared with the simple technique. 
TABLE 3-3 Different element compositions for the simple mixing method in which solids were synthesized from major element of PCX

\begin{tabular}{rrrrcccc}
\hline \multirow{2}{*}{ Exp } & \multicolumn{7}{c}{ Element(mM) } \\
\cline { 2 - 8 } & $\mathrm{Fe}(\mathrm{II})$ & $\mathrm{Fe}(\mathrm{III})$ & $\mathrm{Cl}$ & $\mathrm{Mg}$ & $\mathrm{Al}$ & $\mathrm{SO}_{4}$ & $\mathrm{SiO}_{3}$ \\
\hline 47 & 39.2 & 0.4 & 2178 & & & & \\
48 & 39.2 & 0.4 & 2178 & 22.2 & & & \\
49 & 39.2 & 0.4 & 2178 & & 47.8 & & \\
50 & 39.2 & 0.4 & 2178 & 22.2 & 47.8 & & \\
51 & 39.2 & 13.1 & 2178 & & & & \\
52 & 39.2 & 13.1 & 2178 & 22.2 & & & \\
53 & 39.2 & 13.1 & 2178 & & 47.8 & & \\
54 & 39.2 & 13.1 & 2178 & 22.2 & 47.8 & & \\
55 & 39.2 & 0.4 & 2178 & & & 7.44 & \\
56 & 39.2 & 0.4 & 2178 & & 47.8 & 7.44 & \\
57 & 39.2 & 13.1 & 2178 & & & 7.44 & \\
58 & 39.2 & 13.1 & 2178 & & 47.8 & 7.44 & \\
59 & 39.2 & 0.4 & 2178 & & & & 1.62 \\
\hline
\end{tabular}


TABLE 3-4 Different element compositions and element addition orders for the GR synthesis method in which solids were synthesized from major element of PCX

(a) Solid consisting of $\mathrm{Fe}(\mathrm{II}), \mathrm{Fe}(\mathrm{III})$, and $\mathrm{Cl}$

\begin{tabular}{|c|c|c|c|c|c|c|}
\hline & $\begin{array}{c}\text { Element } \\
\text { addition } \\
\text { order }\end{array}$ & $1^{\text {st }}$ & \multicolumn{2}{|c|}{$2^{\text {nd }}$} & $3^{\text {rd }}$ & $4^{\text {th }}$ \\
\cline { 2 - 7 } & Element & $\mathrm{Cl}$ & $\mathrm{Fe}(\mathrm{II})$ & $\mathrm{Fe}(\mathrm{III})$ & $\mathrm{OH}^{\mathrm{a}}$ & $\begin{array}{c}\text { Adjust } \\
\mathrm{pH}^{\mathrm{b}}\end{array}$ \\
\hline $\begin{array}{c}\text { Exp.71-75 } \\
\text { Exp.76-80 }\end{array}$ & Conc. & $2.17 \mathrm{M}$ & $39.2 \mathrm{mM}$ & $8.7 \mathrm{mM}$ & $70 \mathrm{mM}$ & 12.0 \\
\cline { 3 - 7 } & & & & $110 \mathrm{mM}$ & \\
\hline
\end{tabular}

\begin{tabular}{|c|c|c|c|c|c|c|}
\hline & $\begin{array}{c}\text { Element } \\
\text { addition } \\
\text { order }\end{array}$ & \multicolumn{2}{|c|}{$1^{\text {st }}$} & $2^{\text {nd }}$ & $3^{\text {rd }}$ & $4^{\text {th }}$ \\
\cline { 2 - 7 } & Element & $\mathrm{Fe}(\mathrm{II})$ & $\mathrm{Fe}(\mathrm{III})$ & $\mathrm{OH}^{\mathrm{a}}$ & $\mathrm{Cl}$ & $\begin{array}{c}\text { Adjust } \\
\mathrm{pH}^{\mathrm{b}}\end{array}$ \\
\hline $\begin{array}{c}\text { Exp. 81-85 } \\
\text { Exp. 86-90 }\end{array}$ & Conc. & $39.2 \mathrm{mM}$ & $8.7 \mathrm{mM}$ & $70 \mathrm{mM}$ & $2.17 \mathrm{M}$ & 12.0 \\
\cline { 3 - 7 } & & & $110 \mathrm{mM}$ & & \\
\hline
\end{tabular}

${ }^{\mathrm{a}} \mathrm{NaOH}$ addition rate $\left(\mathrm{Vol}_{\text {Total }}=50000 \mu \mathrm{L}\right)$

i. $10.0 \mu \mathrm{L} / \mathrm{sec}$

ii. $33.3 \mu \mathrm{L} / \mathrm{sec}$

iii. $83.3 \mu \mathrm{L} / \mathrm{sec}$

iv. $167 \mu \mathrm{L} / \mathrm{sec}$

v. $50000 \mu \mathrm{L} / \mathrm{sec}$

${ }^{\mathrm{b}} \mathrm{pH}$ raising rate

i. When $70 \mathrm{mM} \mathrm{NaOH}$ was added $-3.33 \mu \mathrm{L} / \mathrm{sec}$ of $5 \mathrm{M} \mathrm{NaOH}$ was added to raise $\mathrm{pH}$ to 12.0

ii. When $110 \mathrm{mM} \mathrm{NaOH}$ was added $-1.67 \mu \mathrm{L} / \mathrm{sec}$ of $5 \mathrm{M} \mathrm{NaOH}$ was added to raise $\mathrm{pH}$ to 12.0 
Table 3-4 Continued

(b) Solids consisting of $\mathrm{Fe}(\mathrm{II}), \mathrm{Fe}(\mathrm{III}), \mathrm{Cl}$, and one major element, $\mathrm{Mg}, \mathrm{SO}_{4}$, or $\mathrm{SiO}_{3}$, of PCX

\begin{tabular}{|c|c|c|c|c|c|c|c|c|}
\hline \multirow[b]{3}{*}{ Exp. } & $\begin{array}{c}\text { Element } \\
\text { addition } \\
\text { order }\end{array}$ & $1^{\text {st }}$ & \multicolumn{2}{|c|}{$2^{\text {nd }}$} & \multicolumn{3}{|c|}{$3^{\text {rd }} / 4^{\text {th }}$} & $5^{\text {th }}$ \\
\hline & \multirow[t]{2}{*}{ Element } & \multirow[t]{2}{*}{$\mathrm{Cl}$} & \multicolumn{2}{|c|}{$\begin{array}{c}\mathrm{Fe}(\mathrm{II}) \text { and } \mathrm{Fe}(\mathrm{III}) \\
\text { addition }\end{array}$} & \multirow{2}{*}{\multicolumn{2}{|c|}{ Rest elements }} & \multirow[t]{2}{*}{$\mathrm{OH}^{\mathrm{c}}$} & \multirow{2}{*}{$\begin{array}{l}\text { Adjust } \\
\mathrm{pH}^{\mathrm{d}}\end{array}$} \\
\hline & & & $\mathrm{Fe}(\mathrm{II})$ & $\mathrm{Fe}(\mathrm{III})$ & & & & \\
\hline $91-96$ & \multirow[t]{9}{*}{ Conc. } & \multirow[t]{3}{*}{$2.17 \mathrm{M}$} & $39.2 \mathrm{mM}$ & $0.4 \mathrm{mM}$ & $\mathrm{Mg}$ & $22.2 \mathrm{mM}$ & $70 \mathrm{mM}$ & \multirow[t]{3}{*}{12.0} \\
\hline $97-102$ & & & $39.2 \mathrm{mM}$ & $8.7 \mathrm{mM}$ & $\mathrm{Mg}$ & $22.2 \mathrm{mM}$ & $70 \mathrm{mM}$ & \\
\hline $103-108$ & & & $39.2 \mathrm{mM}$ & $0.4 \mathrm{mM}$ & $\mathrm{Mg}$ & $22.2 \mathrm{mM}$ & $110 \mathrm{mM}$ & \\
\hline $109-114$ & & \multirow[t]{3}{*}{$2.17 \mathrm{M}$} & $39.2 \mathrm{mM}$ & $0.4 \mathrm{mM}$ & $\mathrm{SO}_{4}$ & $7.44 \mathrm{mM}$ & $70 \mathrm{mM}$ & \multirow[t]{3}{*}{12.0} \\
\hline $115-120$ & & & $39.2 \mathrm{mM}$ & $8.7 \mathrm{mM}$ & $\mathrm{SO}_{4}$ & $7.44 \mathrm{mM}$ & $70 \mathrm{mM}$ & \\
\hline $121-126$ & & & $39.2 \mathrm{mM}$ & $0.4 \mathrm{mM}$ & $\mathrm{SO}_{4}$ & $7.44 \mathrm{mM}$ & $110 \mathrm{mM}$ & \\
\hline $127-132$ & & \multirow[t]{3}{*}{$2.17 \mathrm{M}$} & $39.2 \mathrm{mM}$ & $0.4 \mathrm{mM}$ & $\mathrm{SiO}_{3}$ & $1.62 \mathrm{mM}$ & $70 \mathrm{mM}$ & \multirow[t]{3}{*}{12.0} \\
\hline $133-138$ & & & $39.2 \mathrm{mM}$ & $8.7 \mathrm{mM}$ & $\mathrm{SiO}_{3}$ & $1.62 \mathrm{mM}$ & $70 \mathrm{mM}$ & \\
\hline $139-144$ & & & $39.2 \mathrm{mM}$ & $0.4 \mathrm{mM}$ & $\mathrm{SiO}_{3}$ & $1.62 \mathrm{mM}$ & $110 \mathrm{mM}$ & \\
\hline
\end{tabular}

${ }^{\mathrm{c}} \mathrm{NaOH}$ addition rate $\left(\mathrm{Vol}_{\text {Total }}=50000 \mu \mathrm{L}\right)$

i. $20.0 \mu \mathrm{L} / \mathrm{sec}$

ii. $83.3 \mu \mathrm{L} / \mathrm{sec}$

iii. $50000 \mu \mathrm{L} / \mathrm{sec}$

${ }_{\mathrm{pH}}^{\mathrm{p}}$ raising rate: $3.33 \mu \mathrm{L} / \mathrm{sec}$ of $5 \mathrm{M} \mathrm{NaOH}$ was added to raise $\mathrm{pH}$ to 12 , except $\mathrm{SO}_{4}$ and $\mathrm{SiO}_{3}$ addition in the case of $110 \mathrm{mM} \mathrm{NaOH}$ used $(\mathrm{pH}$ raising rate $=1.67 \mu \mathrm{L} / \mathrm{sec}$ )

3.3.4 Identification of the active agents through instrumental analyses (XRD, SEM and

\section{SEM-EDS)}

Solids presented in table 3-4 underwent instrumental analyses. Fe(II), Fe(III) and $\mathrm{Cl}$ might be the most important elements that affect formation of the active agent. The synthesis method and $\mathrm{pH}$ were also expected to affect the formation of the active agent. Thus, solids 1-1, 1-2 and 2 (table 3-4) were chosen to examine solids formed under two different $\mathrm{pH}$ values and two different synthesis methods. FSCX solid (solid 3) was examined to investigate whether SCX makes the same solid as PCX did. MSCX solid 
(solid 4) was chosen to investigate whether major elements of PCX (Ca, $\mathrm{Mg}, \mathrm{Al}$, and $\mathrm{SiO}_{3}$ ) have an effect on the formation of the active agent. PCX w/ Fe(II) (solid 5) and PCS w/ Fe (II) (solid 7) were previously investigated for PCE degradation $(23,127)$ and were also chosen for the instrumental analyses. Solids synthesized with only PCX $(10 \%)$ and calcium hydroxide (Solid 6) showed no activity for PCE degradation in a preliminary experiment and they were also examined to observe the role of Fe(II) on the formation of the active agent.

All solids undergoing instrumental analyses were dried in the anaerobic chamber after synthesis. Solids 1 through 4 in table 3-4 were synthesized using the same method as in section 3.3.3. Solid 5 was prepared by mixing ferrous iron, PCX (10\%) and calcium hydroxide. Sufficient calcium hydroxide was added to increase the $\mathrm{pH}$ to around 12 , which was the optimum $\mathrm{pH}$ of $\mathrm{Fe}(\mathrm{II})-\mathrm{DS} / \mathrm{S}$. After adding reagents, the solutions were mixed on the magnetic stirrer for a couple of hours in an anaerobic chamber. Centrifugation was used to attempt to separate the potential active agent from inactive solids. A previous experiment (127) showed that higher levels of activity were observed for solids separated by centrifugation. Two layers of solids were formed after centrifugation- a light blue solid at the top and a white solid at the bottom. The white solid probably consists of lime and other cement hydration products. The light blue solid might contain higher levels of the active agent. Therefore, the colored solid from the top layer was taken and dried in an anaerobic chamber for instrumental analysis (XRD, SEM, SEM-EDS). 
Solid 7 was also prepared by mixing ferrous iron and Portland cement to produce a slurry with solid/solution mass ratio of 0.1 . Portland cement $(2.33 \mathrm{~g})$ and de-aerated deionized water $(23.3 \mathrm{~mL})$ was added to clear borosilicate glasses with the three-part closure (Teflon tape, lead foil tape, Teflon-lined rubber septum). Ferrous iron was added to the Portland cement slurries at the same concentration as used in the PCX experiment. All preparations were conducted in an anaerobic chamber. The glass vials and closures were equilibrated in an anaerobic chamber before conducting the sample preparations. After ferrous iron was added to the cement slurry, the vials were mixed on the shaking table for 5 days outside of the anaerobic chamber. After 5 days, the sample vials were taken into the anaerobic chamber and then transferred to several 250-ml plastic centrifuge bottles. These bottles were tightly sealed with parafilm before taken out from an anaerobic chamber. These bottles were centrifuged at $6000 \mathrm{rpm}(6650 \mathrm{~g})$ for $5 \mathrm{~min}$ and the top layer solid were taken (figure 3-2). This solid was dried in an anaerobic chamber for instrumental analysis (XRD, SEM, SEM-EDS). The $\mathrm{pH}$ was adjusted to 12 using $5 \mathrm{~N} \mathrm{HCl}$. 
TABLE 3-5 Solids to be analyzed by XRD and SEM with EDS

\begin{tabular}{|c|c|c|c|c|c|}
\hline & Solid & $\mathrm{Fe}(\mathrm{II})$ & $\mathrm{Fe}(\mathrm{III})$ & $\mathrm{NaOH}$ & $\mathrm{pH}$ \\
\hline $1-1$ & $\mathrm{Fe}(\mathrm{II})(\mathrm{III}) \mathrm{Cl}$ (GR method) & $39.2 \mathrm{mM}$ & $0.4 \mathrm{mM}$ & $70 \mathrm{mM}$ & neutral \\
\hline $1-2$ & $\mathrm{Fe}(\mathrm{II})(\mathrm{III}) \mathrm{Cl}$ (GR method) & $39.2 \mathrm{mM}$ & $0.4 \mathrm{mM}$ & $110 \mathrm{mM}$ & 12 \\
\hline 2 & $\begin{array}{c}\mathrm{Fe}(\mathrm{II})(\mathrm{III}) \mathrm{Cl} \\
\text { (simple mixing) }\end{array}$ & $39.2 \mathrm{mM}$ & $0.4 \mathrm{mM}$ & & 12 \\
\hline 3 & $\mathrm{FSCX}^{\mathrm{a}}$ & $39.2 \mathrm{mM}$ & $0.4 \mathrm{mM}$ & & 12 \\
\hline 4 & $\mathrm{MSCX}^{\mathrm{b}}$ & $39.2 \mathrm{mM}$ & $0.4 \mathrm{mM}$ & & 12 \\
\hline 5 & PCX w/ Fe(II) & $39.2 \mathrm{mM}$ & & & 11.7 \\
\hline 6 & PCX w/o Fe(II) & & & & 11.7 \\
\hline 7 & $\mathrm{PCS}^{\mathrm{c}} \mathrm{w} / \mathrm{Fe}(\mathrm{II})$ & $39.2 \mathrm{mM}$ & & & 12 \\
\hline
\end{tabular}

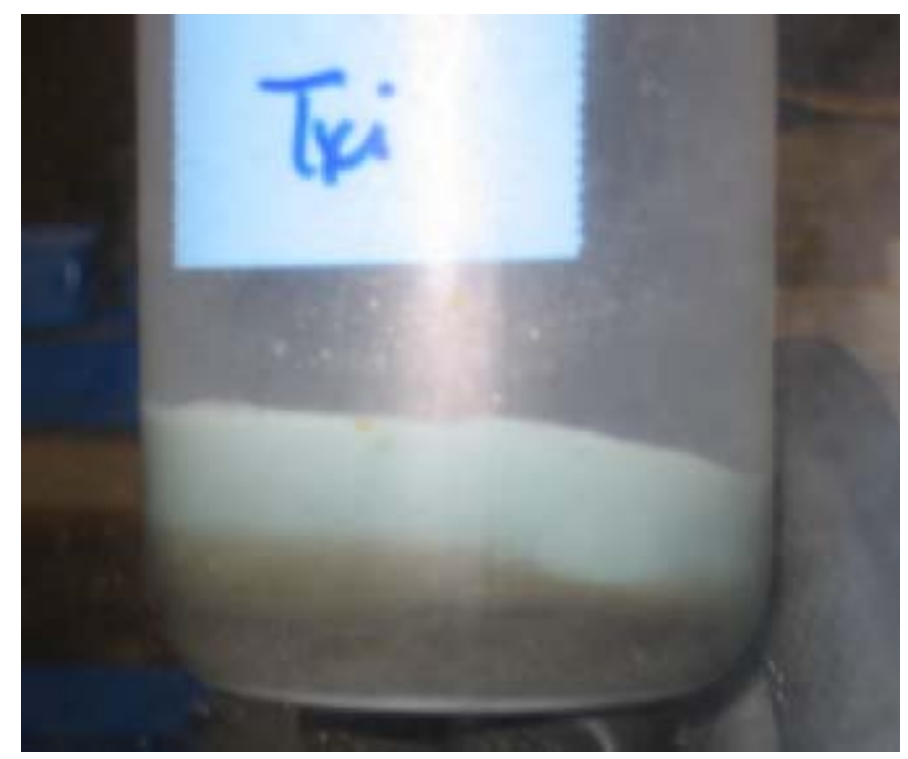

FIGURE 3-2 Two layers of solids after centrifugation of Fe(II) containing PCS solids. 


\subsubsection{Examination of variability of Ordinary Portland Cement (OPC)}

Portland cements from three different cement manufacturers were chosen to examine the variability of cement source on activity of solids produced by mixing them in $10 \%$ slurries with Fe(II). PCE degradation kinetics was measured in tests using at least 10 samples obtained at well-spaced times. Solids were also produced with $10 \%$ PCX for comparison. Kinetic constants were obtained through nonlinear regression using Matlab. These constants were compared to previous results by Hwang (23) and Ko (127). Instrumental analysis (XRD, SEM, SEM-EDS) was applied to solids produced by the various OPCs using the same procedures as in section 3.3.4. 


\section{CHAPTER IV}

RESULTS AND DISCUSSION

\subsection{Identification of conditions that promote formation of the active agents through solid activity tests}

\subsubsection{Evaluation of kinetic constants}

PCE degradation by Fe(II)-based DS/S previously showed pseudo-first order kinetics $(23$, 127). Apparent kinetic constants were determined that considered partitioning of PCE to gas, liquid and solid phases (23);

$$
\frac{d C_{l}}{d t}=-\frac{k}{\left(1+H \frac{V_{g}}{V_{l}}+K_{s}\right)} C_{l}=-\frac{k}{P} C_{l}=-k_{a p p} C_{l}
$$

where $\mathrm{C}_{1}$ : PCE concentration in the liquid phase

$\mathrm{k}$ : corrected pseudo-first-order-rate coefficient

$\mathrm{H}$ : dimensionless Henry's law constant for PCE

$\mathrm{V}_{\mathrm{g}}$ and $\mathrm{V}_{\mathrm{l}}$ : volume of the gas and liquid phases

$\mathrm{K}_{\mathrm{s}}$ : solid phase partition coefficient of PCE (ratio of mass of PCE in all solid phases to mass of PCE in aqueous phase)

P: partitioning factor $=1+\mathrm{HV}_{\mathrm{g}} / \mathrm{V}_{1}+\mathrm{K}_{\mathrm{s}}$

$\mathrm{k}_{\mathrm{app}}$ : apparent pseudo-first-order-rate coefficient

The exponential function was assumed to be valid based on the previous experiments that showed first-order degradation kinetics $(23,127)$. The exponential function $\left(\boldsymbol{C}_{\boldsymbol{l}}=\boldsymbol{C}_{0} \exp \left(-\boldsymbol{k}_{\text {app }} \boldsymbol{t}\right)\right.$ ) was transformed to the natural log function $\left(\ln C_{I}=\ln C_{0}-\boldsymbol{k}_{a p p} \boldsymbol{t}\right)$, which is the same form as a linear function with $\ln C_{l}$ as a y-axis, $\mathrm{t}$ as a $\mathrm{x}$-axis, and $-k_{a p p}$ as a slop, and then the values of $\mathrm{k}_{\mathrm{app}}$ in one-point solid activity 
tests with known values of PCE concentration in liquid phase and time were obtained through hand-calculation in the natural log function. The $95 \%$ confidence intervals for the rate constants were calculated using an equation of the confidence interval on the slope for simple linear regression. The error of estimated solid concentration normalized rate constants was calculated using Taylor Series.

\subsubsection{Effect of $\mathrm{Ca}$}

Table 4-1 shows the pseudo first-order rate constants of PCE reduction with carbonate-pretreated PCX (CPCX) solids. After pretreatment of carbonate to remove $\mathrm{Ca}$ in PCX, the same Ca concentration as PCX was added to one set of experiments (CPCX solid I, exp. 1 and 2) and not to another (CPCX solid II, exp. 3 and 4) to examine $\mathrm{Ca}$ effect on PCE degradation. In addition to the Ca effect, mixing time effects (2 and 24 hours) on the formation of active agents were also examined. As shown in table 4-1, Ca and mixing time did not affect the rate of PCE degradation. The pseudo-first order rate constants normalized by solids, Fe(II), and Fe(III) were observed to have values that had the same order of magnitude. Based solely on results shown in table 4-1, neither the presence of $\mathrm{Ca}$ nor solid mixing time affected the observed rates. Therefore, it appears that these factors do not enhance the formation of the active agents.

Table 4-2 shows composition of the solids produced in experiments with CPCX and PCX produced with different concentrations of Portland cement. As CPCX concentration was increased, the concentration of Fe(II) in the solids decreased and the concentration of Fe(III) in the solids increased. The total concentration of solids also 
increased. Solid phases that do not contain Fe(II) might be more formed to a greater extent with cement extracts formed with higher concentrations of cement. This might be most extensive in the $34.5 \%$ CPCX (exp. 8). In addition, some of Fe(III) might be associated with non-active agents. Although concentrations of $\mathrm{Fe}(\mathrm{II})$ in the solids decreased with increasing PCX contents, the concentration of Fe(III) also decreased, resulting in reduced total iron concentrations. The composition of iron in the solids could also be affected by how they were prepared. Solids were centrifuged and only the top layer of solids were collected and used to conduct PCE reduction tests. More ferrous iron might have been contained in the solids in the bottom layer.

Behavior of the observed rate constants in systems with CPCX and PCX are shown in figure 4-1 and 4-2. The pseudo first-order rate constants for CPCX that were normalized by concentration of solids and $\mathrm{Fe}(\mathrm{III})\left(\mathrm{k}_{\text {solid }}\right.$ and $\left.\mathrm{k}_{\mathrm{Fe}(\mathrm{III})}\right)$ decreased with increasing CPCX contents from 4.5 to $17.3 \%$. However, $\mathrm{k}_{\text {solid }}$ and $\mathrm{k}_{\mathrm{Fe}(\mathrm{III})}$ suddenly increased by 2 times and 5 times, respectively, as CPCX contents increased from $17.3 \%$ to $34.5 \%$. The pseudo first-order rate constant for CPCX normalized by $\mathrm{Fe}(\mathrm{II})$ concentration $\left(\mathrm{k}_{\mathrm{Fe}(\mathrm{II})}\right)$ gradually increased with increasing CPCX contents from 4.5 to $17.3 \%$ and then increased by the factor of 10 from $17.3 \%$ to $34.5 \%$. The values of $\mathrm{k}_{\mathrm{Fe}(\mathrm{II})}$ were the most dependent on CPCX contents.

The observed rate constants ( $\mathrm{k}_{\mathrm{solid}}, \mathrm{k}_{\mathrm{Fe}(\mathrm{III})}$, and $\left.\mathrm{k}_{\mathrm{Fe}(\mathrm{II})}\right)$ of PCX solids increased as PCX contents increased. As PCX concentration increased by $2 \%, \mathrm{k}_{\text {solid }}, \mathrm{k}_{\mathrm{Fe}(\mathrm{III})}$, and $\mathrm{k}_{\mathrm{Fe}(\mathrm{II})}$ values increased by $1.5,3$, and 2 times, respectively. The values of $\mathrm{k}_{\mathrm{Fe}(\mathrm{III})}$ were the most dependent on PCX contents. 
In exp. 5 to 8 , solids were formed in the absence of $\mathrm{Ca}$ and $\mathrm{pH}$ was adjusted with $5 \mathrm{~N} \mathrm{NaOH}$. In exp. 9 to 11 , solids were formed in the presence of $\mathrm{Ca}$ and $\mathrm{pH}$ was adjusted with $1.25 \mathrm{M} \mathrm{Ca}(\mathrm{OH})_{2}$. These modifications might cause the different PCE removal behaviors and less activity of CPCX solids. It probably indicates that the elemental compositions of cement extract strongly affect the formation of active agents. The dependence on chemical compositions in cement extract was also observed when $\mathrm{KOH}$ was used to adjust $\mathrm{pH}$ instead of $\mathrm{Ca}(\mathrm{OH})_{2}$ (127). In the experiment that used $\mathrm{KOH}$, the value of $\mathrm{k}_{\mathrm{Fe} \text { (II) }}$ was one order of magnitude lower than that when $\mathrm{Ca}(\mathrm{OH})_{2}$ was used even though solid concentrations in the experiments with $\mathrm{KOH}$ were much higher than those with $\mathrm{Ca}(\mathrm{OH})_{2}$. That might indicate that $\mathrm{KOH}$ leads to formation of more nonactive solid phases.

Although there was not much effect of Ca (exp. 1 and 2 compared to 3 and 4, table 4-1), solids formed from CPCX and PCX showed different behaviors in terms of PCE removal. Ca extracted from cement in PCX and foreign $\mathrm{Ca}$ added to CPCX could act differently. Ca added to CPCX might not become a component of active agents. Active agents formed in PCX and CPCX systems might be different. In addition, PCE degradation rates of PCX were more strongly affected by cement extract concentrations than those of CPCX. The lack of Ca might lead to form active agents which are less sensitive to the element composition and element concentration. 
TABLE 4-1 Pseudo first-order rate constants for PCE reduction by Fe(II)-PCX solids with and without $\mathrm{Ca}$

\begin{tabular}{|c|c|c|c|c|c|c|}
\hline \multirow[t]{2}{*}{ Exp. } & \multirow[t]{2}{*}{ Solid } & $\begin{array}{l}\text { Mixing } \\
\text { time }\end{array}$ & \multirow[t]{2}{*}{$\mathrm{pH}$} & $\mathrm{k}_{\text {solid }}{ }^{\mathrm{c}}$ & $\mathrm{k}_{\mathrm{Fe}(\mathrm{II})}{ }^{\mathrm{d}}$ & $\mathrm{k}_{\mathrm{Fe}(\mathrm{III})} \mathrm{e}^{\mathrm{e}}$ \\
\hline & & Hour & & $\mathrm{L} /(\mathrm{g} \times \mathrm{d})$ & $(\mathrm{mM} \times \mathrm{d})^{-1}$ & $(\mathrm{mM} \times \mathrm{d})^{-1}$ \\
\hline \multirow[t]{2}{*}{1} & CPCX solid I $^{\mathrm{a}}$ & 24 & 11.6 & $1.3 \mathrm{E}-03$ & $1.2 \mathrm{E}-03$ & $7.2 \mathrm{E}-03$ \\
\hline & & & & $( \pm 51 \%)$ & $( \pm 51 \%)$ & $( \pm 51 \%)$ \\
\hline \multirow[t]{2}{*}{2} & & 2 & 11.7 & $2.0 \mathrm{E}-03$ & $1.9 \mathrm{E}-03$ & $2.0 \mathrm{E}-02$ \\
\hline & & & & $( \pm 7.7 \%)$ & $( \pm 7.9 \%)$ & $( \pm 7.9 \%)$ \\
\hline \multirow[t]{2}{*}{3} & $\mathrm{CPCX}$ solid $\mathrm{II}^{\mathrm{b}}$ & 24 & 11.7 & $1.9 \mathrm{E}-03$ & $1.4 \mathrm{E}-03$ & $1.7 \mathrm{E}-02$ \\
\hline & & & & $( \pm 47 \%)$ & $( \pm 47 \%)$ & $( \pm 47 \%)$ \\
\hline \multirow[t]{2}{*}{4} & & 2 & 11.7 & $1.1 \mathrm{E}-03$ & $5.0 \mathrm{E}-04$ & $7.5 \mathrm{E}-03$ \\
\hline & & & & $( \pm 51 \%)$ & $( \pm 52 \%)$ & $( \pm 52 \%)$ \\
\hline
\end{tabular}

${ }^{\mathrm{a}}$ Carbonate-pretreated PCX adding $39.2 \mathrm{mM} \mathrm{FeCl} 2$ and $1 \mathrm{M} \mathrm{CaCl}_{2}$

${ }^{\mathrm{b}}$ Carbonate-pretreated PCX adding only $39.2 \mathrm{mM} \mathrm{FeCl}_{2}$

${ }^{\mathrm{c}} \mathrm{k}_{\text {solid }}=\mathrm{k}_{\text {app }} /$ solid conc.

${ }^{\mathrm{d}} \mathrm{k}_{\mathrm{Fe}(\mathrm{II})}=\mathrm{k}_{\mathrm{app}} / \mathrm{Fe}(\mathrm{II})$ conc.

${ }^{\mathrm{e}} \mathrm{k}_{\mathrm{Fe}(\mathrm{III})}=\mathrm{k}_{\mathrm{app}} / \mathrm{Fe}(\mathrm{III})$ conc.

$\mathrm{k}_{\mathrm{app}}=$ pseudo-first order rate constant, unit $=$ day $^{-1}$

Initial PCE concentration was $0.242 \mathrm{mM}$

A sampling time for individual experiment was 4 days for exp. 1 and 3; and 3 days for exp. 2 and 4

Uncertainties represent $95 \%$ confidence limits expressed in $\%$ relative to estimate $\mathrm{k}$ 
TABLE 4-2 Iron and solid concentrations in different cement extract contents of 24hourmixed CPCX solid II and Fe(II)-PCX solid

\begin{tabular}{ccccccccc}
\hline & $\begin{array}{c}\text { Cement } \\
\text { Exp. }\end{array}$ & $\begin{array}{c}\text { content } \\
\%(\mathrm{w} / \mathrm{v})\end{array}$ & $\mathrm{pH}$ & $\begin{array}{c}\mathrm{Fe}(\mathrm{II}) \\
\mathrm{mM}\end{array}$ & $\begin{array}{c}\mathrm{Fe}(\mathrm{III}) \\
\mathrm{mM}\end{array}$ & $\begin{array}{c}\mathrm{Fe}(\mathrm{II}) / \\
\mathrm{Fe}(\mathrm{III})\end{array}$ & $\begin{array}{c}\mathrm{Fe}(\mathrm{T}) \\
\mathrm{mM}\end{array}$ & $\begin{array}{c}\text { conc } \\
\mathrm{g} / \mathrm{L}\end{array}$ \\
\hline 5 & $4.5 \% \mathrm{CPCX}$ & 11.9 & 37.7 & 3.15 & 12.0 & 40.8 & 6.01 \\
6 & $8.6 \% \mathrm{CPCX}$ & 11.8 & 35.2 & 4.22 & 8.34 & 39.4 & 8.34 \\
7 & $17.3 \% \mathrm{CPCX}$ & 11.8 & 32.1 & 9.58 & 3.35 & 41.7 & 13.8 \\
8 & $34.5 \% \mathrm{CPCX}$ & 11.7 & 20.2 & 14.5 & 1.39 & 34.7 & 60.2 \\
9 & $6 \%$ PCX & 11.7 & 23.7 & 16.6 & 1.43 & 40.3 & 52.1 \\
10 & $8 \%$ PCX & 11.7 & 23.1 & 9.83 & 2.35 & 32.9 & 73.0 \\
11 & $10 \%$ PCX & 11.7 & 15.8 & 5.17 & 3.06 & 21.0 & 80.3 \\
\hline
\end{tabular}




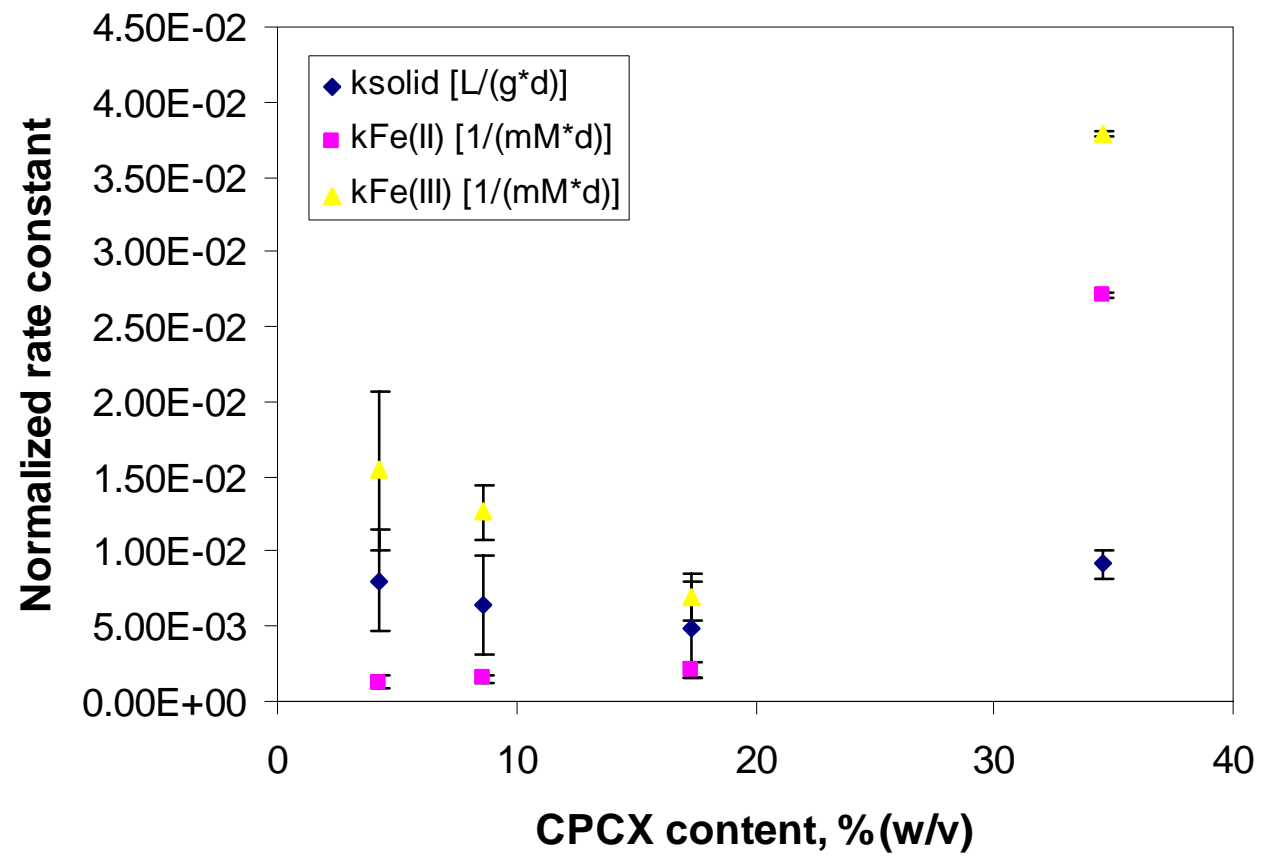

FIGURE 4-1 The variation of normalized pseudo first-order rate constants with respect to $\mathrm{CPCX}$ contents. Solid $=24 \mathrm{~h}$ CPCX solid II, $[\mathrm{PCE}]_{0}=0.242 \mathrm{mM}$, and sampling time $=$ 3.5 days. Error bar represents $95 \%$ confidence interval. 


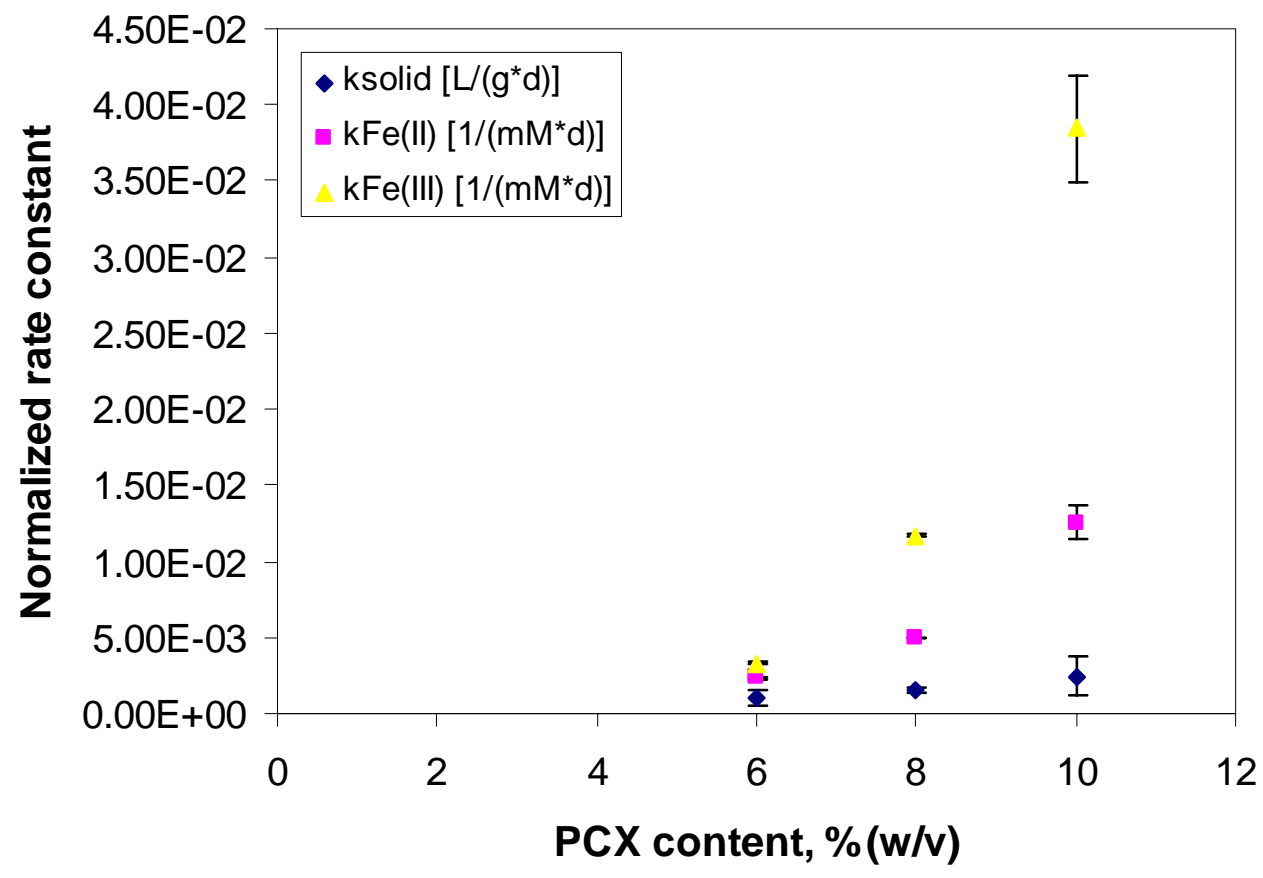

FIGURE 4-2 The variation of normalized pseudo first-order rate constants with respect to $\mathrm{PCX}$ contents. Solid $=\mathrm{Fe}(\mathrm{II})-\mathrm{PCX}$ solid, $[\mathrm{PCE}]_{0}=0.242 \mathrm{mM}$, and sampling time $=4$ days. Error bar represents $95 \%$ confidence interval. 


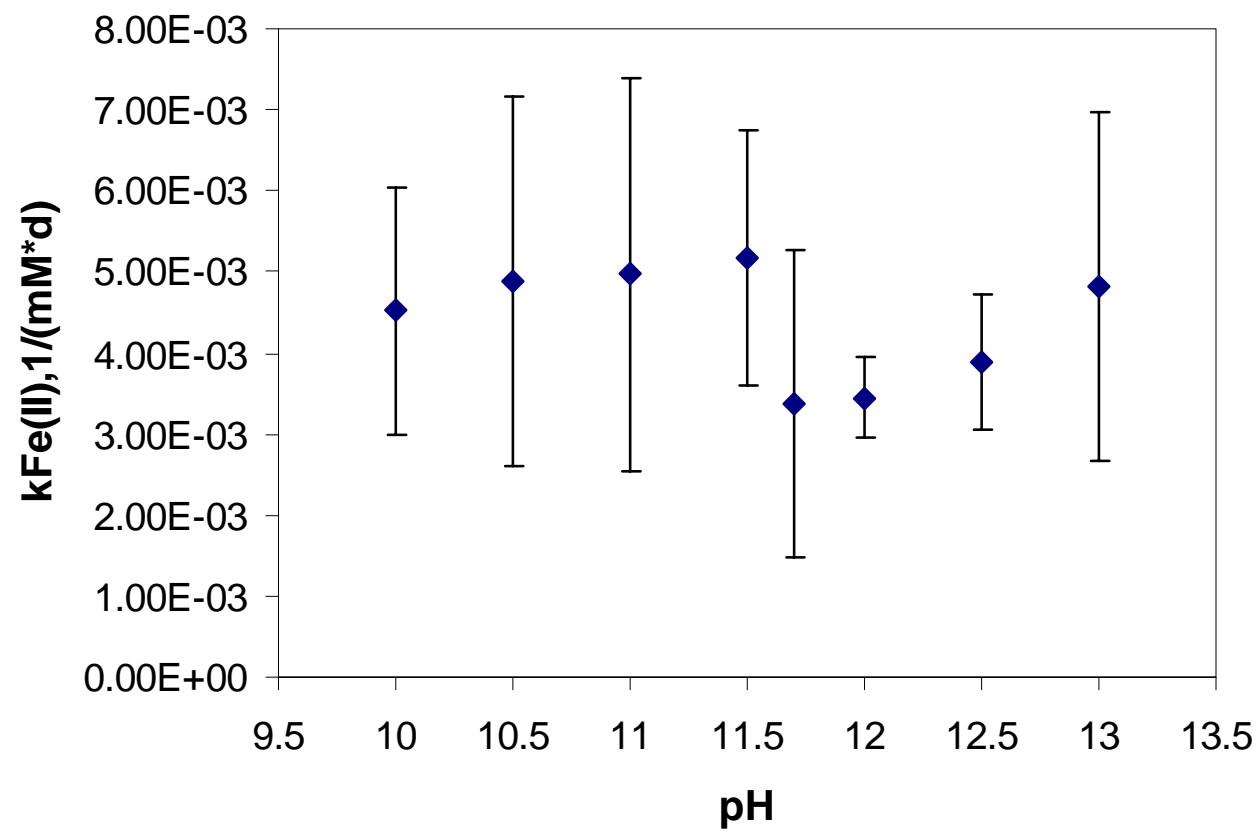

Figure 4-3 The effect of $\mathrm{pH}$ on pseudo first-order rate constants normalized with $\mathrm{Fe}(\mathrm{II})$ concentration $\left(\mathrm{k}_{\mathrm{Fe}(\mathrm{II})}\right)$. Solid $=24 \mathrm{~h}$ CPCX solid II, CPCX content $=34 \%(\mathrm{w} / \mathrm{v})$, $[\mathrm{PCE}]_{0}=0.242 \mathrm{mM}$, and sampling time $=3$ days. Error bar represents $95 \%$ confidence interval. 
Figure 4-3 shows the effect of $\mathrm{pH}$ on activity of solids produced by 24 hour mixing of 34\% CPCX (solid II). The trend of pseudo first-order rate constants in CPCX was totally different from those reported for Fe(II)-DS/S (23). PCE reduction in Fe(II)$\mathrm{DS} / \mathrm{S}$ was the highest at $\mathrm{pH} 12.1$. The effect of $\mathrm{pH}$ on rate constants for PCE degradation fitted well with a normal distribution function (23). Optimal pH of PCE reduction by CPCX was $11.5 . \mathrm{k}_{\mathrm{Fe}(\mathrm{II})}$ values increased with $\mathrm{pH}$ up to 11.5 , sharply decreased and then continued to increase up to $\mathrm{pH}$ 13. The differences between the highest $(\mathrm{pH}$ 12.1) and lowest (pH 10.6) $\mathrm{k}_{\mathrm{Fe}(\mathrm{II})}$ in $\mathrm{Fe}(\mathrm{II})-\mathrm{DS} / \mathrm{S}$ were about the factor of 10 . However, the highest (pH 11.5) and lowest ( $\mathrm{pH} 11.7) \mathrm{k}_{\mathrm{Fe}(\mathrm{II})}$ in CPCX were smaller than $\mathrm{Fe}(\mathrm{II})-\mathrm{DS} / \mathrm{S}$, i.e., $\mathrm{k}_{\mathrm{Fe}(\mathrm{II})}$ at $\mathrm{pH} 11.5$ was about 1.5 time faster than $\mathrm{pH} 11.7 . \mathrm{k}_{\mathrm{Fe}(\mathrm{II})}$ values in all $\mathrm{pH}$ range, from 10.5 to 13 , fell into the same order of magnitude. $\mathrm{k}_{\mathrm{Fe}(\mathrm{II})}$ of $\mathrm{CPCX}$ solids was about one order of magnitude faster than $\mathrm{Fe}(\mathrm{II})-\mathrm{DS} / \mathrm{S}$ solids at $\mathrm{pH} 10.5$ and thee time faster at $\mathrm{pH}$ 11.5. CPCX and Fe(II)-DS/S solids showed the similar activities at $\mathrm{pH} 12$ and 12. 5.

Results of experiments show that $\mathrm{Ca}$ affects the formation of active agents, based on the comparisons of PCE reduction behaviors and solid activities among CPCX, Fe(II)-PCX and Fe(II)-DS/S systems. Those experiments might indicate that formation of the active agent is very sensitive to chemical composition of cement extracts.

\subsubsection{Effect of cement hydration products}

Table 4-3 shows the results of PCE reduction experiments using a mixture of Fe(II) and/or Fe(III) and cement hydration products (tetracalcium aluminate, Friedel's salt, and Kuzel's salt). When no iron was added to the suspensions of cement hydration 
products (CHP), PCE was degraded negligibly or not at all (exp. 12, 17, 22, and 25). When both $\mathrm{Fe}(\mathrm{II})$ and $\mathrm{Fe}(\mathrm{III})$ were added to $\mathrm{C}_{4} \mathrm{AHx}$ suspensions and mixed for 2 hours in the anaerobic chamber, PCE was not degraded (exp. 23). Suspensions of Kuzel's salt mixed for 2 hours with ferrous sulfate showed no activity in degrading PCE (exp. 28). Solid concentrations of Kuzel's salt were not directly measured due to messing up the vial location in the oven during solid drying processes. Generally, the location of sample vials in the oven was recorded in the lab note before oven-drying in order to tract down samples because paper labeling of glass vial samples was unreadable after solid drying. In the case of Kuzel's salt, the vial samples were disturbed and lost their original location so that they could not be identified through their location. Therefore, all solid masses after drying were averaged and their standard deviations were less than $5 \%$. Averaged solid mass was applied to calculate solid concentrations. 
TABLE 4-3 Pseudo first-order rate constants for PCE reduction by cement hydration products (tetracalcium aluminate, Friedel's salt, and Kuzel's salt) by themselves, with $\mathrm{Fe}(\mathrm{II})$ and with both $\mathrm{Fe}(\mathrm{II})$ and $\mathrm{Fe}(\mathrm{III})$

\begin{tabular}{|c|c|c|c|c|c|c|}
\hline Exp. & & Solid & $\mathrm{pH}$ & $\begin{array}{c}\mathrm{k}_{\text {solid }} \\
\mathrm{L} /(\mathrm{g} \times \mathrm{d})\end{array}$ & $\underset{(\mathrm{mM} \times \mathrm{d})^{-1}}{\mathrm{k}_{\mathrm{Fe}(\mathrm{I})}}$ & $\underset{(\mathrm{mM} \times \mathrm{d})^{-1}}{\mathrm{k}_{\mathrm{Fe}(\mathrm{III})}}$ \\
\hline 12 & \multirow[t]{5}{*}{$\mathrm{C}_{4} \mathrm{AHx}$} & no $\mathrm{Fe}(\mathrm{II}), \mathrm{Fe}(\mathrm{III})$ & 11.8 & N/A & N/A & N/A \\
\hline 13 & & $2 \mathrm{~h} \mathrm{Fe}(\mathrm{II})$ & 11.8 & $\begin{array}{r}1.8 \mathrm{E}-04 \\
( \pm 352 \%)\end{array}$ & $\begin{array}{r}1.1 \mathrm{E}-04 \\
( \pm 352 \%)\end{array}$ & $\begin{array}{r}2.1 \mathrm{E}-03 \\
( \pm 352 \%)\end{array}$ \\
\hline 14 & & $2 \mathrm{~h} \mathrm{Fe}(\mathrm{II})+\mathrm{Fe}(\mathrm{III})$ & 11.8 & N/A & N/A & N/A \\
\hline 15 & & 24h Fe(II) & 11.8 & $\begin{array}{c}5.5 \mathrm{E}-04 \\
( \pm 53 \%)\end{array}$ & $\begin{array}{c}3.3 \mathrm{E}-04 \\
( \pm 53 \%)\end{array}$ & $\begin{array}{l}6.2 \mathrm{E}-02 \\
( \pm 53 \%)\end{array}$ \\
\hline 16 & & $24 \mathrm{~h} \mathrm{Fe}(\mathrm{II})+\mathrm{Fe}(\mathrm{III})$ & 11.8 & $\begin{array}{r}1.5 \mathrm{E}-04 \\
( \pm 463 \%)\end{array}$ & $\begin{array}{r}1.2 \mathrm{E}-04 \\
( \pm 187 \%)\end{array}$ & $\begin{array}{r}1.1 \mathrm{E}-04 \\
( \pm 187 \%)\end{array}$ \\
\hline 17 & Friedel's & no $\mathrm{Fe}(\mathrm{II}), \mathrm{Fe}(\mathrm{III})$ & 11.8 & N/A & $\mathrm{N} / \mathrm{A}$ & $\mathrm{N} / \mathrm{A}$ \\
\hline 18 & \multirow[t]{4}{*}{$(10 d)$} & 2h Fe(II) & 11.8 & $\begin{array}{r}1.8 \mathrm{E}-04 \\
( \pm 203 \%)\end{array}$ & $\begin{array}{r}8.9 \mathrm{E}-05 \\
( \pm 203 \%)\end{array}$ & $\begin{array}{r}7.3 \mathrm{E}-04 \\
( \pm 203 \%)\end{array}$ \\
\hline 19 & & $2 \mathrm{~h} \mathrm{Fe}(\mathrm{II})+\mathrm{Fe}(\mathrm{III})$ & 11.8 & $\begin{array}{r}2.1 \mathrm{E}-04 \\
( \pm 62 \%)\end{array}$ & $\begin{array}{l}1.3 \mathrm{E}-04 \\
( \pm 62 \%)\end{array}$ & $\begin{array}{c}2.5 \mathrm{E}-05 \\
( \pm 62 \%)\end{array}$ \\
\hline 20 & & 24h Fe(II) & 11.8 & $\begin{array}{r}4.5 \mathrm{E}-04 \\
( \pm 119 \%)\end{array}$ & $\begin{array}{r}2.3 \mathrm{E}-04 \\
( \pm 119 \%)\end{array}$ & $\begin{array}{r}7.2 \mathrm{E}-04 \\
( \pm 119 \%)\end{array}$ \\
\hline 21 & & $24 \mathrm{~h} \mathrm{Fe}(\mathrm{II})+\mathrm{Fe}(\mathrm{III})$ & 11.8 & $\begin{array}{r}3.1 \mathrm{E}-04 \\
( \pm 135 \%)\end{array}$ & $\begin{array}{r}2.0 \mathrm{E}-04 \\
( \pm 135 \%)\end{array}$ & $\begin{array}{r}6.6 \mathrm{E}-05 \\
( \pm 135 \%)\end{array}$ \\
\hline 22 & Friedel's & no $\mathrm{Fe}(\mathrm{II}), \mathrm{Fe}(\mathrm{III})$ & 12.0 & $\begin{array}{l}7.3 \mathrm{E}-04 \\
( \pm 40 \%)\end{array}$ & & \\
\hline 23 & $(7 d)$ & 2h Fe(II) & 12.1 & $\begin{array}{l}1.8 \mathrm{E}-03 \\
( \pm 20 \%)\end{array}$ & $\begin{array}{c}3.3 \mathrm{E}-04 \\
( \pm 20 \%)\end{array}$ & $\begin{array}{l}7.8 \mathrm{E}-03 \\
( \pm 20 \%)\end{array}$ \\
\hline 24 & & 24h Fe(II) & 12.1 & $\begin{array}{r}2.0 \mathrm{E}-03 \\
( \pm 32 \%)\end{array}$ & $\begin{array}{r}4.2 \mathrm{E}-04 \\
( \pm 32 \%)\end{array}$ & $\begin{array}{l}5.2 \mathrm{E}-03 \\
( \pm 32 \%)\end{array}$ \\
\hline 25 & \multirow[t]{6}{*}{ Kuzel } & no $\mathrm{Fe}(\mathrm{II}), \mathrm{Fe}(\mathrm{III})$ & 12.1 & N/A & N/A & N/A \\
\hline 26 & & $2 \mathrm{~h} \mathrm{FeCl}{ }_{2}$ & 12.1 & $2.7 \mathrm{E}-03^{*}$ & $\begin{array}{r}2.6 \mathrm{E}-03 \\
( \pm 44 \%)\end{array}$ & $\begin{array}{c}2.5 \mathrm{E}-02 \\
( \pm 44 \%)\end{array}$ \\
\hline 27 & & $24 \mathrm{~h} \mathrm{FeCl}{ }_{2}$ & 12.1 & $5.0 \mathrm{E}-04^{*}$ & $\begin{array}{r}4.3 \mathrm{E}-04 \\
( \pm 70 \%)\end{array}$ & $\begin{array}{l}2.4 \mathrm{E}-03 \\
( \pm 70 \%)\end{array}$ \\
\hline 28 & & $2 \mathrm{~h} \mathrm{FeSO}_{4}$ & 12.1 & N/A & N/A & N/A \\
\hline 29 & & $24 \mathrm{~h} \mathrm{FeSO}_{4}$ & 12.1 & $2.2 \mathrm{E}-03^{*}$ & $\begin{array}{l}1.8 \mathrm{E}-03 \\
( \pm 21 \%)\end{array}$ & $\begin{array}{l}7.0 \mathrm{E}-02 \\
( \pm 21 \%)\end{array}$ \\
\hline 11 & & $10 \%(\mathrm{w} / \mathrm{v}) \mathrm{PCX}$ & 11.7 & $\begin{array}{r}2.5 \mathrm{E}-03 \\
( \pm 54 \%)\end{array}$ & $\begin{array}{r}1.3 \mathrm{E}-02 \\
( \pm 9.2 \%)\end{array}$ & $\begin{array}{l}3.8 \mathrm{E}-02 \\
( \pm 9.2 \%) \\
\end{array}$ \\
\hline $\begin{array}{l}{ }^{*} \text { solid } \\
\text { estima } \\
\text { explai } \\
\text { N/A } \\
\text { Initial } \\
\text { Sampl } \\
\text { to 24; } \\
\text { Uncer }\end{array}$ & $\begin{array}{l}\text { not able to } \\
\text { PCE concen } \\
\text { ng times for } \\
\text { ind } 3.8 \text { days } \\
\text { ainties repre }\end{array}$ & $\begin{array}{l}\text { Is in Kuzel's salt (ex } \\
\text { entration; } \mathrm{k}_{\text {solid }}=\mathrm{k}_{\mathrm{app}} \\
\text { timate kinetic constant } \\
\text { ation was } 0.242 \mathrm{mM} \\
\text { ndividual experiment: } \\
\text { or } 25 \text { to } 29 \text {. } \\
\text { ent } 95 \% \text { confidence lin }\end{array}$ & or ex & $\begin{array}{l}\text { not directly } n \\
\text { nc.; the way o } \\
\text { tion of PCE w: } \\
\text { to } 16 ; 3 \text { days } f\end{array}$ & $\begin{array}{l}\text { ured. } k_{\text {solid }} \text { wa } \\
\text { imating solid } \\
\text { served } \\
\text { p. } 17 \text { to } 21 ; 1\end{array}$ & $\begin{array}{l}\text { calculated with } \\
\text { ncentration was } \\
\text { days for exp. } 22\end{array}$ \\
\hline
\end{tabular}


The values of $\mathrm{k}_{\mathrm{Fe}(\mathrm{II})}$, in CHP suspensions were one order to three orders of magnitude lower than those in experiments with Fe(II)-PCX solids (exp. 11). Addition of $48 \mathrm{mM} \mathrm{Fe}(\mathrm{III})$, which is the same concentration as sum of Fe(III) and $\mathrm{Al}$ in PCX, did not improve the solid activities. The mixing time did not affect the solid activities, either.

When cement is mixed with water, its components become hydrated and are changed into other solid phases, called cement hydration products. Four major cement components $\left(\mathrm{C}_{3} \mathrm{~S}, \mathrm{C}_{2} \mathrm{~S}, \mathrm{C}_{3} \mathrm{~A}\right.$ and $\left.\mathrm{C}_{4} \mathrm{AF}\right)$ are changed to $\mathrm{C}-\mathrm{S}-\mathrm{H}$ gel (calcium silicates) and AFm or AFt phases (calcium aluminates). XRD analysis of Fe(II)-PCX solids found that the three highest intense peaks $(8.14 \AA, 4.13 \AA$, and $2.76 \AA$ ) were similar to those in LDHs containing $\mathrm{Cl}$ as interlayer anions, such as Friedel's salts (127). Therefore, PCE reduction tests with CHP were conducted under the hypothesis that CHPs might influence the formation of the active agent or they, themselves, might be the active agent. However, these experiment set did not show any activity of CHPs as dechlorinating agents.

Results of this experiment indicate that the mechanism of solid formation might be different in Fe(II)-PCX suspensions and Fe(II)-DS/S . The particle size and chemical compositions of CHP solids formed in the presence of $\mathrm{Fe}(\mathrm{II})$ (Fe(II)-PCX and Fe(II)$\mathrm{DS} / \mathrm{S}$ ) might be different from those formed in the absence of $\mathrm{Fe}(\mathrm{II})$, even when $\mathrm{Fe}(\mathrm{II})$ were added later such as was done in these experiments with CHP. 


\subsubsection{Effect of synthetic cement extract}

Table 4-4 presents results of experiments with synthetic cement extracts. FSCX (exp. 30) solids showed less activity than Fe(II)-PCX solids (exp. 11, 45 and 46) as seen in values of $\mathrm{k}_{\mathrm{Fe}(\mathrm{II})}$ that are about $50 \%$ lower (Table 4-4),. Although the composition of FSCX simulated PCX as close as possible, the same activities were not obtained. This could result from different chemical compositions of solid phases in each system. It was not guaranteed that all elements were incorporated into solids to the same degree in experiments with FSCX as in experiments with PCX. In other words, chemical compositions of FSCX solids could be different from Fe(II)-PCX solids. Another possible reason could be different $\mathrm{Ca}$ contents, because $5 \mathrm{~N} \mathrm{NaOH}$ was used to adjust pH with FSCX, while $\mathrm{Ca}(\mathrm{OH})_{2}$, was used with PCX.

The absence of silicate (exp. 35) had the most influence on the solid activity of compounds tested and the absence of calcium had the least influence (exp. 43). Solid activities of FSCX without silicate and calcium, measured in terms of $\mathrm{k}_{\mathrm{Fe}(\mathrm{II})}$, were about $80 \%$ and $40 \%$ less than full FSCX solids (exp. 30), respectively. However, all of the elements removed from PCX had similar effects, because their Fe(II)-normalized rate constants were the same order of magnitude.

When major constituents of PCX $(\mathrm{Ca}, \mathrm{Al}$, and $\mathrm{Mg})$ were not added to the synthetic extract, the solids produced (exp. 44) had similar activity as those produced with FSCX (exp. 30). However, significant amounts of TCE were detected, with concentrations as high as $10 \%$ of the initial PCE concentration. This might indicate that the PCE degradation pathway of MSCX solids was different from solids produced by $\mathrm{Fe}(\mathrm{II})-\mathrm{DS} / \mathrm{S}$, 
where no TCE was detected (23). This might also indicate that solid phases formed with MSCX (exp. 44) might be different from ones in formed under other conditions (exp. 30 to 43$)$.

TABLE 4-4 Pseudo first-order rate constants of PCE reduction by various kinds of synthetic cement extracts

\begin{tabular}{|c|c|c|c|c|c|c|}
\hline Exp. & Solid & $\mathrm{pH}$ & $\begin{array}{c}\mathrm{k}_{\text {solid }} \\
\mathrm{L} /(\mathrm{g} \times \mathrm{d})\end{array}$ & $\underset{(\mathrm{mM} \times \mathrm{d})^{-1}}{\mathrm{k}_{\mathrm{Fe}(\mathrm{I})}}$ & $\underset{(\mathrm{mM} \times \mathrm{d})^{-1}}{\mathrm{k}_{\mathrm{Fe}(\mathrm{III})}}$ & $\begin{array}{c}\mathrm{TCE}^{\mathrm{e}} \\
\mathrm{mM}\end{array}$ \\
\hline 30 & $\mathrm{FSCX}^{\mathrm{a}}$ & 12.0 & $\begin{array}{l}9.7 \mathrm{E}-04 \\
( \pm 26 \%)\end{array}$ & $\begin{array}{l}6.1 \mathrm{E}-03 \\
( \pm 26 \%)\end{array}$ & $\begin{array}{l}1.2 \mathrm{E}-02 \\
( \pm 26 \%)\end{array}$ & \\
\hline 31 & FSCX w/o Be & 12.0 & $\begin{array}{r}4.9 \mathrm{E}-04 \\
( \pm 26 \%)\end{array}$ & $\begin{array}{l}2.9 \mathrm{E}-03 \\
( \pm 6.4 \%)\end{array}$ & $\begin{array}{l}7.4 \mathrm{E}-03 \\
( \pm 6.4 \%)\end{array}$ & \\
\hline 32 & $\begin{array}{l}\text { FSCX w/o } \\
\mathrm{BeBa}\end{array}$ & 12.0 & $\begin{array}{r}4.8 \mathrm{E}-04 \\
( \pm 83 \%)\end{array}$ & $\begin{array}{l}2.9 \mathrm{E}-03 \\
( \pm 54 \%)\end{array}$ & $\begin{array}{l}5.7 \mathrm{E}-03 \\
( \pm 54 \%)\end{array}$ & \\
\hline 33 & $\begin{array}{l}\text { FSCX w/o } \\
\mathrm{BeBaB}\end{array}$ & 12.0 & $\begin{array}{l}1.2 \mathrm{E}-03 \\
( \pm 80 \%)\end{array}$ & $\begin{array}{l}6.2 \mathrm{E}-03 \\
( \pm 52 \%)\end{array}$ & $\begin{array}{l}1.1 \mathrm{E}-02 \\
( \pm 52 \%)\end{array}$ & \\
\hline 34 & $\begin{array}{l}\text { FSCX w/o } \\
\mathrm{BeBaBSr}\end{array}$ & 12.0 & $\begin{array}{r}9.7 \mathrm{E}-04 \\
( \pm 144 \%)\end{array}$ & $\begin{array}{l}5.8 \mathrm{E}-03 \\
( \pm 94 \%)\end{array}$ & $\begin{array}{l}1.0 \mathrm{E}-02 \\
( \pm 94 \%)\end{array}$ & \\
\hline 35 & FSCX w/o $\mathrm{SiO}_{3}$ & 12.0 & $\begin{array}{l}2.6 \mathrm{E}-04 \\
( \pm 32 \%)\end{array}$ & $\begin{array}{l}1.2 \mathrm{E}-03 \\
( \pm 32 \%)\end{array}$ & $\begin{array}{l}5.6 \mathrm{E}-03 \\
( \pm 32 \%)\end{array}$ & \\
\hline 36 & FSCX w/o Cu & 12.0 & $\begin{array}{l}8.2 \mathrm{E}-04 \\
( \pm 80 \%)\end{array}$ & $\begin{array}{r}4.4 \mathrm{E}-03 \\
( \pm 66 \%)\end{array}$ & $\begin{array}{l}1.9 \mathrm{E}-02 \\
( \pm 66 \%)\end{array}$ & \\
\hline 37 & FSCX w/o Ni & 12.0 & $\begin{array}{l}5.8 \mathrm{E}-04 \\
( \pm 35 \%)\end{array}$ & $\begin{array}{l}2.7 \mathrm{E}-03 \\
( \pm 35 \%)\end{array}$ & $\begin{array}{l}1.1 \mathrm{E}-02 \\
( \pm 35 \%)\end{array}$ & \\
\hline 38 & FSCX w/o Zn & 12.0 & $\begin{array}{l}3.5 \mathrm{E}-04 \\
( \pm 44 \%)\end{array}$ & $\begin{array}{l}1.8 \mathrm{E}-03 \\
( \pm 44 \%)\end{array}$ & $\begin{array}{l}5.3 \mathrm{E}-03 \\
( \pm 44 \%)\end{array}$ & \\
\hline 39 & FSCX w/o Mn & 12.0 & $\begin{array}{l}4.2 \mathrm{E}-04 \\
( \pm 18 \%)\end{array}$ & $\begin{array}{r}2.2 \mathrm{E}-03 \\
( \pm 16 \%)\end{array}$ & $\begin{array}{l}1.3 \mathrm{E}-02 \\
( \pm 16 \%)\end{array}$ & \\
\hline 40 & $\begin{array}{l}\text { FSCX w/o } \\
\mathrm{Fe}(\mathrm{III})\end{array}$ & 12.0 & $\begin{array}{l}5.0 \mathrm{E}-04 \\
( \pm 18 \%)\end{array}$ & $\begin{array}{l}3.1 \mathrm{E}-03 \\
( \pm 16 \%)\end{array}$ & $\begin{array}{l}6.5 \mathrm{E}-03 \\
( \pm 16 \%)\end{array}$ & \\
\hline 41 & FSCX w/o Mg & 12.0 & $\begin{array}{l}5.8 \mathrm{E}-04 \\
( \pm 7.4 \%)\end{array}$ & $\begin{array}{l}3.2 \mathrm{E}-03 \\
( \pm 7.4 \%)\end{array}$ & $\begin{array}{l}9.0 \mathrm{E}-03 \\
( \pm 7.4 \%)\end{array}$ & \\
\hline 42 & FSCX w/o Al & 12.0 & $\begin{array}{l}4.3 \mathrm{E}-04 \\
( \pm 9.9 \%)\end{array}$ & $\begin{array}{l}2.5 \mathrm{E}-03 \\
( \pm 9.9 \%)\end{array}$ & $\begin{array}{r}7.7 \mathrm{E}-03 \\
( \pm 9.9 \%)\end{array}$ & \\
\hline 43 & FSCX w/o Ca & 12.0 & $\begin{array}{l}6.3 \mathrm{E}-03 \\
( \pm 30 \%)\end{array}$ & $\begin{array}{l}3.5 \mathrm{E}-03 \\
( \pm 30 \%)\end{array}$ & $\begin{array}{r}4.7 \mathrm{E}-02 \\
( \pm 30 \%)\end{array}$ & \\
\hline
\end{tabular}


Table 4-4 Continued

\begin{tabular}{|c|c|c|c|c|c|c|}
\hline Exp. & Solid & $\mathrm{pH}$ & $\begin{array}{c}\mathrm{k}_{\text {solid }} \\
\mathrm{L} /(\mathrm{g} \times \mathrm{d})\end{array}$ & $\begin{array}{c}\mathrm{k}_{\mathrm{Fe}(\mathrm{II})} \\
(\mathrm{mM} \times \mathrm{d})^{-1}\end{array}$ & $\begin{array}{c}\mathrm{k}_{\mathrm{Fe}(\mathrm{III})} \\
(\mathrm{mM} \times \mathrm{d})^{-1}\end{array}$ & $\begin{array}{l}\mathrm{TCE}^{\mathrm{e}} \\
\mathrm{mM}\end{array}$ \\
\hline 44 & $\operatorname{MSCX}^{\mathrm{b}}$ & 12.0 & $\begin{array}{l}1.2 \mathrm{E}-02 \\
( \pm 15 \%)\end{array}$ & $\begin{array}{l}3.8 \mathrm{E}-03 \\
( \pm 15 \%)\end{array}$ & $\begin{array}{l}4.1 \mathrm{E}-02 \\
( \pm 15 \%)\end{array}$ & \multirow[t]{4}{*}{0.02} \\
\hline $45^{\mathrm{d}}$ & $\mathrm{PCX}^{\mathrm{c}}+\mathrm{FeCl}_{2}$ & 11.8 & $\begin{array}{r}6.1 \mathrm{E}-03 \\
( \pm 19 \%)\end{array}$ & $\begin{array}{l}1.1 \mathrm{E}-02 \\
( \pm 4.9 \%)\end{array}$ & $\begin{array}{l}1.1 \mathrm{E}-01 \\
( \pm 4.9 \%)\end{array}$ & \\
\hline $46^{\mathrm{d}}$ & $\mathrm{PCX}^{\mathrm{c}}+\mathrm{FeSO}_{4}$ & 12.2 & $\begin{array}{c}6.0 \mathrm{E}-03 \\
( \pm 17 \%)\end{array}$ & $\begin{array}{l}1.5 \mathrm{E}-02 \\
( \pm 14 \%)\end{array}$ & $\begin{array}{l}1.5 \mathrm{E}-01 \\
( \pm 14 \%)\end{array}$ & \\
\hline 11 & $\mathrm{PCX}^{\mathrm{c}}+\mathrm{FeCl}_{2}$ & 11.7 & $\begin{array}{r}2.5 \mathrm{E}-03 \\
( \pm 54 \%)\end{array}$ & $\begin{array}{l}1.3 \mathrm{E}-02 \\
( \pm 9.2 \%)\end{array}$ & $\begin{array}{l}3.8 \mathrm{E}-02 \\
( \pm 9.2 \%)\end{array}$ & \\
\hline \multicolumn{7}{|c|}{$\begin{array}{l}\mathrm{a} \text { all PCX elements are added, Full element Synthetic Cement Extract (FSCX) } \\
\mathrm{b} \text { all PCX elements are added other than } \mathrm{Ca}, \mathrm{Mg} \text {, and } \mathrm{Al} \text {, Minor element Synthetic }\end{array}$} \\
\hline \multicolumn{7}{|c|}{ Cement Extract (MSCX) } \\
\hline \multicolumn{7}{|c|}{${ }^{c} 10 \%(w / v) P C X$} \\
\hline \multicolumn{7}{|c|}{ d data referenced from Ko's thesis (127) } \\
\hline \multicolumn{7}{|c|}{${ }^{\mathrm{e}}$ approximate estimation of TCE conc. in liquid phase } \\
\hline \multicolumn{7}{|c|}{ Initial PCE concentration was $0.242 \mathrm{mM}$} \\
\hline \multicolumn{7}{|c|}{$\begin{array}{l}\text { A sampling time for individual experiment was } 4.5 \text { days for exp. } 30 \text { to } 34 ; 4.9 \text { days } \\
\text { for exp. } 35 \text { to } 38 ; 5.7 \text { days for exp. } 39 \text { to } 42 \text {; and } 4 \text { days for exp. } 43 ; 6.9 \text { days for exp. } \\
44\end{array}$} \\
\hline
\end{tabular}

\subsubsection{Effect of major element of cement extract}

\subsubsection{Simple mixing method}

Table 4-5 shows results of the PCE degradation experiments conducted with solids synthesized using major elements of cement extract with a simple mixing technique. Adding $\mathrm{Mg}, \mathrm{Al}, \mathrm{SO}_{4}$, or $\mathrm{SiO}_{3}$ (exp. 48 to 59) to $\mathrm{Fe}(\mathrm{II})(\mathrm{III}) \mathrm{Cl}$ slightly improved solid activities (80\%) compared to $\mathrm{Fe}(\mathrm{II})(\mathrm{III}) \mathrm{Cl}$ (exp. 47). Fe(II)(III)Cl solids had values of $\mathrm{k}_{\mathrm{Fe}(\mathrm{II})}$ that were one order of magnitude smaller than the values observed with FSCX solids (exp. 30) and two orders of magnitude smaller than those observed with $\mathrm{Fe}(\mathrm{II})-\mathrm{PCX}$ solids (exp. 45). Fe(II), Fe(III), and $\mathrm{Cl}$ might be the most important 
elements in forming active agents due to the observation that there was not a significant enhancement to activity of solids when other elements were introduced to cement extract. In addition, they might be the main composition of active agents. One of LDHs are potential active agents in $\mathrm{Fe}(\mathrm{II})-\mathrm{DS} / \mathrm{S}$ (127). LDHs are composed of di and trivalent cations in the octahedral sheets and an anion in interlayers between the sheets. Fe(II) could serve as a divalent cation, $\mathrm{Fe}(\mathrm{III})$ as a trivalent cation and $\mathrm{Cl}$ as an anion in potential active agents. Other elements could be either substituted for $\mathrm{Fe}(\mathrm{II}), \mathrm{Fe}(\mathrm{III})$, and/or $\mathrm{Cl}$, to some degree, or absorbed on the surface.

TABLE 4-5 Pseudo first-order rate constants of PCE reduction by solids composed of major elements of cement extract

\begin{tabular}{|c|c|c|c|c|c|}
\hline Exp. & Solid $^{\mathrm{a}}$ & $\mathrm{pH}$ & $\begin{array}{c}\mathrm{k}_{\text {solid }} \\
\mathrm{L} /(\mathrm{g} \times \mathrm{d})\end{array}$ & $\begin{array}{c}\mathrm{k}_{\mathrm{Fe}(\mathrm{II})} \\
(\mathrm{mM} \times \mathrm{d})^{-1}\end{array}$ & $\begin{array}{c}\mathrm{k}_{\mathrm{Fe}(\mathrm{III})} \\
(\mathrm{mM} \times \mathrm{d})^{-1}\end{array}$ \\
\hline 47 & $\mathrm{Fe}(\mathrm{II})(\mathrm{III}) \mathrm{Cl}^{\mathrm{b}}$ & 12.0 & $\begin{array}{l}3.4 \mathrm{E}-03 \\
( \pm 40 \%)\end{array}$ & $\begin{array}{l}8.2 \mathrm{E}-04 \\
( \pm 40 \%)\end{array}$ & $\begin{array}{r}1.6 \mathrm{E}-02 \\
( \pm 40 \%)\end{array}$ \\
\hline 48 & $\mathrm{Fe}(\mathrm{II})(\mathrm{III}) \mathrm{ClMg}^{\mathrm{b}}$ & 12.0 & $\begin{array}{r}4.6 \mathrm{E}-03 \\
( \pm 26 \%)\end{array}$ & $\begin{array}{r}1.5 \mathrm{E}-03 \\
( \pm 25 \%)\end{array}$ & $\begin{array}{c}6.1 \mathrm{E}-03 \\
( \pm 25 \%)\end{array}$ \\
\hline 49 & $\mathrm{Fe}(\mathrm{II})(\mathrm{III}) \mathrm{ClAl}^{\mathrm{b}}$ & 12.0 & $\begin{array}{l}2.6 \mathrm{E}-03 \\
( \pm 7.9 \%)\end{array}$ & $\begin{array}{r}1.2 \mathrm{E}-03 \\
( \pm 7.7 \%)\end{array}$ & $\begin{array}{r}1.1 \mathrm{E}-02 \\
( \pm 7.7 \%)\end{array}$ \\
\hline 50 & $\mathrm{Fe}(\mathrm{II})(\mathrm{III}) \mathrm{ClMgAl}^{\mathrm{b}}$ & 12.0 & $\begin{array}{l}1.9 \mathrm{E}-03 \\
( \pm 31 \%)\end{array}$ & $\begin{array}{l}1.3 \mathrm{E}-03 \\
( \pm 31 \%)\end{array}$ & $\begin{array}{l}1.2 \mathrm{E}-02 \\
( \pm 31 \%)\end{array}$ \\
\hline 51 & $\mathrm{Fe}(\mathrm{II})(\mathrm{III}) \mathrm{Cl}^{\mathrm{c}}$ & 12.0 & $\begin{array}{r}2.5 \mathrm{E}-03 \\
( \pm 30 \%)\end{array}$ & $\begin{array}{l}1.1 \mathrm{E}-03 \\
( \pm 30 \%)\end{array}$ & $\begin{array}{c}5.3 \mathrm{E}-03 \\
( \pm 30 \%)\end{array}$ \\
\hline 52 & $\mathrm{Fe}(\mathrm{II})(\mathrm{III}) \mathrm{ClMg}^{\mathrm{c}}$ & 12.0 & $\begin{array}{l}1.5 \mathrm{E}-03 \\
( \pm 36 \%)\end{array}$ & $\begin{array}{c}7.5 \mathrm{E}-04 \\
( \pm 36 \%)\end{array}$ & $\begin{array}{r}3.4 \mathrm{E}-03 \\
( \pm 36 \%)\end{array}$ \\
\hline 53 & $\mathrm{Fe}(\mathrm{II})(\mathrm{III}) \mathrm{ClAl}^{\mathrm{c}}$ & 12.0 & $\begin{array}{l}3.1 \mathrm{E}-03 \\
( \pm 29 \%)\end{array}$ & $\begin{array}{l}1.5 \mathrm{E}-03 \\
( \pm 28 \%)\end{array}$ & $\begin{array}{l}3.8 \mathrm{E}-03 \\
( \pm 28 \%)\end{array}$ \\
\hline 54 & $\mathrm{Fe}(\mathrm{II})(\mathrm{III}) \mathrm{ClMgAl}^{\mathrm{c}}$ & 12.0 & $\begin{array}{l}1.6 \mathrm{E}-03 \\
( \pm 23 \%)\end{array}$ & $\begin{array}{l}1.1 \mathrm{E}-03 \\
( \pm 23 \%)\end{array}$ & $\begin{array}{r}2.7 \mathrm{E}-03 \\
( \pm 23 \%)\end{array}$ \\
\hline 55 & $\mathrm{Fe}(\mathrm{II})(\mathrm{III}) \mathrm{ClSO}_{4}{ }^{\mathrm{b}}$ & 12.0 & $\begin{array}{c}5.2 \mathrm{E}-03 \\
( \pm 67 \%)\end{array}$ & $\begin{array}{c}1.7 \mathrm{E}-03 \\
( \pm 67 \%)\end{array}$ & $\begin{array}{r}2.0 \mathrm{E}-02 \\
( \pm 67 \%)\end{array}$ \\
\hline
\end{tabular}


Table 4-5 Continued

\begin{tabular}{|c|c|c|c|c|c|}
\hline Exp. & Solid $^{\mathrm{a}}$ & $\mathrm{pH}$ & $\begin{array}{c}\mathrm{k}_{\text {solid }} \\
\mathrm{L} /(\mathrm{g} \times \mathrm{d})\end{array}$ & $\begin{array}{c}\mathrm{k}_{\mathrm{Fe}(\mathrm{II})} \\
(\mathrm{mM} \times \mathrm{d})^{-1}\end{array}$ & $\underset{(\mathrm{mM} \times \mathrm{d} \times)^{-1}}{\mathrm{k}_{\mathrm{F}(\mathrm{II})}}$ \\
\hline 56 & $\mathrm{Fe}(\mathrm{II})(\mathrm{III}) \mathrm{ClSO}_{4} \mathrm{Al}^{\mathrm{b}}$ & 12.0 & & & \\
\hline 57 & $\mathrm{Fe}(\mathrm{II})(\mathrm{III}) \mathrm{ClSO}_{4}{ }^{\mathrm{c}}$ & 12.0 & $\begin{array}{l}2.8 \mathrm{E} \\
( \pm 3.3\end{array}$ & & \\
\hline 58 & $\mathrm{Fe}(\mathrm{II})(\mathrm{III}) \mathrm{ClSO}_{4} \mathrm{Al}^{\mathrm{c}}$ & 12.0 & & & \\
\hline 59 & $\mathrm{III}) \mathrm{ClSiO}_{3}{ }^{\mathrm{b}}$ & 12.0 & $\begin{array}{r}4.4 \mathrm{E}-03 \\
( \pm 33 \%)\end{array}$ & $\begin{array}{l}1.3 \mathrm{E}-03 \\
( \pm 33 \%)\end{array}$ & $\begin{array}{l}1.6 \mathrm{E}-02 \\
( \pm 33 \%)\end{array}$ \\
\hline 30 & FSCX & 12.0 & $\begin{array}{r}9.7 \mathrm{E}-04 \\
( \pm 26 \%)\end{array}$ & $\begin{array}{l}6.1 \mathrm{E}-03 \\
( \pm 26 \%)\end{array}$ & $\begin{array}{l}1.2 \mathrm{E}-02 \\
( \pm 26 \%)\end{array}$ \\
\hline 45 & $\mathrm{FeCl}_{2}+10 \%(\mathrm{w} / \mathrm{v}) \mathrm{PCX}$ & 11.8 & $\begin{array}{l}6.1 \mathrm{E}-03 \\
( \pm 19 \%)\end{array}$ & $\begin{array}{l}1.1 \mathrm{E}-02 \\
( \pm 4.9 \%)\end{array}$ & $\begin{array}{l}1.1 \mathrm{E}-01 \\
( \pm 4.9 \%)\end{array}$ \\
\hline
\end{tabular}

a each solid was named after its composition

${ }^{\mathrm{b}}$ Initial $\mathrm{Fe}(\mathrm{III})$ concentration was $0.4 \mathrm{mM}$

${ }^{c}$ Initial Fe(III) concentration was $13.1 \mathrm{mM}$

Initial PCE concentration was $0.242 \mathrm{mM}$

A sampling time for individual experiment was 8.5 days for exp. 48; 7 days for exp. 48 to 54 and $59 ; 5.6$ days for exp. 55 to 58

Uncertainties represent $95 \%$ confidence limits expressed in \% relative to estimate $\mathrm{k}$

The compositions of solids formed in mixtures of $\mathrm{Fe}(\mathrm{II}), \mathrm{Fe}(\mathrm{III})$ and $\mathrm{Cl}$ are shown in Table 4-6 and results of PCE reduction experiments are shown in table 4-7. Higher Fe(III) concentrations resulted in lower iron recoveries (Table 4-6). When 0.4 $\mathrm{mM} \mathrm{Fe}$ (III) was added, $98 \%$ of iron was recovered, but only $70 \%$ of iron was recovered when $13.1 \mathrm{mM} \mathrm{Fe(III)} \mathrm{was} \mathrm{added.} \mathrm{The} \mathrm{color} \mathrm{of} \mathrm{the} \mathrm{solution} \mathrm{after} \mathrm{digesting} \mathrm{solids} \mathrm{with}$ $1.2 \mathrm{~N} \mathrm{HCl}$ was darker at higher Fe(III) concentrations., and some solid phases would not dissolve. Higher Fe(III) concentrations might have caused another solid phases to form, such as magnetite or ferrihydrite that was resistant to dissolution in $\mathrm{HCl}$. 
Fe(III) concentration did not have a much effect on solid activities as shown in table 4-7. Values of $\mathrm{k}_{\mathrm{Fe}(\mathrm{II})}$ increased $50 \%$ at $6 \mathrm{mM} \mathrm{Fe(III)} \mathrm{(exp} \mathrm{63),} \mathrm{compared} \mathrm{to} 0.4 \mathrm{mM}$ (exp 47, 60). Values of $\mathrm{k}_{\mathrm{Fe}(\mathrm{II})}$ that were one order of magnitude smaller than those observed with FSCX (exp 30) and two order of magnitude smaller than those observed with PCX (exp 45) were observed in Fe(II)(III)Cl solids having different Fe(III) concentrations (exp 60 to 65$)$.

The mixing time used to synthesize solids did not have much affect on the formation of the active agents as shown in table 4-8. Values of $\mathrm{k}_{\mathrm{Fe}(\mathrm{II})}$ were slightly higher $(30 \%)$ with a 1-day mixing time, compared to 3-day mixing time, which had the lowest activity. An active agent could be formed in 2 hours and might reach the best activity within a day based on the solid activity test presented in table 4-8.

TABLE 4-6 Iron and solid concentrations of solids containing $\mathrm{Fe}(\mathrm{II}), \mathrm{Fe}(\mathrm{III})$, and $\mathrm{Cl}$ with the different initial Fe(III) concentration

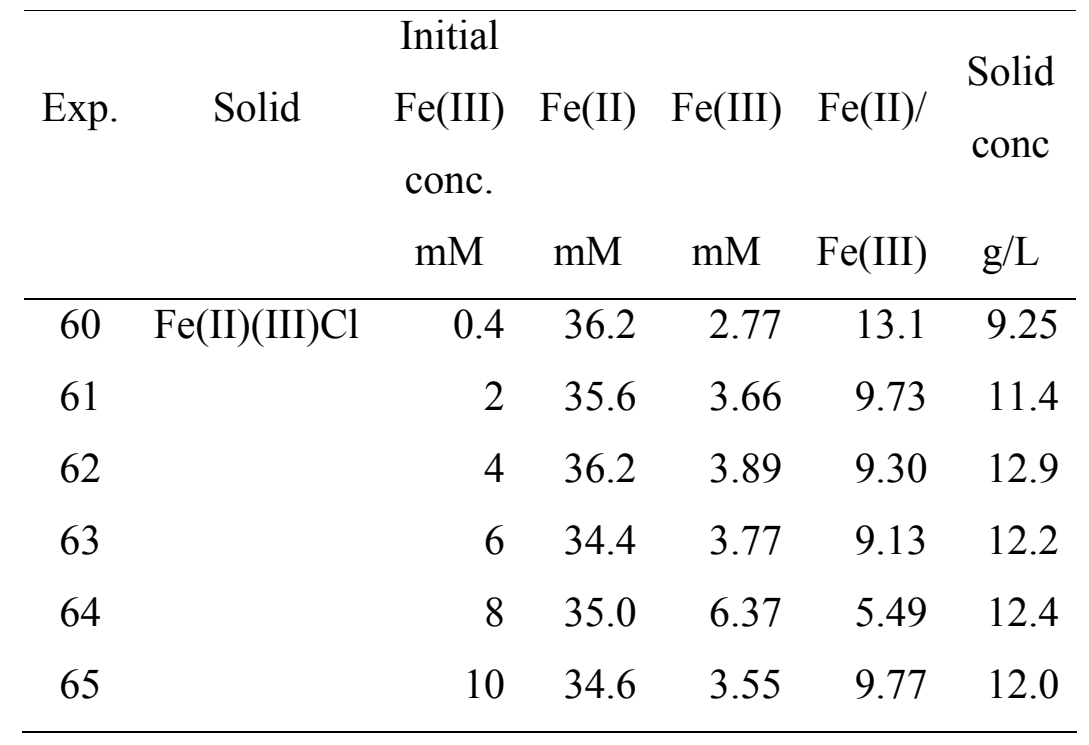


TABLE 4-7 Pseudo first-order rate constants of PCE reduction by solids containing $\mathrm{Fe}(\mathrm{II}), \mathrm{Fe}(\mathrm{III})$, and $\mathrm{Cl}$ with different initial $\mathrm{Fe}(\mathrm{III})$ concentrations

\begin{tabular}{|c|c|c|c|c|c|c|}
\hline Exp. & Solid & $\begin{array}{c}\text { Initial } \\
\text { Fe(III) } \\
\text { conc. } \\
\mathrm{mM}\end{array}$ & $\mathrm{pH}$ & $\begin{array}{c}\mathrm{k}_{\text {solid }} \\
\mathrm{L} /(\mathrm{g} \times \mathrm{d})\end{array}$ & $\begin{array}{c}\mathrm{k}_{\mathrm{Fe}(\mathrm{II})} \\
(\mathrm{mM} \times \mathrm{d})^{-1}\end{array}$ & $\begin{array}{c}\mathrm{k}_{\mathrm{Fe}(\mathrm{III})} \\
(\mathrm{mM} \times \mathrm{d})^{-1}\end{array}$ \\
\hline 60 & $\mathrm{Fe}(\mathrm{II})(\mathrm{III}) \mathrm{Cl}$ & 0.4 & 12.0 & $\begin{array}{l}3.3 \mathrm{E}-03 \\
( \pm 23 \%)\end{array}$ & $\begin{array}{l}8.3 \mathrm{E}-04 \\
( \pm 23 \%)\end{array}$ & $\begin{array}{l}1.1 \mathrm{E}-02 \\
( \pm 23 \%)\end{array}$ \\
\hline 61 & & 2 & 12.0 & $\begin{array}{l}3.1 \mathrm{E}-03 \\
( \pm 53 \%)\end{array}$ & $\begin{array}{c}9.8 \mathrm{E}-04 \\
( \pm 51 \%)\end{array}$ & $\begin{array}{r}9.5 \mathrm{E}-03 \\
( \pm 51 \%)\end{array}$ \\
\hline 62 & & 4 & 12.0 & $\begin{array}{c}2.6 \mathrm{E}-03 \\
( \pm 34 \%)\end{array}$ & $\begin{array}{c}9.2 \mathrm{E}-04 \\
( \pm 32 \%)\end{array}$ & $\begin{array}{l}8.6 \mathrm{E}-03 \\
( \pm 32 \%)\end{array}$ \\
\hline 63 & & 6 & 12.0 & $\begin{array}{c}3.6 \mathrm{E}-03 \\
( \pm 83 \%)\end{array}$ & $\begin{array}{l}1.3 \mathrm{E}-03 \\
( \pm 83 \%)\end{array}$ & $\begin{array}{l}1.2 \mathrm{E}-02 \\
( \pm 83 \%)\end{array}$ \\
\hline 64 & & 8 & 12.0 & $\begin{array}{c}2.9 \mathrm{E}-03 \\
( \pm 31 \%)\end{array}$ & $\begin{array}{l}1.1 \mathrm{E}-03 \\
( \pm 30 \%)\end{array}$ & $\begin{array}{r}5.6 \mathrm{E}-03 \\
( \pm 30 \%)\end{array}$ \\
\hline 65 & & 10 & 12.0 & $\begin{array}{c}3.2 \mathrm{E}-03 \\
( \pm 56 \%)\end{array}$ & $\begin{array}{l}1.1 \mathrm{E}-03 \\
( \pm 56 \%)\end{array}$ & $\begin{array}{c}1.1 \mathrm{E}-02 \\
( \pm 56 \%)\end{array}$ \\
\hline 47 & $\mathrm{Fe}(\mathrm{II})(\mathrm{III}) \mathrm{Cl}$ & 0.4 & 12.0 & $\begin{array}{l}3.4 \mathrm{E}-03 \\
( \pm 40 \%)\end{array}$ & $\begin{array}{l}8.2 \mathrm{E}-04 \\
( \pm 40 \%)\end{array}$ & $\begin{array}{l}1.6 \mathrm{E}-02 \\
( \pm 40 \%)\end{array}$ \\
\hline 51 & $\mathrm{Fe}(\mathrm{II})(\mathrm{III}) \mathrm{Cl}$ & 13.1 & 12.0 & $\begin{array}{l}2.5 \mathrm{E}-03 \\
( \pm 30 \%)\end{array}$ & $\begin{array}{l}1.1 \mathrm{E}-03 \\
( \pm 30 \%)\end{array}$ & $\begin{array}{r}5.3 \mathrm{E}-03 \\
( \pm 30 \%)\end{array}$ \\
\hline 30 & FSCX & 0.4 & 12.0 & $\begin{array}{r}9.7 \mathrm{E}-04 \\
( \pm 26 \%)\end{array}$ & $\begin{array}{c}6.1 \mathrm{E}-03 \\
( \pm 26 \%)\end{array}$ & $\begin{array}{l}1.2 \mathrm{E}-02 \\
( \pm 26 \%)\end{array}$ \\
\hline 45 & $\mathrm{FeCl}_{2}+10 \%(\mathrm{w} / \mathrm{v}) \mathrm{PCX}$ & 0 & 11.8 & $\begin{array}{l}6.1 \mathrm{E}-03 \\
( \pm 19 \%)\end{array}$ & $\begin{array}{l}1.1 \mathrm{E}-02 \\
( \pm 4.9 \%)\end{array}$ & $\begin{array}{l}1.1 \mathrm{E}-01 \\
( \pm 4.9 \%)\end{array}$ \\
\hline
\end{tabular}

Initial PCE concentration was $0.242 \mathrm{mM}$

A sampling time for individual experiment was 7 days

Uncertainties represent $95 \%$ confidence limits expressed in \% relative to estimate $\mathrm{k}$ 
TABLE 4-8 Pseudo first-order rate constants of PCE reduction by solids containing $\mathrm{Fe}(\mathrm{II}), \mathrm{Fe}(\mathrm{III})$, and $\mathrm{Cl}$ with different solid synthesis mixing time

\begin{tabular}{|c|c|c|c|c|c|c|}
\hline Exp. & Solid & $\begin{array}{l}\text { Mixing } \\
\text { time }\end{array}$ & $\mathrm{pH}$ & $\begin{array}{c}\mathrm{k}_{\text {solid }} \\
\mathrm{L} /(\mathrm{g} \times \mathrm{d})\end{array}$ & $\begin{array}{c}\mathrm{k}_{\mathrm{Fe}(\mathrm{II})} \\
(\mathrm{mM} \times \mathrm{d})^{-1}\end{array}$ & $\begin{array}{c}\mathrm{k}_{\mathrm{Fe}(\mathrm{III})} \\
(\mathrm{mM} \times \mathrm{d})^{-1}\end{array}$ \\
\hline 66 & $\mathrm{Fe}(\mathrm{II})(\mathrm{III}) \mathrm{Cl}$ & $2 \mathrm{~h}$ & 12.0 & $\begin{array}{l}3.3 \mathrm{E}-03 \\
( \pm 19 \%)\end{array}$ & $\begin{array}{r}9.8 \mathrm{E}-04 \\
( \pm 19 \%)\end{array}$ & $\begin{array}{r}2.3 \mathrm{E}-02 \\
( \pm 19 \%)\end{array}$ \\
\hline 67 & & $12 \mathrm{~h}$ & 12.0 & $\begin{array}{l}3.1 \mathrm{E}-03 \\
( \pm 13 \%)\end{array}$ & $\begin{array}{l}1.0 \mathrm{E}-03 \\
( \pm 12 \%)\end{array}$ & $\begin{array}{l}1.3 \mathrm{E}-02 \\
( \pm 12 \%)\end{array}$ \\
\hline 68 & & $1 d$ & 12.0 & $\begin{array}{r}3.8 \mathrm{E}-03 \\
( \pm 44 \%)\end{array}$ & $\begin{array}{l}1.3 \mathrm{E}-03 \\
( \pm 44 \%)\end{array}$ & $\begin{array}{r}1.9 \mathrm{E}-02 \\
( \pm 44 \%)\end{array}$ \\
\hline 69 & & $2 \mathrm{~d}$ & 12.0 & $\begin{array}{r}3.1 \mathrm{E}-03 \\
( \pm 25 \%)\end{array}$ & $\begin{array}{l}1.1 \mathrm{E}-03 \\
( \pm 24 \%)\end{array}$ & $\begin{array}{r}1.8 \mathrm{E}-02 \\
( \pm 24 \%)\end{array}$ \\
\hline 70 & & $3 d$ & 12.0 & $\begin{array}{l}3.1 \mathrm{E}-03 \\
( \pm 21 \%)\end{array}$ & $\begin{array}{r}9.7 \mathrm{E}-04 \\
( \pm 17 \%)\end{array}$ & $\begin{array}{r}1.9 \mathrm{E}-02 \\
( \pm 17 \%)\end{array}$ \\
\hline
\end{tabular}

Initial PCE concentration was $0.242 \mathrm{mM}$

A sampling time for individual experiment was 7.9 days

Uncertainties represent $95 \%$ confidence limits expressed in \% relative to estimate $\mathrm{k}$

Various conditions for the solid formation with simple mixing methods with major elements of cement extract did not have much affect on the formation of active agents. All solids formed by the simple mixing method had similar solid activities and lower activities than $\mathrm{Fe}(\mathrm{II})-\mathrm{PCX}$ solids. Although $\mathrm{Fe}(\mathrm{II}), \mathrm{Fe}(\mathrm{III})$, and $\mathrm{Cl}$ might be the most important elements to form active agents, other elements were also required to enhance their activity. This further supports the observation that chemical composition of solids might be critical to determining their level of PCE degradation activity. 


\subsubsection{Adaptation of GR synthesis method}

Table 4-9 shows the results of PCE degradation by $\mathrm{Fe}(\mathrm{II})(\mathrm{III}) \mathrm{Cl}$ solid synthesized by the method used to synthesize green rust (GR) (m6). As seen in table 4-9, five different $\mathrm{NaOH}$ addition rates $(10,33,83,167$, and $50,000 \mu \mathrm{L} / \mathrm{sec})$ did not have much affect on the solid activities synthesized by GR synthesis method. The least active solid was observed in exp. 72, where the solid was synthesized with $\mathrm{Cl}$ addition before other elements, $33 \mu \mathrm{L} / \mathrm{sec}$ of $\mathrm{NaOH}$ addition rate, and neutral $\mathrm{pH}$. The most active solid was observed in exp. 83 with $\mathrm{Cl}$ addition after all other elements, $83 \mu \mathrm{L} / \mathrm{sec}$ of $\mathrm{NaOH}$ addition rate and neutral $\mathrm{pH}$. The normalized kinetic coefficients $\left(\mathrm{k}_{\mathrm{Fe}(\mathrm{II})}\right)$ of the least active solid was $9.39 \times 10^{-4}(\mathrm{mMFe}(\mathrm{II}) \times \mathrm{d})^{-1}$ and the most active solid was $3.02 \times 10^{-3}$ $(\mathrm{mMFe}(\mathrm{II}) \times \mathrm{d})^{-1}$. However, $\mathrm{k}_{\mathrm{Fe}(\mathrm{II})}$ for all types of solids in table 4-9 were about the same order of magnitude, one order of magnitude lower than those observed with FSCX (exp. 30), and two order magnitude lower than those observed with PCX (exp. 45).

The GR synthesis method did not increase activities of most solids compared to those formed with simple mixing. An exception was exp. 83 where a solid was synthesized at neutral $\mathrm{pH}$, with $\mathrm{OH}$ addition rate of $83.3 \mu \mathrm{L} / \mathrm{sec}$ and $\mathrm{Cl}$ addition after $\mathrm{OH}$. The activities of solids in this experiment were about 3 times higher in terms of $\mathrm{k}_{\text {solid }}$ and $\mathrm{k}_{\mathrm{Fe}(\mathrm{II})}$ than those found with the simple mixing technique. This was observed even though the Fe(III) concentrations of the two solids were different. The GR synthesis method produced solids with $8.7 \mathrm{mM} \mathrm{Fe}(\mathrm{III})$ and simple mixing method produced solids with $0.4 \mathrm{mM} \mathrm{Fe}(\mathrm{III})$. 
TABLE 4-9 Pseudo first-order rate constants of PCE reduction by solids containing $\mathrm{Fe}(\mathrm{II}), \mathrm{Fe}(\mathrm{III})$, and $\mathrm{Cl}$ synthesized by GR synthesis method

\begin{tabular}{|c|c|c|c|c|c|}
\hline Exp. & $\begin{array}{c}\text { Solid } \\
\mathrm{Fe}(\mathrm{II})(\mathrm{III}) \mathrm{Cl}^{\mathrm{a}}\end{array}$ & $\mathrm{pH}$ & $\begin{array}{c}\mathrm{k}_{\text {solid }} \\
\mathrm{L} /(\mathrm{g} \times \mathrm{d})\end{array}$ & $\begin{array}{c}\mathrm{k}_{\mathrm{Fe}(\mathrm{II})} \\
(\mathrm{mM} \times \mathrm{d})^{-1}\end{array}$ & $\frac{\mathrm{k}_{\mathrm{Fe}(\mathrm{III})}}{(\mathrm{mM} \times \mathrm{d})^{-1}}$ \\
\hline 71 & $70^{\mathrm{b}}\left(\mathrm{F}^{\mathrm{c}}\right){ }_{1} 0^{\mathrm{d}}$ & 12.0 & $\begin{array}{c}4.4 \mathrm{E}-03 \\
( \pm 57 \%)\end{array}$ & $\begin{array}{l}1.2 \mathrm{E}-03 \\
( \pm 57 \%)\end{array}$ & $\begin{array}{l}8.3 \mathrm{E}-03 \\
( \pm 57 \%)\end{array}$ \\
\hline 72 & $70(\mathrm{~F}) \_33$ & 12.0 & $\begin{array}{c}3.9 \mathrm{E}-03 \\
( \pm 35 \%)\end{array}$ & $\begin{array}{c}9.4 \mathrm{E}-04 \\
( \pm 35 \%)\end{array}$ & $\begin{array}{c}6.3 \mathrm{E}-03 \\
( \pm 35 \%)\end{array}$ \\
\hline 73 & $70(\mathrm{~F}) \_83$ & 12.0 & $\begin{array}{l}5.3 \mathrm{E}-03 \\
( \pm 37 \%)\end{array}$ & $\begin{array}{l}1.1 \mathrm{E}-03 \\
( \pm 37 \%)\end{array}$ & $\begin{array}{l}8.8 \mathrm{E}-03 \\
( \pm 37 \%)\end{array}$ \\
\hline 74 & 70(F)_167 & 12.0 & $\begin{array}{r}4.7 \mathrm{E}-03 \\
( \pm 12 \%)\end{array}$ & $\begin{array}{c}1.0 \mathrm{E}-03 \\
( \pm 9.3 \%)\end{array}$ & $\begin{array}{l}3.6 \mathrm{E}-03 \\
( \pm 9.3 \%)\end{array}$ \\
\hline 75 & $70(\mathrm{~F}) \_50000$ & 12.0 & $\begin{array}{l}1.1 \mathrm{E}-02 \\
( \pm 32 \%)\end{array}$ & $\begin{array}{r}2.2 \mathrm{E}-03 \\
( \pm 32 \%)\end{array}$ & $\begin{array}{r}7.7 \mathrm{E}-02 \\
( \pm 32 \%)\end{array}$ \\
\hline 76 & 110(F)_10 & 12.0 & $\begin{array}{c}2.8 \mathrm{E}-03 \\
( \pm 66 \%)\end{array}$ & $\begin{array}{c}1.1 \mathrm{E}-03 \\
( \pm 66 \%)\end{array}$ & $\begin{array}{l}7.8 \mathrm{E}-03 \\
( \pm 66 \%)\end{array}$ \\
\hline 77 & $110(\mathrm{~F}) \_33$ & 12.0 & $\begin{array}{l}3.0 \mathrm{E}-03 \\
( \pm 26 \%)\end{array}$ & $\begin{array}{l}1.0 \mathrm{E}-03 \\
( \pm 25 \%)\end{array}$ & $\begin{array}{l}1.1 \mathrm{E}-02 \\
( \pm 25 \%)\end{array}$ \\
\hline 78 & $110(\mathrm{~F}) \_83$ & 12.0 & $\begin{array}{c}4.1 \mathrm{E}-03 \\
( \pm 29 \%)\end{array}$ & $\begin{array}{l}1.3 \mathrm{E}-03 \\
( \pm 28 \%)\end{array}$ & $\begin{array}{c}6.5 \mathrm{E}-03 \\
( \pm 28 \%)\end{array}$ \\
\hline 79 & $110(\mathrm{~F}) \_167$ & 12.0 & $\begin{array}{l}3.0 \mathrm{E}-03 \\
( \pm 28 \%)\end{array}$ & $\begin{array}{r}1.1 \mathrm{E}-03 \\
( \pm 28 \%)\end{array}$ & $\begin{array}{r}5.9 \mathrm{E}-03 \\
( \pm 28 \%)\end{array}$ \\
\hline 80 & $110(\mathrm{~F}) \_50000$ & 12.0 & $\begin{array}{r}4.4 \mathrm{E}-03 \\
( \pm 50 \%)\end{array}$ & $\begin{array}{l}1.5 \mathrm{E}-03 \\
( \pm 50 \%)\end{array}$ & $\begin{array}{l}1.4 \mathrm{E}-02 \\
( \pm 50 \%)\end{array}$ \\
\hline 81 & $70\left(\mathrm{~L}^{\mathrm{c}}\right) \_10$ & 12.0 & $\begin{array}{l}5.5 \mathrm{E}-03 \\
( \pm 17 \%)\end{array}$ & $\begin{array}{l}1.5 \mathrm{E}-03 \\
( \pm 15 \%)\end{array}$ & $\begin{array}{l}3.7 \mathrm{E}-02 \\
( \pm 15 \%)\end{array}$ \\
\hline 82 & 70(L)_33 & 12.0 & $\begin{array}{c}6.7 \mathrm{E}-03 \\
( \pm 7.8 \%)\end{array}$ & $\begin{array}{c}1.6 \mathrm{E}-03 \\
( \pm 7.6 \%)\end{array}$ & $\begin{array}{c}1.2 \mathrm{E}-02 \\
( \pm 7.6 \%)\end{array}$ \\
\hline 83 & $70(\mathrm{~L}) \_83$ & 12.0 & $\begin{array}{l}1.0 \mathrm{E}-02 \\
( \pm 47 \%)\end{array}$ & $\begin{array}{l}3.0 \mathrm{E}-03 \\
( \pm 47 \%)\end{array}$ & $\begin{array}{l}1.8 \mathrm{E}-02 \\
( \pm 47 \%)\end{array}$ \\
\hline 84 & 70(L)_167 & 12.0 & $\begin{array}{l}5.7 \mathrm{E}-03 \\
( \pm 20 \%)\end{array}$ & $\begin{array}{r}2.1 \mathrm{E}-03 \\
( \pm 20 \%)\end{array}$ & $\begin{array}{r}1.5 \mathrm{E}-02 \\
( \pm 20 \%)\end{array}$ \\
\hline 85 & $70(\mathrm{~L}) \_50000$ & 12.0 & $\begin{array}{l}8.4 \mathrm{E}-03 \\
( \pm 45 \%)\end{array}$ & $\begin{array}{r}2.7 \mathrm{E}-03 \\
( \pm 44 \%)\end{array}$ & $\begin{array}{r}2.0 \mathrm{E}-02 \\
( \pm 44 \%)\end{array}$ \\
\hline 86 & 110(L)_10 & 12.0 & $\begin{array}{r}2.1 \mathrm{E}-03 \\
( \pm 40 \%)\end{array}$ & $\begin{array}{r}1.1 \mathrm{E}-03 \\
( \pm 40 \%)\end{array}$ & $\begin{array}{r}9.3 \mathrm{E}-03 \\
( \pm 40 \%)\end{array}$ \\
\hline 87 & 110(L)_33 & 12.0 & $\begin{array}{r}4.2 \mathrm{E}-03 \\
( \pm 56 \%)\end{array}$ & $\begin{array}{r}1.3 \mathrm{E}-03 \\
( \pm 56 \%)\end{array}$ & $\begin{array}{r}1.0 \mathrm{E}-02 \\
( \pm 56 \%)\end{array}$ \\
\hline 88 & 110(L)_83 & 12.0 & $\begin{array}{l}8.2 \mathrm{E}-03 \\
( \pm 62 \%)\end{array}$ & $\begin{array}{r}2.2 \mathrm{E}-03 \\
( \pm 62 \%)\end{array}$ & $\begin{array}{l}1.9 \mathrm{E}-02 \\
( \pm 62 \%)\end{array}$ \\
\hline
\end{tabular}


Table 4-9 Continued

\begin{tabular}{|c|c|c|c|c|c|}
\hline Exp. & $\begin{array}{c}\text { Solid } \\
\mathrm{Fe}(\mathrm{II})(\mathrm{III}) \mathrm{Cl}^{\mathrm{a}}\end{array}$ & $\mathrm{pH}$ & $\begin{array}{c}\mathrm{k}_{\text {solid }} \\
\mathrm{L} /(\mathrm{g} \times \mathrm{d})\end{array}$ & $\begin{array}{c}\mathrm{k}_{\mathrm{Fe}(\mathrm{II})} \\
(\mathrm{mM} \times \mathrm{d})^{-1}\end{array}$ & $\begin{array}{c}\mathrm{k}_{\mathrm{Fe}(\mathrm{III})} \\
(\mathrm{mM} \times \mathrm{d})^{-1}\end{array}$ \\
\hline 89 & 110(L)_167 & 12.0 & $\begin{array}{l}3.4 \mathrm{E}-03 \\
( \pm 17 \%)\end{array}$ & $\begin{array}{l}1.1 \mathrm{E}-03 \\
( \pm 17 \%)\end{array}$ & $\begin{array}{r}6.9 \mathrm{E}-02 \\
( \pm 17 \%)\end{array}$ \\
\hline 90 & 110(L)_50000 & 12.0 & $\begin{array}{l}5.3 \mathrm{E}-03 \\
( \pm 21 \%)\end{array}$ & $\begin{array}{l}1.6 \mathrm{E}-03 \\
( \pm 21 \%)\end{array}$ & $\begin{array}{l}2.1 \mathrm{E}-02 \\
( \pm 21 \%)\end{array}$ \\
\hline 68 & $\mathrm{Fe}(\mathrm{II})(\mathrm{III}) \mathrm{Cl}$ & 12.0 & $\begin{array}{r}3.8 \mathrm{E}-03 \\
( \pm 44 \%)\end{array}$ & $\begin{array}{l}1.3 \mathrm{E}-03 \\
( \pm 44 \%)\end{array}$ & $\begin{array}{r}1.9 \mathrm{E}-02 \\
( \pm 44 \%)\end{array}$ \\
\hline 30 & FSCX & 12.0 & $\begin{array}{r}9.7 \mathrm{E}-04 \\
( \pm 26 \%)\end{array}$ & $\begin{array}{r}6.1 \mathrm{E}-03 \\
( \pm 26 \%)\end{array}$ & $\begin{array}{l}1.2 \mathrm{E}-02 \\
( \pm 26 \%)\end{array}$ \\
\hline 45 & PCX & 11.8 & $\begin{array}{r}6.1 \mathrm{E}-03 \\
( \pm 19 \%)\end{array}$ & $\begin{array}{r}1.1 \mathrm{E}-02 \\
( \pm 4.9 \%)\end{array}$ & $\begin{array}{l}1.1 \mathrm{E}-01 \\
( \pm 4.9 \%)\end{array}$ \\
\hline
\end{tabular}

${ }^{a} \mathrm{Fe}(\mathrm{II})(\mathrm{III}) \mathrm{Cl}$ solid was synthesized by adding $\mathrm{Fe}(\mathrm{II}), \mathrm{Fe}(\mathrm{III})$ and $\mathrm{Cl}$; Initial $\mathrm{Fe}(\mathrm{III})$ concentration of solid was $8.7 \mathrm{mM}$

${ }^{\mathrm{b}} \mathrm{NaOH}$ concentration

i. $\quad 70=70 \mathrm{mM} \mathrm{NaOH}$

ii. $110=110 \mathrm{mM} \mathrm{NaOH}$

${ }^{\mathrm{c}} \mathrm{NaCl}$ addition order

(F) $\mathrm{NaCl}$ addition before adding other elements

(L) $\mathrm{NaCl}$ addition after adding other elements

${ }^{\mathrm{d}} \mathrm{NaOH}$ addition rate

i. $10=10.0 \mu \mathrm{L} / \mathrm{sec}$

ii. $33=33.3 \mu \mathrm{L} / \mathrm{sec}$

iii. $83=83.3 \mu \mathrm{L} / \mathrm{sec}$

iv. $167=167 \mu \mathrm{L} / \mathrm{sec}$

v. $5000=50000 \mu \mathrm{L} / \mathrm{sec}$

Initial PCE concentration was $0.242 \mathrm{mM}$

A sampling time for individual experiment was 7.7 days for exp. 71 to $75 ; 6.9$ days for exp. 76 to 85 ; and 7 days for exp. 86 to 90

Uncertainties represent $95 \%$ confidence limits expressed in \% relative to estimate $\mathrm{k}$

Table 4-10 shows the effect of $\mathrm{Mg}$ on the activity of solids synthesized with the GR method (128). As seen in table 4-10, $\mathrm{NaOH}$ addition rates $(20,83$, and $45,000 \mu \mathrm{L} / \mathrm{sec}$ ) did not have much affect on the solid activities. The solids formed in exp. 108 showed the best activity among $\mathrm{Fe}(\mathrm{II})(\mathrm{III}) \mathrm{ClMg}$ solids. This experiment was 
conducted with addition of $0.4 \mathrm{mM} \mathrm{Fe}(\mathrm{III}), 110 \mathrm{mM} \mathrm{NaOH}$ at the rate of $45,000 \mu \mathrm{L} / \mathrm{sec}$ and $22.2 \mathrm{mM} \mathrm{Mg}$ added after $\mathrm{NaOH}$.

Solids formed in exp. 108 were $50 \%$ and $75 \%$ less active based on $\mathrm{k}_{\mathrm{Fe}(\mathrm{II})}$ than solids formed with FSCX (exp. 30) and with Fe(II)-PCX (exp. 45), and had similar activities with solid formed in exp. $83 . \mathrm{Mg}$ did not have much improved solid activity. Significant amounts of TCE were detected, with concentrations as high as 5 to $10 \%$ of the initial PCE concentration, in exp. 93, 96, and 108, like MSCX solids (exp. 44).

TABLE 4-10 Pseudo first-order rate constants of PCE reduction by solids containing $\mathrm{Fe}(\mathrm{II}), \mathrm{Fe}(\mathrm{III}), \mathrm{Cl}$, and $\mathrm{Mg}$ synthesized by GR synthesis method

\begin{tabular}{|c|c|c|c|c|c|c|}
\hline Exp. & $\begin{array}{c}\text { Solid } \\
\mathrm{Fe}(\mathrm{II})(\mathrm{III}) \mathrm{ClMg}^{\mathrm{a}}\end{array}$ & $\mathrm{pH}$ & $\begin{array}{c}\mathrm{k}_{\text {solid }} \\
\mathrm{L} /(\mathrm{g} \times \mathrm{d})\end{array}$ & $\begin{array}{c}\mathrm{k}_{\mathrm{Fe}(\mathrm{II})} \\
(\mathrm{mM} \times \mathrm{d})^{-1}\end{array}$ & $\begin{array}{c}\mathrm{k}_{\mathrm{Fe}(\mathrm{III})} \\
(\mathrm{mM} \times \mathrm{d})^{-1}\end{array}$ & $\begin{array}{l}\mathrm{TCE}^{\mathrm{f}} \\
\mathrm{mM}\end{array}$ \\
\hline 91 & $70^{\mathrm{b}}\left(0.4^{\mathrm{c}}\right)-_{2} 0^{\mathrm{d}}\left(\mathrm{BO}^{\mathrm{e}}\right)$ & 12.0 & $\begin{array}{c}3.4 \mathrm{E}-03 \\
( \pm 30 \%)\end{array}$ & $\begin{array}{l}1.1 \mathrm{E}-03 \\
( \pm 30 \%)\end{array}$ & $\begin{array}{l}1.5 \mathrm{E}-02 \\
( \pm 30 \%)\end{array}$ & \\
\hline 92 & 70(0.4)_83(BO) & 12.0 & $\begin{array}{l}3.5 \mathrm{E}-03 \\
( \pm 15 \%)\end{array}$ & $\begin{array}{l}1.3 \mathrm{E}-03 \\
( \pm 15 \%)\end{array}$ & $\begin{array}{r}2.2 \mathrm{E}-02 \\
( \pm 15 \%)\end{array}$ & \\
\hline 93 & $70(0.4) \_45000(\mathrm{BO})$ & 12.0 & $\begin{array}{c}5.0 \mathrm{E}-03 \\
( \pm 30 \%)\end{array}$ & $\begin{array}{l}1.7 \mathrm{E}-03 \\
( \pm 30 \%)\end{array}$ & $\begin{array}{r}2.4 \mathrm{E}-02 \\
( \pm 30 \%)\end{array}$ & 0.01 \\
\hline 94 & $70(0.4) \_20(\mathrm{AO})$ & 12.0 & $\begin{array}{l}3.3 \mathrm{E}-03 \\
( \pm 30 \%)\end{array}$ & $\begin{array}{l}1.6 \mathrm{E}-03 \\
( \pm 29 \%)\end{array}$ & $\begin{array}{r}1.6 \mathrm{E}-02 \\
( \pm 29 \%)\end{array}$ & \\
\hline 95 & 70(0.4)_83(AO) & 12.0 & $\begin{array}{l}2.9 \mathrm{E}-03 \\
( \pm 25 \%)\end{array}$ & $\begin{array}{l}1.3 \mathrm{E}-03 \\
( \pm 25 \%)\end{array}$ & $\begin{array}{l}1.9 \mathrm{E}-02 \\
( \pm 25 \%)\end{array}$ & \\
\hline 96 & $70(0.4) \_45000(\mathrm{AO})$ & 12.0 & $\begin{array}{r}6.5 \mathrm{E}-03 \\
( \pm 39 \%)\end{array}$ & $\begin{array}{r}2.1 \mathrm{E}-03 \\
( \pm 39 \%)\end{array}$ & $\begin{array}{r}6.0 \mathrm{E}-02 \\
( \pm 39 \%)\end{array}$ & 0.02 \\
\hline 97 & 70(8.7)_20(BO) & 12.0 & $\begin{array}{l}3.7 \mathrm{E}-03 \\
( \pm 29 \%)\end{array}$ & $\begin{array}{l}1.9 \mathrm{E}-03 \\
( \pm 29 \%)\end{array}$ & $\begin{array}{l}6.5 \mathrm{E}-03 \\
( \pm 29 \%)\end{array}$ & \\
\hline 98 & 70(8.7)_83(BO) & 12.0 & $\begin{array}{l}3.2 \mathrm{E}-03 \\
( \pm 28 \%)\end{array}$ & $\begin{array}{l}1.6 \mathrm{E}-03 \\
( \pm 28 \%)\end{array}$ & $\begin{array}{l}6.0 \mathrm{E}-03 \\
( \pm 28 \%)\end{array}$ & \\
\hline 99 & 70(8.7)_45000(BO) & 12.0 & $\begin{array}{r}3.5 \mathrm{E}-03 \\
( \pm 17 \%)\end{array}$ & $\begin{array}{c}1.8 \mathrm{E}-03 \\
( \pm 17 \%)\end{array}$ & $\begin{array}{r}5.6 \mathrm{E}-03 \\
( \pm 17 \%)\end{array}$ & \\
\hline 100 & 70(8.7)_20(AO) & 12.0 & $\begin{array}{l}3.6 \mathrm{E}-03 \\
( \pm 29 \%)\end{array}$ & $\begin{array}{l}1.6 \mathrm{E}-03 \\
( \pm 29 \%)\end{array}$ & $\begin{array}{l}5.0 \mathrm{E}-03 \\
( \pm 29 \%)\end{array}$ & \\
\hline
\end{tabular}


Table 4-10 Continued

\begin{tabular}{|c|c|c|c|c|c|c|}
\hline Exp. & $\begin{array}{c}\text { Solid } \\
\text { Fe(II)(III)ClMg }\end{array}$ & $\mathrm{pH}$ & $\begin{array}{c}\mathrm{k}_{\text {solid }} \\
\mathrm{L} /(\mathrm{g} \times \mathrm{d})\end{array}$ & $\begin{array}{c}\mathrm{k}_{\mathrm{Fe}(\mathrm{II})} \\
(\mathrm{mM} \times \mathrm{d})^{-1}\end{array}$ & $\begin{array}{c}\mathrm{k}_{\mathrm{Fe}(\mathrm{III})} \\
(\mathrm{mM} \times \mathrm{d})^{-1}\end{array}$ & $\begin{array}{l}\mathrm{TCE}^{\mathrm{f}} \\
\mathrm{mM}\end{array}$ \\
\hline 101 & 70(8.7)_83(AO) & 12.0 & $\begin{array}{l}3.9 \mathrm{E}-03 \\
( \pm 91 \%)\end{array}$ & $\begin{array}{l}1.9 \mathrm{E}-03 \\
( \pm 91 \%)\end{array}$ & $\begin{array}{l}6.2 \mathrm{E}-03 \\
( \pm 91 \%)\end{array}$ & \\
\hline 102 & 70(8.7)_45000(AO) & 12.0 & $\begin{array}{l}4.3 \mathrm{E}-03 \\
( \pm 37 \%)\end{array}$ & $\begin{array}{l}2.1 \mathrm{E}-03 \\
( \pm 37 \%)\end{array}$ & $\begin{array}{l}7.4 \mathrm{E}-03 \\
( \pm 37 \%)\end{array}$ & \\
\hline 103 & 110(0.4)_20(BO) & 12.0 & $\begin{array}{l}6.7 \mathrm{E}-03 \\
( \pm 20 \%)\end{array}$ & $\begin{array}{r}2.6 \mathrm{E}-03 \\
( \pm 20 \%)\end{array}$ & $\begin{array}{r}3.2 \mathrm{E}-02 \\
( \pm 20 \%)\end{array}$ & \\
\hline 104 & $110(0.4) \_83(\mathrm{BO})$ & 12.0 & $\begin{array}{l}4.8 \mathrm{E}-03 \\
( \pm 30 \%)\end{array}$ & $\begin{array}{l}2.0 \mathrm{E}-03 \\
( \pm 39 \%)\end{array}$ & $\begin{array}{r}2.1 \mathrm{E}-02 \\
( \pm 39 \%)\end{array}$ & \\
\hline 105 & $110(0.4) \_4500(\mathrm{BO})$ & 12.0 & $\begin{array}{l}5.6 \mathrm{E}-03 \\
( \pm 10 \%)\end{array}$ & $\begin{array}{r}2.2 \mathrm{E}-03 \\
( \pm 10 \%)\end{array}$ & $\begin{array}{r}3.7 \mathrm{E}-02 \\
( \pm 10 \%)\end{array}$ & \\
\hline 106 & 110(0.4)_20(AO) & 12.0 & $\begin{array}{l}3.0 \mathrm{E}-03 \\
( \pm 23 \%)\end{array}$ & $\begin{array}{l}1.4 \mathrm{E}-03 \\
( \pm 23 \%)\end{array}$ & $\begin{array}{l}1.3 \mathrm{E}-02 \\
( \pm 23 \%)\end{array}$ & \\
\hline 107 & $110(0.4) \_83(\mathrm{AO})$ & 12.0 & $\begin{array}{l}5.1 \mathrm{E}-03 \\
( \pm 6.0 \%)\end{array}$ & $\begin{array}{l}2.2 \mathrm{E}-03 \\
( \pm 5.9 \%)\end{array}$ & $\begin{array}{l}2.7 \mathrm{E}-02 \\
( \pm 5.9 \%)\end{array}$ & \\
\hline 108 & 110(0.4)_4500(AO) & 12.0 & $\begin{array}{l}6.5 \mathrm{E}-03 \\
( \pm 23 \%)\end{array}$ & $\begin{array}{l}2.9 \mathrm{E}-03 \\
( \pm 23 \%)\end{array}$ & $\begin{array}{r}9.6 \mathrm{E}-02 \\
( \pm 23 \%)\end{array}$ & 0.02 \\
\hline 83 & 70(L)_83(Fe(II)(III)Cl) & 12.0 & $\begin{array}{l}1.0 \mathrm{E}-02 \\
( \pm 47 \%)\end{array}$ & $\begin{array}{l}3.0 \mathrm{E}-03 \\
( \pm 47 \%)\end{array}$ & $\begin{array}{l}1.8 \mathrm{E}-02 \\
( \pm 47 \%)\end{array}$ & \\
\hline 48 & $\mathrm{Fe}(\mathrm{II})(\mathrm{III}) \mathrm{ClMg}$ & 12.0 & $\begin{array}{l}4.6 \mathrm{E}-03 \\
( \pm 26 \%)\end{array}$ & $\begin{array}{l}1.5 \mathrm{E}-03 \\
( \pm 25 \%)\end{array}$ & $\begin{array}{l}6.1 \mathrm{E}-03 \\
( \pm 25 \%)\end{array}$ & \\
\hline 68 & $\mathrm{Fe}(\mathrm{II})(\mathrm{III}) \mathrm{Cl}$ & 12.0 & $\begin{array}{r}3.8 \mathrm{E}-03 \\
( \pm 44 \%)\end{array}$ & $\begin{array}{l}1.3 \mathrm{E}-03 \\
( \pm 44 \%)\end{array}$ & $\begin{array}{l}1.9 \mathrm{E}-02 \\
( \pm 44 \%)\end{array}$ & \\
\hline 30 & FSCX & 12.0 & $\begin{array}{r}9.7 \mathrm{E}-04 \\
( \pm 26 \%)\end{array}$ & $\begin{array}{r}6.1 \mathrm{E}-03 \\
( \pm 26 \%)\end{array}$ & $\begin{array}{r}1.2 \mathrm{E}-02 \\
( \pm 26 \%)\end{array}$ & \\
\hline 44 & MSCX & 12.0 & $\begin{array}{l}1.2 \mathrm{E}-02 \\
( \pm 15 \%)\end{array}$ & $\begin{array}{r}3.8 \mathrm{E}-03 \\
( \pm 15 \%)\end{array}$ & $\begin{array}{r}4.1 \mathrm{E}-02 \\
( \pm 15 \%)\end{array}$ & 0.02 \\
\hline 45 & PCX & 11.8 & $\begin{array}{l}6.1 \mathrm{E}-03 \\
( \pm 19 \%)\end{array}$ & $\begin{array}{l}1.1 \mathrm{E}-02 \\
( \pm 4.9 \%)\end{array}$ & $\begin{array}{l}1.1 \mathrm{E}-01 \\
( \pm 4.9 \%)\end{array}$ & \\
\hline
\end{tabular}

${ }^{\mathrm{a}} \mathrm{Fe}(\mathrm{II})(\mathrm{III}) \mathrm{ClMg}$ solid was synthesized by adding $\mathrm{Fe}(\mathrm{II}), \mathrm{Fe}(\mathrm{III}), \mathrm{Cl}$ and $\mathrm{Mg}$

${ }^{\mathrm{b}} \mathrm{NaOH}$ concentration

i. $\quad 70=70 \mathrm{mM} \mathrm{NaOH}$

ii. $\quad 110=110 \mathrm{mM} \mathrm{NaOH}$

${ }^{\mathrm{c}} \mathrm{Fe}(\mathrm{III})$ concentration

i. $\quad 0.4=0.4 \mathrm{mM} \mathrm{Fe}(\mathrm{III})$

ii. $\quad 8.7=8.7 \mathrm{mM} \mathrm{Fe}($ III)

${ }^{\mathrm{d}} \mathrm{NaOH}$ addition rate

i. $20=20.0 \mu \mathrm{L} / \mathrm{sec}$

ii. $83=83.3 \mu \mathrm{L} / \mathrm{sec}$

iii. $\quad 45000=45000 \mu \mathrm{L} / \mathrm{sec}$

${ }^{\mathrm{e}} \mathrm{Mg}$ addition order

i. $\quad \mathrm{BO}=$ Before $\mathrm{OH}$ addition

ii. $\mathrm{AO}=$ After $\mathrm{OH}$ addition

festimate of TCE conc. in liquid phase Initial PCE concentration was $0.242 \mathrm{mM}$

A sampling time for individual experiment was 5.7 days for exp. 91 to $96 ; 4$ days for exp. 97 to $102 ; 4.6$ days for exp. 103 to 107; and 4.2 days for exp. 108

Uncertainties represent $95 \%$ confidence limits expressed in \% relative to estimate $\mathrm{k}$ 
Table 4-11 shows the effect of $\mathrm{SO}_{4}$ on the activity of solids synthesized with the GR method. When sulfate was added after addition of $\mathrm{NaOH}$, solids showed activities that were a little higher than when sulfate was added before addition of $\mathrm{NaOH}$. Solids synthesized at high $\mathrm{pH}$ (about 12) showed more activity than those synthesized at neutral pH. Slow addition of $\mathrm{NaOH}(20 \mu \mathrm{L} / \mathrm{sec}$, and $83.3 \mu \mathrm{L} / \mathrm{sec})$ made more active solids than fast addition of $\mathrm{NaOH}(50,000 \mu \mathrm{L} / \mathrm{sec})$.

The most active solid in this set of experiments was observed in experiment 125, which was conducted with $0.4 \mathrm{mM} \mathrm{Fe}(\mathrm{III})$ and $110 \mathrm{mM} \mathrm{NaOH}$. The $\mathrm{NaOH}$ was added at the rate of $83.3 \mu \mathrm{L} / \mathrm{sec}$. These solids were still less active than those produced with

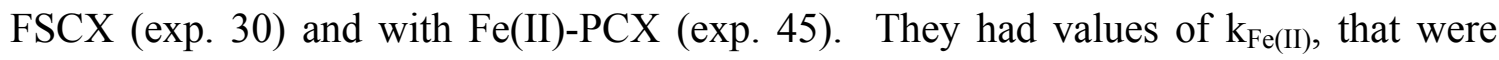
about $60 \%$ and $80 \%$ lower than those for FSCX solids and Fe(II)-PCX solids, respectively

The GR synthesis method was able to make more active solids with normalized rate constants $\left(\mathrm{k}_{\mathrm{solid}}, \mathrm{k}_{\mathrm{Fe}(\mathrm{II})}\right)$ about $50 \%$ higher than those produced by the simple mixing method (exp. 68 and exp. 77). However, certain amounts of TCE were detected, with concentrations as high as 2 to $10 \%$ of the initial PCE concentration, in exp. 110, 111, 114, 123. Sulfate did not have much effect on activity. 
TABLE 4-11 Pseudo first-order rate constants of PCE reduction by solids containing $\mathrm{Fe}(\mathrm{II}), \mathrm{Fe}(\mathrm{III}), \mathrm{Cl}$, and $\mathrm{SO}_{4}$ synthesized by GR synthesis method

\begin{tabular}{|c|c|c|c|c|c|c|}
\hline Exp. & $\begin{array}{c}\text { Solid } \\
\mathrm{Fe}(\mathrm{II})(\mathrm{III}) \mathrm{ClSO}_{4}{ }^{\mathrm{a}}\end{array}$ & $\mathrm{pH}$ & $\begin{array}{c}\mathrm{k}_{\text {solid }} \\
\mathrm{L} /(\mathrm{g} \times \mathrm{d})\end{array}$ & $\begin{array}{c}\mathrm{k}_{\mathrm{Fe}(\mathrm{II})} \\
(\mathrm{mM} \times \mathrm{d})^{-1}\end{array}$ & $\begin{array}{c}\mathrm{k}_{\mathrm{Fe}(\mathrm{III})} \\
(\mathrm{mM} \times \mathrm{d})^{-1}\end{array}$ & $\begin{array}{l}\mathrm{TCE}^{\mathrm{f}} \\
\mathrm{mM}\end{array}$ \\
\hline 109 & $70^{\mathrm{b}}\left(0.4^{\mathrm{c}}\right) \_20^{\mathrm{d}}\left(\mathrm{BO}^{\mathrm{e}}\right)$ & 12.0 & $\begin{array}{r}6.0 \mathrm{E}-03 \\
( \pm 84 \%)\end{array}$ & $\begin{array}{l}1.7 \mathrm{E}-03 \\
( \pm 84 \%)\end{array}$ & $\begin{array}{r}2.7 \mathrm{E}-02 \\
( \pm 84 \%)\end{array}$ & \\
\hline 110 & 70(0.4)_83(BO) & 12.0 & $\begin{array}{l}2.8 \mathrm{E}-03 \\
( \pm 16 \%)\end{array}$ & $\begin{array}{l}1.0 \mathrm{E}-03 \\
( \pm 16 \%)\end{array}$ & $\begin{array}{l}1.1 \mathrm{E}-02 \\
( \pm 16 \%)\end{array}$ & 0.004 \\
\hline 111 & $70(0.4) \_50000(\mathrm{BO})$ & 12.0 & $\begin{array}{l}4.4 \mathrm{E}-03 \\
( \pm 13 \%)\end{array}$ & $\begin{array}{l}1.2 \mathrm{E}-03 \\
( \pm 13 \%)\end{array}$ & $\begin{array}{l}2.4 \mathrm{E}-02 \\
( \pm 13 \%)\end{array}$ & 0.004 \\
\hline 112 & 70(0.4)_20(AO) & 12.0 & $\begin{array}{r}3.1 \mathrm{E}-03 \\
( \pm 16 \%)\end{array}$ & $\begin{array}{r}9.8 \mathrm{E}-04 \\
( \pm 16 \%)\end{array}$ & $\begin{array}{l}8.3 \mathrm{E}-03 \\
( \pm 16 \%)\end{array}$ & \\
\hline 113 & 70(0.4)_83(AO) & 12.0 & $\begin{array}{r}3.5 \mathrm{E}-03 \\
( \pm 426 \%)\end{array}$ & $\begin{array}{l}1.1 \mathrm{E}-03 \\
( \pm 26 \%)\end{array}$ & $\begin{array}{l}1.2 \mathrm{E}-02 \\
( \pm 26 \%)\end{array}$ & \\
\hline 114 & $70(0.4) \_50000(\mathrm{AO})$ & 12.0 & $\begin{array}{c}6.6 \mathrm{E}-03 \\
( \pm 32 \%)\end{array}$ & $\begin{array}{l}1.7 \mathrm{E}-03 \\
( \pm 32 \%)\end{array}$ & $\begin{array}{r}2.7 \mathrm{E}-02 \\
( \pm 32 \%)\end{array}$ & 0.02 \\
\hline 115 & 70(8.7)_20(BO) & 12.0 & $\begin{array}{l}4.4 \mathrm{E}-03 \\
( \pm 11 \%)\end{array}$ & $\begin{array}{l}1.3 \mathrm{E}-03 \\
( \pm 9.2 \%)\end{array}$ & $\begin{array}{l}4.4 \mathrm{E}-03 \\
( \pm 9.2 \%)\end{array}$ & \\
\hline 116 & 70(8.7)_83(BO) & 12.0 & $\begin{array}{l}3.7 \mathrm{E}-03 \\
( \pm 14 \%)\end{array}$ & $\begin{array}{l}1.4 \mathrm{E}-03 \\
( \pm 7.3 \%)\end{array}$ & $\begin{array}{l}7.3 \mathrm{E}-03 \\
( \pm 7.3 \%)\end{array}$ & \\
\hline 117 & 70(8.7)_50000(BO) & 12.0 & $\begin{array}{l}5.1 \mathrm{E}-03 \\
( \pm 97 \%)\end{array}$ & $\begin{array}{l}1.5 \mathrm{E}-03 \\
( \pm 95 \%)\end{array}$ & $\begin{array}{l}1.3 \mathrm{E}-02 \\
( \pm 95 \%)\end{array}$ & \\
\hline 118 & 70(8.7)_20(AO) & 12.0 & $\begin{array}{l}5.2 \mathrm{E}-03 \\
( \pm 39 \%)\end{array}$ & $\begin{array}{l}1.6 \mathrm{E}-03 \\
( \pm 37 \%)\end{array}$ & $\begin{array}{l}6.3 \mathrm{E}-03 \\
( \pm 37 \%)\end{array}$ & \\
\hline 119 & 70(8.7)_83(AO) & 12.0 & $\begin{array}{r}6.2 \mathrm{E}-03 \\
( \pm 283 \%)\end{array}$ & $\begin{array}{l}1.9 \mathrm{E}-03 \\
(211 \%)\end{array}$ & $\begin{array}{r}6.9 \mathrm{E}-03 \\
( \pm 211 \%)\end{array}$ & \\
\hline 120 & 70(8.7)_50000(AO) & 12.0 & $\begin{array}{l}5.8 \mathrm{E}-03 \\
( \pm 18 \%)\end{array}$ & $\begin{array}{l}1.6 \mathrm{E}-03 \\
( \pm 17 \%)\end{array}$ & $\begin{array}{l}9.1 \mathrm{E}-03 \\
( \pm 17 \%)\end{array}$ & \\
\hline 121 & 110(0.4)_20(BO) & 12.0 & $\begin{array}{l}6.5 \mathrm{E}-03 \\
( \pm 13 \%)\end{array}$ & $\begin{array}{l}1.9 \mathrm{E}-03 \\
( \pm 13 \%)\end{array}$ & $\begin{array}{l}1.8 \mathrm{E}-02 \\
( \pm 13 \%)\end{array}$ & \\
\hline 122 & 110(0.4)_83(BO) & 12.0 & $\begin{array}{l}7.3 \mathrm{E}-03 \\
( \pm 23 \%)\end{array}$ & $\begin{array}{l}2.0 \mathrm{E}-03 \\
( \pm 22 \%)\end{array}$ & $\begin{array}{l}1.3 \mathrm{E}-02 \\
( \pm 22 \%)\end{array}$ & \\
\hline 123 & 110(0.4)_5000(BO) & 12.0 & $\begin{array}{r}6.0 \mathrm{E}-03 \\
( \pm 21 \%)\end{array}$ & $\begin{array}{l}1.6 \mathrm{E}-03 \\
( \pm 21 \%)\end{array}$ & $\begin{array}{r}2.1 \mathrm{E}-02 \\
( \pm 21 \%)\end{array}$ & 0.004 \\
\hline 124 & 110(0.4)_20(AO) & 12.0 & $\begin{array}{l}9.4 \mathrm{E}-03 \\
( \pm 24 \%)\end{array}$ & $\begin{array}{l}2.5 \mathrm{E}-03 \\
( \pm 23 \%)\end{array}$ & $\begin{array}{l}2.3 \mathrm{E}-02 \\
( \pm 23 \%)\end{array}$ & \\
\hline 125 & 110(0.4)_83(AO) & 12.0 & $\begin{array}{l}9.7 \mathrm{E}-03 \\
( \pm 31 \%)\end{array}$ & $\begin{array}{l}2.6 \mathrm{E}-03 \\
( \pm 31 \%)\end{array}$ & $\begin{array}{l}1.8 \mathrm{E}-02 \\
( \pm 31 \%)\end{array}$ & \\
\hline 126 & 110(0.4)_5000(AO) & 12.0 & $\begin{array}{l}5.7 \mathrm{E}-03 \\
( \pm 36 \%)\end{array}$ & $\begin{array}{l}1.9 \mathrm{E}-03 \\
( \pm 28 \%)\end{array}$ & $\begin{array}{l}1.2 \mathrm{E}-02 \\
( \pm 28 \%)\end{array}$ & \\
\hline
\end{tabular}


Table 4-11 Continued

\begin{tabular}{|c|c|c|c|c|c|c|}
\hline Exp. & $\begin{array}{c}\text { Solid } \\
\mathrm{Fe}(\mathrm{II})(\mathrm{III}) \mathrm{ClSO}_{4}{ }^{\mathrm{a}}\end{array}$ & $\mathrm{pH}$ & $\begin{array}{c}\mathrm{k}_{\text {solid }} \\
\mathrm{L} /(\mathrm{g} \times \mathrm{d})\end{array}$ & $\begin{array}{c}\mathrm{k}_{\mathrm{Fe}(\mathrm{II})} \\
(\mathrm{mM} \times \mathrm{d})^{-1}\end{array}$ & $\begin{array}{c}\mathrm{k}_{\mathrm{Fe}(\mathrm{III})} \\
(\mathrm{mM} \times \mathrm{d})^{-1}\end{array}$ & $\begin{array}{l}\mathrm{TCE}^{\mathrm{f}} \\
\mathrm{mM}\end{array}$ \\
\hline 83 & 70(L)_83(Fe(II)(III)Cl) & 12.0 & $\begin{array}{l}1.0 \mathrm{E}-02 \\
( \pm 47 \%)\end{array}$ & $\begin{array}{l}3.0 \mathrm{E}-03 \\
( \pm 47 \%)\end{array}$ & $\begin{array}{l}1.8 \mathrm{E}-02 \\
( \pm 47 \%)\end{array}$ & \\
\hline 55 & $\mathrm{Fe}(\mathrm{II})(\mathrm{III}) \mathrm{ClSO}_{4}$ & 12.0 & $\begin{array}{l}5.2 \mathrm{E}-03 \\
( \pm 67 \%)\end{array}$ & $\begin{array}{l}1.7 \mathrm{E}-03 \\
( \pm 67 \%)\end{array}$ & $\begin{array}{r}2.0 \mathrm{E}-02 \\
( \pm 67 \%)\end{array}$ & \\
\hline 68 & $\mathrm{Fe}(\mathrm{II})(\mathrm{III}) \mathrm{Cl}$ & 12.0 & $\begin{array}{r}3.8 \mathrm{E}-03 \\
( \pm 44 \%)\end{array}$ & $\begin{array}{l}1.3 \mathrm{E}-03 \\
( \pm 44 \%)\end{array}$ & $\begin{array}{l}1.9 \mathrm{E}-02 \\
( \pm 44 \%)\end{array}$ & \\
\hline 30 & FSCX & 12.0 & $\begin{array}{r}9.7 \mathrm{E}-04 \\
( \pm 26 \%)\end{array}$ & $\begin{array}{c}6.1 \mathrm{E}-03 \\
( \pm 26 \%)\end{array}$ & $\begin{array}{l}1.2 \mathrm{E}-02 \\
( \pm 26 \%)\end{array}$ & \\
\hline 45 & PCX & 11.8 & $\begin{array}{r}6.1 \mathrm{E}-03 \\
( \pm 19 \%)\end{array}$ & $\begin{array}{l}1.1 \mathrm{E}-02 \\
( \pm 4.9 \%)\end{array}$ & $\begin{array}{l}1.1 \mathrm{E}-01 \\
( \pm 4.9 \%)\end{array}$ & \\
\hline
\end{tabular}

${ }^{\mathrm{a}} \mathrm{Fe}(\mathrm{II})(\mathrm{III}) \mathrm{ClMg}$ solid was synthesized by adding $\mathrm{Fe}(\mathrm{II}), \mathrm{Fe}(\mathrm{III}), \mathrm{Cl}$ and $\mathrm{SO}_{4}$

b: $\mathrm{NaOH}$ concentration

i. $70=70 \mathrm{mM} \mathrm{NaOH}$

ii. $110=110 \mathrm{mM} \mathrm{NaOH}$

c: $\mathrm{Fe}(\mathrm{III})$ concentration

i. $\quad 0.4=0.4 \mathrm{mM} \mathrm{Fe}(\mathrm{III})$

ii. $8.7=8.7 \mathrm{mM} \mathrm{Fe}($ III)

d: $\mathrm{NaOH}$ addition rate

i. $20=20.0 \mu \mathrm{L} / \mathrm{sec}$

ii. $83=83.3 \mu \mathrm{L} / \mathrm{sec}$

iii. $50000=50000 \mu \mathrm{L} / \mathrm{sec}$

e: $\mathrm{SO}_{4}$ addition order

i. $\quad \mathrm{BO}=$ Before $\mathrm{OH}$ addition

ii. $\mathrm{AO}=$ After $\mathrm{OH}$ addition

festimate of TCE conc. in liquid phase

Initial PCE concentration was $0.242 \mathrm{mM}$

A sampling time for individual experiment was 7 days for exp. 109 to $114 ; 4.9$ days for exp. 115 to 120 ; and 5.6 days for exp. 121 to 126

Uncertainties represent 95\% confidence limits expressed in \% relative to estimate $\mathrm{k}$

Table 4-11 shows the effect of $\mathrm{SiO}_{3}$ on the activity of solids synthesized by the

GR method. Solids synthesized at high $\mathrm{pH}$ (about $\mathrm{pH}$ 12) and at neutral $\mathrm{pH}$ showed similar activities. $\mathrm{NaOH}$ addition rates and a silicate addition order were not important factors in forming more active solids. 
The highest solid activities in this set of experiments were observed in exp. 140 and 143. Exp. 140 was conducted with $0.4 \mathrm{mM} \mathrm{Fe}(\mathrm{III}), 110 \mathrm{mM} \mathrm{NaOH}, \mathrm{NaOH}$ addition rate of $83.3 \mu \mathrm{L} / \mathrm{sec}$ and silicate addition before $\mathrm{NaOH}$. Exp. 142 was conducted with 0.4 $\mathrm{mM} \mathrm{Fe}(\mathrm{III}), 110 \mathrm{mM} \mathrm{NaOH}, \mathrm{NaOH}$ addition rate of $20.0 \mu \mathrm{L} / \mathrm{sec}$, and silicate addition after $\mathrm{NaOH}$. The activities in these experiments were lower than those observed for

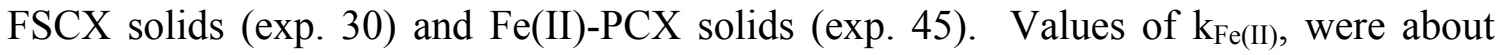
$60 \%$ of those observed for FSCX solids and $80 \%$ of those observed for Fe(II)-PCX solids.

The GR synthesis method was able to make solids with normalized rate constants $\left(\mathrm{k}_{\mathrm{solid}}, \mathrm{k}_{\mathrm{Fe}(\mathrm{II})}\right)$ that were about $50 \%$ higher than those obtained with the simple mixing method (exp. 68 and exp. 77), but TCE was detected in many experiments using the GR synthesis method..

Silicate and sulfate had the almost same effect on the solid activities. Like, $\mathrm{Mg}$ and sulfate, silicate also did not improve solid activities to a major extent. 
TABLE 4-12 Pseudo first-order rate constants of PCE reduction by solids containing $\mathrm{Fe}(\mathrm{II}), \mathrm{Fe}(\mathrm{III}), \mathrm{Cl}$, and $\mathrm{SiO}_{3}$ synthesized by GR synthesis method

\begin{tabular}{|c|c|c|c|c|c|c|}
\hline Exp. & $\begin{array}{c}\text { Solid } \\
\mathrm{Fe}(\mathrm{II})(\mathrm{III}) \mathrm{ClSiO}_{3}{ }^{\mathrm{a}}\end{array}$ & $\mathrm{pH}$ & $\begin{array}{c}\mathrm{k}_{\text {solid }} \\
\mathrm{L} /(\mathrm{g} \times \mathrm{d})\end{array}$ & $\begin{array}{c}\mathrm{k}_{\mathrm{Fe}(\mathrm{II})} \\
(\mathrm{mM} \times \mathrm{d})^{-1}\end{array}$ & $\begin{array}{c}\mathrm{k}_{\mathrm{Fe}(\mathrm{III})} \\
(\mathrm{mM} \times \mathrm{d})^{-1}\end{array}$ & $\begin{array}{l}\mathrm{TCE}^{\mathrm{f}} \\
\mathrm{mM}\end{array}$ \\
\hline 127 & $70^{\mathrm{b}}\left(0.4^{\mathrm{c}}\right) \_20^{\mathrm{d}}\left(\mathrm{BO}^{\mathrm{e}}\right)$ & 12.0 & $\begin{array}{l}5.2 \mathrm{E}-03 \\
( \pm 5.7 \%)\end{array}$ & $\begin{array}{l}1.2 \mathrm{E}-03 \\
( \pm 5.7 \%)\end{array}$ & $\begin{array}{l}2.1 \mathrm{E}-02 \\
( \pm 5.7 \%)\end{array}$ & \\
\hline 128 & 70(0.4)_83(BO) & 12.0 & $\begin{array}{l}7.4 \mathrm{E}-03 \\
( \pm 18 \%)\end{array}$ & $\begin{array}{l}1.9 \mathrm{E}-03 \\
( \pm 18 \%)\end{array}$ & $\begin{array}{l}8.1 \mathrm{E}-02 \\
( \pm 18 \%)\end{array}$ & \\
\hline 129 & $70(0.4) \_50000(\mathrm{BO})$ & 12.0 & $\begin{array}{l}5.0 \mathrm{E}-03 \\
( \pm 30 \%)\end{array}$ & $\begin{array}{l}1.3 \mathrm{E}-03 \\
( \pm 30 \%)\end{array}$ & $\begin{array}{r}2.3 \mathrm{E}-02 \\
( \pm 30 \%)\end{array}$ & 0.003 \\
\hline 130 & 70(0.4)_20(AO) & 12.0 & $\begin{array}{l}4.7 \mathrm{E}-03 \\
( \pm 12 \%)\end{array}$ & $\begin{array}{l}1.6 \mathrm{E}-03 \\
( \pm 12 \%)\end{array}$ & $\begin{array}{l}5.0 \mathrm{E}-02 \\
( \pm 12 \%)\end{array}$ & \\
\hline 131 & 70(0.4)_83(AO) & 12.0 & $\begin{array}{l}6.6 \mathrm{E}-03 \\
( \pm 21 \%)\end{array}$ & $\begin{array}{l}2.2 \mathrm{E}-03 \\
( \pm 21 \%)\end{array}$ & $\begin{array}{l}3.4 \mathrm{E}-02 \\
( \pm 21 \%)\end{array}$ & 0.003 \\
\hline 132 & 70(0.4)_50000(AO) & 12.0 & $\begin{array}{r}4.5 \mathrm{E}-03 \\
( \pm 46 \%)\end{array}$ & $\begin{array}{l}1.6 \mathrm{E}-03 \\
( \pm 46 \%)\end{array}$ & $\begin{array}{c}6.2 \mathrm{E}-03 \\
( \pm 46 \%)\end{array}$ & 0.01 \\
\hline 133 & 70(8.7)_20(BO) & 12.0 & $\begin{array}{l}6.0 \mathrm{E}-03 \\
( \pm 34 \%)\end{array}$ & $\begin{array}{l}2.2 \mathrm{E}-03 \\
( \pm 34 \%)\end{array}$ & $\begin{array}{l}7.0 \mathrm{E}-03 \\
( \pm 34 \%)\end{array}$ & \\
\hline 134 & 70(8.7)_83(BO) & 12.0 & $\begin{array}{l}7.0 \mathrm{E}-03 \\
( \pm 76 \%)\end{array}$ & $\begin{array}{l}1.7 \mathrm{E}-03 \\
( \pm 76 \%)\end{array}$ & $\begin{array}{l}7.1 \mathrm{E}-03 \\
( \pm 76 \%)\end{array}$ & \\
\hline 135 & 70(8.7)_50000(BO) & 12.0 & $\begin{array}{l}6.1 \mathrm{E}-03 \\
( \pm 43 \%)\end{array}$ & $\begin{array}{r}2.3 \mathrm{E}-03 \\
( \pm 43 \%)\end{array}$ & $\begin{array}{l}1.0 \mathrm{E}-02 \\
( \pm 43 \%)\end{array}$ & \\
\hline 136 & 70(8.7)_20(AO) & 12.0 & $\begin{array}{l}6.2 \mathrm{E}-03 \\
( \pm 73 \%)\end{array}$ & $\begin{array}{l}2.2 \mathrm{E}-03 \\
( \pm 73 \%)\end{array}$ & $\begin{array}{l}8.3 \mathrm{E}-03 \\
( \pm 73 \%)\end{array}$ & \\
\hline 137 & 70(8.7)_83(AO) & 12.0 & $\begin{array}{l}8.9 \mathrm{E}-03 \\
( \pm 83 \%)\end{array}$ & $\begin{array}{l}2.5 \mathrm{E}-03 \\
( \pm 83 \%)\end{array}$ & $\begin{array}{l}9.0 \mathrm{E}-03 \\
( \pm 83 \%)\end{array}$ & \\
\hline 138 & 70(8.7)_50000(AO) & 12.0 & $\begin{array}{l}7.1 \mathrm{E}-03 \\
( \pm 9.5 \%)\end{array}$ & $\begin{array}{l}2.2 \mathrm{E}-03 \\
( \pm 9.5 \%)\end{array}$ & $\begin{array}{l}2.3 \mathrm{E}-02 \\
( \pm 9.5 \%)\end{array}$ & \\
\hline 139 & 110(0.4)_20(BO) & 12.0 & $\begin{array}{l}4.0 \mathrm{E}-03 \\
( \pm 31 \%)\end{array}$ & $\begin{array}{l}1.7 \mathrm{E}-03 \\
( \pm 31 \%)\end{array}$ & $\begin{array}{l}1.5 \mathrm{E}-02 \\
( \pm 31 \%)\end{array}$ & \\
\hline 140 & 110(0.4)_83(BO) & 12.0 & $\begin{array}{l}8.6 \mathrm{E}-03 \\
( \pm 17 \%)\end{array}$ & $\begin{array}{l}2.6 \mathrm{E}-03 \\
( \pm 17 \%)\end{array}$ & $\begin{array}{l}4.0 \mathrm{E}-02 \\
( \pm 17 \%)\end{array}$ & 0.003 \\
\hline 141 & $110(0.4) \_5000(\mathrm{BO})$ & 12.0 & $\begin{array}{l}6.1 \mathrm{E}-03 \\
( \pm 6.2 \%)\end{array}$ & $\begin{array}{l}1.6 \mathrm{E}-03 \\
( \pm 5.6 \%)\end{array}$ & $\begin{array}{l}1.7 \mathrm{E}-02 \\
( \pm 5.6 \%)\end{array}$ & 0.03 \\
\hline 142 & 110(0.4)_20(AO) & 12.0 & $\begin{array}{l}6.4 \mathrm{E}-03 \\
( \pm 11 \%)\end{array}$ & $\begin{array}{r}2.6 \mathrm{E}-03 \\
( \pm 11 \%)\end{array}$ & $\begin{array}{r}2.8 \mathrm{E}-02 \\
( \pm 11 \%)\end{array}$ & \\
\hline 143 & 110(0.4)_83(AO) & 12.0 & $\begin{array}{l}7.1 \mathrm{E}-03 \\
( \pm 22 \%)\end{array}$ & $\begin{array}{l}2.3 \mathrm{E}-03 \\
( \pm 22 \%)\end{array}$ & $\begin{array}{r}2.0 \mathrm{E}-02 \\
( \pm 22 \%)\end{array}$ & 0.01 \\
\hline 144 & $110(0.4) \_5000(\mathrm{AO})$ & 12.0 & $\begin{array}{l}4.1 \mathrm{E}-03 \\
( \pm 55 \%)\end{array}$ & $\begin{array}{l}1.3 \mathrm{E}-03 \\
( \pm 55 \%)\end{array}$ & $\begin{array}{l}3.1 \mathrm{E}-02 \\
( \pm 55 \%)\end{array}$ & 0.01 \\
\hline
\end{tabular}


Table 4-12 Continued

\begin{tabular}{|c|c|c|c|c|c|c|}
\hline Exp. & $\begin{array}{c}\text { Solid } \\
\mathrm{Fe}(\mathrm{II})(\mathrm{III}) \mathrm{ClSiO}_{3}{ }^{\mathrm{a}}\end{array}$ & $\mathrm{pH}$ & $\begin{array}{c}\mathrm{k}_{\text {solid }} \\
\mathrm{L} /(\mathrm{g} \times \mathrm{d})\end{array}$ & $\begin{array}{c}\mathrm{k}_{\mathrm{Fe}(\mathrm{II})} \\
(\mathrm{mM} \times \mathrm{d})^{-1}\end{array}$ & $\begin{array}{c}\mathrm{k}_{\mathrm{Fe}(\mathrm{III})} \\
(\mathrm{mM} \times \mathrm{d})^{-1}\end{array}$ & $\begin{array}{l}\mathrm{TCE}^{\mathrm{f}} \\
\mathrm{mM}\end{array}$ \\
\hline 83 & 70(L)_83(Fe(II)(III)Cl) & 12.0 & $\begin{array}{l}1.0 \mathrm{E}-02 \\
( \pm 47 \%)\end{array}$ & $\begin{array}{r}3.0 \mathrm{E}-03 \\
( \pm 47 \%)\end{array}$ & $\begin{array}{l}1.8 \mathrm{E}-02 \\
( \pm 47 \%)\end{array}$ & \\
\hline 59 & $\mathrm{Fe}(\mathrm{II})(\mathrm{III}) \mathrm{ClSiO}_{3}$ & 12.0 & $\begin{array}{r}4.4 \mathrm{E}-03 \\
( \pm 33 \%)\end{array}$ & $\begin{array}{l}1.3 \mathrm{E}-03 \\
( \pm 33 \%)\end{array}$ & $\begin{array}{l}1.6 \mathrm{E}-02 \\
( \pm 33 \%)\end{array}$ & \\
\hline 68 & $\mathrm{Fe}(\mathrm{II})(\mathrm{III}) \mathrm{Cl}$ & 12.0 & $\begin{array}{r}3.8 \mathrm{E}-03 \\
( \pm 44 \%)\end{array}$ & $\begin{array}{l}1.3 \mathrm{E}-03 \\
( \pm 44 \%)\end{array}$ & $\begin{array}{c}1.9 \mathrm{E}-02 \\
( \pm 44 \%)\end{array}$ & \\
\hline 30 & FSCX & 12.0 & $\begin{array}{r}9.7 \mathrm{E}-04 \\
( \pm 26 \%)\end{array}$ & $\begin{array}{r}6.1 \mathrm{E}-03 \\
( \pm 26 \%)\end{array}$ & $\begin{array}{l}1.2 \mathrm{E}-02 \\
( \pm 26 \%)\end{array}$ & \\
\hline 45 & PCX & 11.8 & $\begin{array}{c}6.1 \mathrm{E}-03 \\
( \pm 19 \%)\end{array}$ & $\begin{array}{l}1.1 \mathrm{E}-02 \\
( \pm 4.9 \%)\end{array}$ & $\begin{array}{c}1.1 \mathrm{E}-01 \\
( \pm 4.9 \%)\end{array}$ & \\
\hline
\end{tabular}

${ }^{\mathrm{a}} \mathrm{Fe}(\mathrm{II})(\mathrm{III}) \mathrm{ClMg}$ solid was synthesized by adding $\mathrm{Fe}(\mathrm{II}), \mathrm{Fe}(\mathrm{III}), \mathrm{Cl}$ and $\mathrm{SiO}_{3}$

b: $\mathrm{NaOH}$ concentration iii. $70=70 \mathrm{mM} \mathrm{NaOH}$

iv. $110=110 \mathrm{mM} \mathrm{NaOH}$

c: Fe(III) concentration

iii. $0.4=0.4 \mathrm{mM} \mathrm{Fe}(\mathrm{III})$

iv. $8.7=8.7 \mathrm{mM} \mathrm{Fe}(\mathrm{III})$

d: $\mathrm{NaOH}$ addition rate

iv. $20=20.0 \mu \mathrm{L} / \mathrm{sec}$

v. $83=83.3 \mu \mathrm{L} / \mathrm{sec}$

vi. $50000=50000 \mu \mathrm{L} / \mathrm{sec}$

e: $\mathrm{SiO}_{3}$ addition order

iii. $\mathrm{BO}=$ Before $\mathrm{OH}$ addition

iv. $\mathrm{AO}=\mathrm{After} \mathrm{OH}$ addition

${ }^{f}$ estimate of TCE conc. in liquid phase

Initial PCE concentration was $0.242 \mathrm{mM}$

A sampling time for individual experiment was 5.8 days for exp. 127 to 132; 4.9 days for exp. 133 to 138; and 4.5 days for exp. 139 to 144

Uncertainties represent $95 \%$ confidence limits expressed in \% relative to estimate $\mathrm{k}$

The solid activity was not changed by synthesis methods (GR synthesis method or simple mixing method). For some cases when $\mathrm{NaOH}$ was added at a rate of $50000 \mu \mathrm{L} / \mathrm{sec}$ there were significant amounts of TCE were detected, with concentrations ranging from 5 to $12 \%$ of initial PCE concentration. TCE concentrations were particularly high when silicate was added to $\mathrm{Fe}(\mathrm{II})(\mathrm{III}) \mathrm{Cl}$ solids. Although silicate was a 
major element in ordinary Portland cement (OPC), silicate alone might not facilitate formation of the active solid. Solids prepared with additional $\mathrm{Mg}$ showed the best activities of the three compounds tested $\left(\mathrm{Mg}, \mathrm{SO}_{4}, \mathrm{SiO}_{3}\right)$. However, experiments with these solids also showed accumulation of TCE.

\subsection{Identification of the active agents through instrumental analyses}

\subsection{1 $10 \%$ Portland cement slurry (10\% PCS)}

Figure 4-4 showed the x-ray diffraction (XRD) pattern for 10\% PCS with and without Fe(II). CPCS stands for Capitol Portland cement slurry. The major solid phases found through XRD analysis in solids from a 10\% cement slurry containing $\mathrm{Fe}(\mathrm{II})(10 \%$ CPCSFe) were calcium chloroaluminate hydrates (Friedel's salt), calcium aluminate hydrates and calcium aluminum silicate hydrates.

The peaks of Friedel's salts and calcium aluminate hydrates were very close and similar with one another, especially the first highest intensity peak having d-values of $7.8 \AA$ A. However, these solids could be easily distinguished by their second and third highest intensity peaks of 3.9 and $3.8 \AA$. Peaks circled in figure 4-4(a) and (b) show the distinctive differences between solids containing Fe(II) and solids not containing Fe(II). The intensity of the peak of $2.87 \AA$ at $31 \theta$ is higher in CPCSFe. Ettringite was identified in the solids from the $10 \%$ cement slurry that did not contain Fe(II) (CPCS). Most Ettringite peaks disappeared in CPCSFe.

In general, Ettringite can be formed within 30 minutes when cement is mixed with water $(41,42)$. Introducing $\mathrm{Fe}(\mathrm{II})$ into the cement slurry system might facilitate the 
formation of Friedel's salts rather than Ettringite, so that the formation of Ettringite was either inhibited or decelerated.

Typical XRD patterns of the amorphous phase were observed between $25 \theta$ and 40 $\theta$ (41). These patterns indicated $\mathrm{CSH}$ gel, which constitutes about $90 \%$, of cement hydration products.

Adding Fe(II) did not make any new solids that could be identified by XRD. Fe(II) might be incorporated into Friedel's salts through isomorphous substitution for calcium or adsorbed onto their surfaces. 
(a)

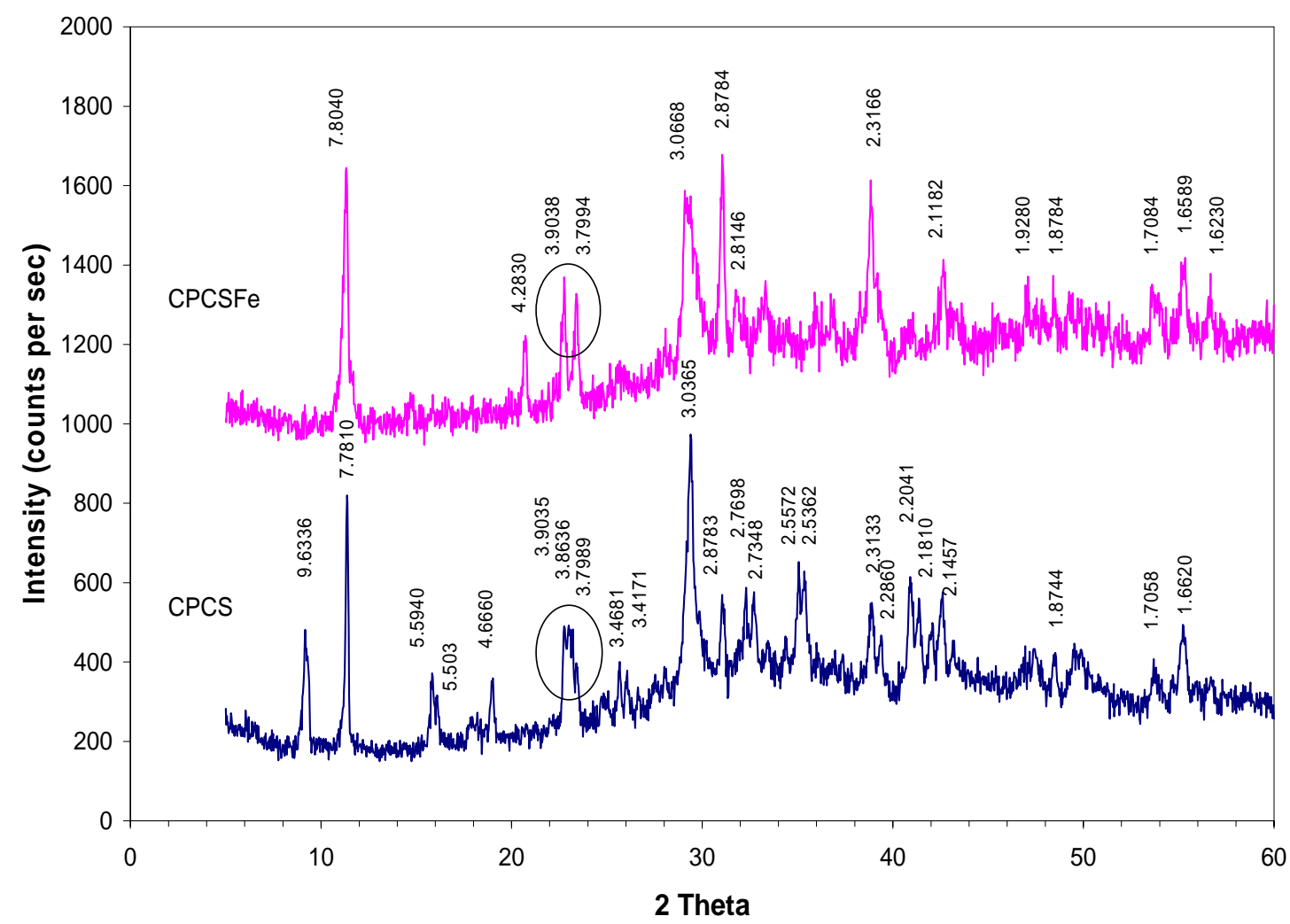

FIGURE 4-4 X-ray patterns of 10\% Capitol cement slurry. (a) CPCSFe $=10 \%$ Capitol Portland cement slurry with Fe(II); CPCS = 10\% Capitol Portland cement slurry without $\mathrm{Fe}(\mathrm{II})$; unit of d-spacing values $=\AA$. (b) Mineral identification using software program, JADE, of CPCS. (c) Mineral identification using software program, JADE, of CPCSFe. Note: Backgrounds of figure (b) and (c) were adjusted by JADE. Thanks to the Texas Transportation Institute for the use of the Rigu automatic diffract. 
(b)

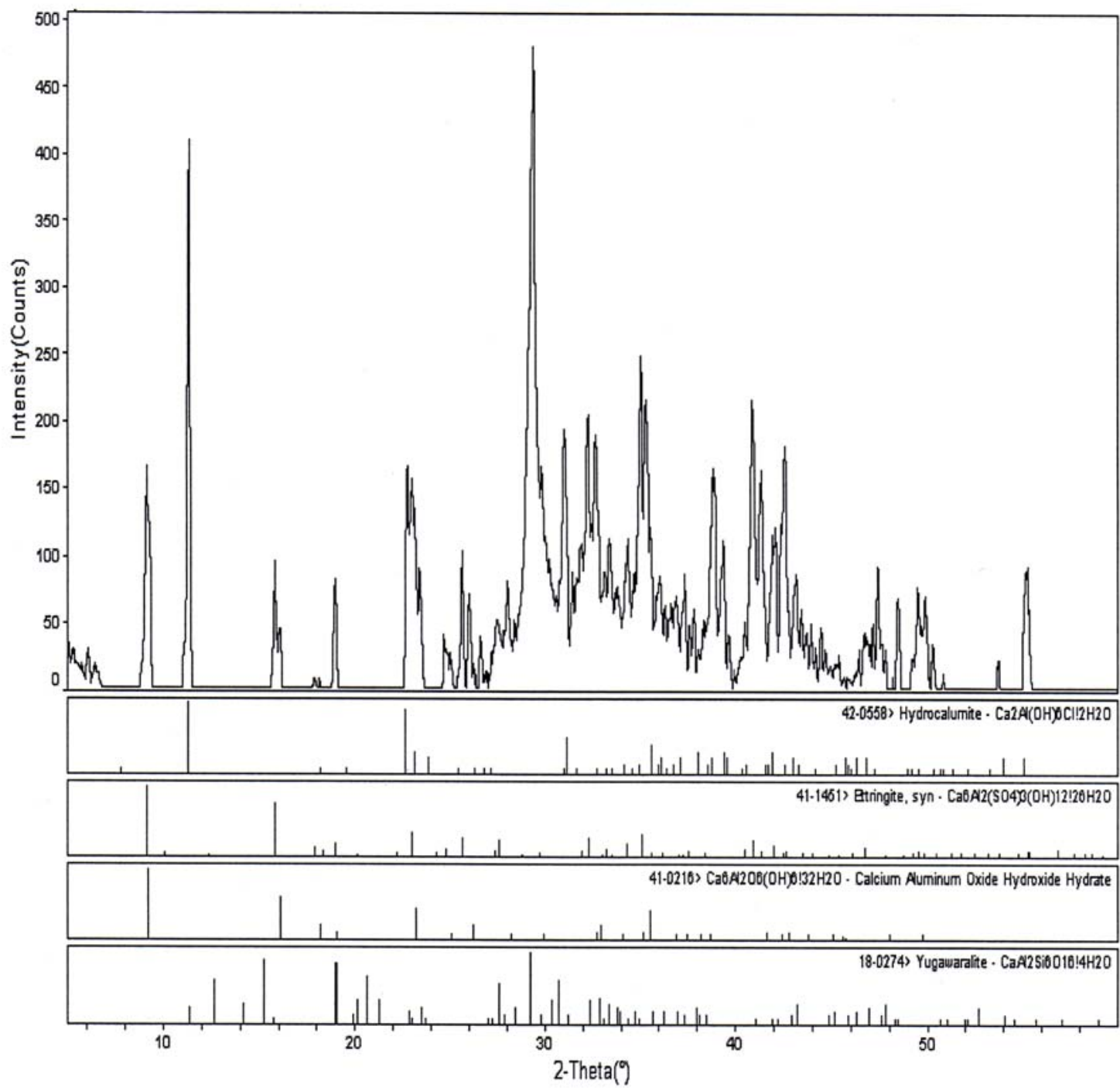

FIGURE 4-4 Continued 
(c)

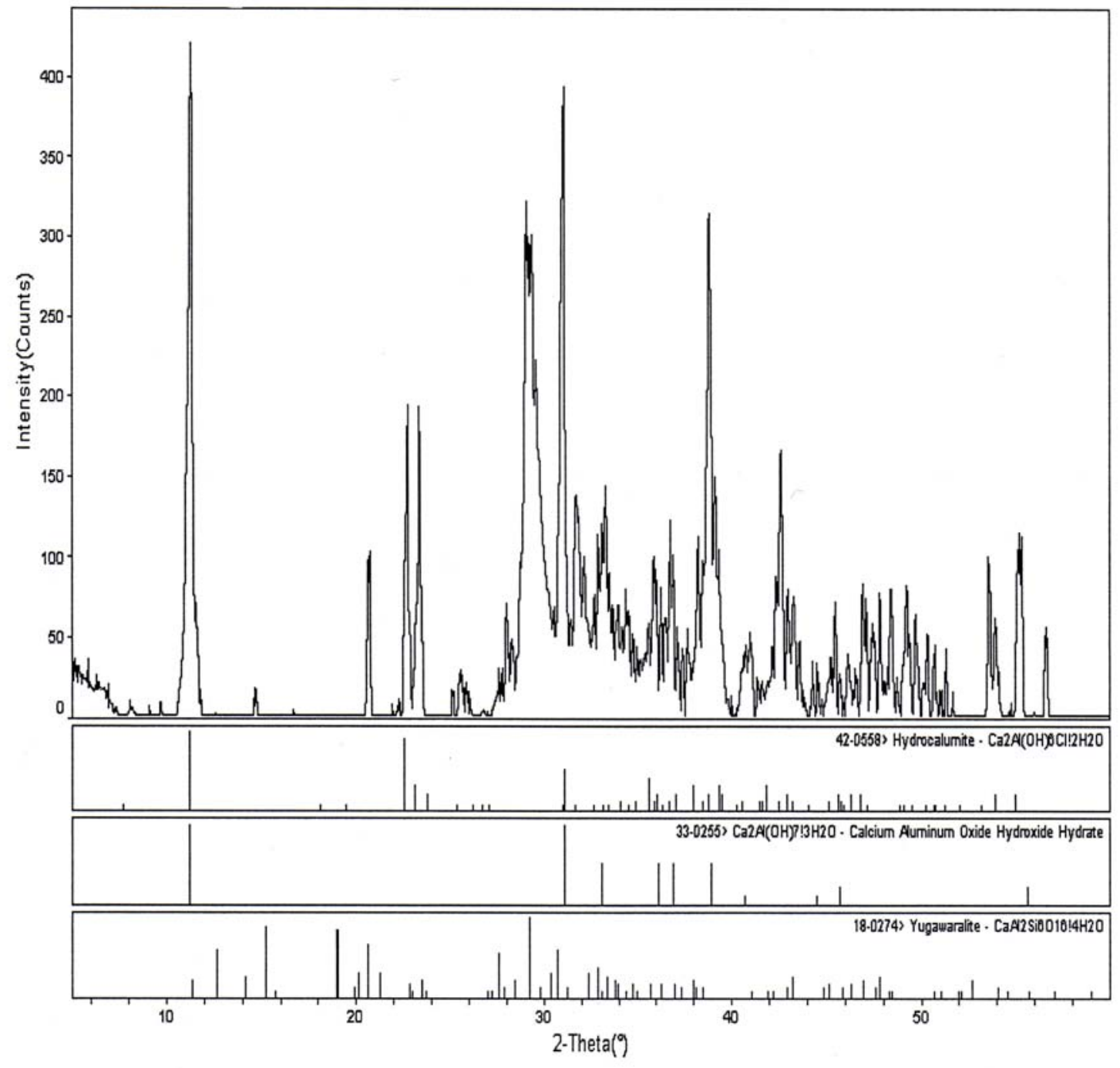

FIGURE 4-4 Continued 
Figure 4-5 through 4-7 showed scanning electron microscopic (SEM) images and energy dispersive spectrometer (EDS) spectra of $10 \%$ CPCS without (figure 4-5 and 46) and with (figure 4-7) Fe(II). EDS spectra were taken from a hexagonal particle. Needle-like crystals of Ettringite and hexagonal plates of Friedel's salt were found in cement slurry systems. In figure 4-6, a very low peak of Fe was observed. It might come from substitution of $\mathrm{Fe}(\mathrm{III})$ for $\mathrm{Al}$ in Friedel's salt or in calcium aluminate hydrates, which has a layered structure.

The particle sizes of the hexagonal plates typically vary from a few micrometers to around $50 \mu \mathrm{m}$ (64). The SEM images show that the particle sizes were reduced when Fe(II) was added. These phenomena might be related to the activities of the solids for PCE degradation.

Major elements in hexagonal plates were $\mathrm{Ca}, \mathrm{Al}, \mathrm{Si}$, and $\mathrm{Cl}$. S might be present but its peaks would not be clearly observed because of overlap with Au peaks. Fe was also detected in hexagonal plates when Fe(II) was added

Based on XRD, SEM and EDS analyses, the possible active solids for PCE degradation might be AFm phases, such as Friedel's salt, calcium aluminate hydrates and/or calcium aluminum silicate hydrates. Fe(II) could be adsorbed on the surfaces of those solids or incorporated into their structure through isomorphous substitution. 


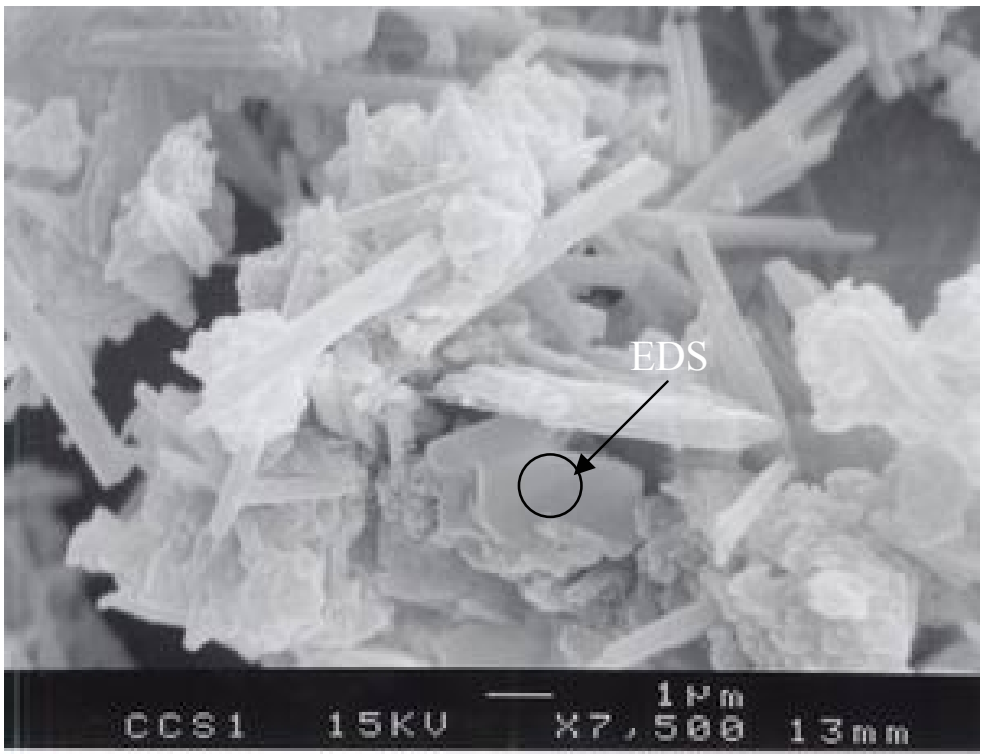

Capitol Cement Slurry without Fe(II):CCS1

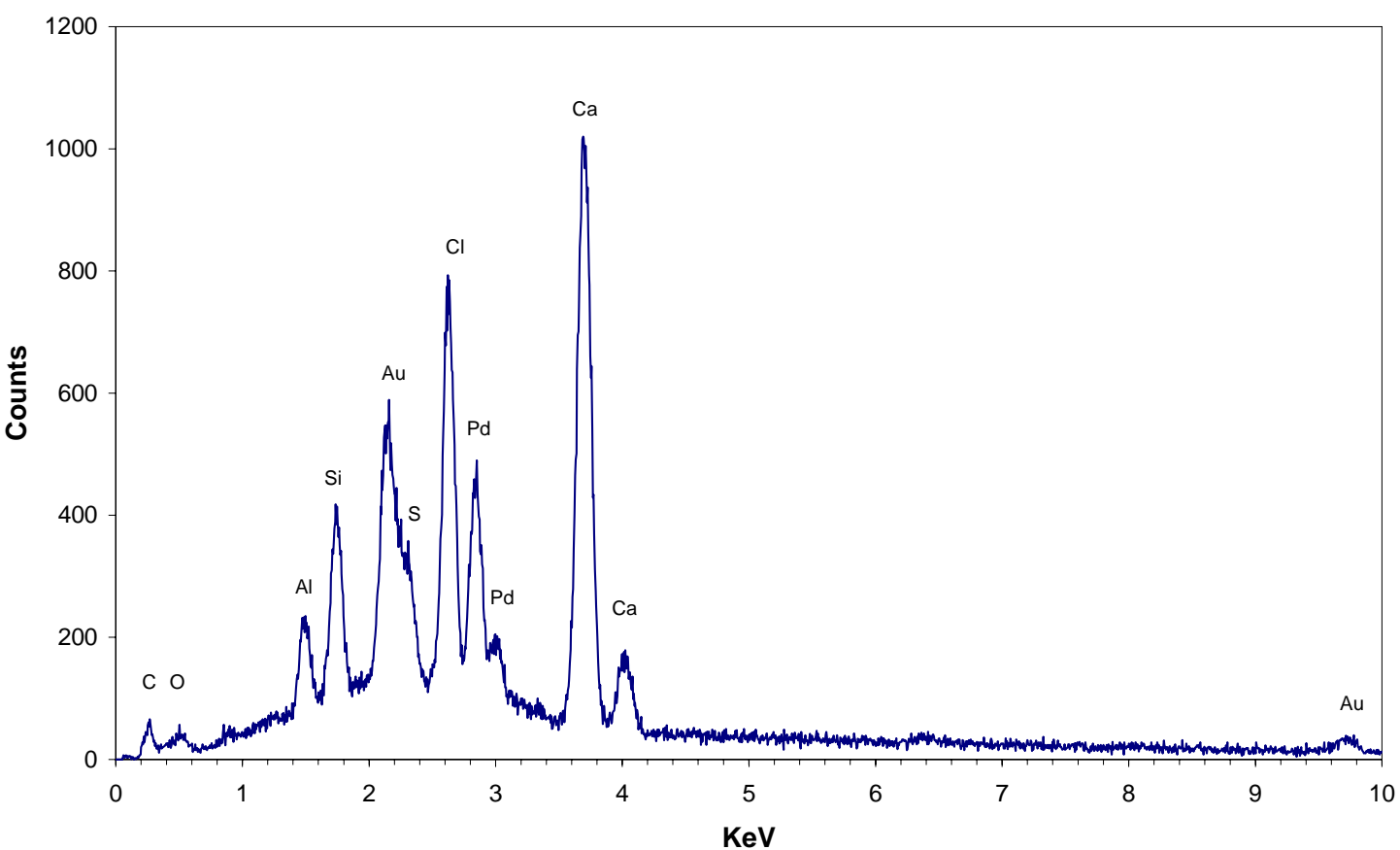

FIGURE 4-5 The first SEM image and EDS of Capitol cement slurry without $\mathrm{Fe}(\mathrm{II})$. 


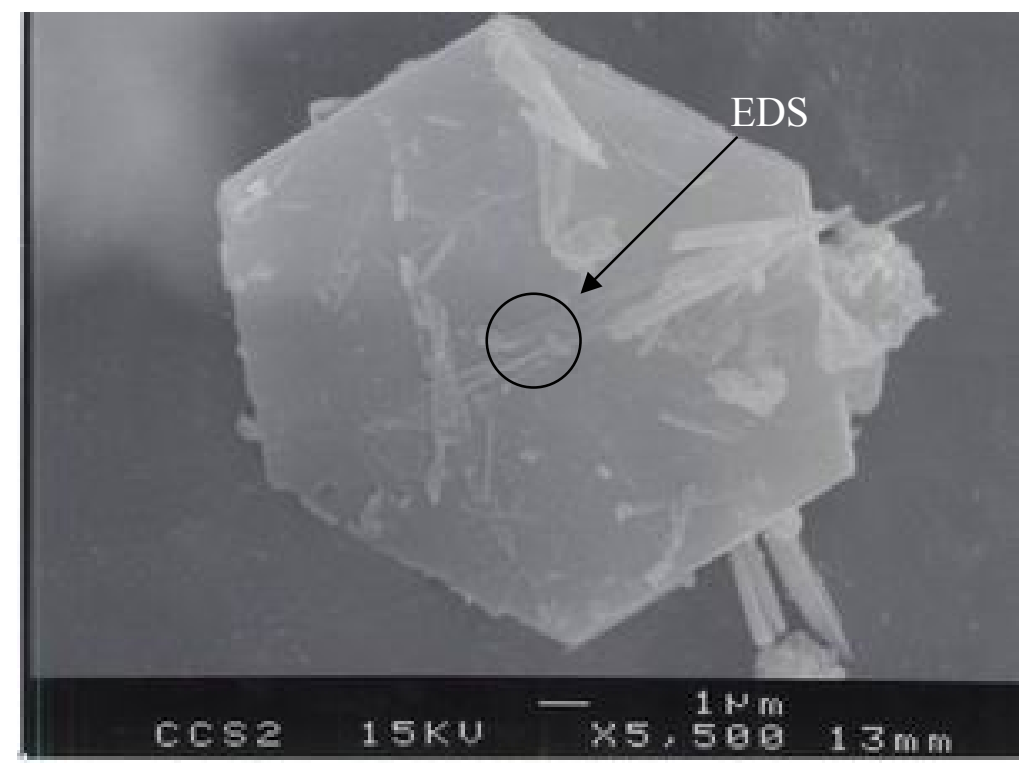

Capitol Cement Slurry without Fe(II):CCS2

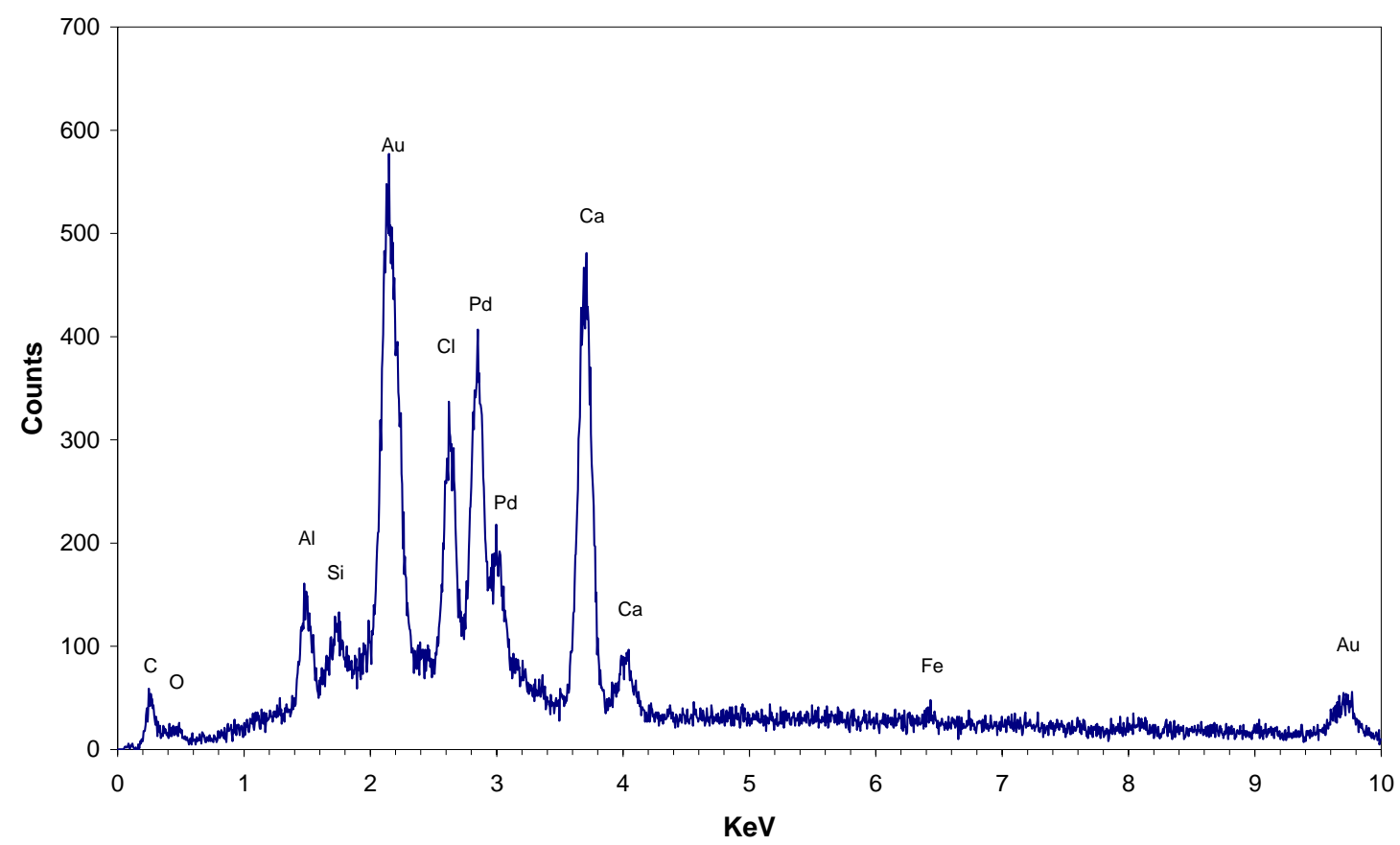

FIGURE 4-6 The second SEM image and EDS of Capitol cement slurry without Fe(II). 


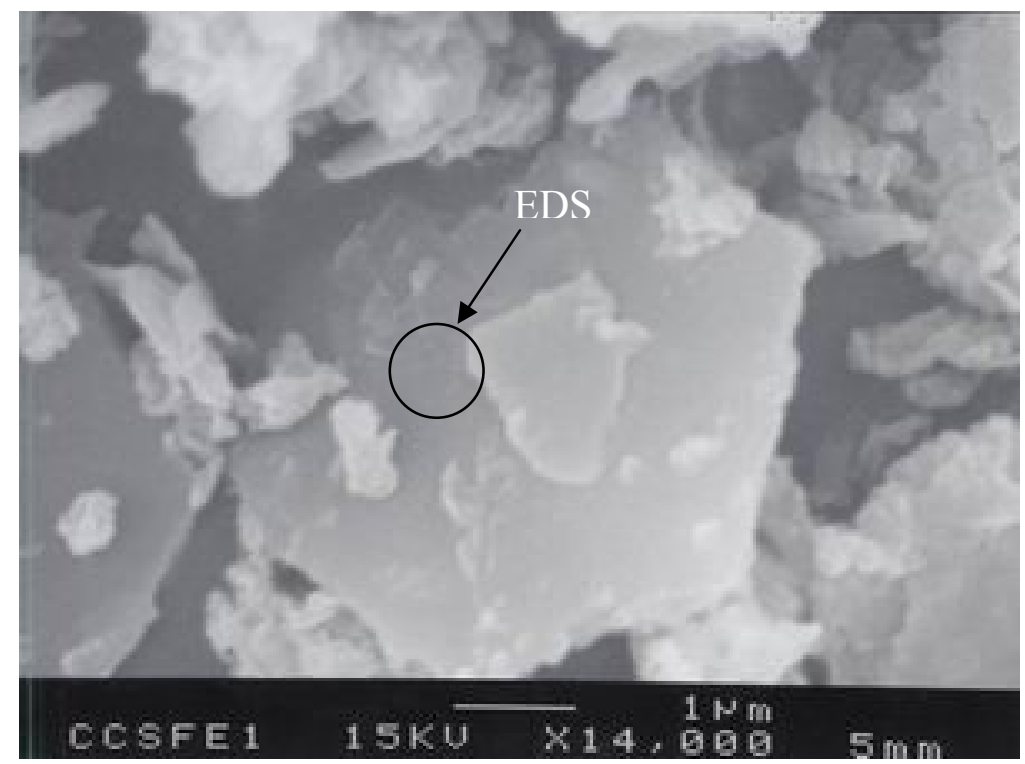

Capitol Cement Slurry with Fe(II):CCSFE1

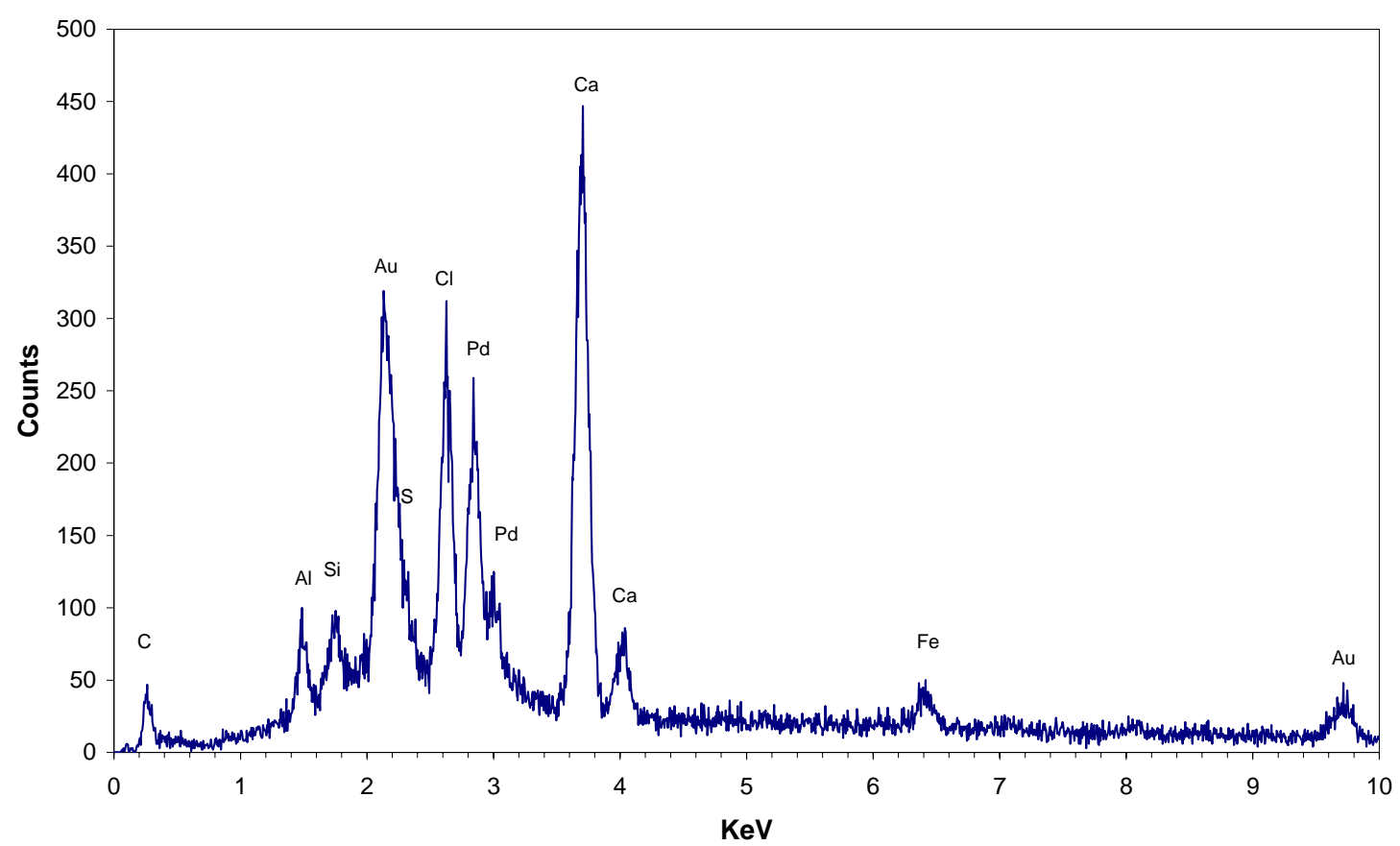

FIGURE 4-7 SEM image and EDS of Capitol cement slurry with Fe(II). 


\subsection{2 $10 \%$ Portland cement extract (10\% PCX)}

Figure 4-8 shows the XRD patterns (figure 4-8(a)) and peak identifications (figure 4-8(b)) of solids formed in 10\% PCX. CPCX stands for Capitol Portland cement extract and CPCXFe for Fe(II) containing Capitol Portland cement extract. Portlandite and Friedel's salts were identified in 10\% CPCXFe solids to which Fe(II) was added. They were major solids formed in CPCXFe. Peaks of Friedel's salts were more clearly observed when $\mathrm{Fe}(\mathrm{II})$ was added to $10 \% \mathrm{PCX}$, as was observed for $10 \%$ cement slurry solids. The $\mathrm{pH}$ in these slurries was increased by addition of $1.25 \mathrm{M}$ of $\mathrm{Ca}(\mathrm{OH})_{2}$, which resulted in considerable amounts of $\mathrm{Ca}(\mathrm{OH})_{2}$ remaining in the suspension that would also remain after solid separation through centrifugation.

The highest intensity peak in $10 \%$ CPCXFe was observed at $38.3 \theta$ with $2.3481 \AA$ of d-spacing, which is associated with Friedel's salt (the fourth highest peak in $\beta$ form Friedel's salt, JCPD 35-105). The highest intensity peak in 10\% CPCX was found at about $33.8 \theta$ with $2.6483 \AA$ of d-spacing, which is associated with Portlandite. The peak of $2.7662 \AA$ might come from calcium aluminum silicate hydrates (JCPD 18-274), but the first and second highest intensity peaks $(3.1 \AA$ and $5.8 \AA$ ) of calcium aluminum silicate hydrates were not detected.

Portlandite was a major solid phase detected in CPCX. Peaks of 4.2186, 3.4139, 3.1997, and $2.7962 \AA$ in figure 4-8(a) were calcium silicate hydrates (JCPD 39-1373) and peaks of $3.0662,2.9530$, and $2.8955 \AA$ were calcium aluminum silicate (JCPD 23105). The $8.5180 \AA$ peak might be calcium aluminum oxide sulfite hydrate (the highest intensity peak, JCPD 41-477), but other peaks of calcium aluminum oxide sulfite 
hydrate were not matched, other than the one at $4.2186 \AA$ in figure $4-8(a)$. Intensity and d-spacing values of CPCX were not exactly matched with references. This might be the result of different chemical composition and atomic arrangement of CPCX solids compared to the referenced solids. Portlandite and calcium aluminum silicate probably were the dominant solid phases formed in $10 \%$ CPCX. Friedel's salt peaks were not observed in CPCX.

XRD patterns of $10 \% \mathrm{CPCXFe}$ were similar to those of $10 \% \mathrm{CPCSFe}$ as seen in figure 4-1. Peaks from either calcium aluminum silicate hydrate or calcium aluminate hydrate in $10 \%$ CPCXFe were not observed as strongly as they were for $10 \%$ CPCSFe. However, both cement slurries and cement extracts with Fe(II) addition showed the presence of Friedel's salts. XRD patterns of 10\% CPCXFe also supported that hypothesis that Friedel's salt is an active agent for dechlorination in Fe(II)-DS/S.

Figure 4-9 to 10 shows scanning electron microscopic (SEM) images and energy dispersive spectrometer (EDS) spectra of $10 \%$ CPCX without (figure 4-9) and with (figure 4-10) Fe(II). EDS spectra were taken from single hexagonal particle. Although SEM images of $10 \%$ CPCX did not show the perfect hexagonal shapes observed in $10 \%$ CPCS, thin plates having nearly hexagonal angles were observed. Particle sizes in 10\% PCX were 1 to $3 \mu \mathrm{m}$, which were smaller than those in $10 \%$ CPCS by more than a few micrometers. They were so aggregated so that an image of an individual particle could not be seen. 
(a)

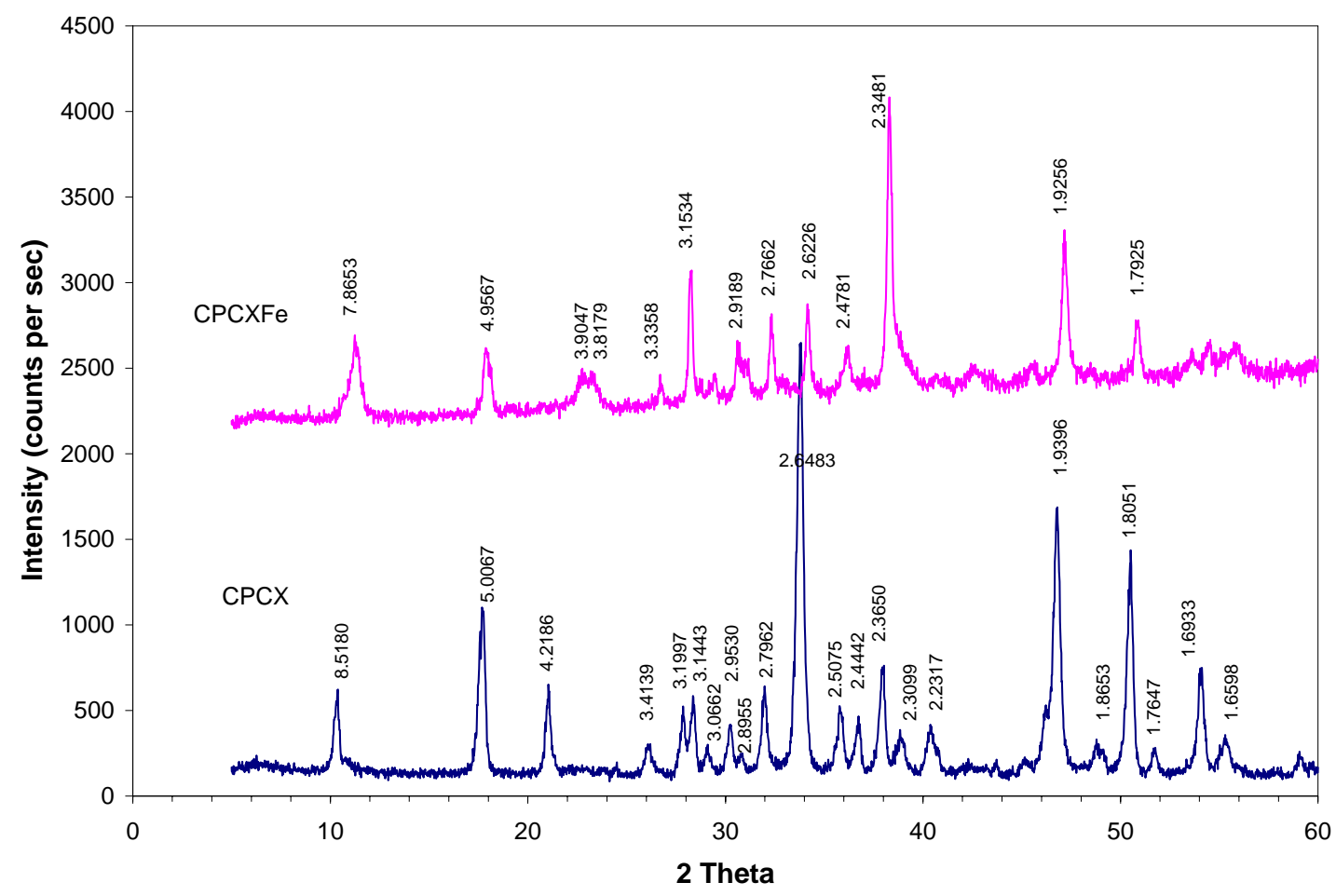

FIGRUE 4-8 X-ray patterns of 10\% Capitol cement extract. (a) $\mathrm{CPCXFe}=10 \%$ Capitol Portland cement extract with Fe(II); CPCX $=10 \%$ Capitol Portland cement extract without $\mathrm{Fe}(\mathrm{II})$; Unit of d-spacing values is $\AA$. (b) Mineral identification using software program, JADE, of CPCXFe. Note: Backgrounds of figure (b) was adjusted by JADE. Thanks to the Texas Transportation Institute for the use of the Rigu automatic diffract. 
(b)

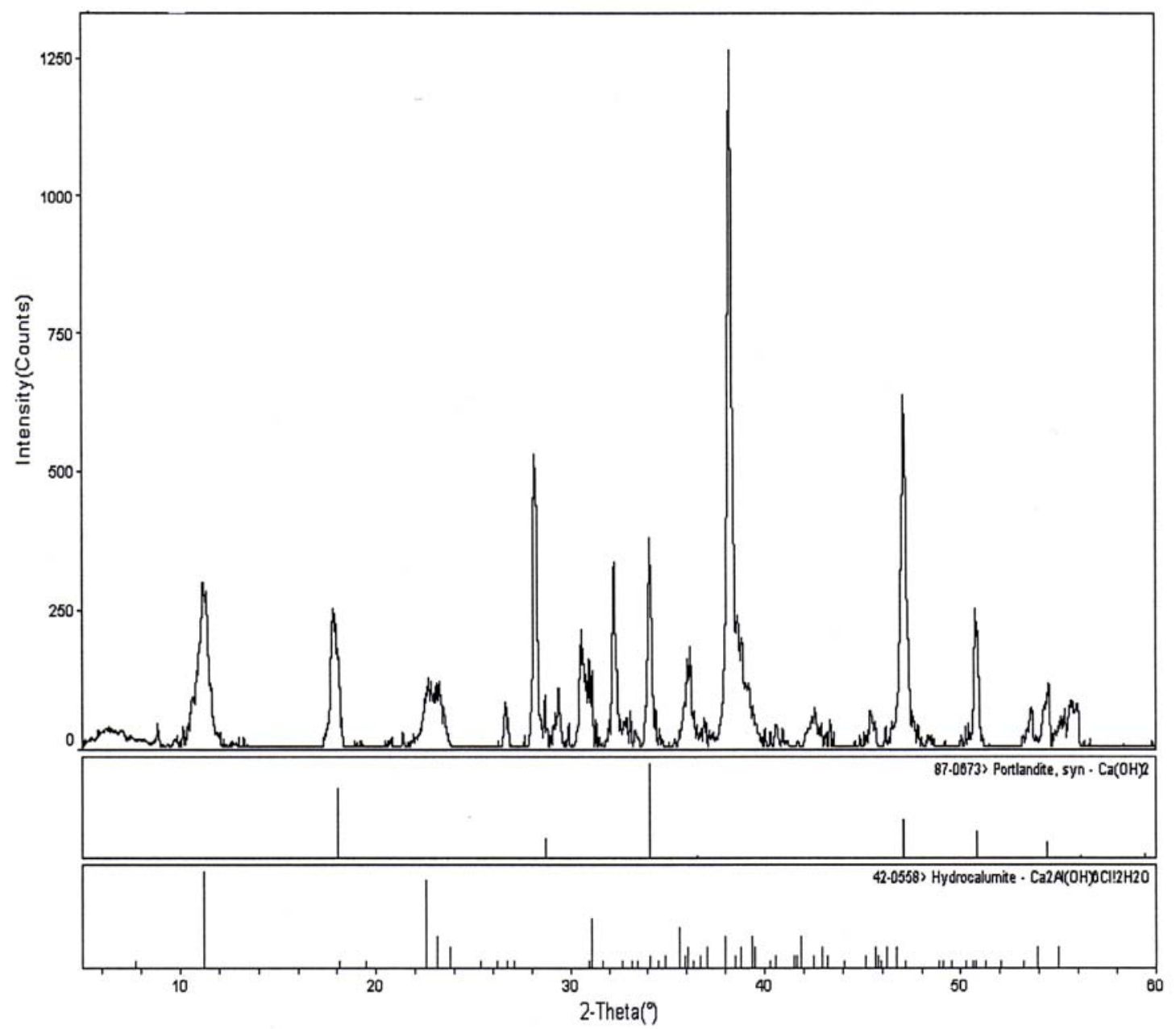

FIGURE 4-8 Continued 
High concentrations of $\mathrm{Cl}$ were observed in EDS spectra in systems with and without addition of $\mathrm{Fe}(\mathrm{II})$. They were the result of the addition of $2.1 \mathrm{~N} \mathrm{HCl}$ that was used to prepare the cement extracts. Based on EDS spectra, solids in figure 4-9 might be Portlandite. Although Portlandite and calcium aluminum silicate probably were the dominant solid phases formed in 10\% CPCX, neither Al nor Si was detected in EDS analysis of circled area in figure $4-9$. When cement is hydrated, about $20 \%$ of the hydration products are Portlandite (42). Furthermore, high concentrations of $\mathrm{Ca}(\mathrm{OH})_{2}$ were added to $10 \%$ cement extract during solid preparation of CPCX and solids were not separated, unlike preparation of $10 \% \mathrm{CPCXFe}$, when the top layer of solids was separated from the other solids. Therefore, significant amounts of Portlandite would be expected to be present in $10 \% \mathrm{CPCX}$ solids, compared to other solid phases that were not found in SEM and EDS analysis. However, based on XRD analysis, other solid phases are also present in 10\% CPCX solids. Along with $\mathrm{Ca}$, and $\mathrm{Cl}, \mathrm{Fe}$ and $\mathrm{Al}$ were detected in $10 \%$ CPCXFe solids as well as a low count of $\mathrm{Mg}$ and $\mathrm{Si}$. A low degree of substitution of $\mathrm{Mg}$ for $\mathrm{Ca}$ might have occurred. Peaks found in figure 4-9 might be associated with Friedel's salt or calcium aluminum silicate hydrate. Presence of Si could be the result of a substitution for Al in AFm phases. Another possibility is that Si exists as an interlayer anion in possible LDH that appear as particles with thin hexagonal plate shapes in the SEM. 


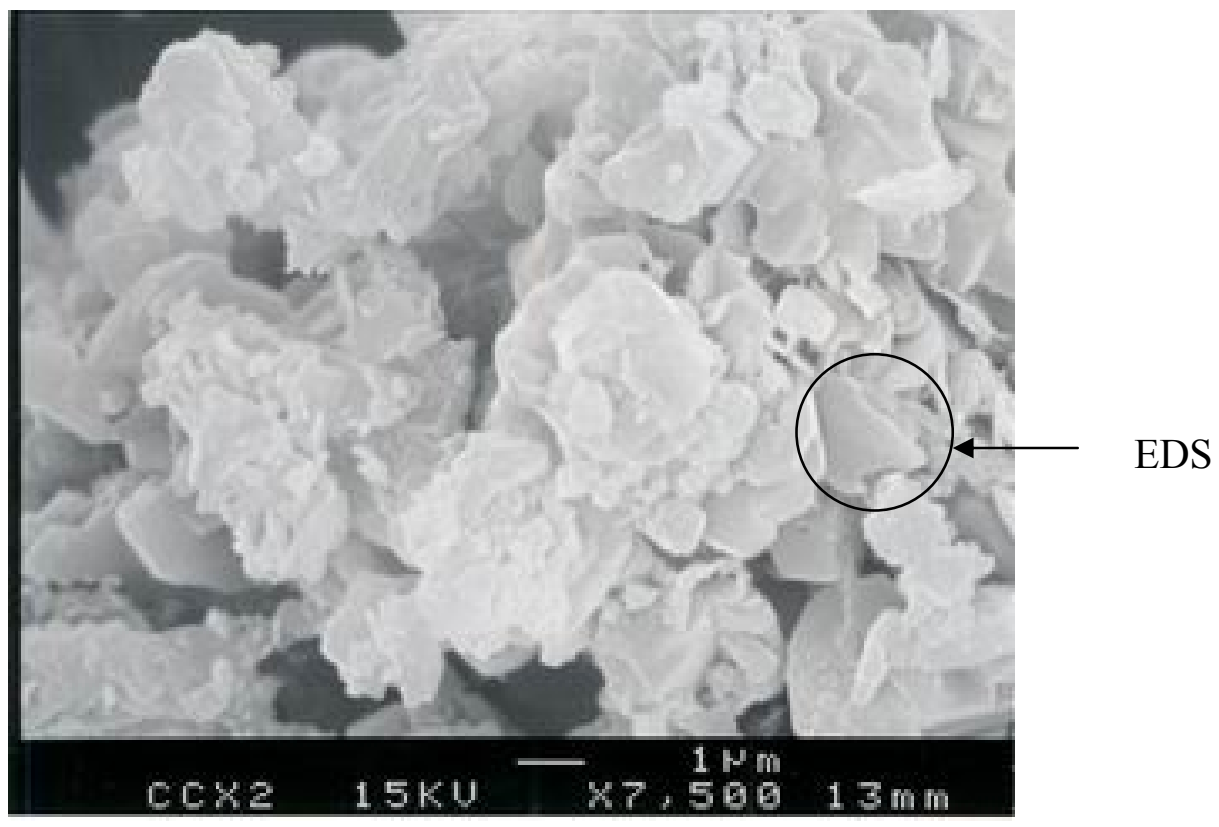

Capitol Cement Extract without Fe(II):CCX2

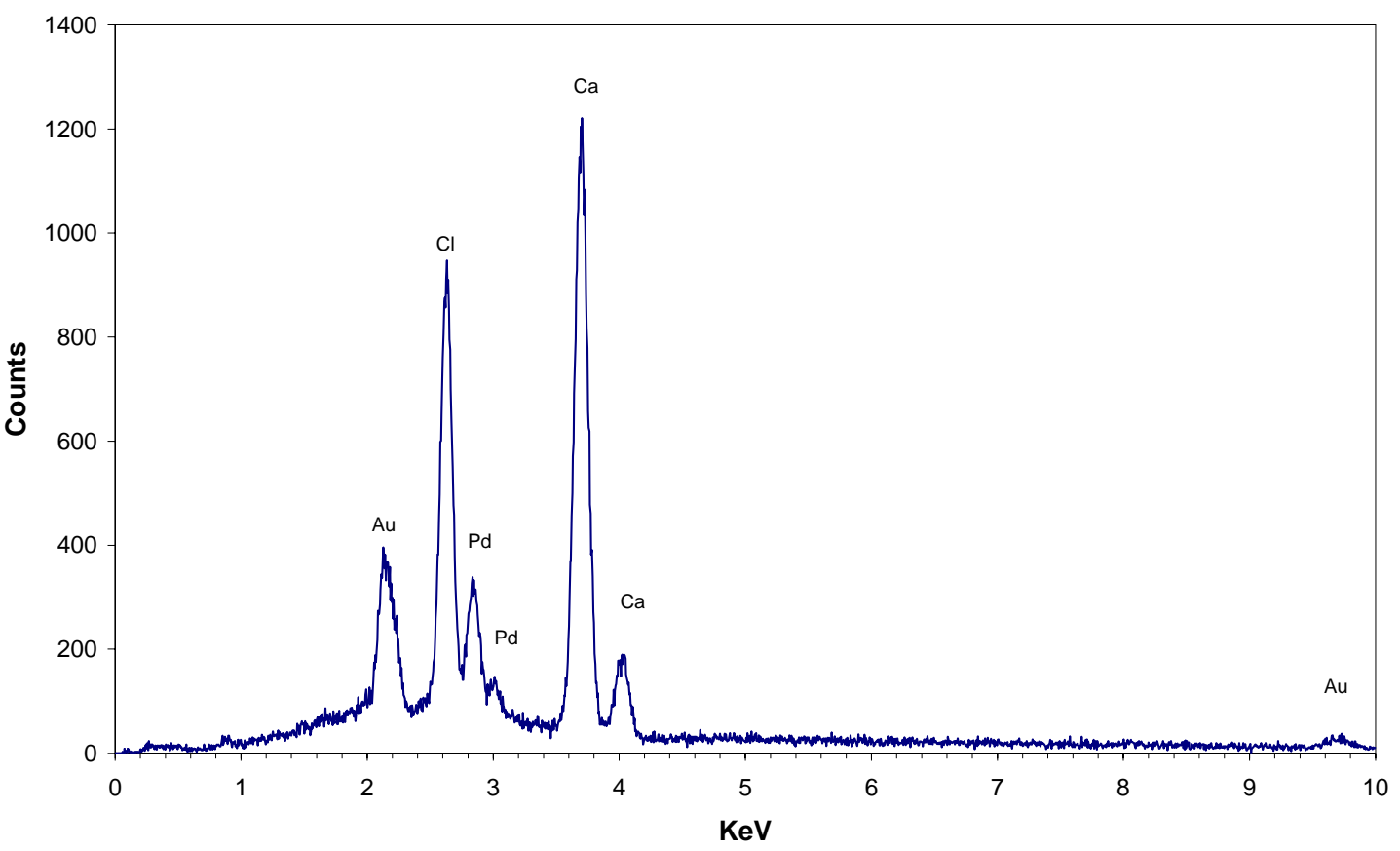

FIGURE 4-9 SEM image and EDS of Capitol cement extract without Fe(II). 


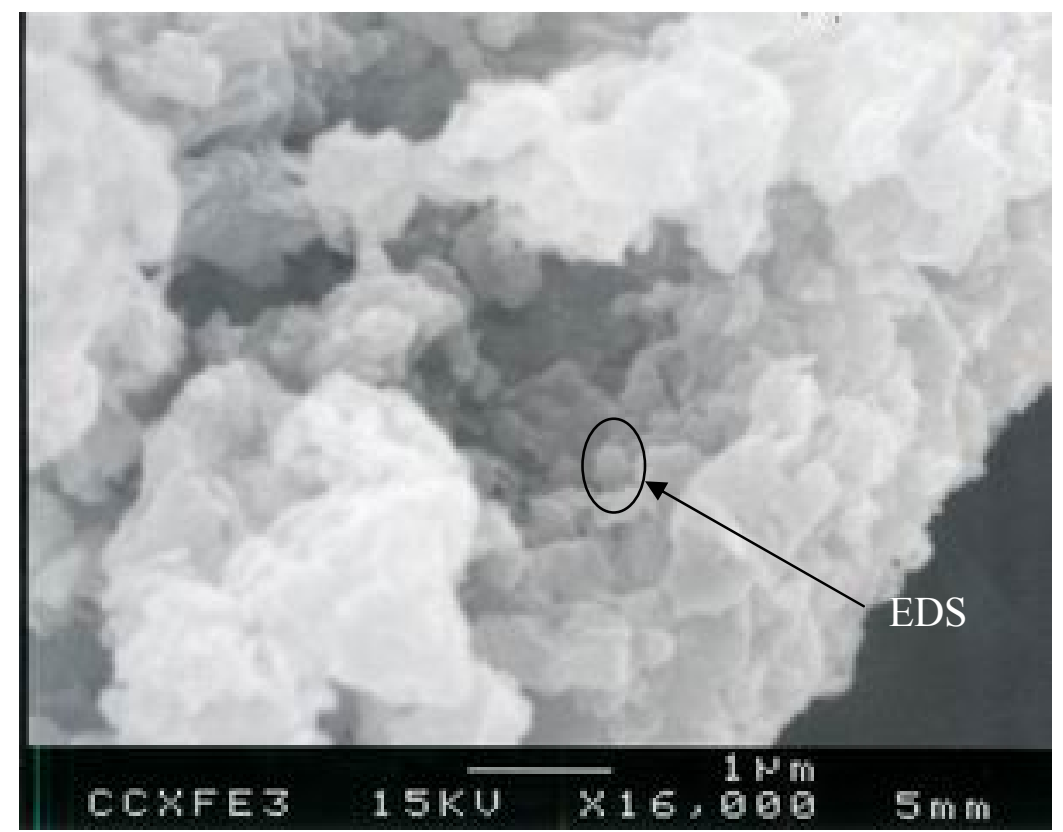

\section{Capitol Cement Extract with Fe(II):CCXFE3}

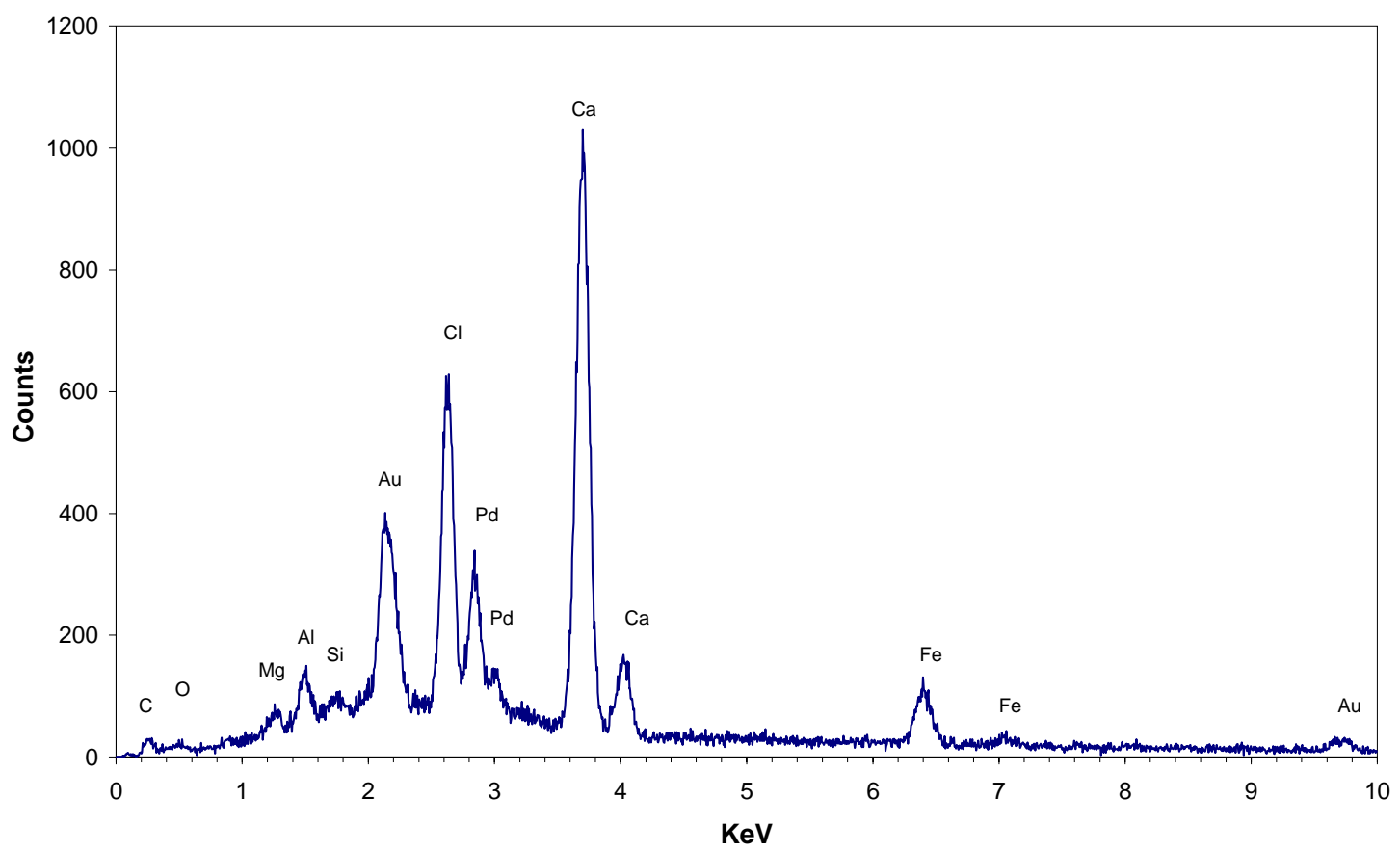

FIGURE 4-10 SEM image and EDS of Capitol cement extract with Fe(II). 


\subsubsection{Synthetic cement extract (SCX)}

\subsubsection{Full synthetic cement extract (FSCX)}

Portlandite was identified as the major solid formed in the FSCX system. Friedel's salt was not formed. The rest of the peaks were much matched reasonably well with calcium silicate hydrates (JCPDS 23-125), except for the peak of $8.03 \AA$. If this peak were considered to come from GR_Cl, it and a peak of $3.95 \AA$ would match well, but the third most intense peak of GR_Cl $(2.7 \AA)$ would be missing. Therefore, it is not clear to which solid the $8.03 \AA$ peak should be assigned. The other peaks could be GR_Cl or/and calcium silicate hydrates.

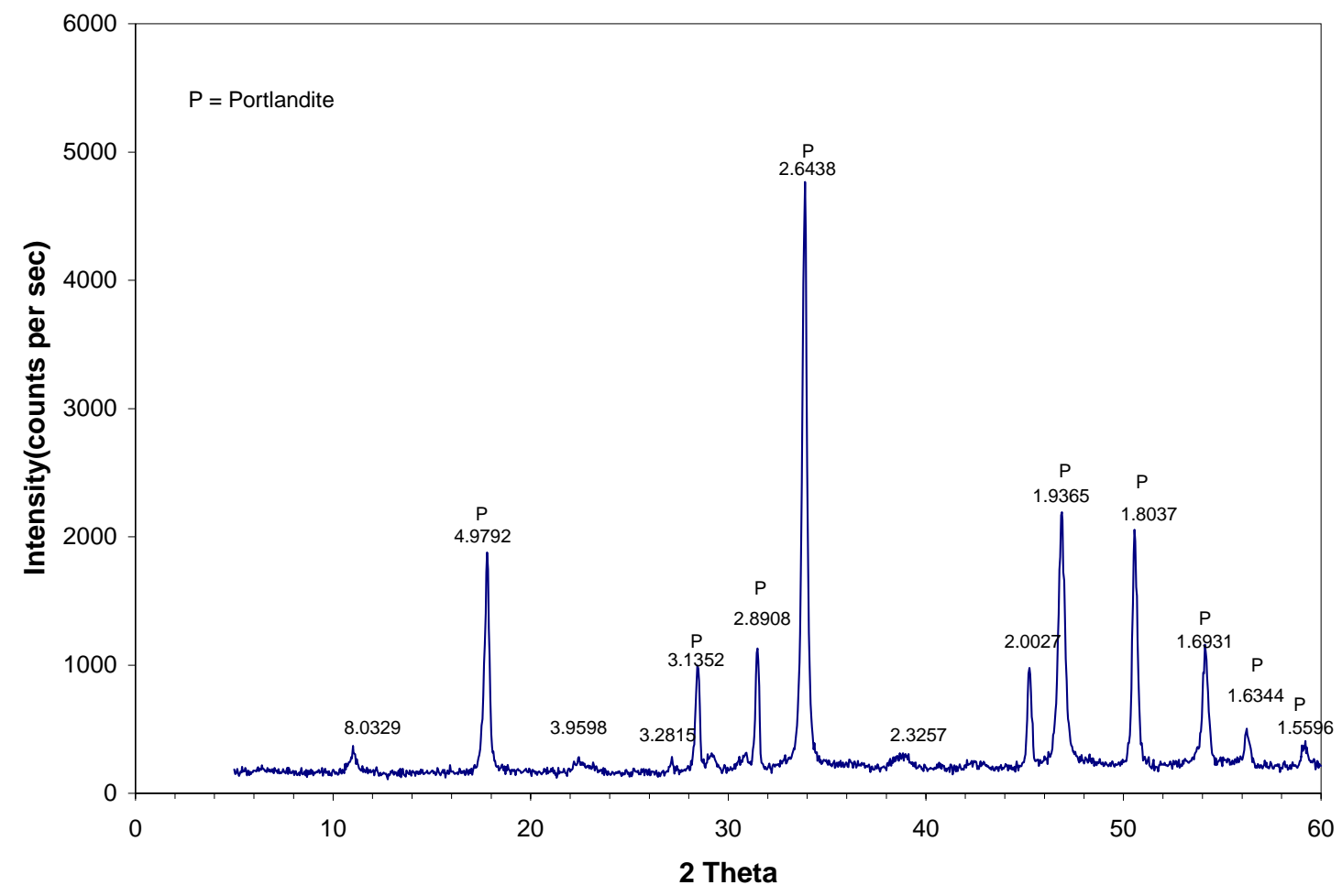

FIGURE 4-11 XRD patterns of FSCXFe solids. Unit of d-spacing is $\AA$; FSCXFe = Full element synthetic cement extract with $\mathrm{Fe}(\mathrm{II})$. 


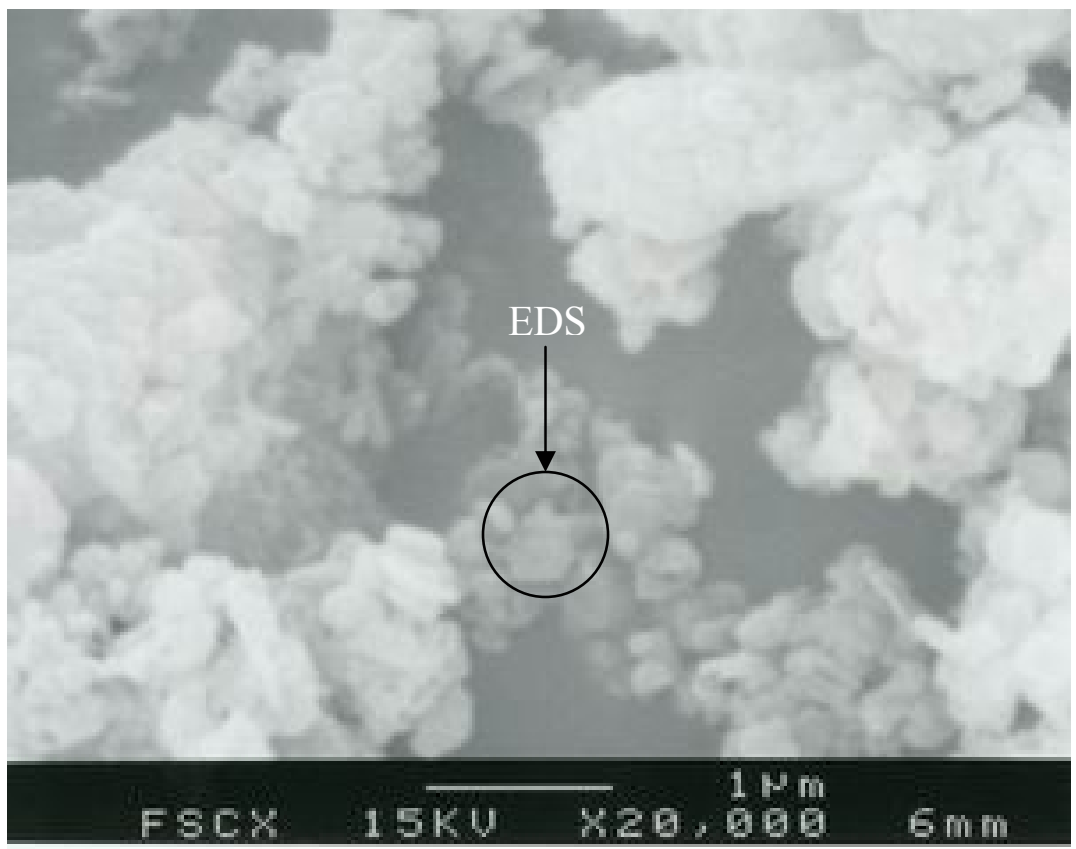

Full Synthetic Cement Extract with Fe(II):FSCX

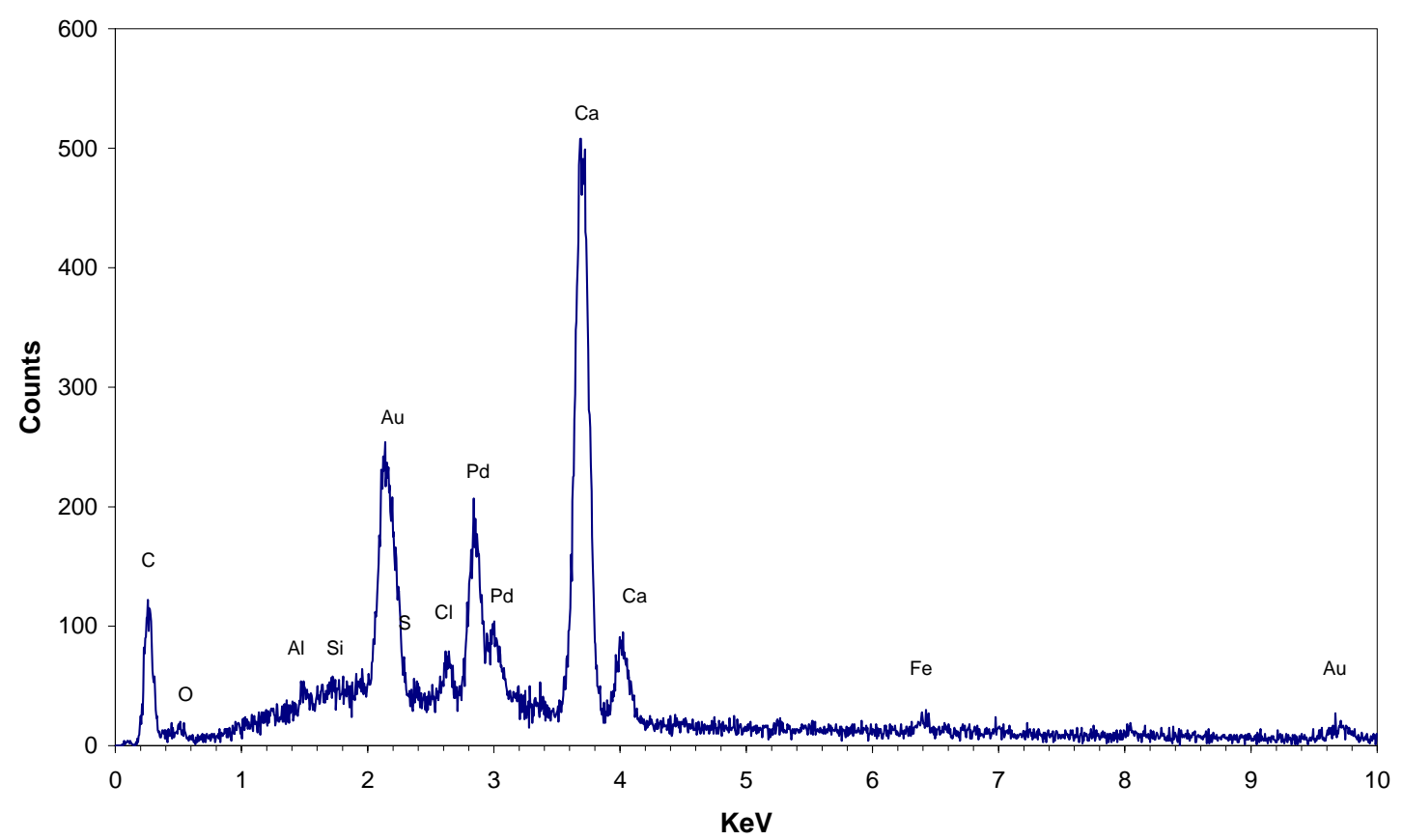

FIGURE 4-12 SEM image and EDS of full synthetic cement extract with Fe(II). 
Figure 4-12 shows the SEM image and EDS spectra of full synthetic cement extract with $\mathrm{Fe}(\mathrm{II})$ addition (FSCXFe). EDS spectra were taken from single hexagonal particle. Like the cement slurry and cement extract systems, hexagonal plates were observed in FSCXFe solids. However, particle sizes of these solid were much smaller, less than $0.5 \mu \mathrm{m}$, than observed in the PCS and PCX system. Based on XRD and EDS spectra, these hexagonal plates might be Portlandite. Mostly $\mathrm{Ca}$ and a small amount of $\mathrm{Al}, \mathrm{Si}, \mathrm{Cl}, \mathrm{S}$, and $\mathrm{Fe}$ comprised the FSCXFe solids. Fe concentration in FSCXFe was lower than that in PCSFe and PCXFe solids. Even though FSCX contained the same concentrations of elements as the cement extract, all instrument analyses, as well as a PCE degradation test, indicated that solids formed in FSCX were different from ones formed in the cement slurry or the cement extract.

\subsubsection{Minor synthetic cement extract (MSCX)}

Halite and ferrous hydroxide were identified through XRD analysis as being present in solids formed in MSCX, as shown in figure 4-13. Halite came from addition of $\mathrm{NaCl}$ to keep the same $\mathrm{Cl}$ concentration as cement $\mathrm{Cl}$. The MSCX produced different kinds of solids than were produced in the cement slurry, cement extract and full synthetic cement extract. This might be caused by the absence of major elements, especially $\mathrm{Ca}$ and $\mathrm{Al}$, which are major components of the solids formed in the cement slurry and the cement extract. 


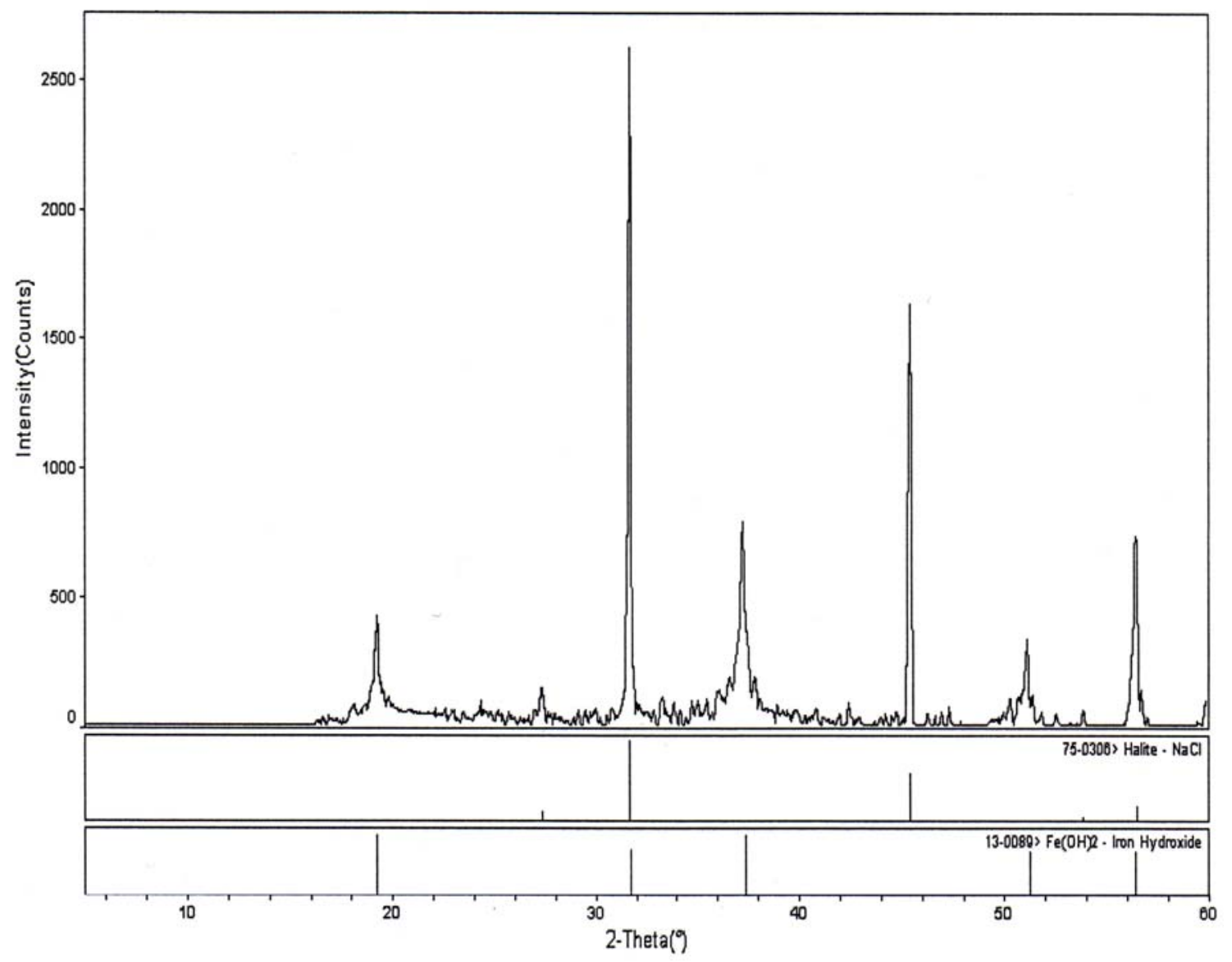

FIGURE 4-13 XRD pattern and mineral identification using software program, JADE, of MSCXFe solids. MSCXFe = Minor element synthetic cement extract with Fe(II). Note: Backgrounds of figure was adjusted by JADE. Thanks to the Texas Transportation Institute for the use of the Rigu automatic diffract. 


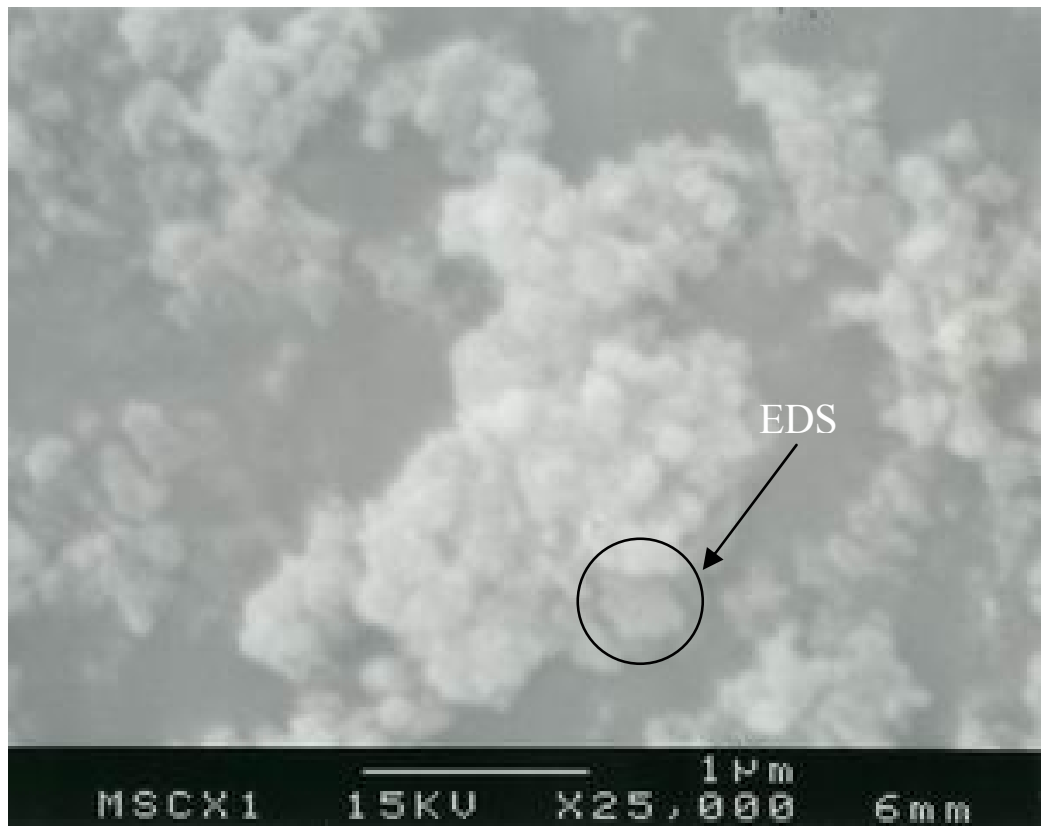

Minor element Synthetic Cement Extract with Fe(II):MSCX1

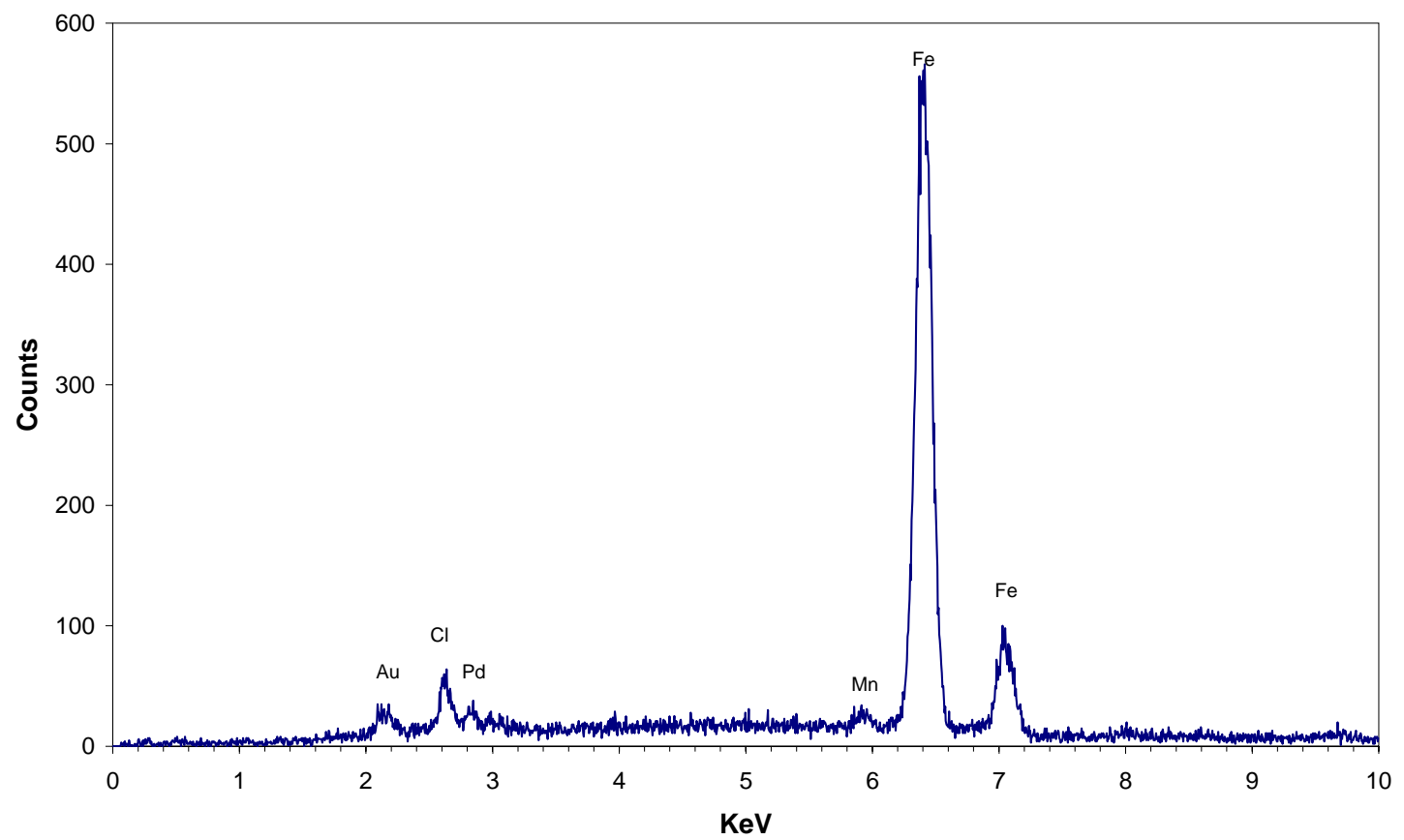

FIGURE 4-14 SEM image and EDS of minor elements synthetic cement extract with $\mathrm{Fe}(\mathrm{II})$. 
Figure 4-14 shows the SEM image and EDS spectra of MSCXFe solids. EDS spectra were taken from single hexagonal particle. Even though many cement elements were added, solids in figure 4-14 were composed mainly of $\mathrm{Fe}$ and $\mathrm{Cl}$ and small amounts of $\mathrm{Mn}$. This might confirm the hypothesis that iron and chloride are important in forming active agents for PCE degradation. Particle sizes of MSCXFe solids were very small, about $0.3 \mu \mathrm{m}$, compared to those formed in the cement slurry and the cement extract. Small particles were too aggregated to allow an image to be taken of an individual particle. The particle shapes were also hexagonal even though MSCXFe solids were different from solids formed in cement systems, based on XRD analysis.

\subsubsection{3 $\mathrm{Fe}(\mathrm{II})(\mathrm{III}) \mathrm{Cl}$}

Figure 4-14 shows the XRD patterns of solids formed in the mixture of $\mathrm{FeCl}_{2}$, $\mathrm{FeCl}_{3}$ and $\mathrm{NaCl}(\mathrm{Fe}(\mathrm{II})(\mathrm{III}) \mathrm{Cl})$ with simple mixing at $\mathrm{pH} 12$ (Fe(II)(III)Cl_Simple Mixing). It also shows the patters of solids formed using methods similar to those that are used to synthesize green rust (GR)at neutral pH (Fe(II)(III)Cl_GRN) and at pH 12 (Fe(II)(III)Cl_GR12). Ferrous hydroxide and halite were found, regardless of the synthesis method and $\mathrm{pH}$. A large amount $(2.2 \mathrm{M})$ of $\mathrm{NaCl}$ was added to keep the same concentration of chloride as in the cement extract. Extra $\mathrm{NaCl}$ might be left after reactions. During drying, white solids were observed along with colored solids, which could have been halite formed from excess $\mathrm{NaCl}$.

Green rust chloride (GR_Cl) was not formed in the neutral $\mathrm{pH}$ system. This might be due to low concentration $(0.4 \mathrm{mM})$ of ferric iron GR_Cl has a ratio of $\mathrm{Fe}(\mathrm{II})$ to 
Fe(III) of 3 , but the ratio in this system was around 10 . The color of solids produced by Fe(II)(III)Cl_GRN was dark green, the same color as GR_Cl. However, XRD peaks of GR_Cl were not observed. Their gray color also indicates the lack of GR.

Solid phases identified here were the same as in MSCXFe. In the absence of major elements of cement, only iron could participate in the formation of solids. It was not clear whether $\mathrm{Cl}$ was included in the solid structure or adsorbed onto the surface of solids, due to the high concentration of $\mathrm{NaCl}$. Theoretically, $0.4 \mathrm{mM}$ of $\mathrm{Cl}$ could compensate the charge deficit produced if all the Fe(III) that was added formed the mixed iron hydroxide $\left(\mathrm{Fe}(\mathrm{II})_{3} \mathrm{Fe}(\mathrm{III})(\mathrm{OH})_{8}{ }^{+}\right)$that is typical of Green Rust. It might be possible that the amount of GR_Cl formed in $\mathrm{Fe}(\mathrm{II})(\mathrm{III}) \mathrm{Cl}$ system is too small to be detected by XRD.

The backgrounds of the diffractograms of solids from MSCXFe, Fe(II)(III)Cl_Simple Mixing and Fe(II)(III)Cl_GR12 were gradually increasing, even though backgrounds were adjusted to zero by the JADE software. This phenomenon occurred due to fluorescent x-radiation of high amount of $\mathrm{Fe}$ in $\mathrm{Cu}$ radiation. However, these high backgrounds were not observed in the Fe(II)(III)Cl_GRN system, which was analyzed by $\mathrm{Cu}$ radiation with a monochrometer between the sample and detector (118) 
(a) Fe(II)(III)Cl_Simple Mixing

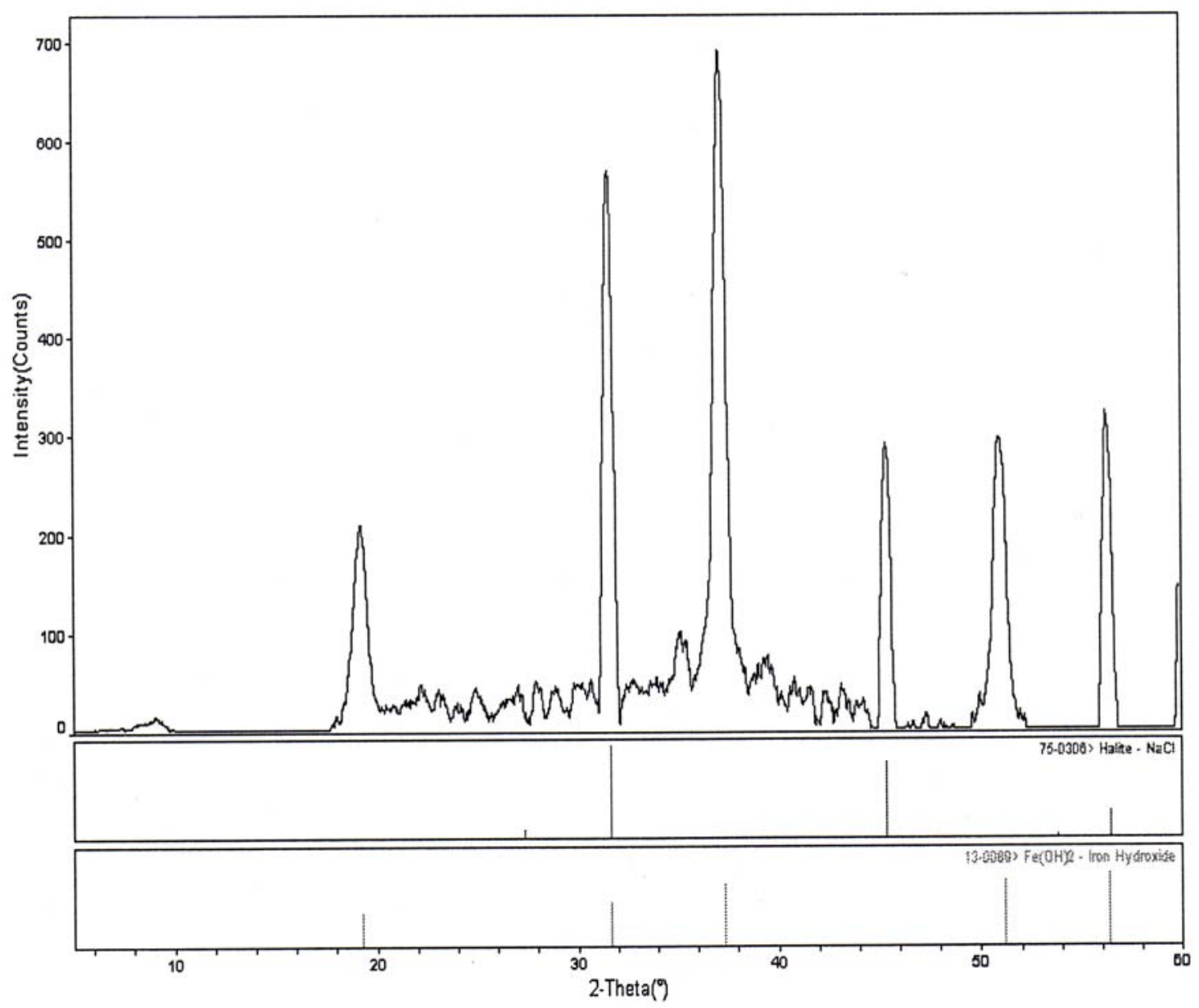

FIGURE 4-15 XRD pattern and mineral identification using software program, JADE, of $\mathrm{Fe}(\mathrm{II})(\mathrm{III}) \mathrm{Cl}$ solids. The background of (a) and (b) were adjusted by JADE; Capital H stands for Halite and capital F stands for Ferrous Hydroxide in (c). Thanks to the Texas Transportation Institute for the use of the Rigu automatic diffract of (a) and (b). 
(b)Fe(II)(III)Cl_GR12

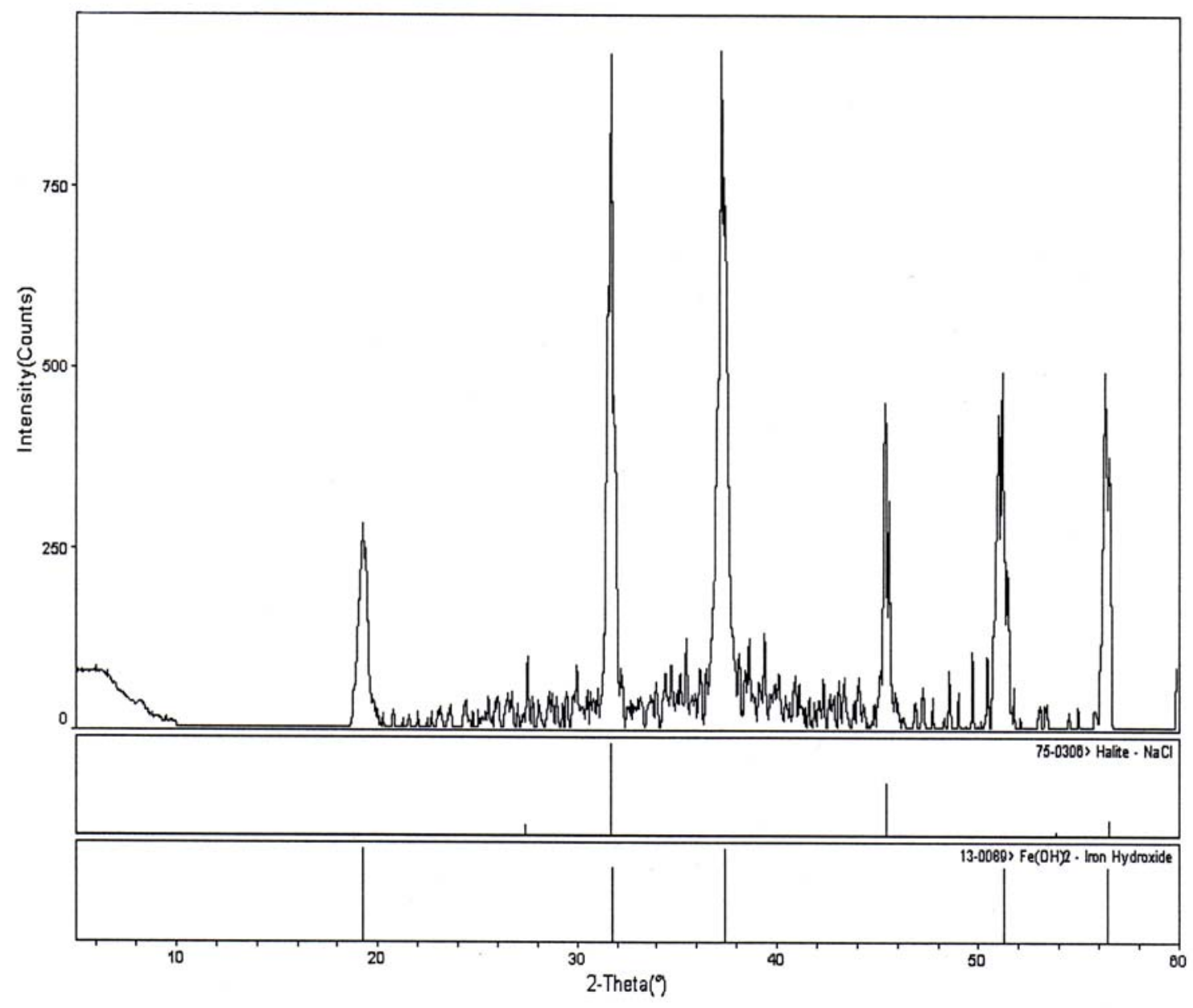

FIGURE 4-15 Continued 
(c)Fe(II)(III)Cl_GRN

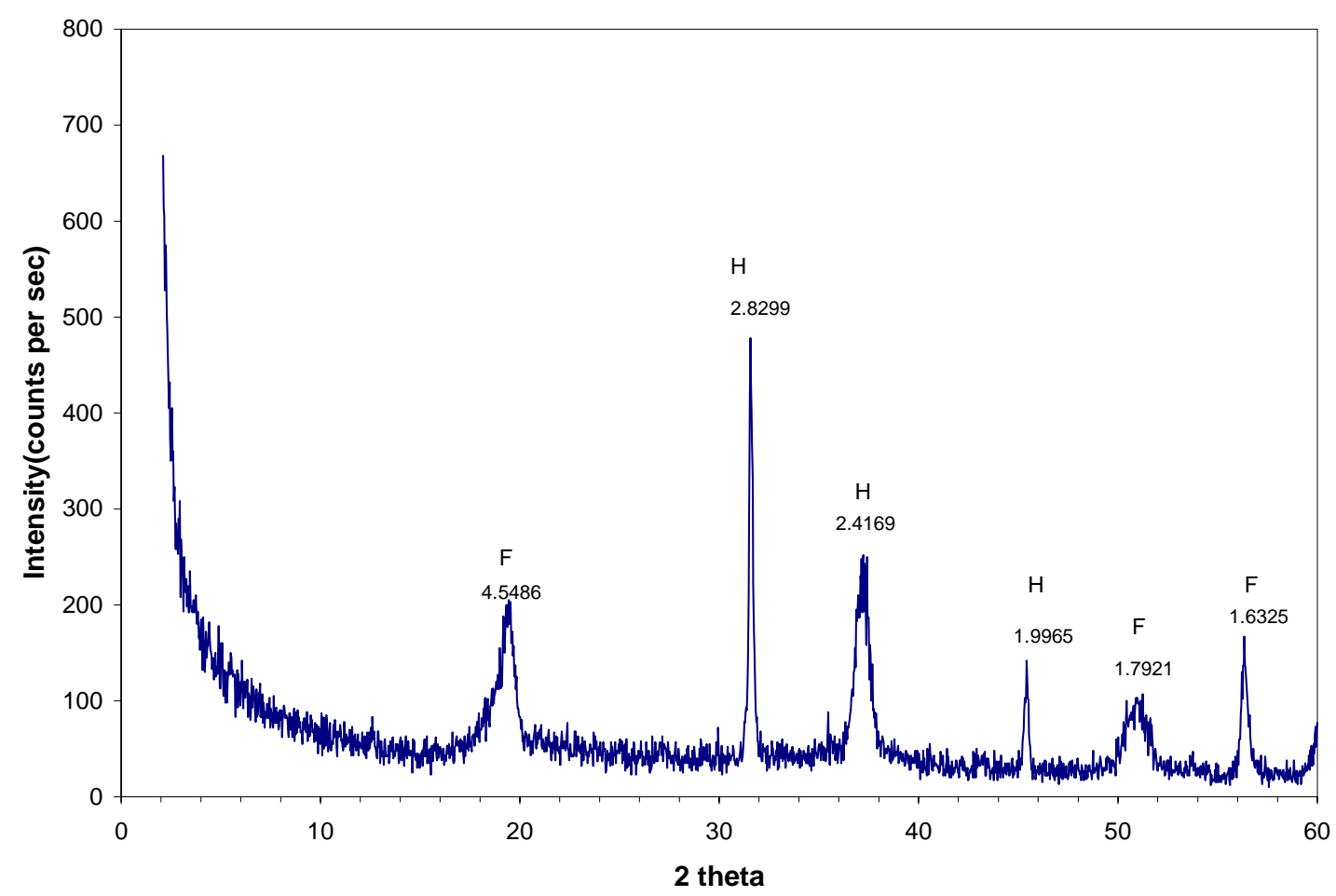

FIGURE 4-15 Continued 
Figures 4-16 through 4-18 show the SEM images and EDS spectra of $\mathrm{Fe}(\mathrm{II})(\mathrm{III}) \mathrm{Cl}$ solids synthesized by different methods and at different $\mathrm{pH}$. EDS spectra were taken from single hexagonal particle. Solids in all three systems had hexagonal shapes. However, their sizes were much smaller when they had been formed at $\mathrm{pH} 12$, $\left(\mathrm{Fe}(\mathrm{II})(\mathrm{III}) \mathrm{Cl} \_\right.$simple mixing and $\left.\mathrm{Fe}(\mathrm{II})(\mathrm{III}) \mathrm{Cl} \_\mathrm{GR} 12\right)$ than at neutral pH (Fe(II)(III)Cl_GRN). The particle sizes of Fe(II)(III)Cl_GR12, Fe(II)(III)_Simple Mixing and Fe(II)(III)Cl_GRN were about $0.5 \mu \mathrm{m}, 0.2 \mu \mathrm{m}$, and 4 to $5 \mu \mathrm{m}$, respectively . The method of mixing the solids during formation did not have much of an effect on the types of solids formed. The coprecipitation method and simply mixing all of the elements at once formed the same kind of solids. The $\mathrm{pH}$ during solid formation showed much more of an affect that the synthesis method, particularly on the size of the solids formed.

Actually, it was not clearly shown in figure 4-18 that solids formed at neutral pH-(Fe(II)(III)Cl_GRN)-were aggregated particles or single particles. They had similar shapes as reported for GR_Cl (69), but they could be an intermediate stage between ferrous hydroxide and GR_Cl.

Particle sizes of green rust have been reported to vary from 0.02 to about $1 \mu \mathrm{m}$ (70) to larger than $2 \mu \mathrm{m}$ (69), probably due to the variation of crystal growth rates. The smaller particles are the larger surface area they have. Thus, the smaller particles might be more preferable for PCE degradation because they would have more active surface sites. 


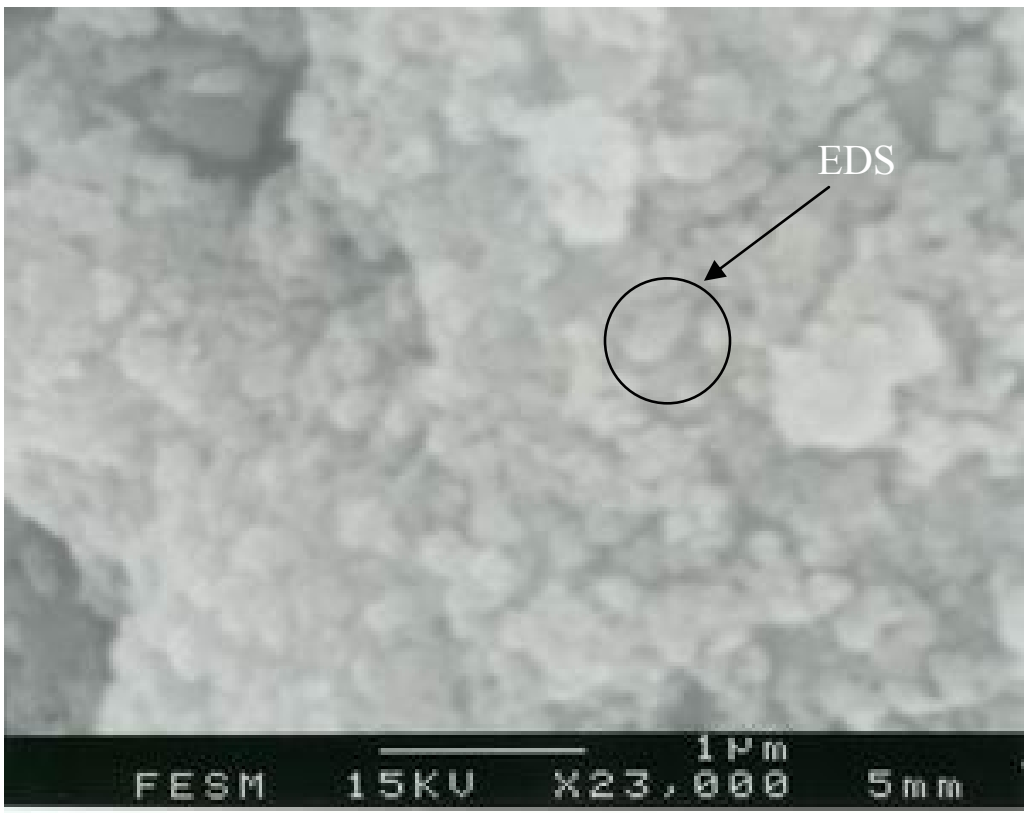

Fe(II)(III)Cl_simple mixing:FESM

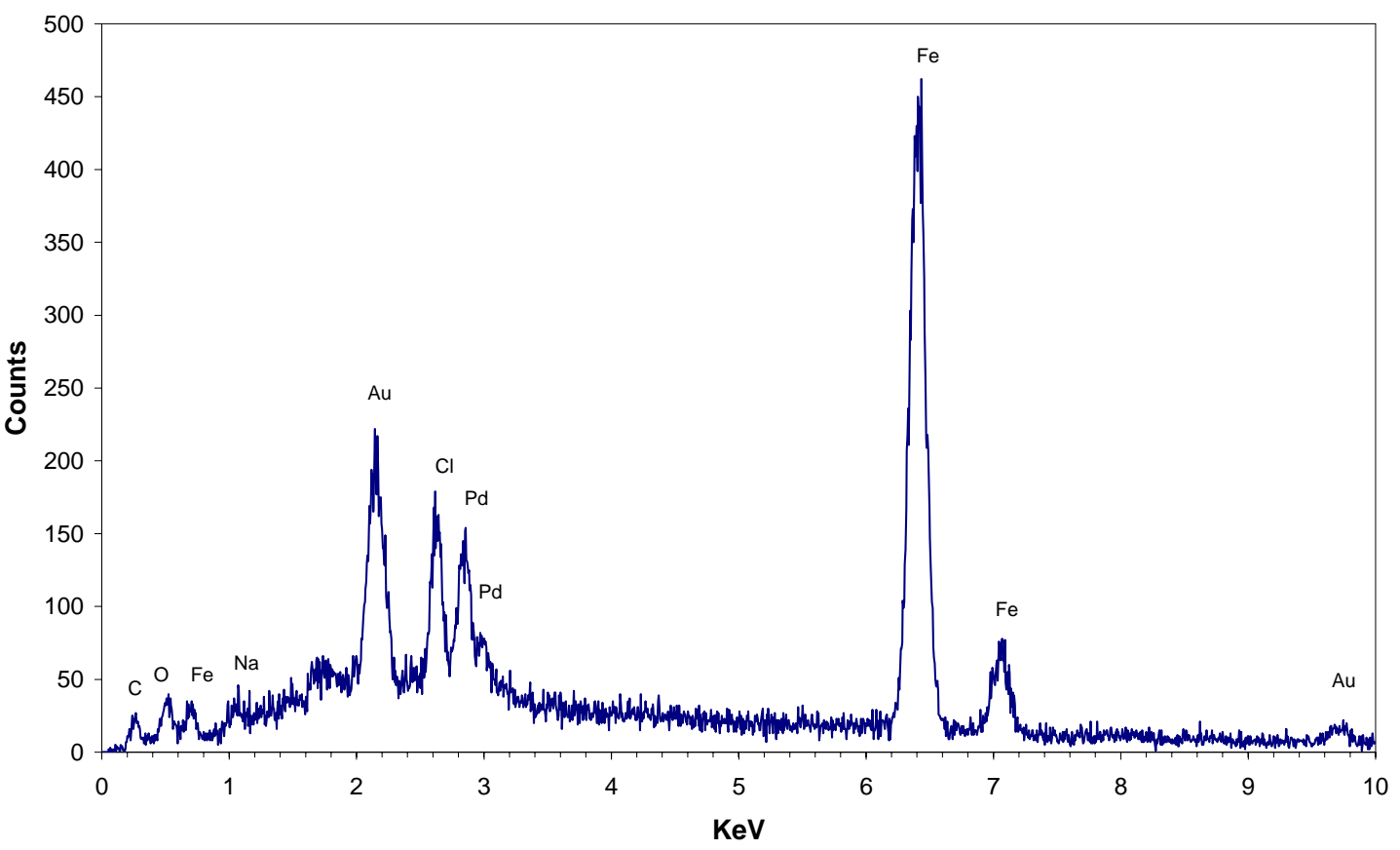

FIGURE 4-16 SEM image and EDS of Fe(II)(III)Cl_Simple Mixing. 


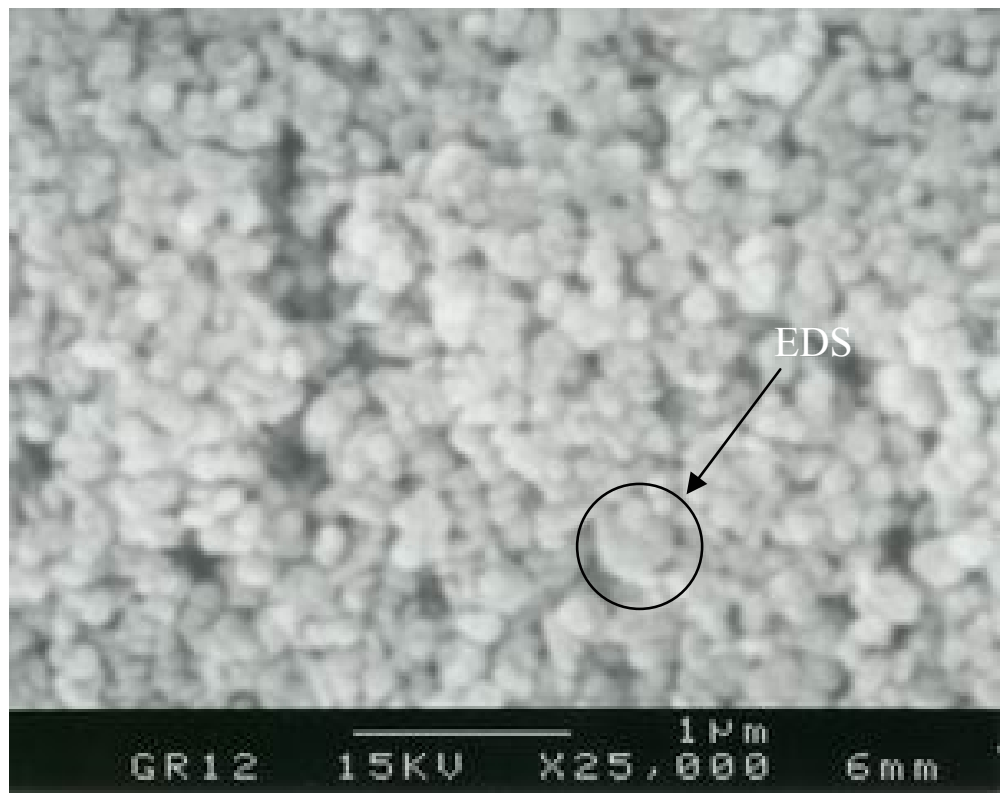

Fe(II)(III)Cl_GR12:GR12

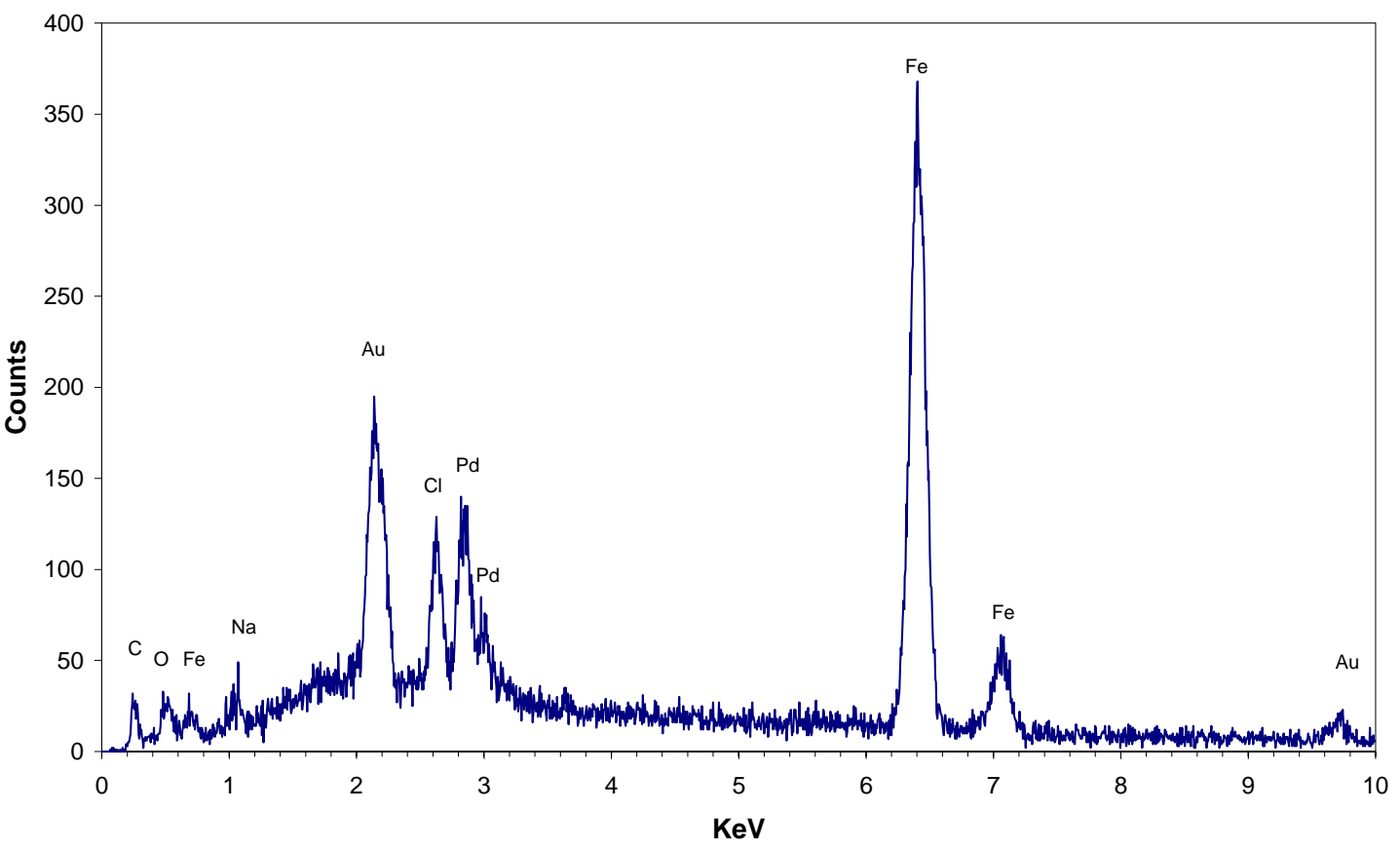

FIGURE 4-17 SEM image and EDS of Fe(II)(III)Cl_GR12. 


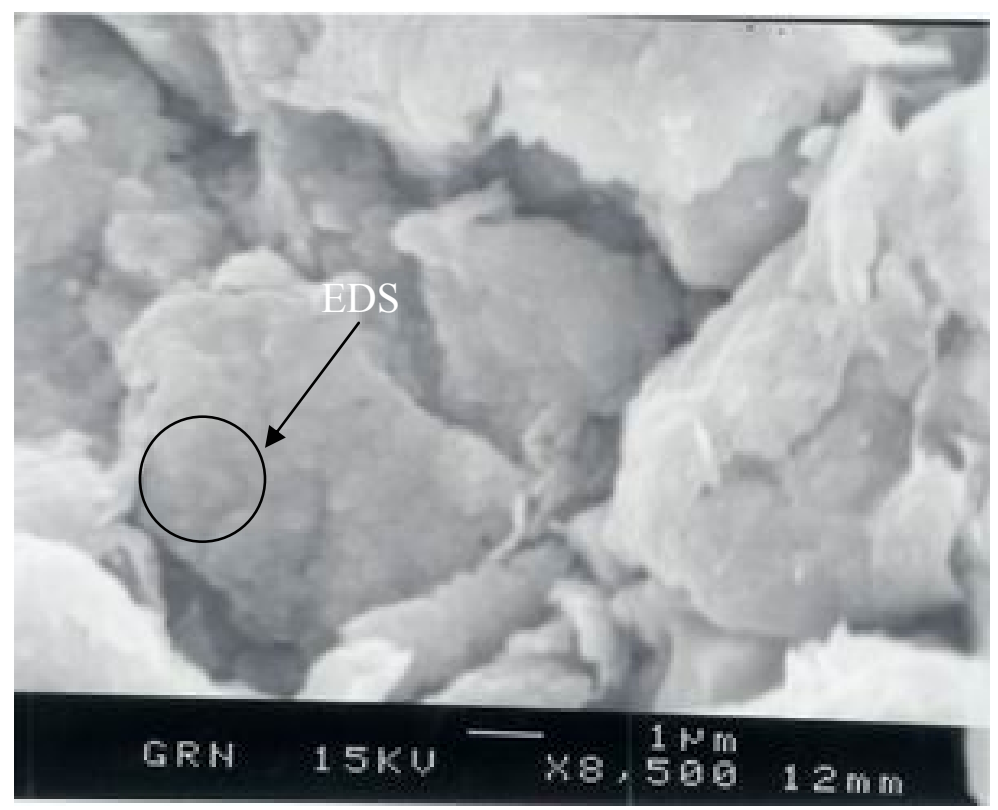

Fe(II)(III)CI_GRN:GRN

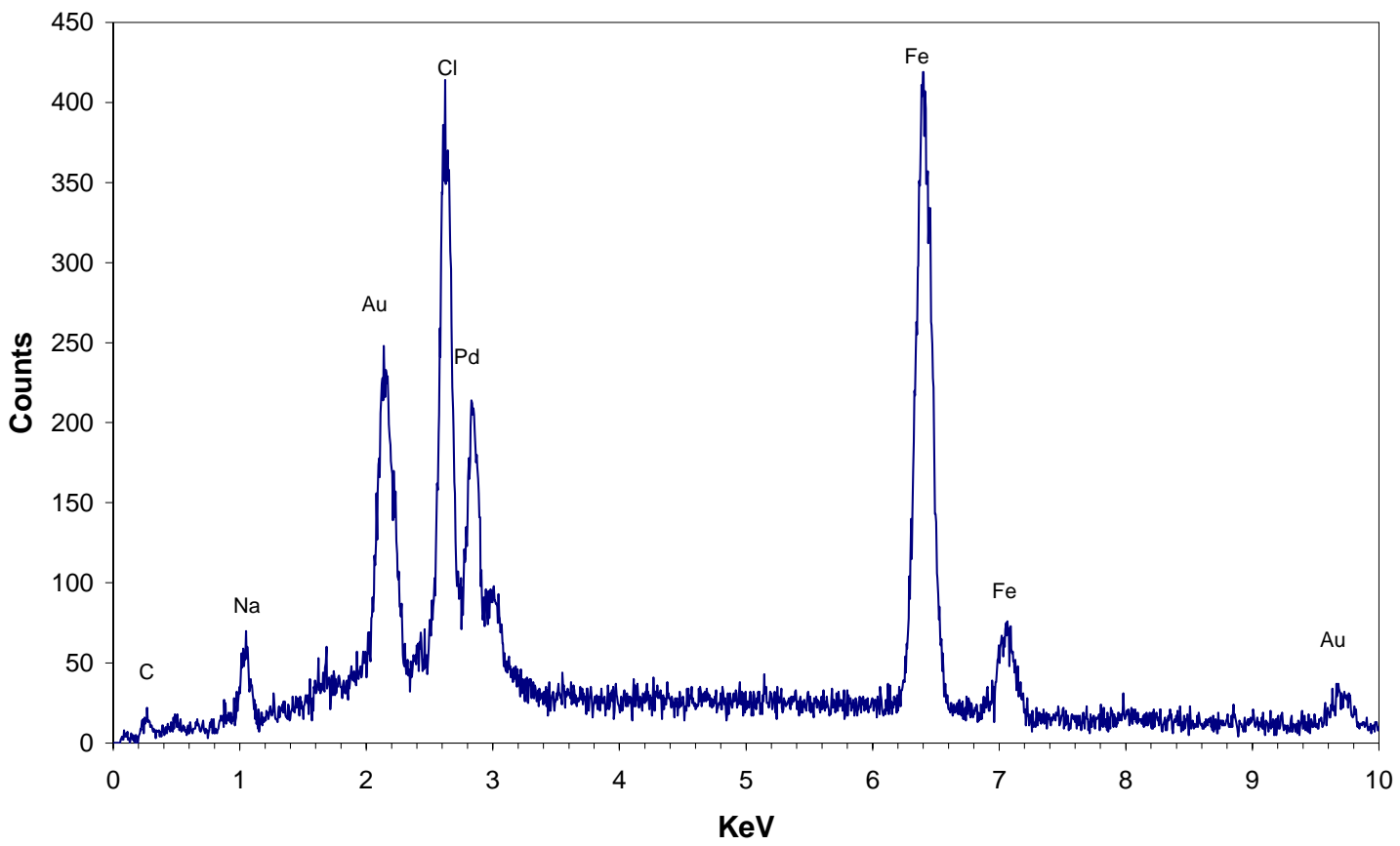

FIGURE 4-18 SEM image and EDS of Fe(II)(III)Cl_GRN. 


\subsection{Examination of variability of ordinary Portland cement (OPC)}

4.3.1 PCE degradation kinetic tests

4.3.1.1 $10 \%$ cement slurry solids with Fe(II)

Table 4-13 and figure 4-19 and 4-20 shows the results of PCE degradation experiments using $10 \%$ cement slurries from four different cement manufacturers (Txi, Quikrete, Lehigh, Capitol). They were type I Portland cements, except Txi, which was type II Portland cement. The first and second order rate constants were obtained by nonlinear regressions using Matlab. PCE degradation experiments were conducted at an average $\mathrm{pH}$ of 12.6 with variation of \pm 0.05 .

Both first and second order kinetic models were fitted to the data for PCE degradation by the Txi cement slurry (TPCSFe, exp. 145) and these models fitted the data equally well. The pseudo first order rate constant for TPCSFe was 2 times higher than that for experiments conducted by Huang with Capitol Portland cement slurries with Fe(II) (CPCSFe) (23). The first order kinetic model fitted data from the experiment with Lehigh cement (LPCSFe, exp 147) better than the second order model. The pseudo first order rate constant for LPCSFe was 2.5 times higher than CPCSFe and 1.5 times higher than TPCSFe. About 50\% of PCE was degraded in both TPCSFe and LPCSFe after 3 days. Experiments with 10\% Quikrete cement slurry and Fe(II) (QPCSFe, exp. 146) showed unique PCE degradation behavior (Figure 4-19). The kinetic data fit a second-order model better than a first-order model, in contrast to data from experiments with other cement slurries. The second order kinetic model fit the initial and final data points well, but did not fit points in the middle very well. Values predicted by the kinetic 
model were much below the measured values for data from days 4 to 11 . Although it was the same type of cement as Capitol, it showed a different kinetic behavior of PCE degradation. About $50 \%$ of PCE was degraded within 10 hours and then the rate of PCE degradation slowed. Approximately $75 \%$ of PCE was removed within 7 days. Uncertainties in the calculated rate constants for these three cement slurry systems were significantly higher than those for CPCSFe. This is especially true for coefficients obtained with QPCSFe.

Another behavior that was different for Capitol cement was the detection of TCE. TPCSFe did not show accumulation of any TCE during the experimental period. However, some TCE was detected during PCE degradation experiments by LPCSFe and QPCSFe. TCE concentrations equal to about $20 \%$ of the PCE concentration in controls were measured in experiments with QPCSFe after 2 days. Then, TCE concentrations decreased to below $0.6 \%$ of the PCE concentration in the control after 10 days. TCE concentrations slowly increased in LPCSFe and reached a maximum of $20 \%$ of the control at 5 days. TCE concentration in LPCSFe also decreased to below $0.1 \%$ of the control after 10 days.

The PCE degradation by CPCSFe followed a reductive elimination pathway, where TCE was not detected (23). Although byproducts of PCE degradation other than TCE were not investigated in this experiment, detection of TCE indicates that PCE degradation by LPCS and QPCS might follow a hydrogenolysis pathway.

Solid phases formed in different cement slurry systems might be similar due to similar chemical compositions of Portland cements and the same experiment conditions, 
such as $\mathrm{pH}$ and initial Fe(II) and PCE concentrations. It was not clear why four cement slurry systems showed the different behavior when degrading PCE.

TABLE 4-13 The Fe(II) concentration normalized first and second order rate constants for PCE degradation in various slurries made with Fe(II) and 10\% cement

\begin{tabular}{|c|c|c|c|c|c|c|}
\hline Exp & $\begin{array}{l}10 \% \text { cement } \\
\text { slurry }\end{array}$ & $\mathrm{pH}$ & $\mathrm{k}_{1 \mathrm{Fe}(\mathrm{II})}{ }^{\mathrm{a}}$ & $\mathrm{SS}_{1}{ }^{\mathrm{b}}$ & $\mathrm{k}_{2 \mathrm{Fe}(\mathrm{II})}{ }^{\mathrm{c}}$ & $\mathrm{SS}_{2}{ }^{\mathrm{d}}$ \\
\hline 145 & $\mathrm{TPCSFe}^{\mathrm{e}}$ & 12.6 & $\begin{array}{l}4.1 \mathrm{E}-03 \\
( \pm 22 \%)\end{array}$ & $1.0 \mathrm{E}-03$ & \multirow{4}{*}{$\begin{array}{l}4.5 \mathrm{E}-02 \\
( \pm 26 \%) \\
1.7 \mathrm{E}-01 \\
( \pm 67 \%) \\
5.9 \mathrm{E}-02 \\
( \pm 48 \%)\end{array}$} & $1.1 \mathrm{E}-03$ \\
\hline 146 & $\mathrm{QPCSFe}^{\mathrm{f}}$ & 12.6 & $\begin{array}{r}2.5 \mathrm{E}-02 \\
( \pm 97 \%)\end{array}$ & $1.0 \mathrm{E}-02$ & & $4.0 \mathrm{E}-03$ \\
\hline 147 & $\mathrm{LPCSFe}^{\mathrm{g}}$ & 12.6 & $\begin{array}{l}7.0 \mathrm{E}-03 \\
( \pm 14 \%)\end{array}$ & \multirow[t]{2}{*}{$3.9 \mathrm{E}-04$} & & \multirow[t]{2}{*}{ 4.6E-03 } \\
\hline & $\mathrm{CPCSFe}^{\mathrm{h}}$ & 12.6 & $\begin{array}{l}2.6 \mathrm{E}-03 \\
( \pm 5.4 \%)\end{array}$ & & & \\
\hline
\end{tabular}

${ }^{a} k_{1}$ was the $\mathrm{Fe}(\mathrm{II})$ concentration normalized first order rate constant; Unit $=(\mathrm{mM}$ $\mathrm{Fe}(\mathrm{II}) \times$ day $)^{-1}$

${ }^{\mathrm{b}} \mathrm{SS}_{1}$ was the sum of square of the first order rate model

${ }^{c} k_{2}$ was the $\mathrm{Fe}(\mathrm{II})$ concentration normalized second order rate constant; Unit $=(\mathrm{mM}$ $\mathrm{Fe}(\mathrm{II}) \times \mathrm{mM}$ PCE $\times$ day $)^{-1}$

${ }^{\mathrm{d}} \mathrm{SS}_{2}$ was the sum of squares of the second order rate model

${ }^{\mathrm{e}} \mathrm{TPCSF}$ stands for $\mathrm{Fe}(\mathrm{II})$-containing $10 \%$ Txi cement slurry

${ }^{\mathrm{f}} \mathrm{QPCSFe}$ stands for Fe(II)-containing 10\% Quikrete cement slurry

${ }^{\mathrm{g}} \mathrm{LPCSFe}$ stands for $\mathrm{Fe}(\mathrm{II})$-containing $10 \%$ Lehigh cement slurry

${ }^{\mathrm{h}} \mathrm{CPCSFe}$ stands for Fe(II)-containing 10\% Capitol cement slurry. The first order rate constant was referenced from Hwang (23)

Uncertainties represent $95 \%$ confidence limits expressed in \% relative to estimate $\mathrm{k}$ Initial PCE concentration was $0.242 \mathrm{mM}$ 


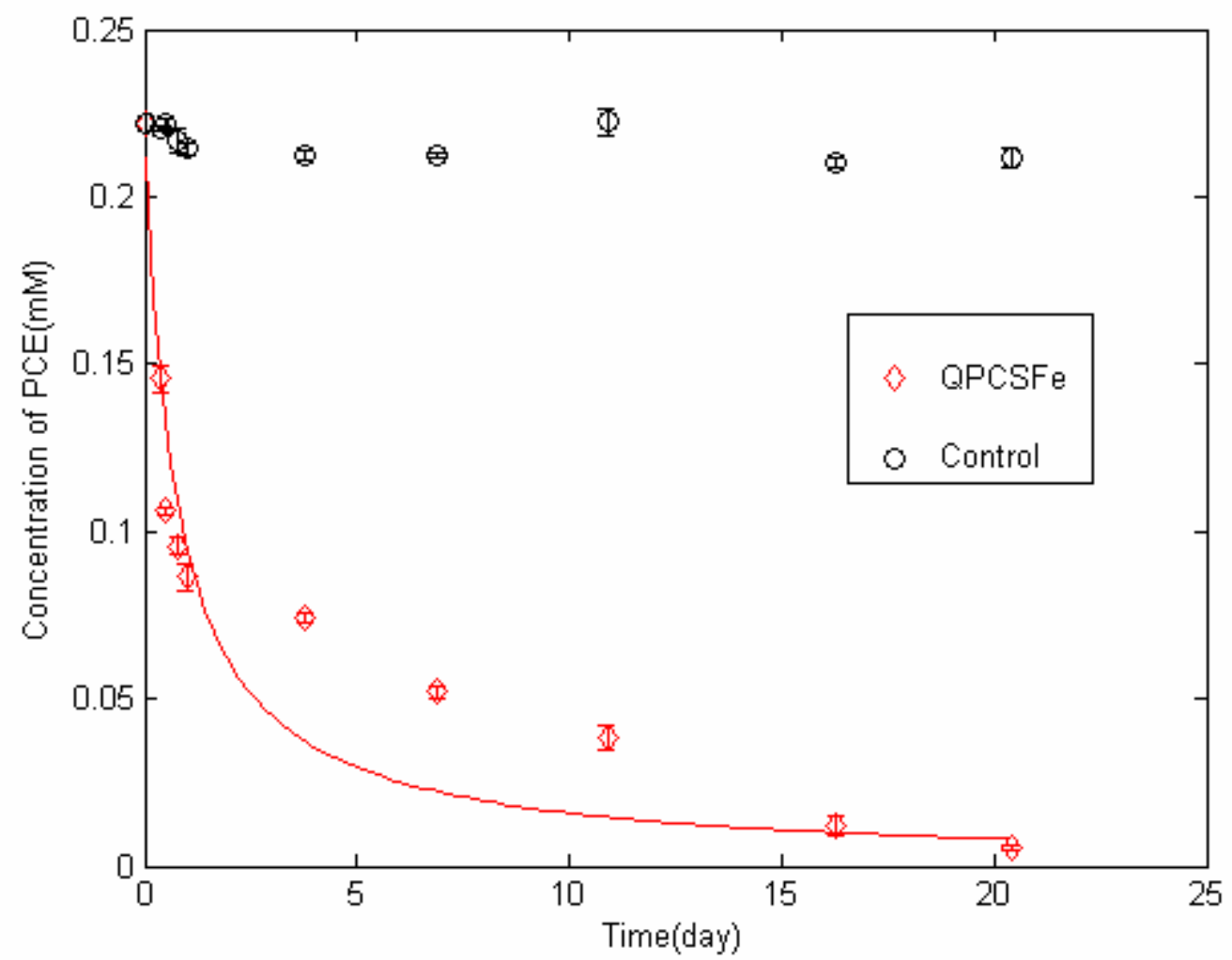

FIGURE 4-19 Kinetics of PCE reduction by slurries prepared with Fe(II) and 10\% Quikrete cement, QPCSFe. $[\mathrm{PCE}]_{0}=0.242 \mathrm{mM}$. The solid line represented the second order kinetic model fit. 


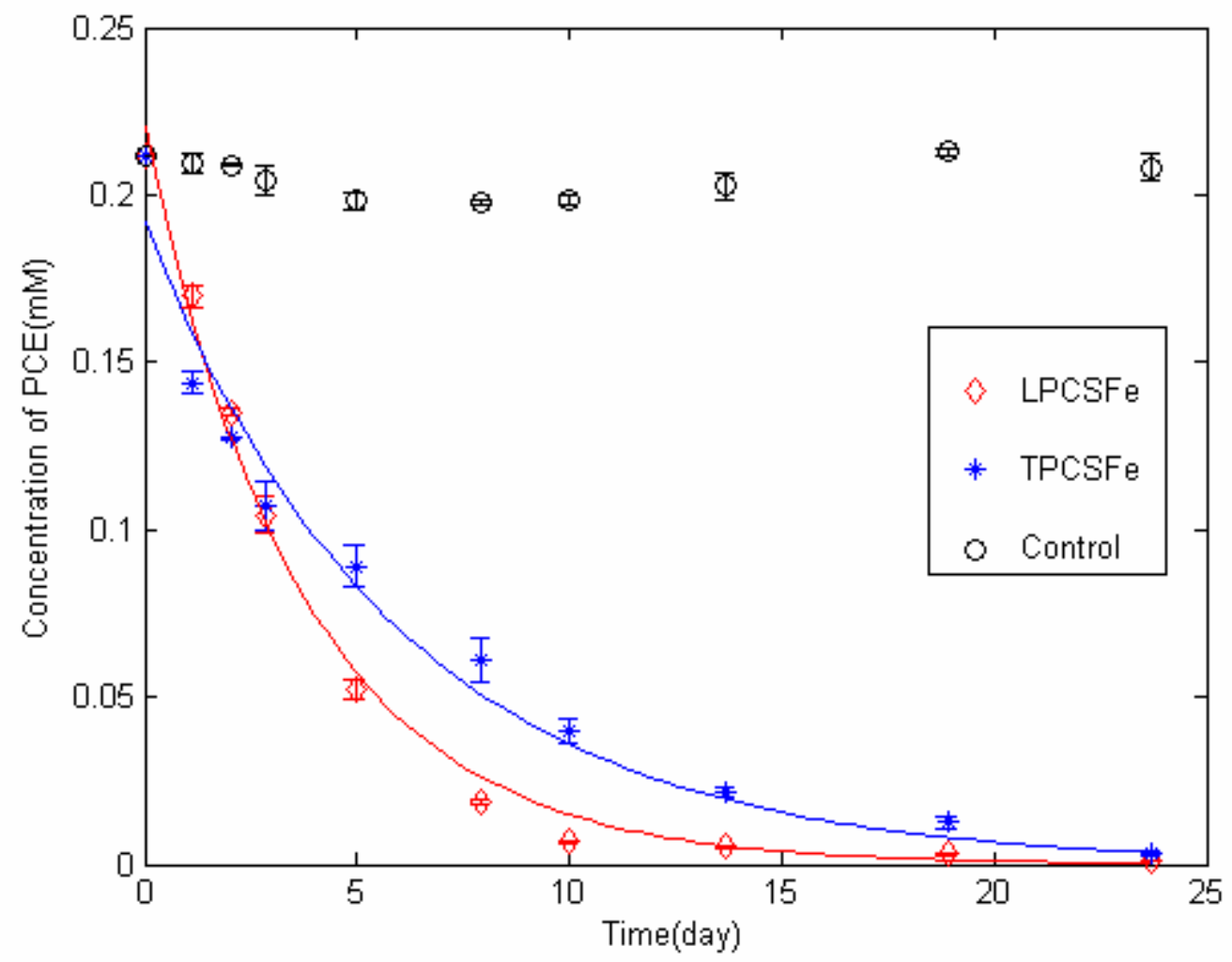

FIGURE 4-20 Kinetics of PCE reduction by slurries prepared with $\mathrm{Fe}(\mathrm{II})$ and $10 \%$ Lehigh and Txi cements, LPCSFe and TPCSFe, respectively. $[\mathrm{PCE}]_{0}=0.242 \mathrm{mM}$. The solid lines represented the first order kinetic model fit. 


\subsubsection{2 $10 \%$ cement extract solids with $\mathrm{Fe}(\mathrm{II})$}

Table 4-14 and Figure 4-21 and 4-22 show results of the PCE degradation experiments conducted with $10 \%$ cement extract from four different cement manufacturers (Txi, Quikrete, Lehigh, Capitol). The first- and second-order rate constants were obtained by nonlinear regressions using Matlab. PCE degradation experiments were conducted at an average $\mathrm{pH}$ of 11.6 with variation of \pm 0.05 for experiments with extracts made from Txi (TPCXFe), Lehigh (LPCXFe) and Quikrete $(\mathrm{QPCXFe})$ cements. Although the same concentration of $\mathrm{Ca}(\mathrm{OH})_{2}(1.25 \mathrm{M})$ was used in all experiments, $\mathrm{pH}$ values in experiments with TPCXFe, LPCXFe, and QPCXFe were lower than those with CPCXFe. This might result from lower initial $\mathrm{pH}$ of the cement extracts after acid digestion. The $\mathrm{pH}$ of $\mathrm{CPCX}$ was about 4 and others were about 3, even though the same $\mathrm{HCl}$ concentration $(2.2 \mathrm{~N})$ was used to dissolve the four different cements.

The first kinetic model fitted well to TPCXFe (exp. 148) and the second order kinetic model fitted well to QPCXFe (exp. 149) and LPCXFe (exp. 150). The pseudo first-order rate constant normalized by Fe(II) for TPCXFe was one order of magnitude lower than that for CPCXFe. About $50 \%$ of PCE was removed within 7 days and 95\% was removed at the last sampling time (37 days). TPCXFe showed a $\mathrm{k}_{\mathrm{Fe}(\mathrm{II})}$ that was about $40 \%$ lower than that for TPCSFe. This contrasts with CPXFe, which had a $\mathrm{k}_{\mathrm{Fe}(\mathrm{II})}$ that was one order of magnitude higher than that for CPCSFe.

Results from experiments with QPCXFe and LPCXFe can be compared to those from experiments with CPCXFe by calculating an approximate first-order rate constant 
by multiplying the second order rate constant by the average concentration observed during the experiment, i.e., the approximate first order rate constant $=$ the second order rate constant $\times$ average concentration $\left(\mathrm{k}_{1}=\mathrm{k}_{2} \times \mathrm{C}_{\mathrm{avg}}\right)$. Calculated first order rate constants normalized by $\mathrm{Fe}(\mathrm{II})$ concentration $\left(\mathrm{k}_{\mathrm{Fe}(\mathrm{II})}\right)$ for QPCXFe and LPCXFe were $2.3 \times 10^{-3}(\mathrm{mMFe}(\mathrm{II}) \times \text { day })^{-1}$ and $4.8 \times 10^{-3}(\mathrm{mMFe}(\mathrm{II}) \times \text { day })^{-1}$, respectively. These are one order of magnitude lower than $\mathrm{k}_{\mathrm{Fe}(\mathrm{II})}$ of $\mathrm{CPCXFe}$, which was $1.1 \times 10^{-2}(\mathrm{mMFe}(\mathrm{II}) \times \text { day })^{-1}$. The experiments with QPCXFe and LPCXFe showed lower solid activities than CPCX, when measured as the time required for removal of specific percentages of the initial PCE. About $50 \%$ of initial PCE was removed by QPCXFe within 9 days and approximately $92 \%$ of PCE was removed after 37 days, which was the last sampling time. Experiments with LPCXFe showed 50\% removal of PCE within 3 days, which is a similar half-life as that observed for CPCXFe. The PCE degradation rate slowed after that and it took 37 days to remove $93 \%$ of the initial PCE. This compares to reaching 98\% PCE removal in 21 days with CPCXFe. Moreover, TCE was consistently detected in the range of 5 to $10 \%$ of PCE concentration in the control for QPCXFe. After 20 days, TCE concentration increased to $15 \%$ and was steady until the last sampling time. TCE was also detected in LPCXFe after one day and reached at maximum of $14 \%$ of the PCE concentration in the control after 7 days. TCE was not detected after 10 days.

Although the second-order kinetic model gave a little bit better fit to QPCXFe than the first-order kinetic model, it did not fit data points well. It underestimates in the middle of three data points and overestimates the last four data points, although it estimates well the first three data points. Data from experiments with QPCSFe and 
QPCXFe did not fit well to any kinetic model. Solids from the experiment with QPCXFe showed the one order of magnitude lower solid activity than those from experiments with QPCSFe. The second order kinetic model fitted well to data from experiments with LPCXFe, while the first-order kinetic model provided a better fit to data from experiments with LPCSFe.

Different PCE degradation behavior was observed in experiments with cement extract and cement slurry even though they used the same brand of cement. The fact that TPCXFe, LPCXFe, and QPCXFe had lower solid activities than CPCXFe might be caused by either formation of lower amounts of the active solids or similar amounts that have lower activity, due to larger particle size or different chemical composition. After centrifugation of the mixture of PCX and Fe(II), the concentration of Fe(II) recovered in the blue solids at the top of the pellet was about $30 \mathrm{mM}$ and concentration of solids was about $45 \mathrm{~g} / \mathrm{L}$. The concentration of Fe(II) recovered from CPCXFe solids was $20 \mathrm{mM}$ and concentration of solids was $31 \mathrm{~g} / \mathrm{L}$. The ratio of Fe(II) to solids was about 0.67 for TPCXFe, LPCXFe, and QPCXFe and about 0.97 with CPCXFe. This supports the observation that less active solids were formed in TPCXFe, LPCXFe, and QPCXFe because they contained less Fe(II). It might also indicate that formation of active solids was very sensitive to $\mathrm{pH}$, because $\mathrm{pH}$ values of experiments with those three PCXs were 0.2 lower than $\mathrm{pH}$ of $\mathrm{CPCX}$. Another possible reason might be the different $\mathrm{Fe}$ (II) to Fe(III) ratio in the solids. The Fe(II) to Fe(III) ratio in CPCXFe solid suspensions was 3, 12 in TPCXFe, and 19 in QPCXFe and LPCXFe. The high degree of Fe(II) oxidation to Fe(III) might produce more active solids. Another possible reason might be the 
formation of different kinds of active solid phases. They might have slightly different chemical compositions so that they might not produce the same solids

Formation of TCE indicates that PCX solids might follow a hydrogenolysis pathway for PCE degradation such as observed for experiments with cement slurries. PCE degradation rates of PCX solids were slower than observed for experiments with PCS solids.

TABLE 4-14 The Fe(II) concentration normalized first and second order rate constants for PCE degradation in various Fe(II) containing 10\% cement extracts

\begin{tabular}{|c|c|c|c|c|c|c|}
\hline Exp & $\begin{array}{c}10 \% \\
\text { cement } \\
\text { slurry }\end{array}$ & $\mathrm{pH}$ & $\mathrm{k}_{1 \mathrm{Fe}(\mathrm{II})}{ }^{\mathrm{a}}$ & $\mathrm{SS}_{1}{ }^{\mathrm{b}}$ & $\mathrm{k}_{2 \mathrm{Fe}(\mathrm{II})}{ }^{\mathrm{c}}$ & $\mathrm{SS}_{2}{ }^{\mathrm{d}}$ \\
\hline 148 & $\mathrm{TPCXFe}^{\mathrm{e}}$ & 11.6 & $\begin{array}{c}2.9 \mathrm{E}-03 \\
( \pm 16 \%)\end{array}$ & 7.6E-04 & $\begin{array}{c}2.7 \mathrm{E}-02 \\
( \pm 22 \%)\end{array}$ & 2.4E-03 \\
\hline 149 & $\mathrm{QPCXFe}^{\mathrm{f}}$ & 11.6 & $\begin{array}{r}2.2 \mathrm{E}-03 \\
( \pm 21 \%)\end{array}$ & $1.5 \mathrm{E}-03$ & $\begin{array}{l}2.0 \mathrm{E}-02 \\
( \pm 26 \%)\end{array}$ & $1.3 \mathrm{E}-03$ \\
\hline 150 & $\mathrm{LPCXFe}^{\mathrm{g}}$ & 11.6 & $\begin{array}{l}5.1 \mathrm{E}-03 \\
( \pm 38 \%)\end{array}$ & $3.3 \mathrm{E}-03$ & $\begin{array}{l}6.3 \mathrm{E}-02 \\
( \pm 14 \%)\end{array}$ & $3.3 \mathrm{E}-04$ \\
\hline 45 & $\mathrm{CPCXFe}^{\mathrm{h}}$ & 11.8 & $\begin{array}{l}1.1 \mathrm{E}-02 \\
( \pm 4.9 \%)\end{array}$ & & & \\
\hline
\end{tabular}

\footnotetext{
${ }^{a} k_{1}$ was the $\mathrm{Fe}(\mathrm{II})$ concentration normalized first order rate constant; Unit $=(\mathrm{mM}$ $\mathrm{Fe}(\mathrm{II}) \times$ day $)^{-1}$

${ }^{\mathrm{b}} \mathrm{SS}_{1}$ was the sum of square of the first order rate model

${ }^{c} k_{2}$ was the $\mathrm{Fe}(\mathrm{II})$ concentration normalized second order rate constant; Unit $=(\mathrm{mM}$ $\mathrm{Fe}(\mathrm{II}) \times \mathrm{mM}$ PCE $\times$ day $)^{-1}$

${ }^{\mathrm{d}} \mathrm{SS}_{2}$ was the sum of squares of the second order rate model

${ }^{\mathrm{e}} \mathrm{TPCXFe}$ stands for Fe(II)-containing 10\% Txi cement extract

${ }^{\mathrm{f}} \mathrm{QPCXFe}$ stands for Fe(II)-containing 10\% Quikrete cement extract

${ }^{g}$ LPCXFe stands for Fe(II)-containing 10\% Lehigh cement extract

${ }^{\mathrm{h}} \mathrm{CPCXFe}$ stands for $\mathrm{Fe}(\mathrm{II})$-containing $10 \%$ Capitol cement extract; The $\mathrm{Fe}(\mathrm{II})$ concentration normalized first order rate constant was referenced from Ko(127) Uncertainties represent $95 \%$ confidence limits expressed in \% relative to estimate $\mathrm{k}$ Initial PCE concentration was $0.242 \mathrm{mM}$
} 


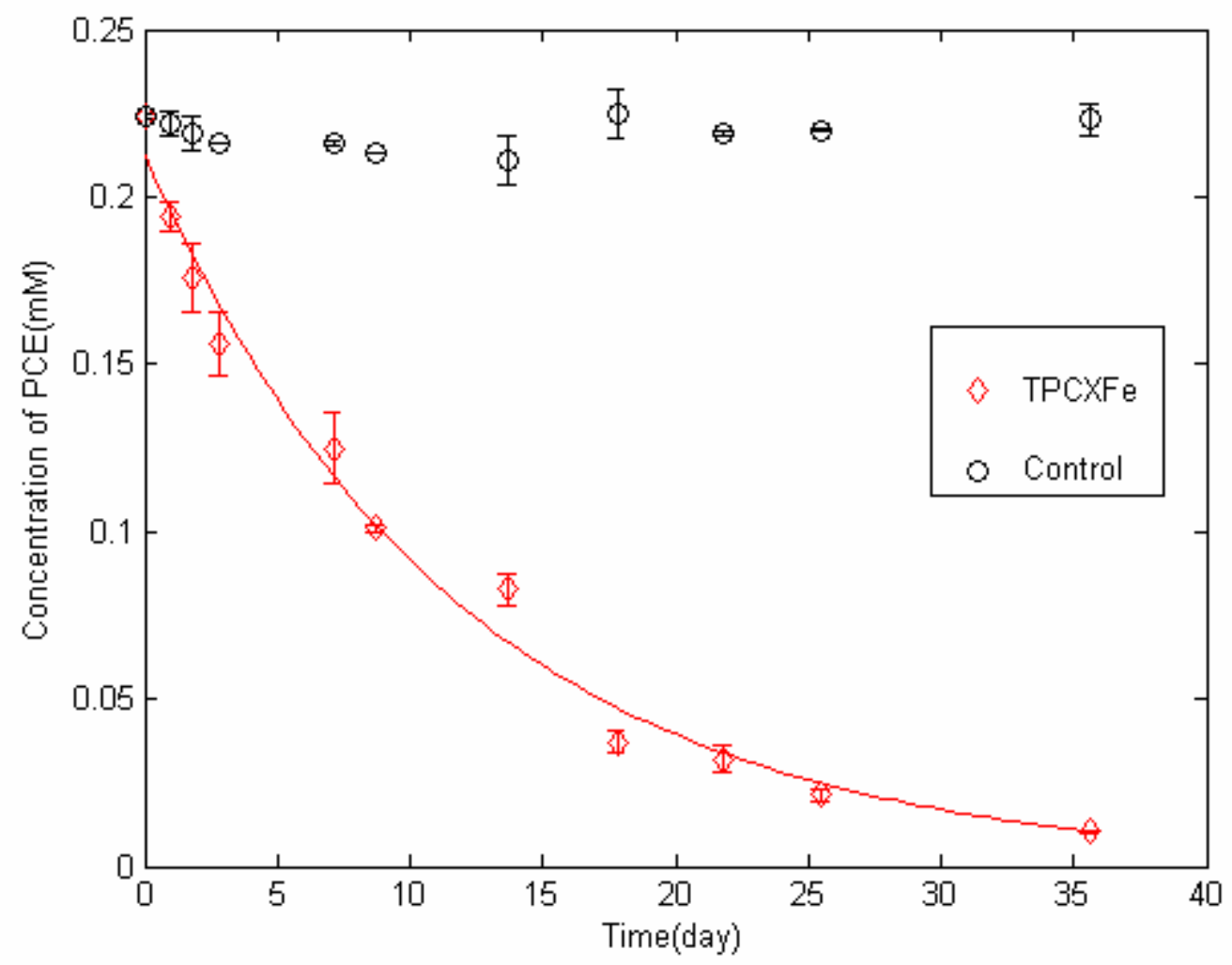

FIGURE 4-21 Kinetics of PCE reduction by extracts prepared with Fe(II) and 10\% Txi cement, TPCXFe. $[\mathrm{PCE}]_{0}=0.242 \mathrm{mM}$. The solid line represented the first order kinetic model fit. 


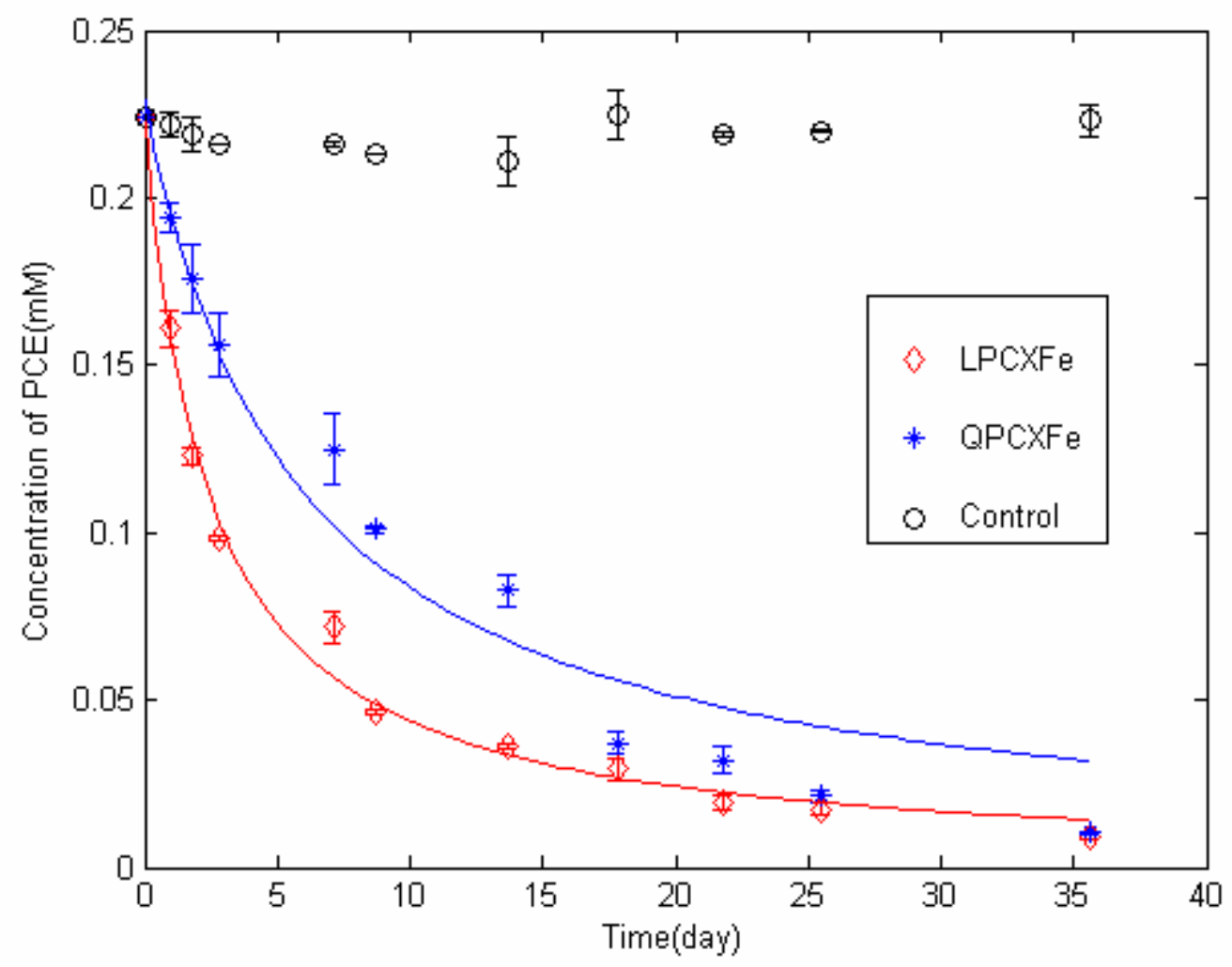

FIGURE 4-22 Kinetics of PCE reduction by extracts prepared with $\mathrm{Fe}(\mathrm{II})$ and $10 \%$ Lehigh and Quikrete cement, LPCXFe and QPCXFe, respectively. [PCE $]_{0}=0.242 \mathrm{mM}$. The solid lines represented the second order kinetic model fit. 


\subsubsection{Instrumental analyses: XRD, SEM and EDS}

\subsubsection{1 $10 \%$ cement slurry solids}

Figure 4-23 shows the x-ray diffractograms for TPCSFe, QPCSFe, LPCSFe and Table 4-15 presents a comparison of d-spacings for them with CPCS and CPCSFe. Peaks at $9.50 \AA, 5.54 \AA$ and $2.75 \AA$ in TPCSFe solids represent Ettringite. Peaks at $7.7 \AA$ and $3.78 \AA$ represent Friedel's salt. The peak at $3.85 \AA$ might come from either Ettringite or Friedel's salt. Peaks at $3.03 \AA, 3.20 \AA$, and $2.87 \AA$ represent calcium aluminum silicate hydrate. Other minor peaks could be considered as either Friedel's salt or calcium aluminum silicate hydrates. The presence of Ettringite in TPCSFe was different from CPCSFe where Ettringite was not observed.

LPCSFe, QPCSFe and CPCSFe had similar XRD patterns. Friedel's salts were the most positively identified in QPCSFe, with peaks at $8.01 \AA, 3.95 \AA$, and $3.84 \AA$ and in LPCSFe with peaks at $8.02 \AA, 3.97 \AA$, and $3.86 \AA$. Calcium aluminum silicate hydrates were identified with peaks at $3.07 \AA$ in QPCSFe and LPCSFe. Peaks at $4.35 \AA$ in both solids also could represent calcium aluminum silicate hydrates. Ettringite peaks were not observed in either solid. Peaks from Friedel's salt in QPCSFe showed a higher intensity than in LPCSFe, maybe because they were more highly crystalline. Peaks at 2.34 and $2.31 \AA$ would be Friedel's salts. They were recognized as high intensity peaks in reference solids $\left(7^{\text {th }}\right.$ and $\left.8^{\text {th }},\right)$, but they showed higher intensity in LPCSFe and QPCSFe than peaks at 3.96 and $3.85 \AA$, which were the second, and third high intense ones in reference solids. 


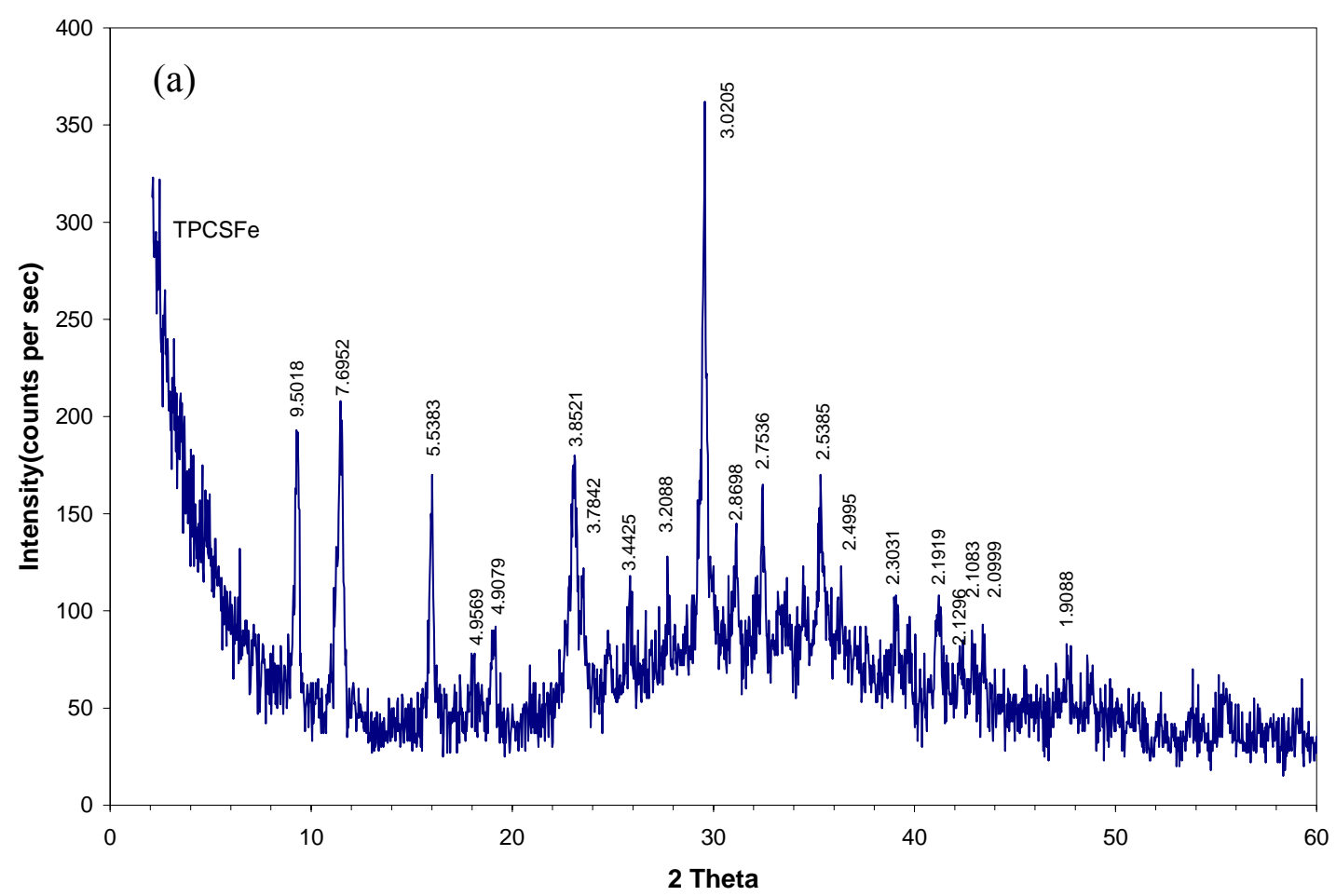

FIGURE 4-23 XRD patterns of solids prepared with Fe(II) and 10\% Portland cement.

The unit of d-spacing is $\AA$. (a) solids prepared with Fe(II) and 10\% Txi Portland cement (TPCSFe); (b) solids prepared with Fe(II) and 10\% Quikrete Portland cement (QPCSFe);

(c) solids prepared with Fe(II) and 10\% Lehigh Portland cement (LPCSFe). 

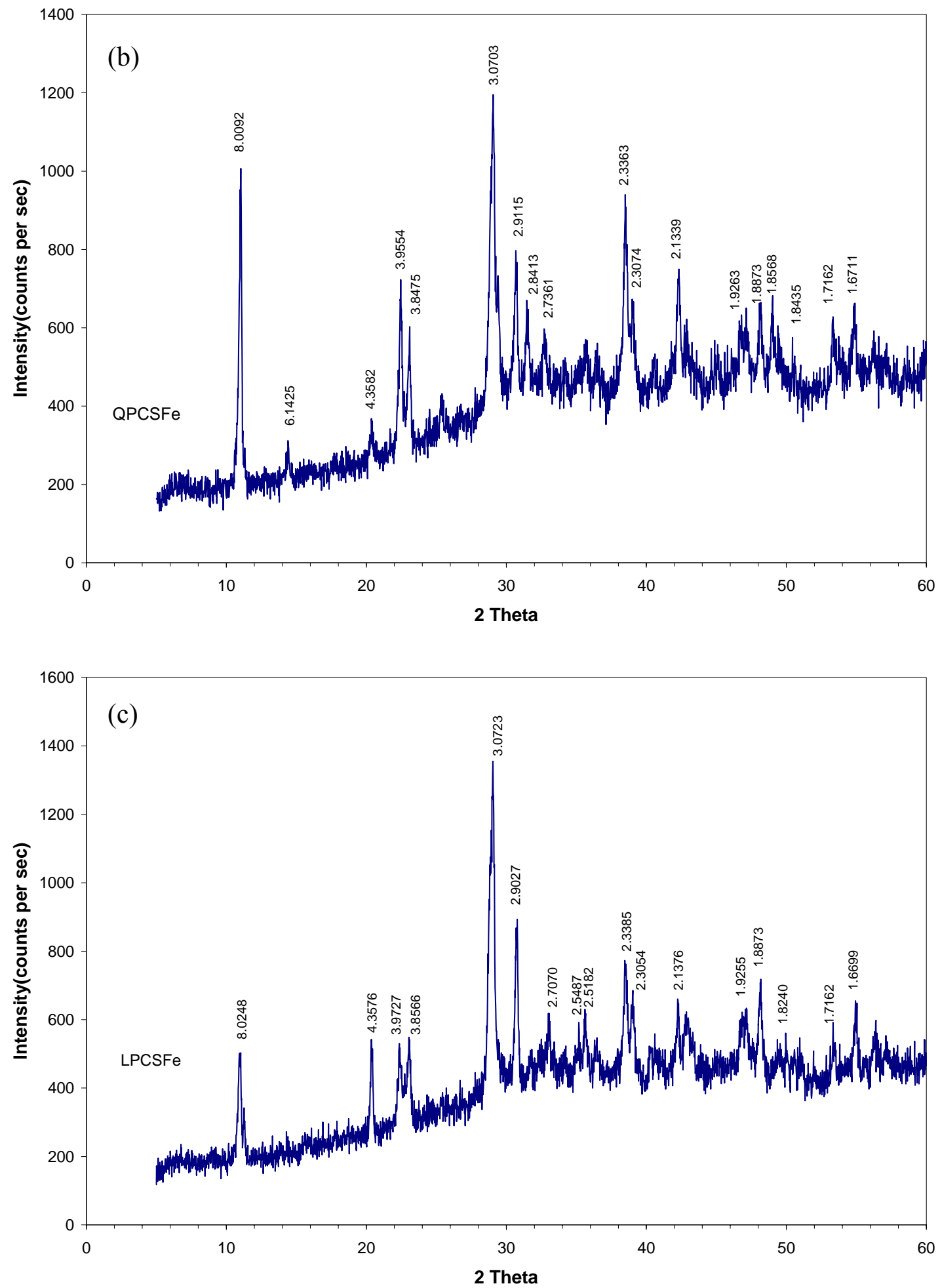

FIGURE 4-23 Continued 
TABLE 4-15 The comparison of d-spacing values of $10 \%$ cement slurry solids, unit $=\AA$

\begin{tabular}{crrrrr}
\hline $\begin{array}{c}\text { Highest } \\
\text { intensity }\end{array}$ & CPCS & CPCSFe & TPCSFe & QPCSFe & LPCSFe \\
\hline $1^{\text {st }}$ & $7.78^{\mathrm{a}}$ & $7.80^{\mathrm{a}}$ & $3.02^{\mathrm{c}}$ & $8.01^{\mathrm{a}}$ & $3.07^{\mathrm{c}}$ \\
$2^{\text {nd }}$ & $3.03^{\mathrm{c}}$ & $2.89^{\mathrm{c}}$ & $9.50^{\mathrm{b}}$ & $3.07^{\mathrm{c}}$ & $2.90^{\mathrm{c}}$ \\
$3^{\text {rd }}$ & $9.63^{\mathrm{b}}$ & 2.32 & $7.70^{\mathrm{a}}$ & 2.34 & $8.02^{\mathrm{a}}$ \\
$4^{\text {th }}$ & 2.56 & $3.07^{\mathrm{c}}$ & $5.54^{\mathrm{b}}$ & $3.96^{\mathrm{a}}$ & 2.34 \\
$5^{\text {th }}$ & 2.20 & $3.90^{\mathrm{a}}$ & $3.85^{\mathrm{a}, \mathrm{b}}$ & $2.91^{\mathrm{c}}$ & 4.36 \\
$6^{\text {th }}$ & $3.90^{\mathrm{a}}$ & $3.80^{\mathrm{a}}$ & $3.78^{\mathrm{a}}$ & $3.85^{\mathrm{a}}$ & 1.89 \\
$7^{\text {th }}$ & 2.54 & 2.12 & 2.54 & 2.13 & $3.86^{\mathrm{a}}$ \\
$8^{\text {th }}$ & $3.86^{\mathrm{a}, \mathrm{b}}$ & 1.88 & 2.75 & 2.31 & 2.31 \\
$9^{\text {th }}$ & 2.31 & 1.93 & $2.87^{\mathrm{c}}$ & 2.84 & $3.97^{\mathrm{a}}$ \\
$1^{\text {th }}$ & 2.12 & 2.81 & 3.21 & 1.86 & 1.67 \\
\hline
\end{tabular}

${ }^{a}$ The first three most intense peaks of Friedel's salts

${ }^{\mathrm{b}}$ The first three most intense peaks of Ettringite

${ }^{c}$ The first three most intense peaks of calcium aluminum silicate hydrates

The different degree of crystallization and different amounts of solids might cause intensities to differ from standards and from one another. However, four $\mathrm{Fe}(\mathrm{II})$ containing cement slurry solids had very similar XRD patterns. Friedel's salts and calcium aluminum silicate hydrates were identified in all four solids. Ettringite was only identified in TPCSFe. d-spacing values and the order of high intensity peaks were a little bit different from reference solids. This might be caused by different chemical compositions of reference solids compared to solids formed in cement slurries with $\mathrm{Fe}(\mathrm{II})$. 
Figures 4-24 to 4-26 show the SEM images and EDS spectra of TPCSFe, QPCSFe, and LPCSFe solids. EDS spectra of three PCSFe solids were taken from a certain region within single hexagonal particle. Hexagonal thin plates were the dominant solid phases in mixtures containing Fe(II). Hexagonal shapes were the most clearly observed in QPCSFe. Particle sizes of three sets of solids were around 3 to $7 \mu \mathrm{m}$, which were similar to those for CPCSFe solids. EDS spectra showed that the same elements as $\mathrm{CPCSFe}(\mathrm{Ca}, \mathrm{Cl}, \mathrm{Al}, \mathrm{Si}$, and $\mathrm{Fe})$ are present in all three solids. Small amounts of $\mathrm{Mg}$ were detected in LPCSFe solids.

Apparently, the results of XRD, SEM images and EDS spectra showed that $\mathrm{Fe}(\mathrm{II})$ containing cement slurry solids from four different cement had the same element presence, similar particle sizes, and similar kinds of solid phases. These instrumental analyses results supported the hypothesis that solids formed in Portland cement system are similar as long as they are formed from the same types of ordinary Portland cement. However, the results of PCE degradation kinetic experiment showed variations among the four different Fe(II)-containing cement slurry solids. One possible reason might be different chemical composition, for instance, the ratio of $\mathrm{Fe}(\mathrm{II})$ to $\mathrm{Fe}(\mathrm{III})$ might be different among the different $\mathrm{Fe}(\mathrm{II})$-containing cement slurry solids. A quantitative elemental analysis was not conducted so that this hypothesis could not be thoroughly investigated. 


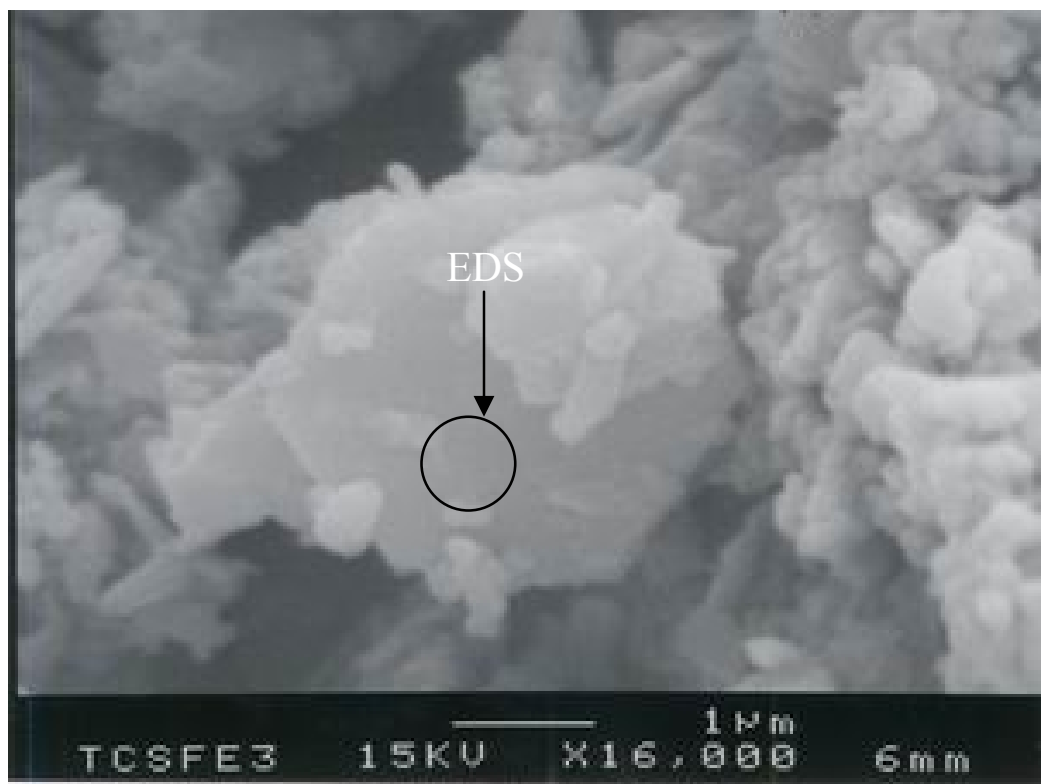

Txi Cement Slurry with Fe(II):TCSFE3

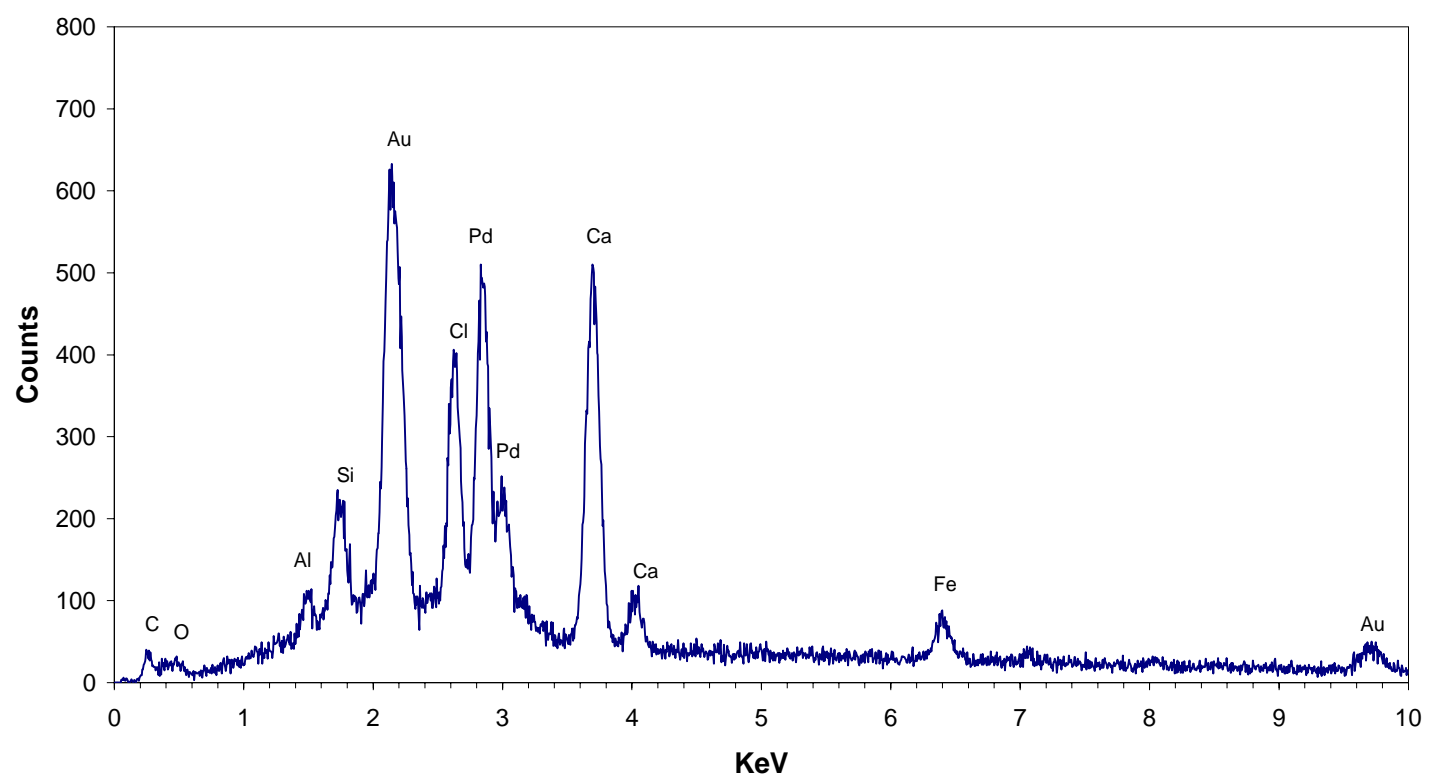

FIGURE 4-24 SEM image and EDS of solids prepared with Fe(II) and 10\% Txi cement. 


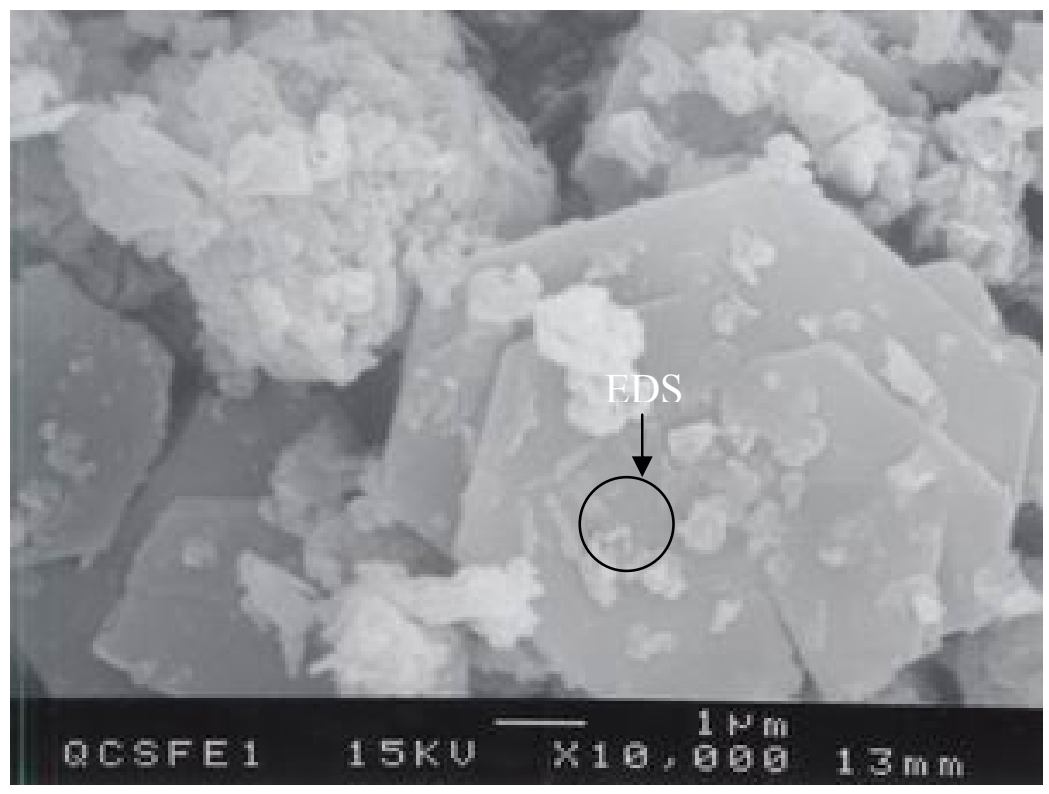

Quikrete Cement Slurry with Fe(II):QCSFE1

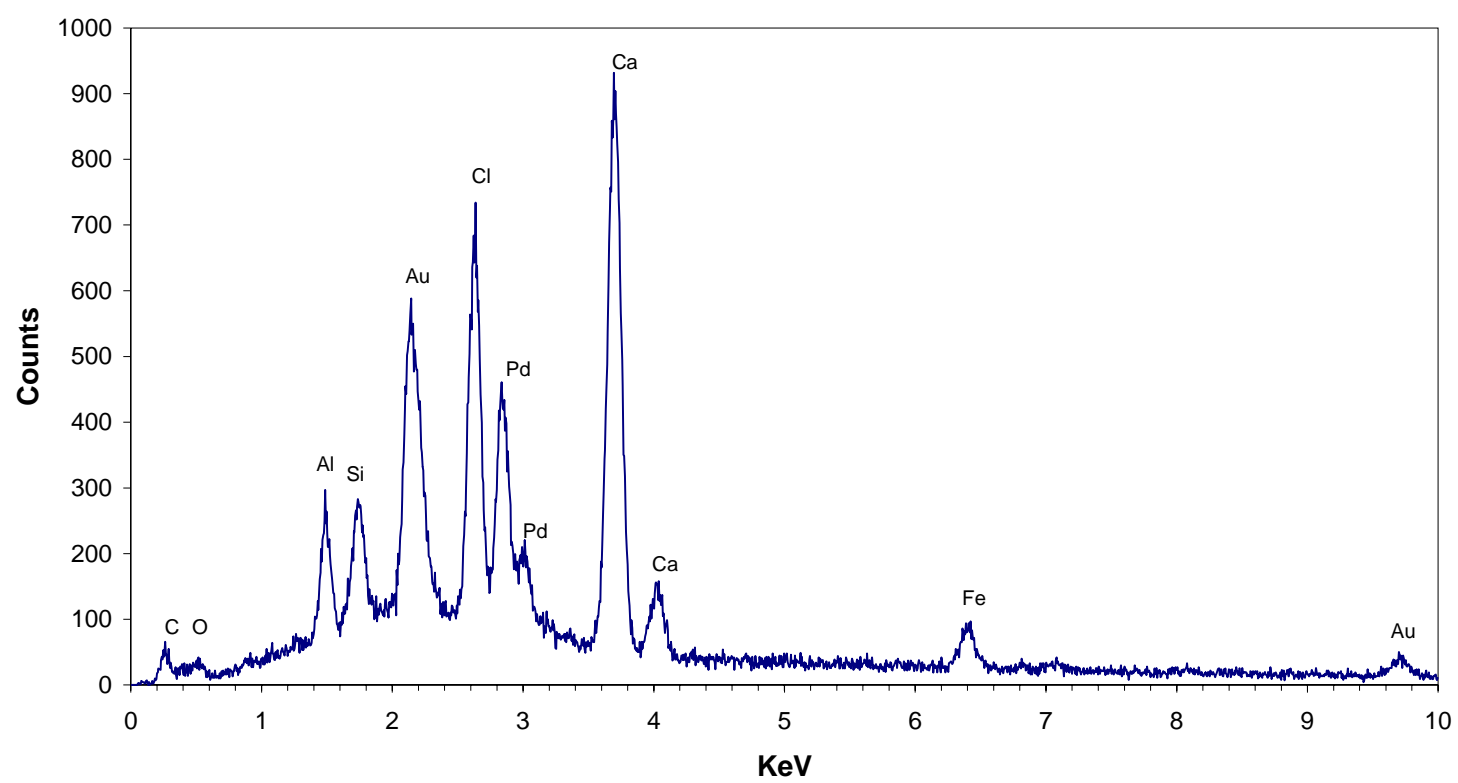

FIGURE 4-25 SEM image and EDS of solids prepared with Fe(II) and 10\%

Quikrete cement. 


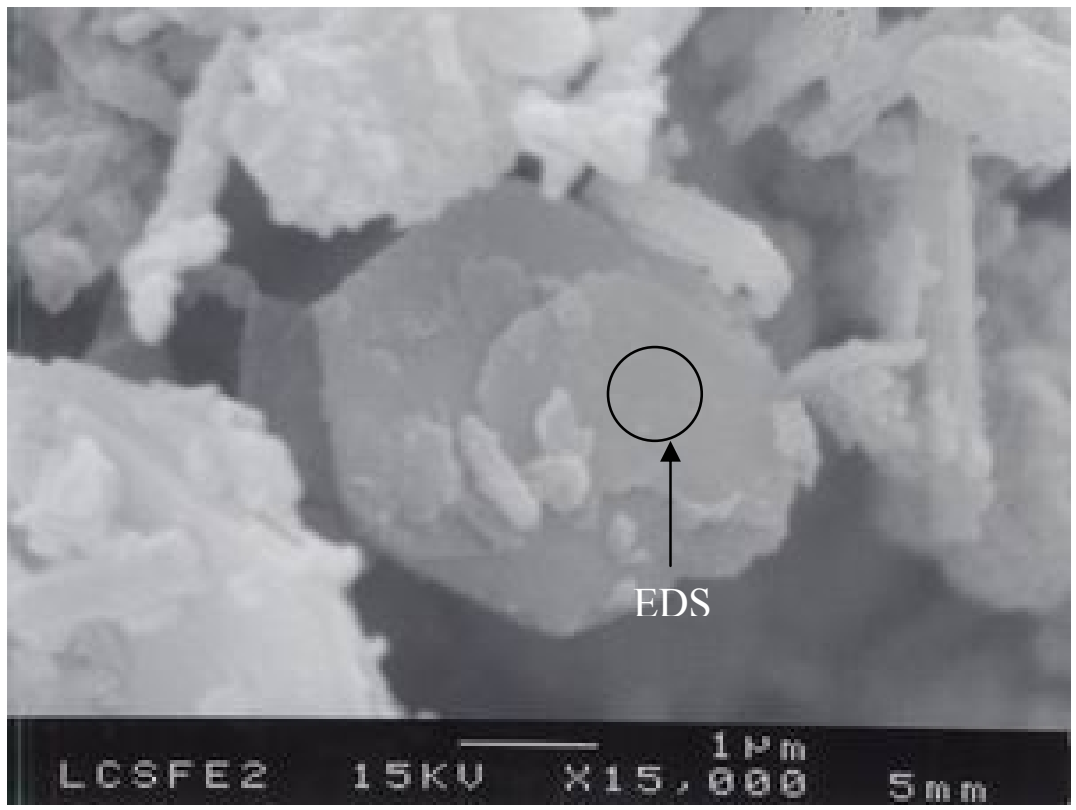

Lehigh Cement Slurry with Fe(II):LCSFE2

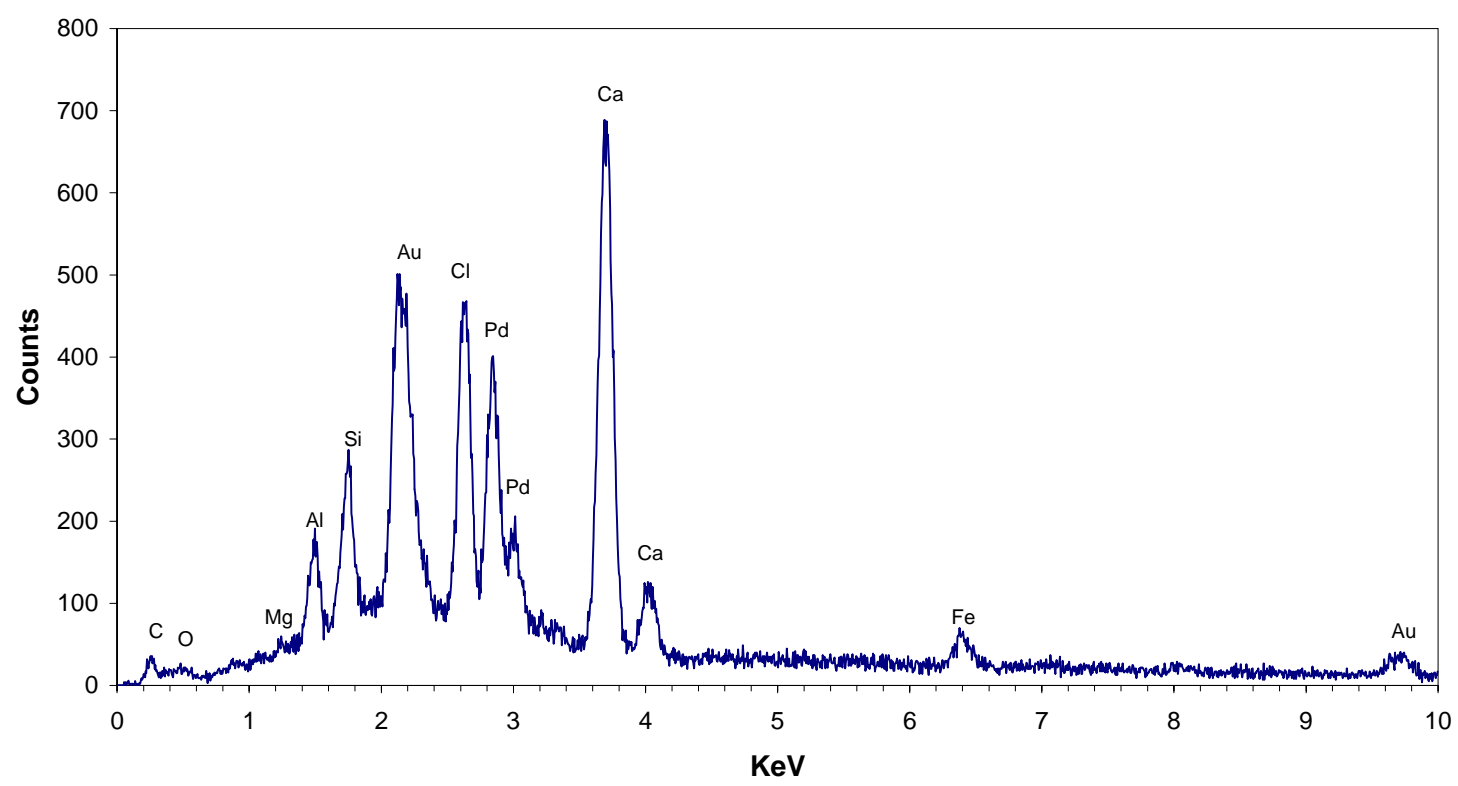

FIGURE 4-26 SEM image and EDS of solids prepared with Fe(II) and 10\%

Lehigh cement. 


\subsubsection{2 $10 \%$ cement extract solids}

Figures 4-27 and 4-28 and Tables 4-16 and 4-17 show the XRD patterns of solids prepared with three $10 \%$ Portland cement extract solids with and without Fe(II). Extracts were prepared using Portland cements from Txi (TPCX, TPCXFe), Quikrete (QPCX, QPCXFe), and Lehigh (LPCX, LPCXFe). Solids in these slurries contained the same solid phases, because their d-spacing values and intensities were very similar with one another.

The solid phases identified in 10\% Portland cement extract solids were the same: Portlandite, calcium aluminum hydroxide hydrate, and calcium aluminum silicate hydrate. Friedel's salts were not identified in PCX solids without Fe(II) addition. Peak no.1 in TPCX, QPCX, and LPCX had a d-spacing of $8.1 \AA$ and it was the most intense peak. On the other hand, a peak at the number 1 position in CPCX had a d-spacing $0.4 \AA$ larger and an intensity that was not as high as those in TPCX, QPCX, and LPCX. Peaks from Portlandite showed the highest intensity in CPCX and peaks from calcium aluminum hydroxide hydrates showed a higher intensity than the other three.

The same kinds of solid phases were identified in Fe(II)-containing $10 \%$ Portland cement extract solids: Portlandite, Friedel's salt, calcium aluminum silicate hydrate and calcium aluminum hydroxide hydrate. Significant amounts of Portlandite were detected due to $\mathrm{pH}$ adjustment of PCXFe solids. Like CPCXFe, peaks from Friedel's salts in three PCXFe solids were clearly observed with peaks at 3.9 and $3.8 \AA$. Addition of $\mathrm{Fe}(\mathrm{II})$ might facilitate the formation of Friedel's salts. Several peaks from Friedel's salt and calcium aluminum hydroxide hydrate were very close to each other 
due to their similar crystal structures. Thus, it was difficult to say whether Fe(II) was associated with Friedel's salt alone or with both solids, based on the sole observation of the appearance of Friedel's salt in PCXFe solids based on XRD analysis.

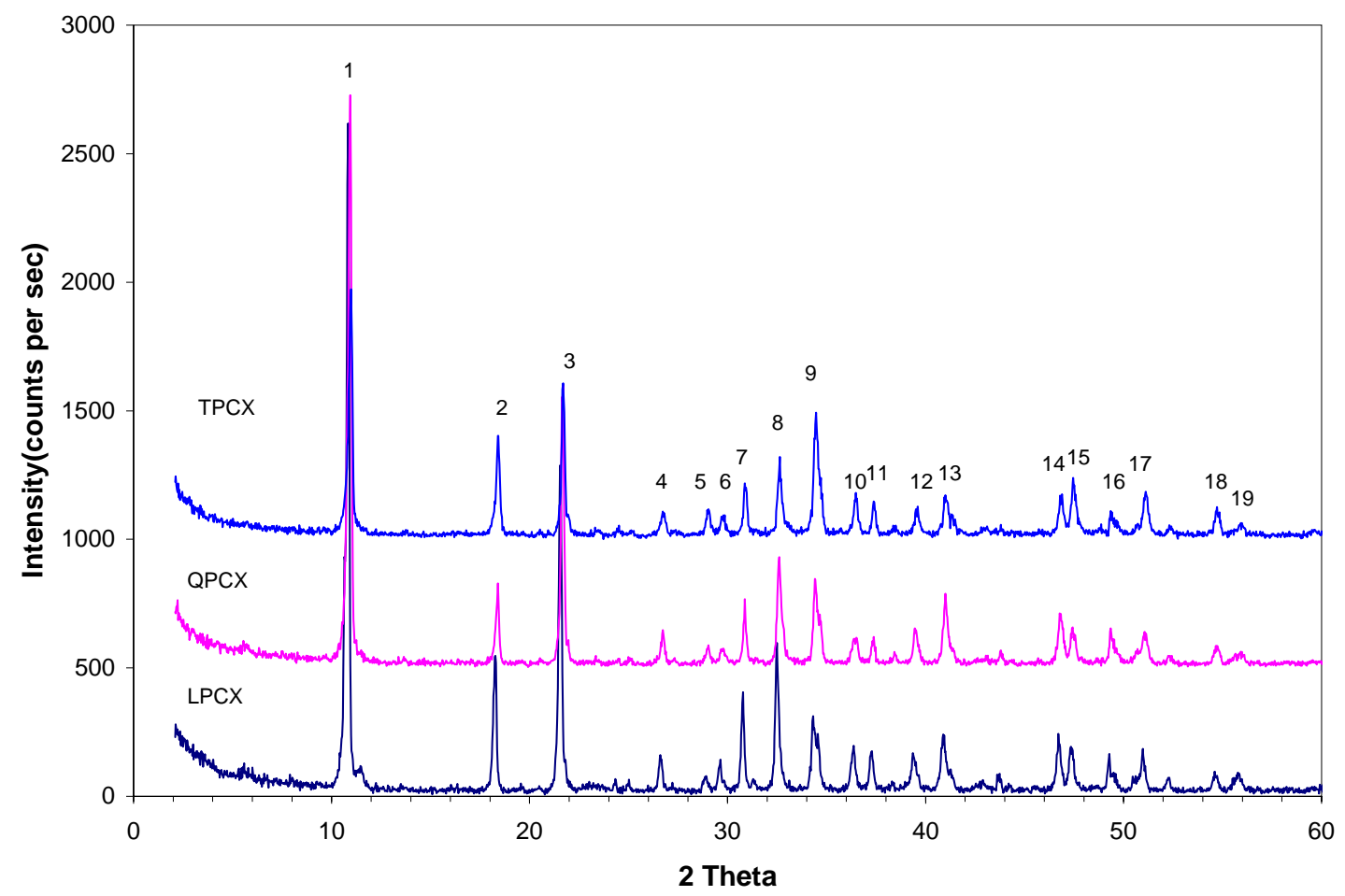

FIGURE 4-27 X-ray diffractograms of solids prepared with 10\% Portland cement extracts without $\mathrm{Fe}(\mathrm{II})$. Extracts were made from cements prepared by Txi (TPCX), Quikrete (QPCX), and Lehigh (LPCX). 
TABLE 4-16 Corresponding d-spacing values of peaks in Figure 4-27 and comparison to $\mathrm{CPCX}$, unit $=\AA$

\begin{tabular}{cccccc}
\hline Peak no & LPCX & QPCX & TPCX & CPCX & Possible solid \\
\hline 1 & 8.1626 & 8.0900 & 8.0734 & 8.5180 & CAH $^{\mathrm{a}}$ \\
2 & 4.8598 & 4.8205 & 4.8205 & 5.0067 & $\mathrm{P}^{\mathrm{b}}$ \\
3 & 4.1222 & 4.0996 & 4.0940 & 4.2186 & $\mathrm{CAH}$ \\
4 & 3.3472 & 3.3324 & 3.3251 & 3.4139 & $\mathrm{P}$ \\
& & & & 3.1997 & $\mathrm{CASH}^{\mathrm{c}}$ \\
5 & & & & 3.1443 & $\mathrm{P}, \mathrm{CASH}$ \\
6 & 3.0175 & 3.0755 & 3.0755 & 3.0662 & $\mathrm{CASH}$ \\
& & & 2.9997 & & $\mathrm{CASH}$ \\
7 & 2.9053 & 2.8943 & 2.8915 & 2.8955 & $\mathrm{CASH}$ \\
8 & 2.7536 & 2.7462 & 2.7437 & 2.7962 & $\mathrm{P}$ \\
9 & 2.6108 & 2.6042 & 2.6020 & 2.6483 & $\mathrm{P}$ \\
10 & 2.4709 & 2.4571 & 2.4630 & 2.5075 & $\mathrm{CAH}$ \\
11 & 2.4113 & 2.4057 & 2.4038 & 2.4442 & $\mathrm{CAH}$ \\
& & & & 2.3650 & \\
12 & 2.2857 & 2.2807 & 2.2757 & 2.3099 & $\mathrm{CAH}$ \\
13 & 2.2052 & 2.1990 & 2.1990 & 2.2317 & $\mathrm{CAH}$ \\
14 & 1.9431 & 1.9384 & 1.9384 & 1.9396 & $\mathrm{CAH}$ \\
15 & 1.9176 & 1.9141 & 1.9130 & & $\mathrm{P}$ \\
16 & 1.8483 & 1.8452 & 1.8441 & 1.8653 & CAH, CASH \\
17 & 1.7902 & 1.7863 & 1.7853 & 1.8051 & $\mathrm{P}$ \\
18 & 1.6786 & 1.6769 & 1.6752 & 1.6933 & P \\
19 & 1.6462 & & & 1.6598 & \\
\hline
\end{tabular}

${ }^{\mathrm{a}} \mathrm{CAH}=$ calcium aluminum hydroxide hydrate ${ }^{\mathrm{b}} \mathrm{P}=$ Portlandite

${ }^{\mathrm{c}} \mathrm{CASH}=$ calcium aluminum silicate hydrate 


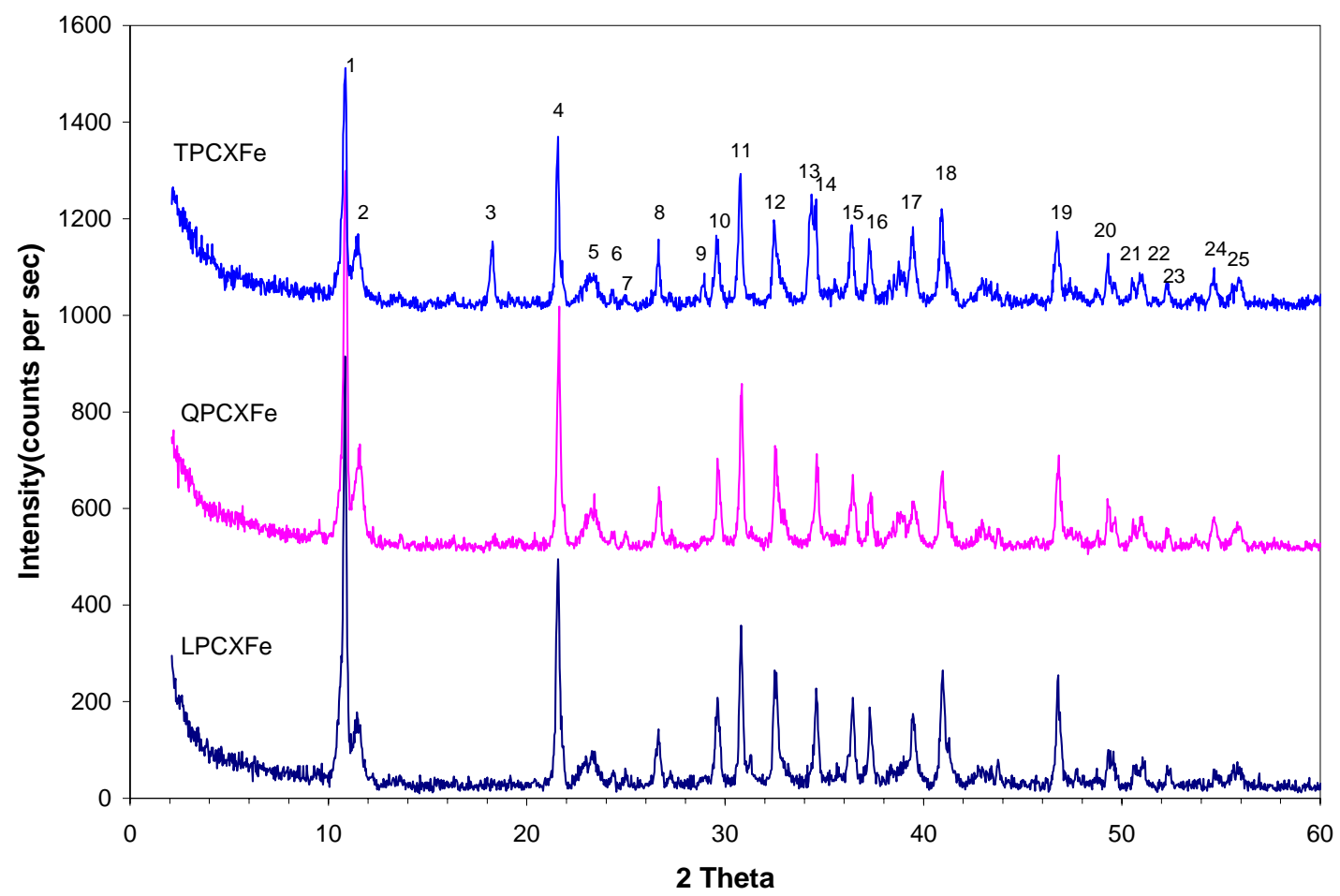

FIGURE 4-28 X-ray diffractogram of solids prepared with Fe(II) and 10\% Portland cement extracts prepared from cements made by Txi (TPCXFe), Quikrete (QPCXFe), and Lehigh (LPCXFe). 
TABLE 4-17 Corresponding d-spacing values of peaks in Figure 4-28 and comparison to those in CPCXFe, unit $=\AA$

\begin{tabular}{crrrcc}
\hline Peak no. & LPCXFe & QPCXFe & TPCXFe & CPCXFe & Possible solid \\
\hline 1 & 8.1626 & 8.1402 & 8.1852 & & CAH $^{\mathrm{a}}$ \\
2 & 7.7557 & 7.6356 & 7.7557 & 7.8653 & $\mathrm{FS}^{\mathrm{b}}$ \\
3 & & & 4.8598 & 4.9567 & $\mathrm{P}^{\mathrm{c}}$ \\
4 & 4.1222 & 4.1109 & 4.1222 & & $\mathrm{CAH}$ \\
5 & 4.0662 & 4.0552 & 4.0772 & & $\mathrm{CAH}$ \\
6 & 3.8920 & 3.8325 & 3.8423 & 3.9047 & $\mathrm{FS}$ \\
7 & 3.8082 & 3.7938 & 3.7986 & 3.8179 & $\mathrm{FS}$ \\
8 & 3.3435 & 3.3398 & 3.3435 & 3.3358 & $\mathrm{P}$ \\
9 & & & 3.0880 & 3.1534 & $\mathrm{P}$ \\
10 & 3.0115 & 3.0115 & 3.0175 & & $\mathrm{CASH}^{\mathrm{d}}$ \\
11 & 2.9025 & 2.8998 & 2.9053 & 2.9187 & $\mathrm{CASH}$ \\
12 & 2.7511 & 2.7511 & 2.7560 & 2.7662 & $\mathrm{CASH}$ \\
13 & & & 2.6130 & 2.6226 & $\mathrm{P}$ \\
14 & 2.5911 & 2.5885 & 2.5932 & & \\
15 & 2.4656 & 2.4617 & 2.4676 & 2.4781 & $\mathrm{CAH}$ \\
16 & 2.4082 & 2.4082 & 2.4100 & 2.3481 & FS, CAH \\
17 & 2.2812 & 2.2796 & 2.2829 & & FS \\
18 & 2.2011 & 2.2042 & 2.2042 & & FS, CAH \\
19 & 1.9411 & 1.9411 & 1.9423 & 1.9256 & $\mathrm{P}$ \\
20 & 1.8466 & 1.8466 & 1.8476 & & CAH, CASH \\
21 & 1.8005 & 1.8035 & 1.8045 & & CAH \\
22 & 1.7867 & 1.7896 & 1.7906 & 1.7925 & $\mathrm{P}$ \\
23 & 1.7484 & 1.7468 & 1.7484 & & FS \\
24 & 1.6772 & 1.6781 & 1.6789 & & FS, CAH \\
25 & 1.6448 & 1.6416 & 1.6432 & & FS \\
\hline
\end{tabular}

${ }^{\mathrm{a}} \mathrm{CAH}=$ calcium aluminum hydroxide hydrate

${ }^{\mathrm{b}} \mathrm{FS}=$ Friedel's salt

${ }^{\mathrm{c}} \mathrm{P}=$ Portlandite

${ }^{\mathrm{d}} \mathrm{CASH}=$ calcium aluminum silicate hydrate 
Figures 4-29 through 4-33 show SEM images and EDS spectra for TPCXFe, QPCXFe, and LPCXFe solids. EDS spectra of three PCXFe solids were taken from a certain region within a single hexagonal particle. Solids with hexagonal shapes were observed in all three $\mathrm{Fe}(\mathrm{II})$-containing 10\% cement extract solids, like CPCXFe. Although individual particle shape was not clearly observed in QPCXFe and LPCXFe, particle sizes of QPCXFe and LPCXFe solids were around 0.5 to $1 \mu \mathrm{m}$ and TPCXFe solids were around $5 \mu \mathrm{m}$. Aggregated small hexagonal particles were observed next to a large hexagonal particle in Figure 4-29. The size of small particles was much smaller than in PCSFe solids (3 to $7 \mu \mathrm{m}$ ) and it was similar to sizes observed in PCXFe solids (0.3 to $1 \mu \mathrm{m})$.

EDS spectra results showed that the major elements in Fe(II)-containing cement extract solids were $\mathrm{Ca}, \mathrm{Cl}, \mathrm{Al}$, and $\mathrm{Fe}$. Low amounts of $\mathrm{Si}$ and $\mathrm{Mg}$ were also detected. High amounts of $\mathrm{Cl}$ in all solids came from a high concentration of $\mathrm{HCl}$ used to digest the cement to produce the extract. The particle shown in Figure 4-29 was probably Portlandite based on EDS spectra and a bigger particle size. In general, the particle size of Friedel's salts was around 2 to $3 \mu \mathrm{m}$ and the size of tetra-calcium aluminum hydrates was around $1 \mu \mathrm{m}$ or less than $1 \mu \mathrm{m}$. Portlandite was a bigger particle, with sizes up to $100 \mu \mathrm{m}(42,65)$.Calcium aluminum hydroxide hydrates probably were shown as aggregates of smaller particles. Based on the particle size comparison, the major solid phases in TPCXFe, QPCXFe, and LPCXFe were calcium aluminum hydroxide hydrates rather than Friedel's salt, which was the dominant solid, phase in CPCXFe. 


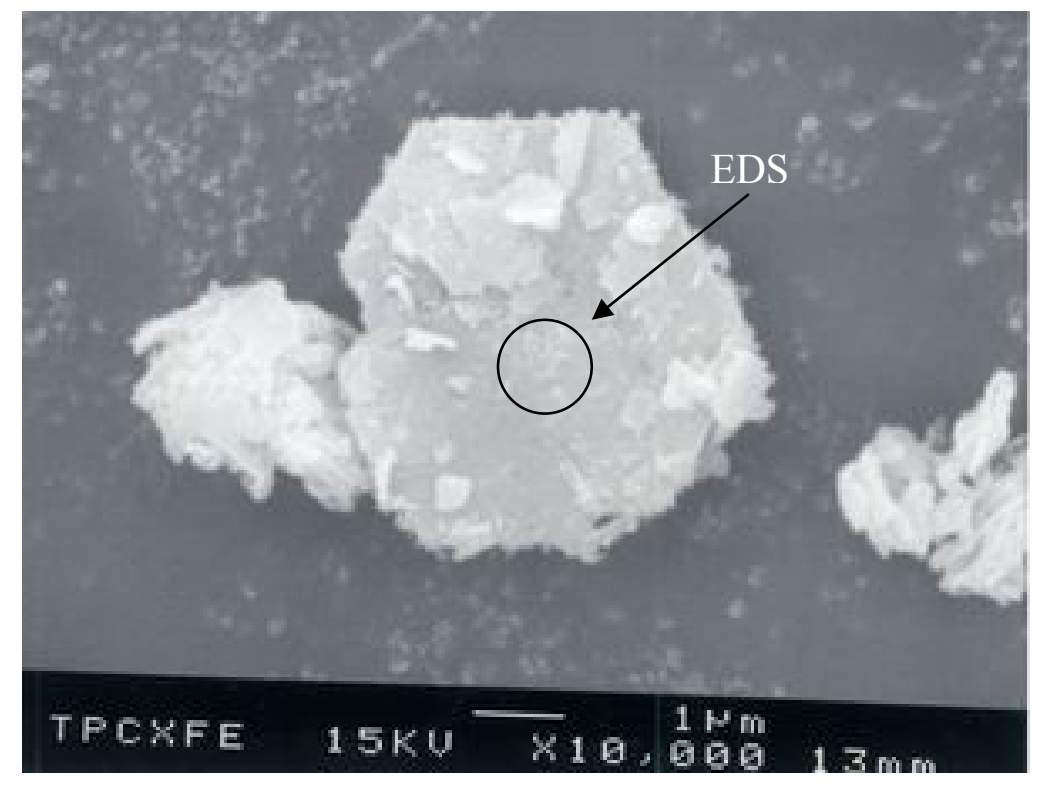

Txi Cement Extract with Fe(II):TPCXFE

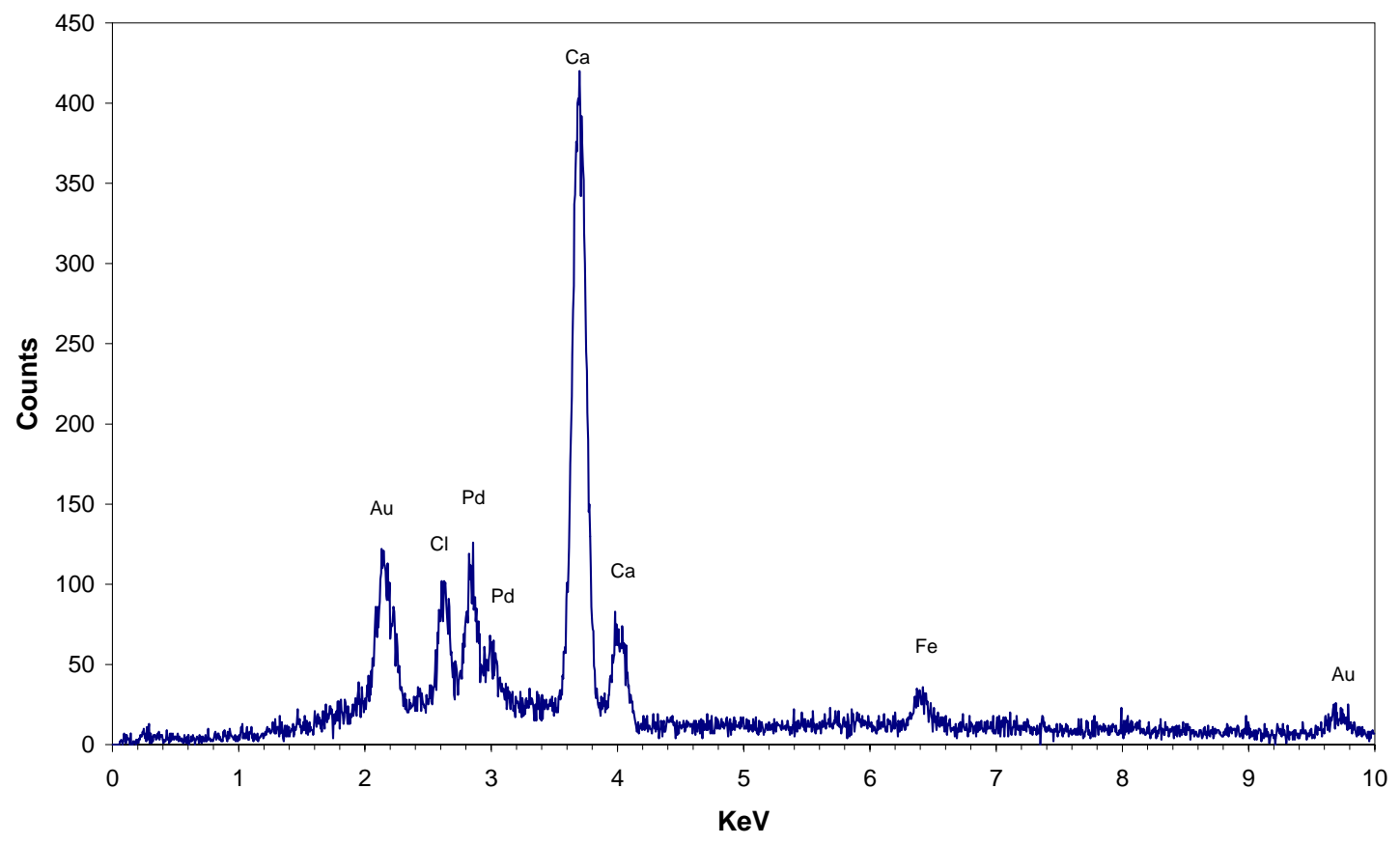

FIGURE 4-29 SEM image and EDS of solids prepared with Fe(II) and 10\% Txi cement extract. 


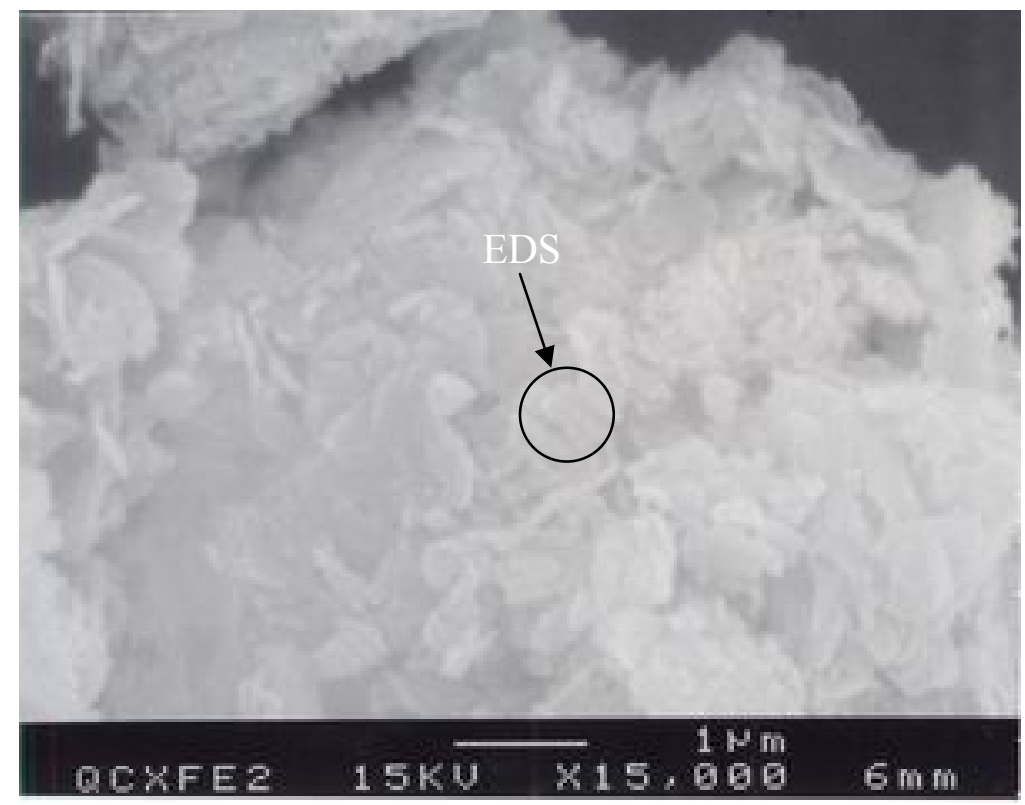

Quikrete Cement Extract with Fe(II):QCXFE2

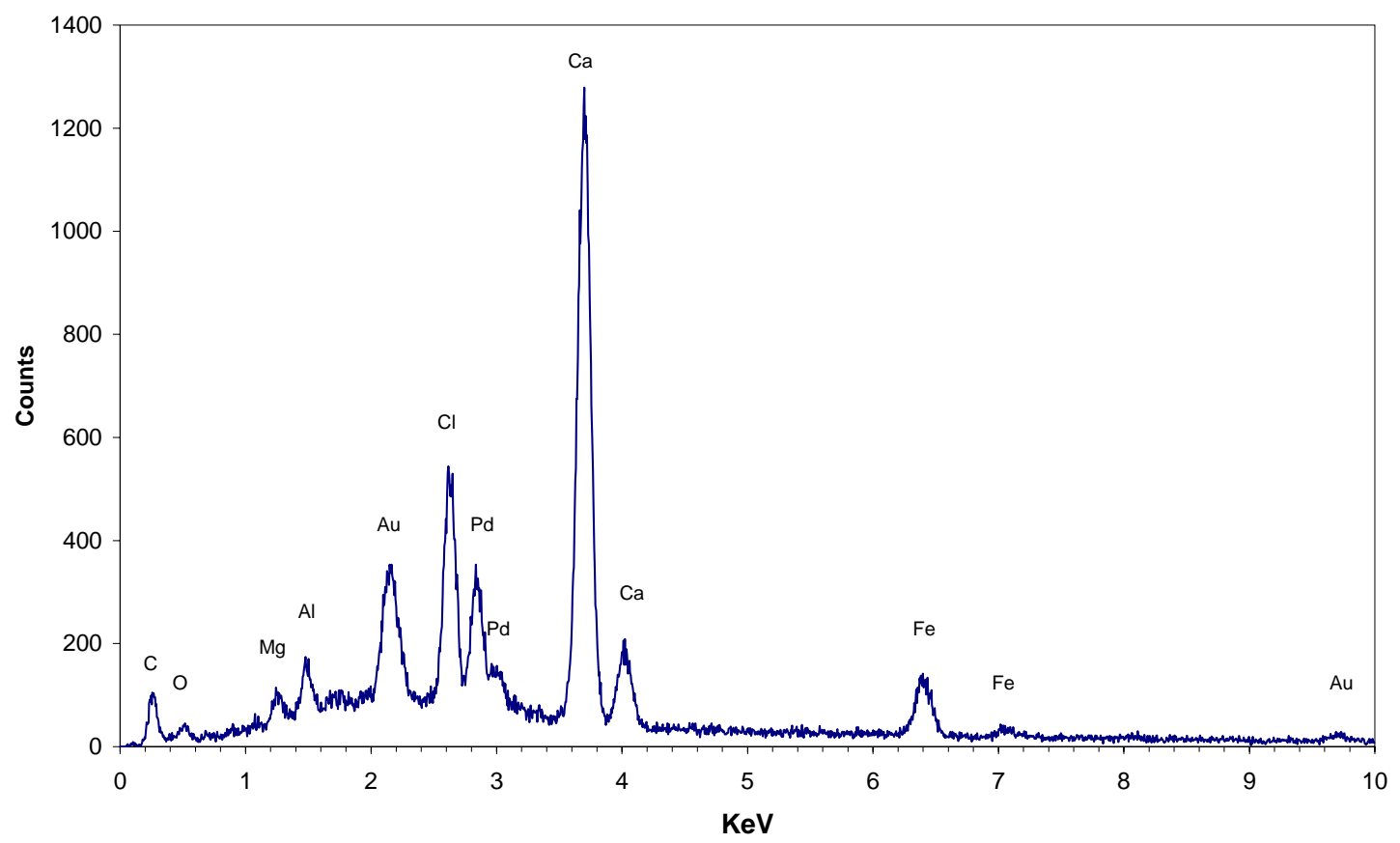

FIGURE 4-30 The first SEM image and EDS of solids prepared with Fe(II) and $10 \%$ Quikrete cement extract. 


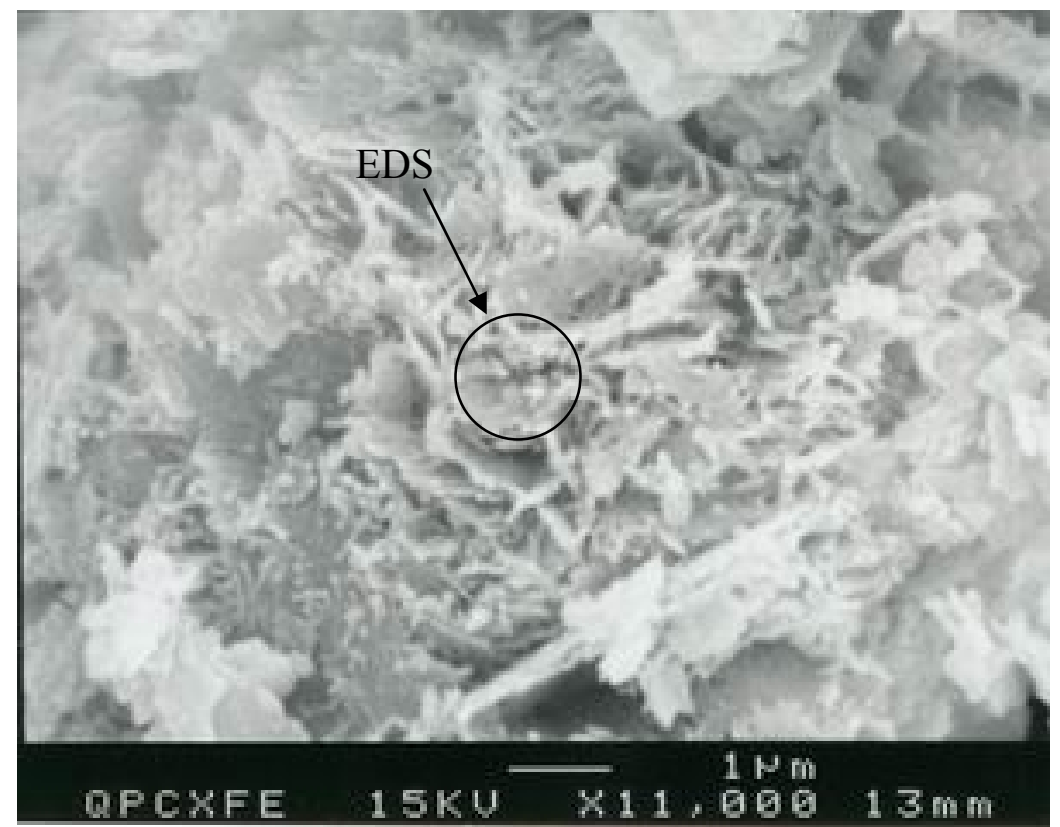

Quikrete Cement Extract with Fe(II):QCXFE

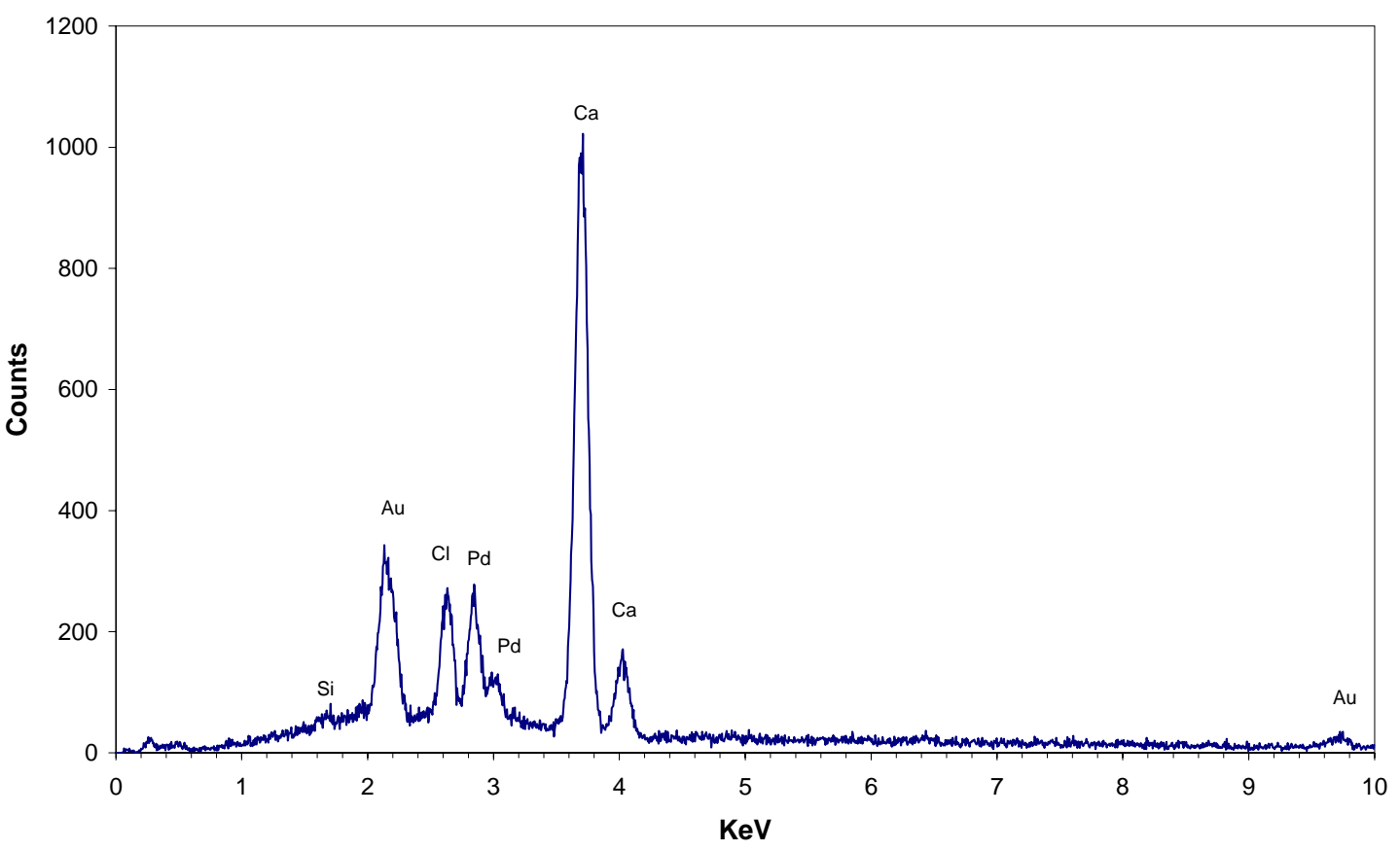

FIGURE 4-31 The second SEM image and EDS of solids prepared with Fe(II) and 10\% Quikrete cement extract. 


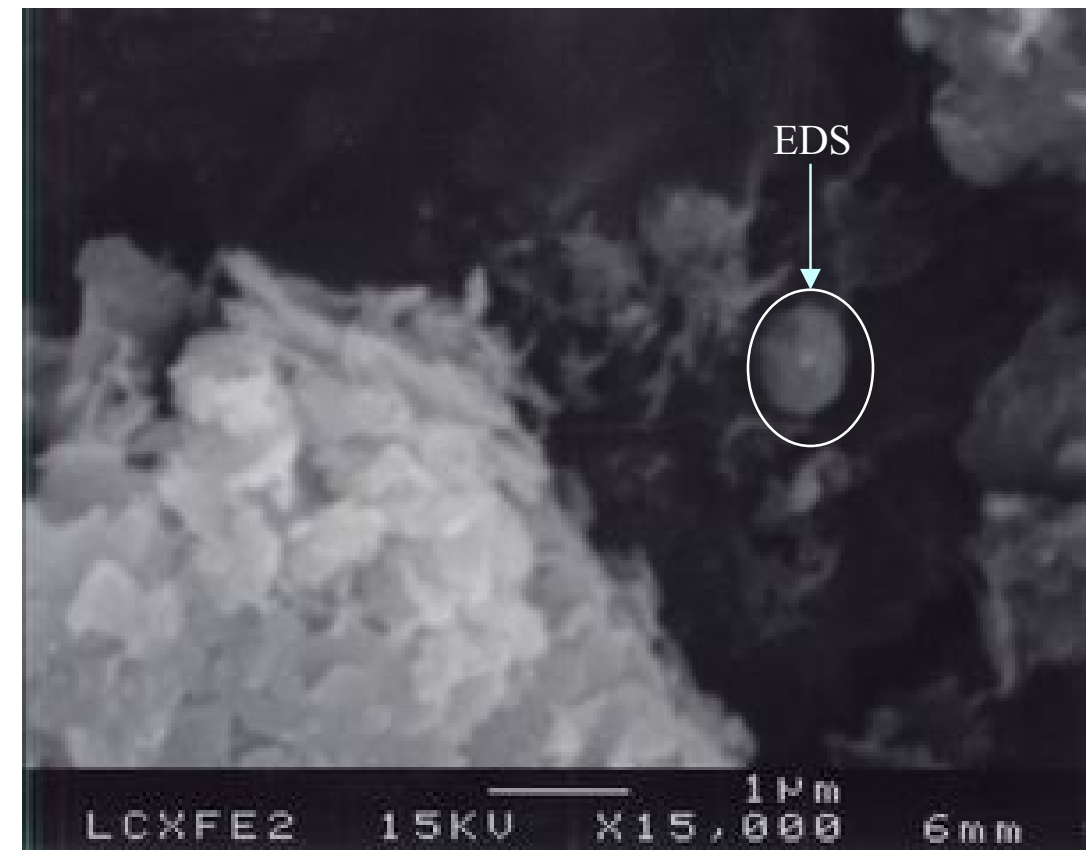

Lehigh Cement Extract with Fe(II):LCXFE2

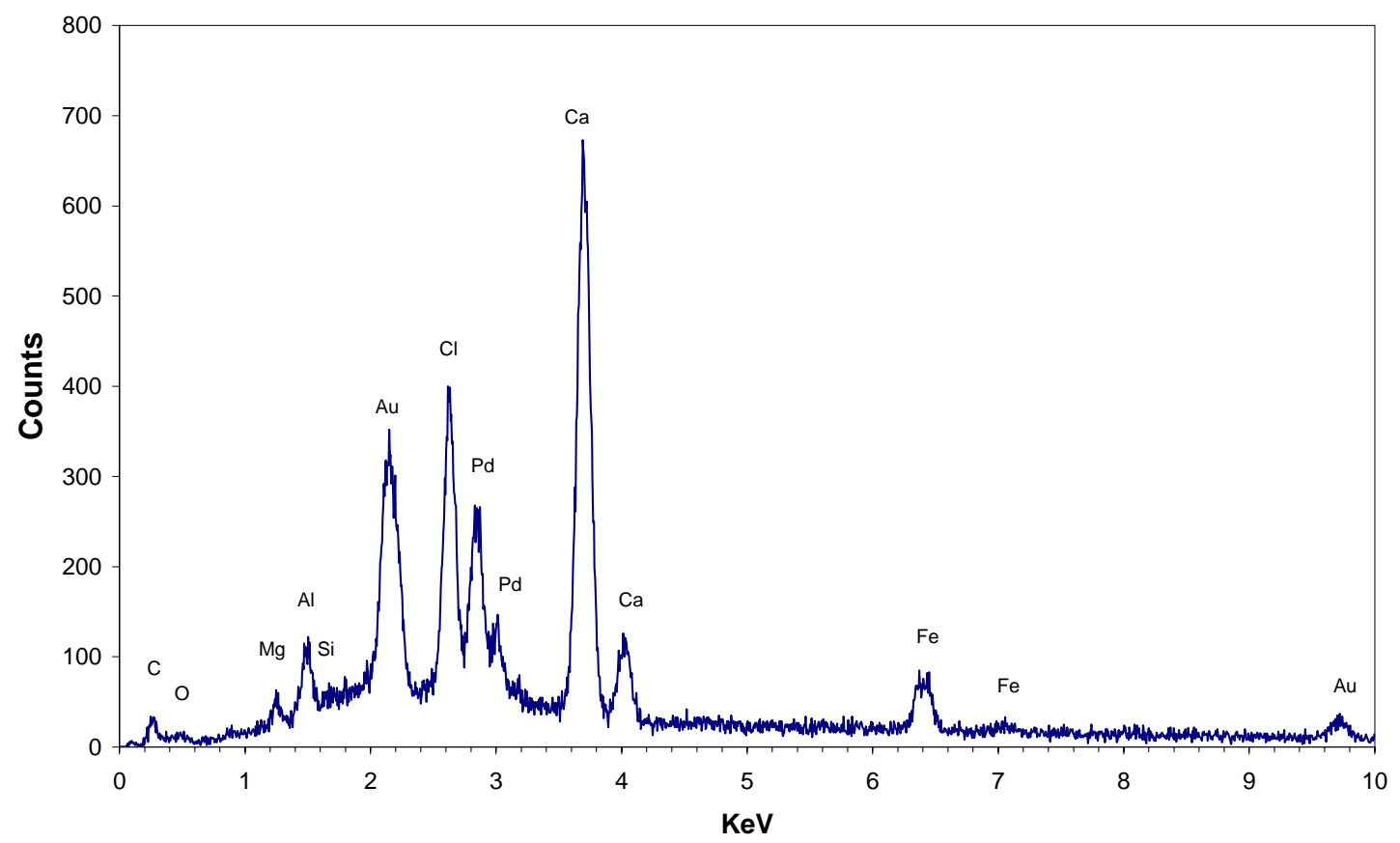

FIGURE 4-32 The first SEM image and EDS of solids prepared with Fe(II) and 10\% Lehigh cement extract. 


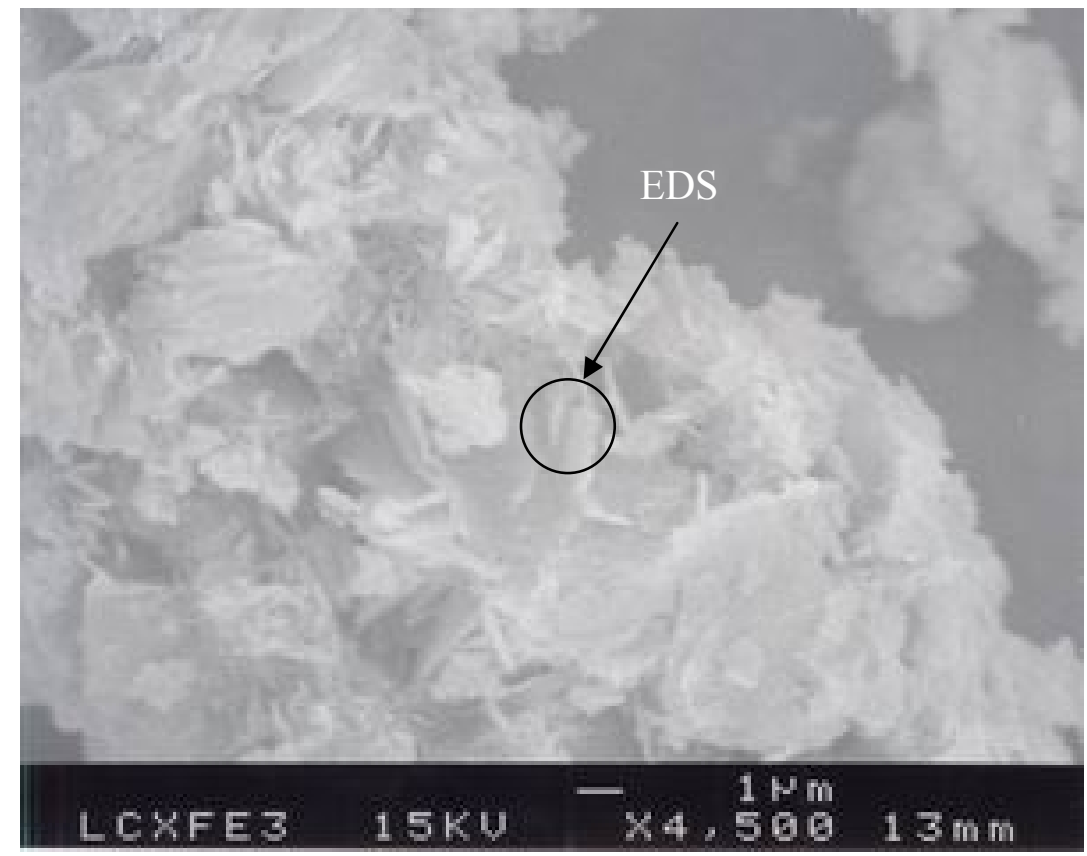

Lehigh Cement Extract with Fe(II):LCXFE3

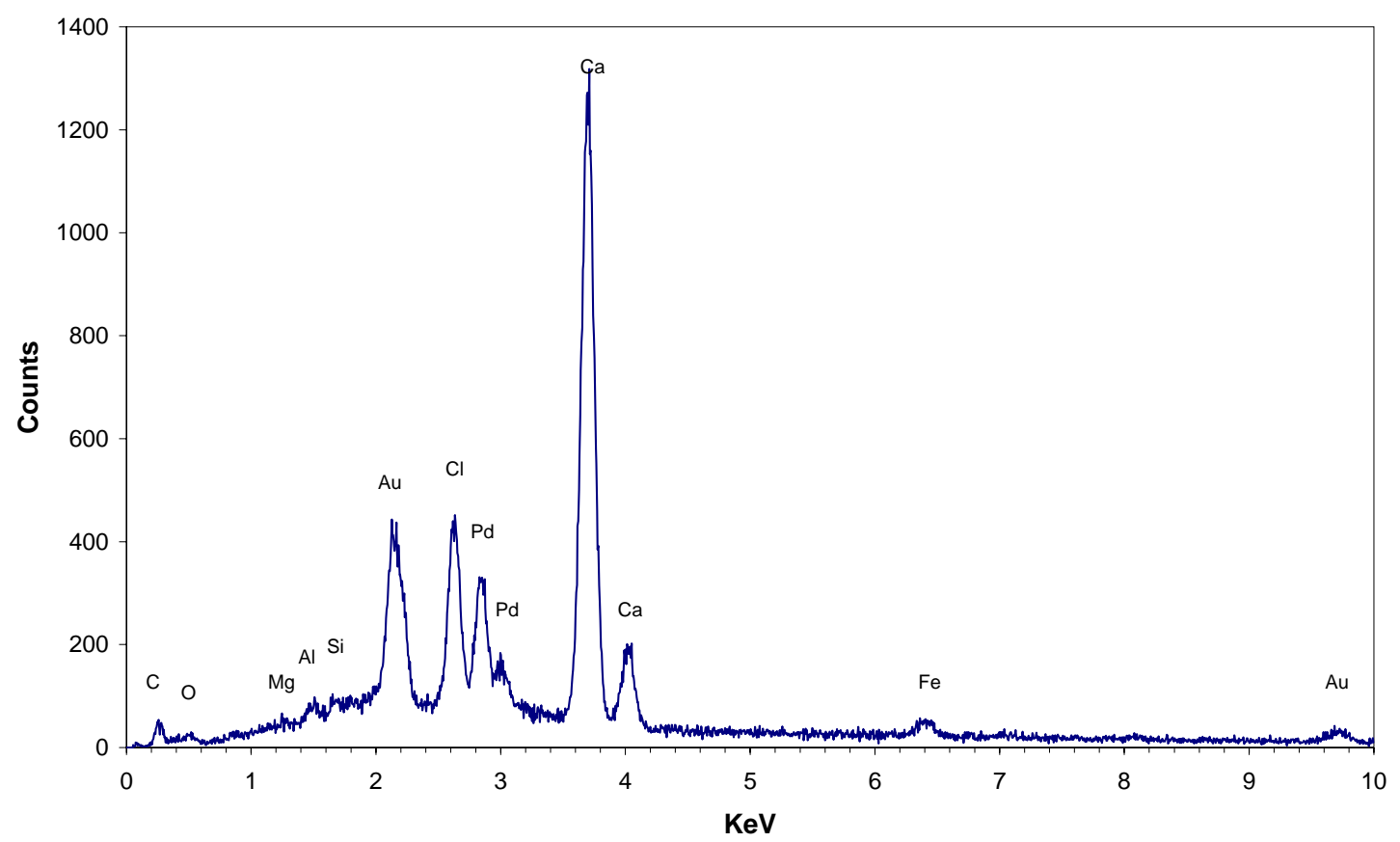

FIGURE 4-33 The second SEM image and EDS of solids prepared with Fe(II) and 10\% Lehigh cement extract. 
Interestingly, a much smaller amount of $\mathrm{Fe}$ was found in EDS spectra for solids prepared from Lehigh extract (Figure 4-33) and no Fe was detected for solids prepared from Quikrete extracts (Figure 4-31), where hexagonal shape particles were not observed. These pictures probably showed type II calcium silicate hydrate (C-S-H) (41). Figure 4-31 and 4-33 supported the supposition that Fe is preferably associated with hexagonal particles. Although it could not be known if Fe was adsorbed or substituted, it was clearly shown that hexagonal solids are associated with Fe. 


\section{CHAPTER V}

\section{SUMMARY AND CONCLUSION}

Fe(II)-based degradative solidification/stabilization (Fe(II)-DS/S) technology has been developed as a modification of conventional $\mathrm{S} / \mathrm{S}$ treatment. While inorganic contaminants are contained, organic contaminants, such as chlorinated aliphatic compounds, are degraded by $\mathrm{Fe}(\mathrm{II})-\mathrm{DS} / \mathrm{S}$. The goal of this research was to identify the active agents for PCE degradation during $\mathrm{Fe}(\mathrm{II})-\mathrm{DS} / \mathrm{S}$ and to determine the conditions that promote the formation of this active agents.

Experiments designed to identify the preferable conditions for the formation of active agents showed that the most essential elements in active agents were $\mathrm{Fe}(\mathrm{II})$, $\mathrm{Fe}(\mathrm{III})$, and $\mathrm{Cl}$. Pseudo first-order rate constants normalized by $\mathrm{Fe}(\mathrm{II})\left(\mathrm{k}_{\mathrm{Fe}(\mathrm{II})}\right)$ and solid concentrations $\left(\mathrm{k}_{\text {solid }}\right)$ for solids synthesized with a mixture of $\mathrm{Fe}(\mathrm{II}), \mathrm{Fe}(\mathrm{III})$, and $\mathrm{Cl}$ (identified as $\mathrm{Fe}(\mathrm{II})(\mathrm{III}) \mathrm{Cl})$ were $1.3 \times 10^{-3}(\mathrm{mM} \mathrm{Fe}(\mathrm{II}) \cdot \text { day })^{-1}$ and $3.8 \times 10^{-3} \mathrm{~L} \cdot($ day $\cdot \mathrm{g}$ of solid) ${ }^{-1}$, respectively. The value of $\mathrm{k}_{\mathrm{Fe}(\mathrm{II})}$ for solids produced with full cement extract elements (FSCX) was the same order of magnitude, $\left(6.1 \times 10^{-3}(\mathrm{mM} \mathrm{Fe}(\mathrm{II}) \cdot \text { day })^{-1}\right)$ as that for $\mathrm{Fe}(\mathrm{II})(\mathrm{II}) \mathrm{Cl}$. The value of $\mathrm{k}_{\text {solid }}$ was one order magnitude lower $\left(9.7 \times 10^{-4} \mathrm{~L} \cdot(\right.$ day $\cdot \mathrm{g}$ of solid $)^{-1}$ ) than that for Fe(II)(III)Cl. The lower value of $\mathrm{k}_{\text {solid }}$ for FSCX might be caused by higher amounts $\mathrm{NaOH}$ added to increase $\mathrm{pH}$. Solids formed in synthetic cement extract had one order magnitude less activity in terms of $\mathrm{k}_{\mathrm{Fe}(\mathrm{II})}$ than solids formed in Fe(II) containing Portland cement extract (Fe(II)-PCX) solids. Solids produced in the mixture of $\mathrm{Fe}(\mathrm{II})$ and/or $\mathrm{Fe}(\mathrm{III})$ and cement hydration products; especially $\mathrm{AFm}$ phases, 
such as Friedel's salts, monosulfates, and tetracalcium aluminates; also showed about one to two orders of magnitude lower $\mathrm{k}_{\mathrm{Fe}(\mathrm{II})}$ values than $\mathrm{Fe}(\mathrm{II})-\mathrm{PCX}$.

Although Fe(II)-PCX solids might be a mixture of active and inactive solids, they had higher activity than FSCX and Fe(II)-cement hydration product solids that should have been more pure than Fe(II)-PCX solids. Those experiments showed that the conditions of the mixture of Fe(II) and either FSCX or cement hydration product might not produce the same active agents as Fe(II)-PCX solids for PCE degradation. XRD analyses of $\mathrm{Fe}(\mathrm{II})-\mathrm{PCS}$ and Fe(II)-PCX solids showed that Fe(II) facilitated the formation of Friedel's salts in those system. The effect of Friedel's salt on PCE degradation was evaluated in experiments where Fe(II) was mixed with Friedel's salt that had been formed in advance. These conditions might be different from those used when Fe(II) was added to PCS and PCX. In addition, SEM images and XRD analyses showed that solids formed in FSCX were different from those formed from PCX and PCS. Furthermore, EDS spectra indicate that FSCX solids were mainly composed of Ca and a little bit of $\mathrm{Fe}, \mathrm{Cl}, \mathrm{Al}$, and Si. Although many other elements were added to synthesize active solids, these elements were not involved to form FSCX solids. Simply mixing all components might not be the best condition for formation of active solids. Elemental compositions of the mixtures and the conditions affecting solid formation might be the most important factors in determining how active solids are formed.

In addition, $\mathrm{Ca}$ might be also an important element in affecting formation an active agent in addition to $\mathrm{Fe}(\mathrm{II}), \mathrm{Fe}(\mathrm{III})$, and $\mathrm{Cl}$. PCE degradation kinetics using solids formed from $\mathrm{PCX}$ after $\mathrm{Ca}$ was removed were different from experiments using 
untreated PCX and Fe(II)-DS/S. The effects of $\mathrm{pH}$ and cement extract content of $\mathrm{Ca}$ treated PCX (CPCX) were different behaviors from Fe(II)-DS/S (23) and less activity than untreated PCX. $\mathrm{k}_{\mathrm{Fe}(\mathrm{II})}$ values of CPCX increased with $\mathrm{pH}$ up to 11.5 , sharply decreased and then continued to increase up to $\mathrm{pH} 13$ while the effect of $\mathrm{pH}$ on rate constants for PCE degradation of $\mathrm{Fe}(\mathrm{II})-\mathrm{DS} / \mathrm{S}$ fitted well with a normal distribution function with optimal $\mathrm{pH}$ of 12.1 (23). PCE degradation rates of CPCX were less affected by cement extract contents than those of PCX. Even though PCE degradation did not occur without $\mathrm{Fe}(\mathrm{II})$, Ca might be another element of an active agent so that solids formed in the absence of $\mathrm{Ca}$ would have different activities compared to those formed in the presence of $\mathrm{Ca}$. Instrumental analyses showed that $\mathrm{Fe}(\mathrm{II})(\mathrm{III}) \mathrm{Cl}$ and MSCX solids, where Ca was not included, were different from Fe(II)-PCX and Fe(II)PCS solids. Ferrous hydroxides were identified in Fe(II)(III)Cl and MSCX systems by XRD analysis. Fe(II)-PCX and Fe(II)-PCS solids were mainly composed of calcium aluminum hydroxide hydrate, calcium aluminum silicate hydrate, and Friedel's salt. They were composed of $\mathrm{Ca}, \mathrm{Fe}, \mathrm{Cl}, \mathrm{Al}$ and $\mathrm{Si}$ while $\mathrm{Fe}$ and $\mathrm{Cl}$ were main elements of $\mathrm{Fe}(\mathrm{II})(\mathrm{III}) \mathrm{Cl}$ and MSCX solids. Particle sizes were also different. $\mathrm{Fe}(\mathrm{II})(\mathrm{III}) \mathrm{Cl}$ and MSCX solids were much smaller (less than a micron) than Fe(II)-PCX and Fe(II)-PCS solids (a few microns).

An interesting phenomenon found by analysis of SEM images and EDS spectra was that Fe tended to be associated with hexagonal thin plate particles, which were supposed to be a LDH. Fe contents in particles with different shapes were low or below detection limits. This supports the hypothesis that active agents in Fe(II)-DS/S system is 
a LDH, which includes AFm phases. It cannot be determined whether Fe was structural or adsorbed onto the surface of the AFm phases. However, it does limit number of possible active agents in $\mathrm{Fe}(\mathrm{II})-\mathrm{DS} / \mathrm{S}$ system. Moreover, solid particle sizes of $\mathrm{Fe}(\mathrm{II})(\mathrm{III}) \mathrm{Cl}$ solids synthesized at $\mathrm{pH} 12$ were 10 to 20 times smaller than those at neutral $\mathrm{pH}$. This might indicate that the high surface area of solids were responsible for the high solid activity at high $\mathrm{pH}$ in $\mathrm{Fe}(\mathrm{II})-\mathrm{DS} / \mathrm{S}$ system.

Finally, kinetic experiments designed to examine the variation of ordinary Portland cement (OPC) showed different PCE degradation behaviors with each OPC. Solids from cement slurries containing Fe(II) and made with Capitol, Txi and Lehigh cements (CPCSFe, TPCSFe, and LPCSFe) followed pseudo first-order kinetics while those made from Quikrete cement (QPCSFe) followed second-order kinetics. Solids made by adding Fe(II) to extracts of Capitol and Txi (CPCXFe and TPCXFe) followed pseudo first-order kinetics, while those made from Lehigh and Quikrete cement extract solids (LPCXFe and QPCXFe) followed the second-order kinetics. TCE was detected in LPCSFe, QPCSFe, LPCXFe, and QPCXFe. Slurries with Fe(II) made from four different cements formed the same kind of solids, although their kinetic behaviors were different. This might be caused by different compositions of the cements, such as different $\mathrm{Fe}(\mathrm{II})$ to $\mathrm{Fe}(\mathrm{III})$ ratios. In the case of solids made from extracts, the main solid phases might be different because of their different particle sizes. Calcium aluminum hydroxide hydrates dominated solids made with Txi, Quikrete, and Lehigh cements and their particle sizes were $1 \mu \mathrm{m}$ or less. However, Friedel's salt was the major phase found in solids made with Capitol cements and had particle sizes in the range of 2 to $3 \mu \mathrm{m}$. 
The experimental studies presented here indicate that possible active agents in $\mathrm{Fe}(\mathrm{II})-\mathrm{DS} / \mathrm{S}$ system are a type of AFm phases, either tetracalcium aluminate or Friedel's salt. This is based on the observation that Fe(II) added to cement slurries or extracts is likely to be associated with particles that are thin hexagonal plates. However, it has not been determined if the Fe(II) is structural or adsorbed.

Although instrumental analyses indicate that AFm phases might be the possible active agents in $\mathrm{Fe}(\mathrm{II})-\mathrm{DS} / \mathrm{S}$, solid activity tests were unable to confirm this. This might result from differences between simulated and real conditions for the formation of active agents. Therefore, the first step of future research should be concentrated on the identification of desired conditions of the formation of active agents without cement. The second step should concentrate on developing both qualitative and quantitative solid analysis techniques that could be used to identify active agents more precisely. Finally, characterization of active agents and elucidation of dechlorination mechanism in Fe(II)DS/S system will be necessary to apply identified active agents to various contaminated systems, such as soil, groundwater, or wastewater. 


\section{LITERATURE CITED}

1. LaGrega, M. D.; Buckingham, P. L.; Evans, J. C. Hazardous Waste Management; McGraw-Hill: New York, 1994

2. U.S. EPA Common Chemicals Found at Superfund Sites; EPA 540/R-94/044; Office of Emergency and Remedial Response: Washington, DC, 1994.

3. U.S. Department of Health and Human Services, Public Health Service. Agency for Toxic Substances and Disease Registry (ASTDR) Toxicological Profile for Tetrachloroethylene; Atlanta, GA, September, 1997, retrieved at URL http://www.atsdr.cdc.gov/toxprofiles/phsl8.html

4. Federal Remediation Technologies Roundtable. Remediation Technologies Screening Matrix and Reference Guide, Version 4.0, retrieved at URL http://www.frtr.gov

5. Birnbaum, L.; Burke, T.; Carberry, J. B.; Clark, E.; Daisey, J. et al. Environ. Sci. Technol. 1996, 30, 24A-44A

6. Cudahay, J. Thermal Destruction. Seminar/Workshop on Innovative Site Remediation Technologies; American Academy of Environmental Engineers: Annapolis, MD, 1994

7. Vogel, R. M.; Craddle, C. S.; McCarty, P. L. Environ. Sci. Technol. 1987, 21, 722736

8. Macalady, D. L. J. Contam. Hydrol. 1986, 1, 1-28

9. Tsukano Y. J. Contam. Hydrol. 1986, 1, 47-63 
10. Kriegman-King, M. R.; Reinhard, M. Environ. Sci. Technol. 1994, 28, 692-700

11. Kriegman-King, M. R.; Reinhard, M. Environ. Sci. Technol. 1992, 26, 2198-2206

12. Amonette, J. E.; Szecsody, J. E.; Schaef, H. T.; Templeton, J. C.; Gorby, Y. A.; Fruchter, J. S. Abiotic Reduction of Aquifer Materials by Dithoinite: A Promising In-situ Remediation Technology. $33^{\text {rd }}$ Hanford Symposium on Health and the Environment, November 7-11, 1994, Pasco, WA; Battelle Press: Columbus, OH, 1994; pp851-881

13. Arnold, W. A.; Roberts, A. L. Environ. Sci. Technol. 2000, 34, 1794-1805

14. Johnson, T. J.; Scherer, M. M.; Tratnyek, P. G. Environ. Sci. Technol. 1996, 30, 2634-2640

15. Zhang, W-X.; Wang, C-B.; Lien, H-L. Catal. Today, 1998, 40, 387-395

16. Fennelly, J. P; Roberts, A. L. Environ. Sci. Technol. 1998, 32, 1980-1988

17. Kim, Y-H.; Carraway, E. R. Envniron. Sci. Technol. 2000, 34, 2014-2017

18. Doong, R-A.; Chen, K-T.; Tsai, H-C. Envniron. Sci. Technol. 2003, 37, 2575-2581

19. Roberts, A. L.; Totten, L. A.; Arnold, W. A.; Burris, D. R.; Campbell, T. J. Environ. Sci. Technol. 1996, 30, 2654-2659

20. Scherer, M. M.; Balko, B. A.; Gallagher, D. A.; Tratnyek, P. G. Environ. Sci. Technol. 1998, 32, 3026-3033

21. Arnold, W. A.; Roberts, A. L. Environ. Sci. Technol. 1998, 32, 3017-3025

22. Arnold, W. A.; Ball, W. P.; Roberts, A. L. J. Contam. Hydrol. 1999, 40, 183-200

23. Hwang, I.; Batchelor, B. Environ. Sci. Technol. 2000, 34, 5017-5022

24. Hwang, I.; Batchelor, B. Chemosphere, 2002, 48, 1019-1027 
25. Jung, B.; Batchelor, B. Transformation of 1,1,1,-trichloroethane by Fe(II) in Cement Slurries. In The $4^{\text {th }}$ Proceedings of the International Conference on Remediation of Chlorinated and Recalcitrant Compounds, May 24-27, 2004, Monterey, CA; in press

26. Erbs, M.; Hansen, H. C. B.; Olsen, C. E. Environ. Sci. Technol. 1999, 33, 307-311

27. Lee, W.; Batchelor, B. Environ. Sci. Technol. 2002, 36, 5348-5354

28. O’Loughin, E. J.; Kemner, K. M.; Burris, D. R. Envoron. Sci. Technol. 2003, 37, $2905-2912$

29. Choi, J.; Batchelor, B. Methods for Producing High-Activity Modified Green Rusts. In The $4^{\text {th }}$ Proceedings of the International Conference on Remediation of Chlorinated and Recalcitrant Compounds, May 24-27, 2004, Monterey, CA; in press

30. Butler, E. C.; Hayes, K. F. Environ. Sci. Technol. 2000, 34, 422-429

31. Butler, E. C.; Hayes, K. F. Environ. Sci. Technol. 1998, 32, 1276-1284

32. Butler, E. C.; Hayes, K. F. Environ. Sci. Technol. 1999, 33, 2021-2027

33. Jeong, H. Y.; Hayes, K. F. Environ. Sci. Technol. 2003, 37, 4650-4655

34. Gander, J. W.; Parkin, G. F.; Scherer, M. M. Environ. Sci. Technol. 2002, 36, 45404546

35. Weerasooriya, R.; Dharmasena, B. Chemosphere, 2001, 42, 389-396

36. Lee, W.; Batchelor, B. Environ. Sci. Technol. 2002, 36, 5147-5154

37. Mccormick, M. L.; Adrianens, P. Environ. Sci. Technol. 2004, 38, 1045-1053

38. Maithreepala, R. A.; Doong, R-A. Environ. Sci. Technol. 2004, 38, 260-268

39. Reinhard, M.; Curtis, G. P.; Kriegman, M. R. Abiotic Reductive Dechlorination of Carbon Tetrachloride and Hexachloroethane by Environmental Reductans; 
EPA/600/S2-90/040; United States Environmental Protection Agency: Ada, OK, September, 1990

40. Kriegman-King, M. R.; Reinhard, M. Envniron. Sci. Technol. 1992, 26, 2198-2206

41. Talyor, H. F. W. Cement Chemistry, $2^{\text {nd }}$ ed; Thomas Telford: London, England, 1997

42. St John, D. A.; Poole, A.W.; Sims, I. Concrete Petrography, Arnold: London, England, 1998

43. Stutzman, P. Chemistry and Structure of Hydration Products. In Cements Research Progress; American Ceramic Society: Columbus, OH, 1998; pp 29-65

44. Glasser, F. P. Chemistry of Cement-Solidified Waste Forms. In Chemistry and Microstructure of Solidified Waste Forms; Spence, R. D., Ed; Lewis Publishers: Boca Raton, FL, 1993

45. Csizmadia, J.; Balazs, G.; Tamas, F. D. Cem. Concr. Res. 2001, 31, 577-588

46. Suryavanshi, A. K.; Scantlebury, J. D.; Lyon, S. B. Cem. Concr. Res. 1995, 25, 581592

47. Birnin-Yauri, U. A.; Glasser, F. P. Cem. Concr. Res. 1998, 28, 1713-1723

48. Czernin, W. Cement Chemistry and Physics for Civil Engineers, $2^{\text {nd }}$ English ed; George Godwin Ltd: London, England, 1980

49. Copeland, L. E.; Kantro, D. L. Chemistry of Hydration of Portland Cement at Ordinary Temperature. In The Chemistry of Cements, Academy Press: London, England, 1964; Vol. 1, pp313-370

50. Rapin, J-P.; Walcarius, A.; Lefevre, G.; Francois, M. Acta Cryst. 1999, C55, 19571959 
51. Renaudin, G.; Kubel, F.; Rivera, J.-P.; Francois, M. Cem. Concr. Res. 1999, 29, $1937-1942$

52. Zhouri, E.; Hajbi, A. E. Ann. Chim. Sci. Mat. 1999, 24, 57-62

53. Roy, A. D.; Forano, C.; Malki, K. E.; Bess, J-P. Anionic Clays: Trends in Pillaring Chemistry. In Expanded Clays and Other Microporous Solids; Occelli, M. L., Robson, H. E. Eds; Van Nostrand Reinhold: New York, 1992; pp108-169

54. You, Y.; Vance, G. F.; Zhao, H. Colloids Surf. A. 2002, 205, 161-172

55. You, Y.; Vance, G. F.; Zhao, H. App. Clay Sci. 2001, 20, 13-25

56. Refait, P.; Simon, L.; Genin, J. M. R. Envoron. Sci. Technol. 2000, 34, 819-825

57. Miyata, S. Clays Clay Miner. 1983, 31, 305-311

58. Seida, Y.; Nakano, Y. Wat. Res. 2000, 34, 1487-1494

59. Goswamee, R. L.; Sengupta, P.; Bhattacharyya, K. G.; Dutta, D. K. Appl. Clay Sci. 1998, $13,21-34$

60. Simon, L.; Genin, J. M. R. Corros. Sci. 1997, 39, 1673-1685

61. Sagoe-Crentsil, K. K.; Glasser, F. P. Corrosion, 1993, 49, 457-463

62. Refait, Ph.; Drissi, S. H.; Pykiewicz. J.; Genin, J. M. R. Corros. Sci. 1997, 39, 16991710

63. Goldstein, J. I.; Newbury, D. E.; Echlin, P.; Joy, D. C.; Roming, A. D.; Lyman, C. E.; Fiori, C.; Lifshin, E. Scanning Electron Microscopy and X-ray Microanalysis : A Text for Biologists, Materials Scientists, and Geologists, $2^{\text {nd }}$ ed ; Plenum Press: New York, 1981 
64. Stutzman, P. E. Scanning Electron Microscopy in Concrete Petrography, In Materials Science of Concrete Special Volume: Calcium Hydroxide in Concrete; Skalny, J. P., Gebauer, J., Odler, I.Eds; The American Ceramic Society: Columbus, OH, 2001; pp59-72

65. Luo, R.; Cai, Y.; Wang, C.; Huang, X. Cem. Concr. Res. 2003, 33, 1-7

66. Tronto, J.; Reis, M. J.; Silverio, F.; Balbo, V. R.; Marchetti, J. M.; Valim, J. B. J. Phys. Chem. Solids, 2004, 65, 475-480

67. Beres, A.; Palinko, I.; Kiricsi, I.; Mizukami, F. Solid State Ionics, 2001, 141-142, $259-263$

68. Peulon, S.; Antony, H.; Legrand, L.; Chausse, A. Electrochimi. Acta, 2004, 49, 2891-2899

69. Peulon, S.; Legrand, L.; Antony, H.; Chausse, A. Electrochem. Commun., 2003, 5, 208-213

70. Gehin, A.; Ruby, C.; Abdelmoula, O.; Benali, O.; Ghanbaja, J.; Refait, P.; Genin, JM. R. Solid State Sci. 2002, 4, 61-66

71. Carja, G.; Nakamura, R.; Niiyama, H. Appl. Catal. A. 2002, 236, 91-102

72. Middeldorp, P. J. M.; Luijten, M. L. G.C.; van de Pas, B. A.; van Eekert, M. H. A.; Kengen, S. W. M.; Schraa, G.; Stams, A. J. M. Biorem. J. 1999, 3, 151-169

73. Vogel, T. M.; McCarty, P. L. Envoron. Sci. Technol. 1987, 21, 1208-1213

74. Adrain, L.; Gorisch, H. Res. Microbiol. 2002, 153, 131-137

75. Freedman, D. L.; Grossett, J. M. Appl. Environ. Microbiol. 1989, 55, 2144-2151 
76. deBruin, W. P.; Kotterman, M. J.; Posthusmsu, M. A.; Schraa, G.; Zehnder, A. J. B. Appl. Environ. Microbiol. 1992, 58, 1996-2000

77. Gao, J.; Skeen, R. S.; Hooker, B. S.; Quesenberry, R. D. Wat. Res. 1997, 31, 24792486

78. He, J.; Sung, Y.; Dollhopf, M. E.; Fathepure, B. Z.; Tiedje, J. M.; Loffler, F. E. Envoron. Sci. Technol. 2002, 36, 3945-3952

79. Gatell-Maymo, X.; Chien, Y-T.; Gossett, J. M.; Zinder, S. H. Science, 1997, 276, $1568-1571$

80. Bradley, P. M.; Chapelle, F. H. Envoron. Sci. Technol. 1997, 31, 2692-2696

81. Chen, C.; Puhakka, J. A. ; Ferguson, J. F. Envoron. Sci. Technol. 1996, 30, 542-547

82. Skubal, K. L.; Haack, S. K.; Forney, L. J.; Adriaens, P. Phys, Chem. Earth B. 1999, $24,517-527$

83. Doong, R-A.; Wu, S-C.; Chen, T-F. Chemosphere, 1996, 32, 377-390

84. Mohn, W. W.; Tiedje, J. M. Microbiol. Rev. 1992, 56, 482-507

85. Ferguson, J. F.; Pietari, J. M. H. Environ. Pollut. 2000, 107, 209-215

86. Krumholz, L. R.; Sharp, R.; Fishbain, S. Appl. Environ. Microbiol. 1996, 62, 41084113

87. Krumholz, L. R. Int. J. Syst. Bacteriol. 1997, 47, 1262-1263

88. Beurskens, J. E. M.; Dekker, C. G. C.; van den Heuvel, H.; Swart, M.; de Wolf, J.; Dolfing, J. Envoron. Sci. Technol. 1994, 28, 701-706

89. Holliger, C.; Schraa, G.; Stams, A. J. M.; Zehnder, A. J. B. Appl. Environ. Microbiol. 1992, 58, 1636-1644 
90. Middeldorp, P. J. M.; de Wolf, J.; Zehnder, A. J. B.; Scharr, G. Appl. Environ. Microbiol. 1997, 63, 1225-1229

91. Kengen, S. W. M.; Breidenbach, C. G.; Felske, A.; Schraa, G.; Stams, A.J. M.; de Vos, W. M. Appl. Environ. Microbiol. 1999, 65, 2312-2316

92. Skubal, K. L.; Barcelona, M. J.; Adriaens, P. J. Contam. Hydrol. 2001, 49, 151-169

93. Gerritse, J.; Kloetstra, G.; Alphenaar, A.; Spuij, F.; Urlings, L.; Gottschal, J. C. InSitu Bioremediation of Soil Polluted with Chlorinated Ethenes by Imposing Sequential Anaerobic and Aerobic Conditions. The $3^{\text {rd }}$ International Symposium on In Situ and On-Site Bioremediation, April, 1995, San Diego, CA; Battell Press: Columbus, OH, 1995 ; ppB5

94. Gregory, K. B.; Mason, M. G.; Picken, H. D.; Weathers, L. J.; Parkin, G. F. Envrion. Eng. Sci. 2000, 17, 169-198

95. Kao, C. M.; Chen, Y. L.; Chen, S. C.; Yeh, T. Y.; Wu, W. S. Wat. Res. 2003, 37, 4885-4894

96. Kao, C. M.; Chen, S. C.; Wang, J. Y.; Chen, Y. L.; Lee, S. Z. Wat. Res. 2003, 37, $27-$ 38

97. Kao, C. M.; Lei, S. E. Wat. Res. 2000, 34, 835-845

98. Komatsu, T.; Shinmyo, J.; Momonoi, K. Wat. Sci. Tech. 1997, 36, 125-132

99. Eisenbeis, M.; Kreisel-Bauer, P.; Scholz-Muramatsu, H. Wat. Sci. Tech. 1997, 36, $191-198$

100. Matheson, L. J.; Tratnyek, P. G. Envoron. Sci. Technol. 1994, 28, 2045-2053 
101. Conner, J. R.; Hoeffner, S. L. Critical Reviews in Environ. Sci. Technol. 1998, 28, $325-396$

102. Fanning, D. S.; Ragenhorst, M. C.; Burch, S. N.; Islam, K. R.; Tangren, S. A. Sulfides and Sulfate. In Soil Mineralogy with Environmental Applications, Dixon, et al., Eds.; Soil Science Society of America: Madison, WI., 2002

103. Sakaguchi, T.; Burgess, J. G.; Matsunaga, T. Nature, 1993, 365, 47-49

104. Bazylinskin, D. A.; Moskowitz, B. M. Microbial Biomineralization of Magnetic Iron Minerals : Microbiology, Magnetism, and Environmental Significance, In Geomicrobiology: Interactions between Microbes and Mineals, Banfield, et al., Eds; Reviews in Mineralogy, Mineralogical Society of American: Washington, DC, 1997 ; Vol. 35

105. Glasauer, S.; Weidler, P. G.; Langley, S.; Beveridge, T. J. Geochim. Cosmochimi. Acta, 2003, 67, 1277-1288

106. Lovley, D. R.; Woodward, J. C.; Chapelle, F. H. Nature, 1994, 370, 128-131

107. Cornell, R. M.; Schwertmann, U. The Iron Oxides: Structure, Properties, Reactions, Occurrence, and Uses, Wiley-VCH: Weinheim, Germany,1996

108. Segal, M. G.; Sellers, R. M. J. Chem. Soc. Chem. Comm. 1980, 863, 991-993

109. Arnold, R. G.; DiChristina, T. J.; Hoffman, M. R. Biotechnol. Bioeng. 1986, 32, $1081-1096$

110. Mann, S.; Sparks, N. H. C.; Couling, S. B.; Larcombe, M. C.; Frankel, R. B. J. Chem. Soc. Faraday Trans. 1, 1989, 85, 3033-3044

111. Gillham, R. W.; O’Hannesin, S. F. Ground Water 1994, 32, 958-967 
112. O’Hannesin, S. F.; Gillham, R. W. Ground Water 1998, 36, 164-170

113. Furukawa, Y.; Kim, J-W.; Watkins, J.; Wiklin, R. T. Environ. Sci. Technol. 2002, $36,5469-5475$

114. Phillips, D. H.; Watson, D. B.; Roh, Y.; Gu, B. J. Environ. Qual. 2003, 32, 20332045

115. Gu, B.; Phelps, T. J.; Liang, L. Dickey, M. J.; Roh, Y.; Kinsall, B. L.; Palumbo, A. V.; Jacobs, G. K. Environ. Sci. Technol. 1999, 33, 2170-2177

116. Klein, C.; Hurlbult, C. S. Jr. Manual of Mineralogy; $21^{\text {st }}$ ed.; John Wiley \& Sons, Inc.: New York, 1999

117. Schulze, D. G. An Introduction to Soil Mineralogy, In Soil Mineralogy with Environmental Applications, Dixon, J. B., Schulze, D. G., Eds.; Soil Science Society of America: Madison, WI., 2002

118. Zussman, J. X-ray Diffraction, In Physical Methods in Determinative Mineralogy, Zussman, J. Ed.; $2^{\text {nd }}$ ed.; Academy Press: New York, 1977; pp391-473

119. Nesse, W. D. Introduction to Mineralogy, Oxford University Press: New York, 2000

120. White, G. N.; Dixon, J. B. Soil Mineralogy Laboratory Manual, Texas A\&M University: College Station, 2003

121. Whittig, L. D.; Allardice, W. R. X-ray Diffraction Techniquies, In Methods of Soil Analysis, Part 1. Physical and Mineralogical Methods, Klute, A. Ed.; $2^{\text {nd }}$ ed.; Soil Science Society of America: Madison, WI, 1986 
122. Long, J. V. P., Electron Probe Microanalysis, In Physical Methos in Determinative Mineralogy, Zussman, Ed; $2^{\text {nd }}$ ed.; Academy Press: New York, NY 1977

123. Gibbs, C. R. Analy. Chem. 1976, 48, 1197-120

124. Ghorab, H.Y.; Kishar, E. A.; Elfetouh, S. H. A. Cem. Concr. Res. 1998, 28, 763771

125. Chudek, J. A.; Hunter, G.; Jone, M. R.; Scrimgeour, S. N.; Hewlett, P. C.; Kudryavtsev, A. B. J. Mater. Sci. 2000, 35, 4275-4288

126. Glasser, F. P.; Kindness, A.; Stronach, S. A. Cem. Concr. Res. 1999, 29, 861-866

127. Ko, S. B. M.S. Thesis, Texas A\&M University: College Station, 2001

128. Gehin, A.; Ruby, C.; Abdelmoula, M.; Benali, O.; Ghanbaja, J.; Refait, P.; Genin, J. M. R. Solid State Sci. 2002, 4, 61-66 


\section{APPENDIX A}

\section{TABULATED DATA}

TABLE A-1 Changes in aqueous phase PCE concentration over time in the activity tests

\begin{tabular}{rrrrrrrr}
\hline $\begin{array}{c}\text { Time } \\
\text { days }\end{array}$ & $\begin{array}{c}\text { Exp. 1 } \\
\text { PCE conc. } \\
\text { mM }\end{array}$ & $\begin{array}{c}\text { Time } \\
\text { days }\end{array}$ & $\begin{array}{c}\text { Exp. 2 } \\
\text { PCE conc. } \\
\text { mM }\end{array}$ & $\begin{array}{c}\text { Time } \\
\text { days }\end{array}$ & $\begin{array}{c}\text { Pxp. 3 } \\
\text { PCE conc. } \\
\text { mM }\end{array}$ & $\begin{array}{c}\text { Time } \\
\text { days }\end{array}$ & $\begin{array}{c}\text { Exp. 4 conc. } \\
\text { mM }\end{array}$ \\
\hline 4 & 0.206 & 3 & 0.176 & 4 & 0.207 & 3 & 0.196 \\
4 & 0.204 & 3 & 0.178 & 4 & 0.205 & 3 & 0.202 \\
4 & 0.199 & 3 & 0.177 & 4 & 0.197 & 3 & 0.210 \\
4 & 0.189 & 3 & 0.176 & 4 & 0.199 & 3 & 0.210 \\
4 & 0.191 & 3 & 0.178 & 4 & 0.196 & 3 & 0.205 \\
4 & 0.191 & 3 & 0.176 & 4 & 0.199 & 3 & 0.201 \\
4 & 0.180 & 3 & 0.180 & 4 & 0.193 & 3 & 0.204 \\
4 & 0.194 & 3 & 0.172 & 4 & 0.192 & 3 & 0.195 \\
4 & 0.193 & & & 4 & 0.191 & 3 & 0.207 \\
\hline
\end{tabular}

\begin{tabular}{|c|c|c|c|c|c|c|c|}
\hline \multicolumn{2}{|c|}{ Exp. 5} & \multicolumn{2}{|c|}{ Exp.6 } & \multicolumn{2}{|c|}{ Exp. 7} & \multicolumn{2}{|c|}{ Exp. 8} \\
\hline $\begin{array}{l}\text { Time } \\
\text { days }\end{array}$ & $\begin{array}{c}\text { PCE conc. } \\
\mathrm{mM}\end{array}$ & $\begin{array}{l}\text { Time } \\
\text { days }\end{array}$ & $\begin{array}{c}\text { PCE conc. } \\
\mathrm{mM}\end{array}$ & $\begin{array}{l}\text { Time } \\
\text { days }\end{array}$ & $\begin{array}{c}\text { PCE conc. } \\
\mathrm{mM}\end{array}$ & $\begin{array}{l}\text { Time } \\
\text { days }\end{array}$ & $\begin{array}{l}\text { PCE conc. } \\
\mathrm{mM}\end{array}$ \\
\hline 3.5 & 0.196 & 3.5 & 0.165 & 3.5 & 0.130 & 3.5 & 0.0285 \\
\hline 3.5 & 0.139 & 3.5 & 0.187 & 3.5 & 0.176 & 3.5 & 0.0274 \\
\hline 3.5 & 0.173 & 3.5 & 0.148 & 3.5 & 0.170 & 3.5 & 0.0319 \\
\hline
\end{tabular}

\begin{tabular}{|c|c|c|c|c|c|}
\hline \multicolumn{2}{|c|}{ Exp. 9} & \multicolumn{2}{|c|}{ Exp.10 } & \multicolumn{2}{|c|}{ Exp.11 } \\
\hline $\begin{array}{l}\text { Time } \\
\text { days }\end{array}$ & $\begin{array}{c}\text { PCE conc. } \\
\text { mM }\end{array}$ & $\begin{array}{l}\text { Time } \\
\text { days }\end{array}$ & $\begin{array}{c}\text { PCE conc. } \\
\mathrm{mM}\end{array}$ & $\begin{array}{l}\text { Time } \\
\text { days }\end{array}$ & $\begin{array}{c}\text { PCE conc. } \\
\mathrm{mM}\end{array}$ \\
\hline 3.5 & 0.196 & 3.5 & 0.165 & 3.5 & 0.130 \\
\hline 3.5 & 0.139 & 3.5 & 0.187 & 3.5 & 0.176 \\
\hline 3.5 & 0.173 & 3.5 & 0.148 & 3.5 & 0.170 \\
\hline
\end{tabular}

\begin{tabular}{rrrrrr}
\hline \multicolumn{2}{c}{ Exp.13 } & \multicolumn{2}{c}{ Exp. 15 } & \multicolumn{2}{c}{ Exp. 16 } \\
Time & $\begin{array}{c}\text { PCE conc. } \\
\text { days }\end{array}$ & $\begin{array}{c}\text { Time } \\
\text { PCE conc. } \\
\text { days }\end{array}$ & $\begin{array}{c}\text { Time } \\
\text { days }\end{array}$ & $\begin{array}{c}\text { PCE conc. } \\
\text { mM }\end{array}$ \\
\hline 4 & 0.198 & 4 & 0.187 & 4 & 0.196 \\
4 & 0.198 & 4 & 0.191 & 4 & 0.195 \\
4 & 0.211 & & & 4 & 0.191 \\
\hline
\end{tabular}


TABLE A-1 Continued

\begin{tabular}{rrrrrrrr}
\hline \multirow{2}{*}{$\begin{array}{c}\text { Exp. 18 } \\
\text { dime }\end{array}$} & $\begin{array}{c}\text { PCE conc. } \\
\text { mM }\end{array}$ & $\begin{array}{c}\text { Time } \\
\text { days }\end{array}$ & $\begin{array}{c}\text { Exp.19 } \\
\text { PCE conc. } \\
\text { mM }\end{array}$ & $\begin{array}{c}\text { Time } \\
\text { days }\end{array}$ & $\begin{array}{c}\text { Exp. 20 } \\
\text { PCE conc. } \\
\text { mM }\end{array}$ & $\begin{array}{c}\text { Time } \\
\text { days }\end{array}$ & $\begin{array}{c}\text { Pxp. 21 } \\
\text { mM }\end{array}$ \\
\hline 3 & 0.193 & 3 & 0.194 & 3 & 0.193 & 3 & 0.190 \\
3 & 0.195 & 3 & 0.193 & 3 & 0.193 & 3 & 0.193 \\
3 & 0.196 & 3 & 0.194 & 3 & 0.189 & 3 & 0.195 \\
\hline
\end{tabular}

\begin{tabular}{rrrrrr}
\hline \multicolumn{2}{c}{ Exp. 22 } & \multicolumn{2}{c}{ Exp.23 } & \multicolumn{2}{c}{ Exp. 24 } \\
Time & $\begin{array}{c}\text { PCE conc. } \\
\text { days }\end{array}$ & $\begin{array}{c}\text { Time } \\
\text { days }\end{array}$ & $\begin{array}{c}\text { PCE conc. } \\
\mathrm{mM}\end{array}$ & $\begin{array}{c}\text { Time } \\
\text { days }\end{array}$ & $\begin{array}{c}\text { PCE conc. } \\
\mathrm{mM}\end{array}$ \\
\hline 13 & 0.200 & 13 & 0.171 & 13 & 0.175 \\
13 & 0.197 & 13 & 0.171 & 13 & 0.180 \\
13 & 0.197 & 13 & 0.179 & & \\
\hline
\end{tabular}

\begin{tabular}{rrrrrr}
\hline $\begin{array}{r}\text { Time } \\
\text { Exp. 26 } \\
\text { PCE conc. } \\
\text { mM }\end{array}$ & $\begin{array}{r}\text { Time } \\
\text { days }\end{array}$ & $\begin{array}{c}\text { Exp.27 } \\
\text { PCE conc. } \\
\text { mM }\end{array}$ & $\begin{array}{r}\text { Time } \\
\text { days }\end{array}$ & $\begin{array}{c}\text { Exp. 29 } \\
\text { PCE conc. } \\
\text { mM }\end{array}$ \\
\hline 3.8 & 0.143 & 3.8 & 0.192 & 3.8 & 0.159 \\
3.8 & 0.153 & 3.8 & 0.196 & 3.8 & 0.155 \\
\hline
\end{tabular}

\begin{tabular}{rrrrrrrr}
\hline \multicolumn{2}{c}{ Exp. 30 } & \multicolumn{2}{c}{ Exp.31 } & \multicolumn{2}{c}{ Exp. 32 } & \multicolumn{2}{c}{ Exp. 33 } \\
Time & $\begin{array}{c}\text { PCE conc. } \\
\text { days }\end{array}$ & $\begin{array}{c}\text { Time } \\
\text { days }\end{array}$ & $\begin{array}{c}\text { PCE conc. } \\
\text { mM }\end{array}$ & $\begin{array}{r}\text { Time } \\
\text { days }\end{array}$ & $\begin{array}{c}\text { PCE conc. } \\
\text { mM }\end{array}$ & $\begin{array}{r}\text { Time } \\
\text { days }\end{array}$ & $\begin{array}{c}\text { PCE conc. } \\
\text { mM }\end{array}$ \\
\hline 4.5 & 0.110 & 4.5 & 0.149 & 4.5 & 0.146 & 4.5 & 0.115 \\
4.5 & 0.117 & 4.5 & 0.142 & 4.5 & 0.158 & 4.5 & 0.114 \\
& & 4.5 & 0.145 & 4.5 & 0.154 & 4.5 & 0.114 \\
\hline
\end{tabular}

\begin{tabular}{rrrrrrrr}
\hline \multicolumn{2}{c}{ Exp. 34 } & \multicolumn{2}{c}{ Exp.35 } & \multicolumn{2}{c}{ Exp. 36 } & \multicolumn{2}{c}{ Exp. 37 } \\
Time & $\begin{array}{c}\text { PCE conc. } \\
\text { days }\end{array}$ & $\begin{array}{c}\text { Time } \\
\text { days }\end{array}$ & $\begin{array}{c}\text { PCE conc. } \\
\text { mM }\end{array}$ & $\begin{array}{c}\text { Time } \\
\text { days }\end{array}$ & $\begin{array}{c}\text { PCE conc. } \\
\text { mM }\end{array}$ & $\begin{array}{c}\text { Time } \\
\text { days }\end{array}$ & $\begin{array}{c}\text { PCE conc. } \\
\text { mM }\end{array}$ \\
\hline 4.5 & 0.126 & 4.9 & 0.175 & 4.9 & 0.129 & 4.9 & 0.137 \\
4.5 & 0.126 & 4.9 & 0.172 & 4.9 & 0.114 & 4.9 & 0.140 \\
4.5 & 0.119 & 4.9 & 0.174 & & & 4.9 & 0.145 \\
\hline
\end{tabular}


TABLE A-1 Continued

\begin{tabular}{rrrrrrrr}
\hline \multicolumn{2}{c}{ Exp. 38 } & \multicolumn{2}{c}{ Exp.39 } & \multicolumn{2}{c}{ Exp. 40 } & \multicolumn{2}{c}{ Exp. 41 } \\
$\begin{array}{r}\text { Time } \\
\text { days }\end{array}$ & $\begin{array}{c}\text { PCE conc. } \\
\text { mM }\end{array}$ & $\begin{array}{c}\text { Time } \\
\text { days }\end{array}$ & $\begin{array}{c}\text { PCE conc. } \\
\text { mM }\end{array}$ & $\begin{array}{r}\text { Time } \\
\text { days }\end{array}$ & $\begin{array}{c}\text { PCE conc. } \\
\text { mM }\end{array}$ & $\begin{array}{c}\text { Time } \\
\text { days }\end{array}$ & $\begin{array}{c}\text { PCE conc. } \\
\text { mM }\end{array}$ \\
\hline 4.9 & 0.157 & 5.7 & 0.153 & 5.7 & 0.139 & 5.7 & 0.133 \\
4.9 & 0.164 & 5.7 & 0.151 & 5.7 & 0.142 & 5.7 & 0.134 \\
4.9 & 0.167 & & & 5.7 & 0.147 & 5.7 & 0.134 \\
\hline
\end{tabular}

\begin{tabular}{|c|c|}
\hline \multicolumn{2}{|c|}{ Exp. 42} \\
\hline $\begin{array}{l}\text { Time } \\
\text { days }\end{array}$ & $\begin{array}{c}\text { PCE conc. } \\
\mathrm{mM}\end{array}$ \\
\hline 5.7 & 0.149 \\
\hline 5.7 & 0.152 \\
\hline 5.7 & 0.150 \\
\hline
\end{tabular}

\begin{tabular}{|c|c|c|c|}
\hline \multicolumn{2}{|c|}{ Exp. 43} & \multicolumn{2}{|c|}{ Exp. 44} \\
\hline $\begin{array}{l}\text { Time } \\
\text { days }\end{array}$ & $\begin{array}{c}\text { PCE conc. } \\
\mathrm{mM}\end{array}$ & $\begin{array}{l}\text { Time } \\
\text { days }\end{array}$ & $\begin{array}{c}\text { PCE conc. } \\
\mathrm{mM}\end{array}$ \\
\hline 4 & 0.127 & 6.9 & 0.0793 \\
\hline 4 & 0.135 & 6.9 & 0.0737 \\
\hline 4 & 0.130 & 6.9 & 0.0962 \\
\hline 4 & 0.139 & 6.9 & 0.0792 \\
\hline 4 & 0.148 & 6.9 & 0.0857 \\
\hline 4 & 0.134 & 6.9 & 0.0700 \\
\hline 4 & 0.143 & 6.9 & 0.0732 \\
\hline 4 & 0.130 & 6.9 & 0.0983 \\
\hline \multirow[t]{6}{*}{4} & 0.134 & 6.9 & 0.0714 \\
\hline & & 6.9 & 0.0701 \\
\hline & & 6.9 & 0.0698 \\
\hline & & 6.9 & 0.0762 \\
\hline & & 6.9 & 0.0834 \\
\hline & & 6.9 & 0.0806 \\
\hline
\end{tabular}


TABLE A-1 Continued

\begin{tabular}{|c|c|c|c|c|c|c|c|}
\hline \multicolumn{2}{|c|}{ Exp. 47} & \multicolumn{2}{|c|}{ Exp.48 } & \multicolumn{2}{|c|}{ Exp. 49} & \multicolumn{2}{|c|}{ Exp. 50} \\
\hline $\begin{array}{l}\text { Time } \\
\text { days }\end{array}$ & $\begin{array}{l}\text { PCE conc. } \\
\text { mM }\end{array}$ & $\begin{array}{l}\text { Time } \\
\text { days }\end{array}$ & $\begin{array}{l}\text { PCE conc. } \\
\mathrm{mM}\end{array}$ & $\begin{array}{l}\text { Time } \\
\text { days }\end{array}$ & $\begin{array}{c}\text { PCE conc. } \\
\mathrm{mM}\end{array}$ & $\begin{array}{l}\text { Time } \\
\text { days }\end{array}$ & $\begin{array}{l}\text { PCE conc. } \\
\mathrm{mM}\end{array}$ \\
\hline 8.5 & 0.141 & 7 & 0.146 & 7 & 0.163 & 7 & 0.160 \\
\hline 8.5 & 0.166 & 7 & 0.142 & 7 & 0.164 & 7 & 0.162 \\
\hline 8.5 & 0.140 & 7 & 0.154 & 7 & 0.161 & 7 & 0.151 \\
\hline 8.5 & 0.154 & & & & & & \\
\hline 8.5 & 0.166 & & & & & & \\
\hline 8.5 & 0.171 & & & & & & \\
\hline 8.5 & 0.165 & & & & & & \\
\hline 8.5 & 0.166 & & & & & & \\
\hline 8.5 & 0.165 & & & & & & \\
\hline 8.5 & 0.149 & & & & & & \\
\hline 8.5 & 0.169 & & & & & & \\
\hline 8.5 & 0.147 & & & & & & \\
\hline 8.5 & 0.169 & & & & & & \\
\hline 8.5 & 0.170 & & & & & & \\
\hline 8.5 & 0.165 & & & & & & \\
\hline 8.5 & 0.166 & & & & & & \\
\hline 8.5 & 0.165 & & & & & & \\
\hline 8.5 & 0.146 & & & & & & \\
\hline
\end{tabular}

\begin{tabular}{|c|c|c|c|c|c|c|c|}
\hline \multicolumn{2}{|c|}{ Exp. 51} & \multicolumn{2}{|c|}{ Exp.52 } & \multicolumn{2}{|c|}{ Exp. 53} & \multicolumn{2}{|c|}{ Exp. 54} \\
\hline $\begin{array}{l}\text { Time } \\
\text { days }\end{array}$ & $\begin{array}{c}\text { PCE conc. } \\
\mathrm{mM}\end{array}$ & $\begin{array}{l}\text { Time } \\
\text { days }\end{array}$ & $\begin{array}{c}\text { PCE conc. } \\
\text { mM }\end{array}$ & $\begin{array}{l}\text { Time } \\
\text { days }\end{array}$ & $\begin{array}{l}\text { PCE conc. } \\
\mathrm{mM}\end{array}$ & $\begin{array}{l}\text { Time } \\
\text { days }\end{array}$ & $\begin{array}{l}\text { PCE conc. } \\
\text { mM }\end{array}$ \\
\hline 7 & 0.153 & 7 & 0.167 & 7 & 0.143 & 7 & 0.151 \\
\hline 7 & 0.161 & 7 & 0.167 & 7 & 0.145 & 7 & 0.158 \\
\hline 7 & 0.161 & 7 & 0.175 & 7 & 0.134 & 7 & 0.150 \\
\hline
\end{tabular}

\begin{tabular}{rrrrrrrr}
\hline \multicolumn{2}{c}{ Exp. 55 } & \multicolumn{2}{c}{ Exp.56 } & \multicolumn{2}{c}{ Exp. 57 } & \multicolumn{2}{c}{ Exp. 58 } \\
Time & $\begin{array}{c}\text { PCE conc. } \\
\text { days }\end{array}$ & $\begin{array}{c}\text { Time } \\
\text { days }\end{array}$ & $\begin{array}{c}\text { PCE conc. } \\
\text { mM }\end{array}$ & $\begin{array}{c}\text { Time } \\
\text { days }\end{array}$ & $\begin{array}{c}\text { PCE conc. } \\
\text { mM }\end{array}$ & $\begin{array}{c}\text { Time } \\
\text { days }\end{array}$ & $\begin{array}{c}\text { PCE conc. } \\
\mathrm{mM}\end{array}$ \\
\hline 5.6 & 0.142 & 5.6 & 0.161 & 5.6 & 0.166 & 5.6 & 0.163 \\
5.6 & 0.148 & 5.6 & 0.168 & 5.6 & 0.166 & 5.6 & 0.160 \\
5.6 & 0.166 & 5.6 & 0.164 & 5.6 & 0.166 & 5.6 & 0.159 \\
\hline
\end{tabular}




\section{TABLE A-1 Continued}

\begin{tabular}{rr}
\hline $\begin{array}{c}\text { Time } \\
\text { days }\end{array}$ & $\begin{array}{c}\text { PCE conc. } \\
\text { mM }\end{array}$ \\
\hline 7 & 0.136 \\
7 & 0.167 \\
7 & 0.162 \\
7 & 0.139 \\
7 & 0.158 \\
7 & 0.164 \\
7 & 0.157 \\
7 & 0.152 \\
7 & 0.141 \\
7 & 0.135 \\
7 & 0.165 \\
7 & 0.155 \\
7 & 0.153 \\
7 & 0.152 \\
7 & 0.159 \\
\hline
\end{tabular}

\begin{tabular}{rrrrrrrr}
\hline \multicolumn{2}{c}{ Exp. 60 } & \multicolumn{2}{c}{ Exp.61 } & \multicolumn{2}{c}{ Exp. 62 } & \multicolumn{2}{c}{ Exp.63 } \\
$\begin{array}{r}\text { Time } \\
\text { days }\end{array}$ & $\begin{array}{c}\text { PCE conc. } \\
\mathrm{mM}\end{array}$ & $\begin{array}{c}\text { Time } \\
\text { days }\end{array}$ & $\begin{array}{c}\text { PCE conc. } \\
\mathrm{mM}\end{array}$ & $\begin{array}{c}\text { Time } \\
\text { days }\end{array}$ & $\begin{array}{c}\text { PCE conc. } \\
\mathrm{mM}\end{array}$ & $\begin{array}{c}\text { Time } \\
\text { days }\end{array}$ & $\begin{array}{c}\text { PCE conc. } \\
\mathrm{mM}\end{array}$ \\
\hline 7 & 0.158 & 7 & 0.146 & 7 & 0.152 & 7 & 0.155 \\
7 & 0.159 & 7 & 0.161 & 7 & 0.162 & 7 & 0.153 \\
7 & 0.164 & 7 & 0.159 & 7 & 0.157 & 7 & 0.129 \\
\hline
\end{tabular}

\begin{tabular}{|c|c|c|c|c|c|c|c|}
\hline \multicolumn{2}{|c|}{ Exp. 64} & \multicolumn{2}{|c|}{ Exp.65 } & \multicolumn{2}{|c|}{ Exp. 66} & \multicolumn{2}{|c|}{ Exp.67 } \\
\hline $\begin{array}{l}\text { Time } \\
\text { days }\end{array}$ & $\begin{array}{c}\text { PCE conc. } \\
\mathrm{mM}\end{array}$ & $\begin{array}{l}\text { Time } \\
\text { days }\end{array}$ & $\begin{array}{c}\text { PCE conc. } \\
\mathrm{mM}\end{array}$ & $\begin{array}{l}\text { Time } \\
\text { days }\end{array}$ & $\begin{array}{c}\text { PCE conc. } \\
\text { mM }\end{array}$ & $\begin{array}{l}\text { Time } \\
\text { days }\end{array}$ & $\begin{array}{c}\text { PCE conc. } \\
\text { mM }\end{array}$ \\
\hline 7 & 0.157 & 7 & 0.156 & 7.9 & 0.154 & 7.9 & 0.151 \\
\hline 7 & 0.149 & 7 & 0.157 & 7.9 & 0.156 & 7.9 & 0.152 \\
\hline 7 & 0.156 & 7 & 0.141 & 7.9 & 0.149 & 7.9 & 0.155 \\
\hline
\end{tabular}

\begin{tabular}{rrrrrr}
\hline \multicolumn{2}{c}{ Exp.68 } & \multicolumn{2}{c}{ Exp.69 } & \multicolumn{2}{c}{ Exp. 70 } \\
$\begin{array}{r}\text { Time } \\
\text { days }\end{array}$ & $\begin{array}{c}\text { PCE conc. } \\
\text { mM }\end{array}$ & $\begin{array}{c}\text { Time } \\
\text { days }\end{array}$ & $\begin{array}{c}\text { PCE conc. } \\
\text { mM }\end{array}$ & $\begin{array}{c}\text { Time } \\
\text { days }\end{array}$ & $\begin{array}{c}\text { PCE conc. } \\
\text { mM }\end{array}$ \\
\hline 7.9 & 0.145 & 7.9 & 0.157 & 7.9 & 0.158 \\
7.9 & 0.147 & 7.9 & 0.151 & 7.9 & 0.153 \\
7.9 & 0.130 & 7.9 & 0.148 & 7.9 & 0.158 \\
\hline
\end{tabular}


TABLE A-1 Continued

\begin{tabular}{rrrrrrrr}
\hline \multicolumn{2}{c}{ Exp. 71 } & \multicolumn{2}{c}{ Exp.72 } & \multicolumn{2}{c}{ Exp. 73 } & \multicolumn{2}{c}{ Exp.74 } \\
Time & $\begin{array}{c}\text { PCE conc. } \\
\text { days }\end{array}$ & $\begin{array}{c}\text { Time } \\
\text { days }\end{array}$ & $\begin{array}{c}\text { PCE conc. } \\
\text { mM }\end{array}$ & $\begin{array}{c}\text { Time } \\
\text { days }\end{array}$ & $\begin{array}{c}\text { PCE conc. } \\
\text { mM }\end{array}$ & $\begin{array}{c}\text { Time } \\
\text { days }\end{array}$ & $\begin{array}{c}\text { PCE conc. } \\
\text { mM }\end{array}$ \\
\hline 7.7 & 0.154 & 7.7 & 0.168 & 7.7 & 0.149 & 7.7 & 0.159 \\
7.7 & 0.158 & 7.7 & 0.157 & 7.7 & 0.144 & 7.7 & 0.157 \\
7.7 & 0.136 & 7.7 & 0.158 & 7.7 & 0.159 & & \\
\hline
\end{tabular}

\begin{tabular}{|c|c|c|c|c|c|c|c|}
\hline \multicolumn{2}{|c|}{ Exp.75 } & \multicolumn{2}{|c|}{ Exp. 76} & \multicolumn{2}{|c|}{ Exp.77 } & \multicolumn{2}{|c|}{ Exp. 78} \\
\hline $\begin{array}{l}\text { Time } \\
\text { days }\end{array}$ & $\begin{array}{c}\text { PCE conc. } \\
\text { mM }\end{array}$ & $\begin{array}{l}\text { Time } \\
\text { days }\end{array}$ & $\begin{array}{c}\text { PCE conc. } \\
\text { mM }\end{array}$ & $\begin{array}{l}\text { Time } \\
\text { days }\end{array}$ & $\begin{array}{c}\text { PCE conc. } \\
\text { mM }\end{array}$ & $\begin{array}{l}\text { Time } \\
\text { days }\end{array}$ & $\begin{array}{l}\text { PCE conc. } \\
\text { mM }\end{array}$ \\
\hline 7.7 & 0.110 & 6.9 & 0.160 & 6.9 & 0.159 & 6.9 & 0.136 \\
\hline 7.7 & 0.120 & 6.9 & 0.159 & 6.9 & 0.157 & 6.9 & 0.153 \\
\hline & & 6.9 & 0.164 & 6.9 & 0.159 & 6.9 & 0.151 \\
\hline
\end{tabular}

\begin{tabular}{|c|c|c|c|c|c|c|c|}
\hline \multicolumn{2}{|c|}{ Exp.79 } & \multicolumn{2}{|c|}{ Exp. 80} & \multicolumn{2}{|c|}{ Exp.81 } & \multicolumn{2}{|c|}{ Exp. 82} \\
\hline $\begin{array}{l}\text { Time } \\
\text { days }\end{array}$ & $\begin{array}{c}\text { PCE conc. } \\
\text { mM }\end{array}$ & $\begin{array}{l}\text { Time } \\
\text { days }\end{array}$ & $\begin{array}{c}\text { PCE conc. } \\
\mathrm{mM}\end{array}$ & $\begin{array}{l}\text { Time } \\
\text { days }\end{array}$ & $\begin{array}{c}\text { PCE conc. } \\
\text { mM }\end{array}$ & $\begin{array}{l}\text { Time } \\
\text { days }\end{array}$ & $\begin{array}{c}\text { PCE conc. } \\
\text { mM }\end{array}$ \\
\hline 6.9 & 0.161 & 6.9 & 0.151 & 6.9 & 0.130 & 6.9 & 0.140 \\
\hline 6.9 & 0.154 & 6.9 & 0.150 & 6.9 & 0.152 & 6.9 & 0.151 \\
\hline 6.9 & 0.155 & 6.9 & 0.135 & 6.9 & 0.155 & 6.9 & 0.145 \\
\hline
\end{tabular}

\begin{tabular}{|c|c|c|c|c|c|c|c|}
\hline \multicolumn{2}{|c|}{ Exp.83 } & \multicolumn{2}{|c|}{ Exp. 84} & \multicolumn{2}{|c|}{ Exp.85 } & \multicolumn{2}{|c|}{ Exp. 86} \\
\hline $\begin{array}{l}\text { Time } \\
\text { days }\end{array}$ & $\begin{array}{l}\text { PCE conc. } \\
\text { mM }\end{array}$ & $\begin{array}{l}\text { Time } \\
\text { days }\end{array}$ & $\begin{array}{l}\text { PCE conc. } \\
\mathrm{mM}\end{array}$ & $\begin{array}{l}\text { Time } \\
\text { days }\end{array}$ & $\begin{array}{l}\text { PCE conc. } \\
\mathrm{mM}\end{array}$ & $\begin{array}{l}\text { Time } \\
\text { days }\end{array}$ & $\begin{array}{l}\text { PCE conc. } \\
\text { mM }\end{array}$ \\
\hline 6.9 & 0.093 & 6.9 & 0.122 & 6.9 & 0.135 & 7 & 0.156 \\
\hline 6.9 & 0.103 & 6.9 & 0.133 & 6.9 & 0.112 & 7 & 0.159 \\
\hline 6.9 & 0.110 & 6.9 & 0.136 & 6.9 & 0.114 & 7 & 0.145 \\
\hline
\end{tabular}

\begin{tabular}{|c|c|c|c|c|c|c|c|}
\hline \multicolumn{2}{|c|}{ Exp.87 } & \multicolumn{2}{|c|}{ Exp. 88} & \multicolumn{2}{|c|}{ Exp.89 } & \multicolumn{2}{|c|}{ Exp. 90} \\
\hline $\begin{array}{l}\text { Time } \\
\text { days }\end{array}$ & $\begin{array}{l}\text { PCE conc. } \\
\mathrm{mM}\end{array}$ & $\begin{array}{l}\text { Time } \\
\text { days }\end{array}$ & $\begin{array}{l}\text { PCE conc. } \\
\mathrm{mM}\end{array}$ & $\begin{array}{l}\text { Time } \\
\text { days }\end{array}$ & $\begin{array}{l}\text { PCE conc. } \\
\mathrm{mM}\end{array}$ & $\begin{array}{l}\text { Time } \\
\text { days }\end{array}$ & $\begin{array}{l}\text { PCE conc. } \\
\mathrm{mM}\end{array}$ \\
\hline 7 & 0.152 & 7 & 0.126 & 7 & 0.153 & 7 & 0.141 \\
\hline 7 & 0.132 & 7 & 0.106 & 7 & 0.150 & 7 & 0.133 \\
\hline 7 & 0.152 & & & 7 & 0.155 & 7 & 0.141 \\
\hline
\end{tabular}


TABLE A-1 Continued

\begin{tabular}{rrrrrrrr}
\hline \multicolumn{2}{c}{ Exp.91 } & \multicolumn{2}{c}{ Exp.92 } & \multicolumn{2}{c}{ Exp.93 } & \multicolumn{2}{c}{ Exp. 94 } \\
Time & $\begin{array}{c}\text { PCE conc. } \\
\text { days }\end{array}$ & $\begin{array}{c}\text { Time } \\
\text { days }\end{array}$ & $\begin{array}{c}\text { PCE conc. } \\
\text { mM }\end{array}$ & $\begin{array}{c}\text { Time } \\
\text { days }\end{array}$ & $\begin{array}{c}\text { PCE conc. } \\
\text { mM }\end{array}$ & $\begin{array}{c}\text { Time } \\
\text { days }\end{array}$ & $\begin{array}{c}\text { PCE conc. } \\
\text { mM }\end{array}$ \\
\hline 5.7 & 0.160 & 5.7 & 0.152 & 5.7 & 0.139 & 5.7 & 0.166 \\
5.7 & 0.163 & 5.7 & 0.151 & 5.7 & 0.136 & 5.7 & 0.158 \\
5.7 & 0.154 & 5.7 & 0.156 & 5.7 & 0.148 & 5.7 & 0.163 \\
\hline
\end{tabular}

\begin{tabular}{|c|c|c|c|c|c|c|c|}
\hline \multicolumn{2}{|c|}{ Exp.95 } & \multicolumn{2}{|c|}{ Exp. 96} & \multicolumn{2}{|c|}{ Exp.97 } & \multicolumn{2}{|c|}{ Exp. 98} \\
\hline $\begin{array}{l}\text { Time } \\
\text { days }\end{array}$ & $\begin{array}{c}\text { PCE conc. } \\
\text { mM }\end{array}$ & $\begin{array}{l}\text { Time } \\
\text { days }\end{array}$ & $\begin{array}{c}\text { PCE conc. } \\
\text { mM }\end{array}$ & $\begin{array}{l}\text { Time } \\
\text { days }\end{array}$ & $\begin{array}{l}\text { PCE conc. } \\
\text { mM }\end{array}$ & $\begin{array}{l}\text { Time } \\
\text { days }\end{array}$ & $\begin{array}{c}\text { PCE conc. } \\
\text { mM }\end{array}$ \\
\hline 5.7 & 0.154 & 5.7 & 0.123 & 4 & 0.149 & 4 & 0.155 \\
\hline 5.7 & 0.159 & 5.7 & 0.122 & 4 & 0.157 & 4 & 0.164 \\
\hline 5.7 & 0.151 & 5.7 & 0.140 & 4 & 0.159 & 4 & 0.160 \\
\hline
\end{tabular}

\begin{tabular}{rrrrrrrr}
\hline $\begin{array}{r}\text { Time } \\
\text { days }\end{array}$ & $\begin{array}{c}\text { Pxp conc. } \\
\text { PM }\end{array}$ & $\begin{array}{c}\text { Time } \\
\text { days }\end{array}$ & $\begin{array}{c}\text { Exp. 100 conc. } \\
\text { mM }\end{array}$ & $\begin{array}{c}\text { Time } \\
\text { days }\end{array}$ & $\begin{array}{c}\text { Exp.101 } \\
\text { PCE conc. } \\
\text { mM }\end{array}$ & $\begin{array}{c}\text { Time } \\
\text { days }\end{array}$ & $\begin{array}{c}\text { Exp 102 conc. } \\
\text { mM }\end{array}$ \\
\hline 4 & 0.157 & 4 & 0.164 & 4 & 0.163 & 4 & 0.141 \\
4 & 0.154 & 4 & 0.164 & 4 & 0.162 & 4 & 0.153 \\
4 & 0.160 & 4 & 0.157 & 4 & 0.135 & 4 & 0.153 \\
\hline
\end{tabular}

\begin{tabular}{rcrrrrrr}
\hline \multicolumn{2}{c}{ Exp.103 } & \multicolumn{2}{c}{ Exp. 104 } & \multicolumn{2}{c}{ Exp.105 } & \multicolumn{2}{c}{ Exp. 106 } \\
Time & $\begin{array}{c}\text { PCE conc. } \\
\text { days }\end{array}$ & $\begin{array}{c}\text { Time } \\
\text { mM }\end{array}$ & $\begin{array}{c}\text { PCE conc. } \\
\text { days }\end{array}$ & $\begin{array}{c}\text { Time } \\
\text { days }\end{array}$ & $\begin{array}{c}\text { PCE conc. } \\
\text { mM }\end{array}$ & $\begin{array}{c}\text { Time } \\
\text { days }\end{array}$ & $\begin{array}{c}\text { PCE conc. } \\
\mathrm{mM}\end{array}$ \\
\hline 4.6 & 0.129 & 4.6 & 0.136 & 4.6 & 0.144 & 4.6 & 0.167 \\
4.6 & 0.134 & 4.6 & 0.152 & 4.6 & 0.141 & 4.6 & 0.158 \\
& & 4.6 & 0.154 & 4.6 & 0.138 & 4.6 & 0.165 \\
\hline
\end{tabular}


TABLE A-1 Continued

\begin{tabular}{cccc}
\hline \multicolumn{2}{c}{ Exp.107 } & \multicolumn{2}{c}{ Exp. 108 } \\
Time & $\begin{array}{c}\text { PCE conc. } \\
\text { days }\end{array}$ & $\begin{array}{c}\text { Time } \\
\text { mM }\end{array}$ & $\begin{array}{c}\text { PCE conc. } \\
\text { days }\end{array}$ \\
\hline 4.6 & 0.143 & 4.2 & 0.145 \\
4.6 & 0.142 & 4.2 & 0.143 \\
4.6 & 0.140 & 4.2 & 0.139 \\
& & 4.2 & 0.126 \\
& & 4.2 & 0.130 \\
& & 4.2 & 0.138 \\
& & 4.2 & 0.124 \\
& & 4.2 & 0.127 \\
& & 4.2 & 0.118 \\
& & 4.2 & 0.136 \\
& & 4.2 & 0.126 \\
& & 4.2 & 0.135 \\
& & 4.2 & 0.139 \\
& & 4.2 & 0.143 \\
& & 4.2 & 0.147 \\
\hline
\end{tabular}

\begin{tabular}{rrrrrrrr}
\hline \multicolumn{2}{c}{ Exp.109 } & \multicolumn{2}{c}{ Exp. 110 } & \multicolumn{2}{c}{ Exp. 111 } & \multicolumn{2}{c}{ Exp. 112 } \\
$\begin{array}{r}\text { Time } \\
\text { days }\end{array}$ & $\begin{array}{c}\text { PCE conc. } \\
\text { mM }\end{array}$ & $\begin{array}{c}\text { Time } \\
\text { days }\end{array}$ & $\begin{array}{c}\text { PCE conc. } \\
\text { mM }\end{array}$ & $\begin{array}{c}\text { Time } \\
\text { days }\end{array}$ & $\begin{array}{c}\text { PCE conc. } \\
\text { mM }\end{array}$ & $\begin{array}{r}\text { Time } \\
\text { days }\end{array}$ & $\begin{array}{c}\text { PCE conc. } \\
\text { mM }\end{array}$ \\
\hline 7 & 0.108 & 7 & 0.163 & 7 & 0.153 & 7 & 0.161 \\
7 & 0.145 & 7 & 0.157 & 7 & 0.151 & 7 & 0.157 \\
7 & 0.140 & 7 & 0.159 & 7 & 0.148 & 7 & 0.163 \\
\hline
\end{tabular}

\begin{tabular}{rrrrrrrr}
\hline \multicolumn{2}{c}{ Exp.113 } & \multicolumn{2}{c}{ Exp. 114 } & \multicolumn{2}{c}{ Exp.115 } & \multicolumn{2}{c}{ Exp. 116 } \\
$\begin{array}{r}\text { Time } \\
\text { days }\end{array}$ & $\begin{array}{c}\text { PCE conc. } \\
\text { mM }\end{array}$ & $\begin{array}{c}\text { Time } \\
\text { days }\end{array}$ & $\begin{array}{c}\text { PCE conc. } \\
\text { mM }\end{array}$ & $\begin{array}{c}\text { Time } \\
\text { days }\end{array}$ & $\begin{array}{c}\text { PCE conc. } \\
\text { mM }\end{array}$ & $\begin{array}{c}\text { Time } \\
\text { days }\end{array}$ & $\begin{array}{c}\text { PCE conc. } \\
\text { mM }\end{array}$ \\
\hline 7 & 0.152 & 7 & 0.127 & 4.9 & 0.167 & 4.9 & 0.163 \\
7 & 0.160 & 7 & 0.129 & 4.9 & 0.164 & 4.9 & 0.165 \\
7 & 0.160 & 7 & 0.142 & 4.9 & 0.165 & 4.9 & 0.164 \\
\hline
\end{tabular}

\begin{tabular}{rrrrrrrr}
\hline \multicolumn{2}{c}{ Exp.117 } & \multicolumn{2}{c}{ Exp. 118 } & \multicolumn{2}{c}{ Exp.119 } & \multicolumn{2}{c}{ Exp. 120 } \\
$\begin{array}{r}\text { Time } \\
\text { days }\end{array}$ & $\begin{array}{c}\text { PCE conc. } \\
\mathrm{mM}\end{array}$ & $\begin{array}{c}\text { Time } \\
\text { days }\end{array}$ & $\begin{array}{c}\text { PCE conc. } \\
\mathrm{mM}\end{array}$ & $\begin{array}{c}\text { Time } \\
\text { days }\end{array}$ & $\begin{array}{c}\text { PCE conc. } \\
\mathrm{mM}\end{array}$ & $\begin{array}{c}\text { Time } \\
\text { days }\end{array}$ & $\begin{array}{c}\text { PCE conc. } \\
\mathrm{mM}\end{array}$ \\
\hline 4.9 & 0.160 & 4.9 & 0.154 & 4.9 & 0.163 & 4.9 & 0.155 \\
4.9 & 0.164 & 4.9 & 0.151 & 4.9 & 0.137 & 4.9 & 0.159 \\
& & 4.9 & 0.162 & & & 4.9 & 0.161 \\
\hline
\end{tabular}


TABLE A-1 Continued

\begin{tabular}{rrrrrrrr}
\hline \multicolumn{2}{c}{ Exp.121 } & \multicolumn{2}{c}{ Exp. 122 } & \multicolumn{2}{c}{ Exp.123 } & \multicolumn{2}{c}{ Exp. 124 } \\
Time & $\begin{array}{c}\text { PCE conc. } \\
\text { days }\end{array}$ & $\begin{array}{c}\text { Time } \\
\text { days }\end{array}$ & $\begin{array}{c}\text { PCE conc. } \\
\text { mM }\end{array}$ & $\begin{array}{c}\text { Time } \\
\text { days }\end{array}$ & $\begin{array}{c}\text { PCE conc. } \\
\text { mM }\end{array}$ & $\begin{array}{c}\text { Time } \\
\text { days }\end{array}$ & $\begin{array}{c}\text { PCE conc. } \\
\text { mM }\end{array}$ \\
\hline 5.6 & 0.138 & 5.6 & 0.140 & 5.6 & 0.142 & 5.6 & 0.127 \\
5.6 & 0.144 & 5.6 & 0.133 & 5.6 & 0.143 & 5.6 & 0.117 \\
5.6 & 0.142 & 5.6 & 0.144 & 5.6 & 0.150 & 5.6 & 0.128 \\
\hline
\end{tabular}

\begin{tabular}{rrrr}
\hline \multicolumn{2}{c}{ Exp.125 } & \multicolumn{2}{c}{ Exp. 126 } \\
Time & $\begin{array}{c}\text { PCE conc. } \\
\text { days }\end{array}$ & $\begin{array}{c}\text { Time } \\
\text { days }\end{array}$ & $\begin{array}{c}\text { PCE conc. } \\
\mathrm{mM}\end{array}$ \\
\hline 5.6 & 0.116 & 5.6 & 0.145 \\
5.6 & 0.118 & 5.6 & 0.137 \\
5.6 & 0.131 & & \\
\hline
\end{tabular}

\begin{tabular}{rrrrrrrr}
\hline \multicolumn{2}{c}{ Exp.127 } & \multicolumn{2}{c}{ Exp. 128 } & \multicolumn{2}{c}{ Exp. 129 } & \multicolumn{2}{c}{ Exp. 130 } \\
Time & $\begin{array}{c}\text { PCE conc. } \\
\text { days }\end{array}$ & $\begin{array}{c}\text { Time } \\
\text { mM }\end{array}$ & $\begin{array}{c}\text { days } \\
\text { PCE conc. } \\
\text { mM }\end{array}$ & $\begin{array}{c}\text { Time } \\
\text { days }\end{array}$ & $\begin{array}{c}\text { PCE conc. } \\
\text { mM }\end{array}$ & $\begin{array}{c}\text { Time } \\
\text { days }\end{array}$ & $\begin{array}{c}\text { PCE conc. } \\
\text { mM }\end{array}$ \\
\hline 5.8 & 0.158 & 5.8 & 0.163 & 5.8 & 0.139 & 5.8 & 0.157 \\
5.8 & 0.158 & 5.8 & 0.162 & 5.8 & 0.128 & 5.8 & 0.160 \\
5.8 & 0.156 & 5.8 & 0.157 & 5.8 & 0.141 & 5.8 & 0.156 \\
\hline
\end{tabular}

\begin{tabular}{rrrrrrrr}
\hline \multicolumn{2}{c}{ Exp.131 } & \multicolumn{2}{c}{ Exp. 132 } & \multicolumn{2}{c}{ Exp.133 } & \multicolumn{2}{c}{ Exp. 134 } \\
$\begin{array}{r}\text { Time } \\
\text { days }\end{array}$ & $\begin{array}{c}\text { PCE conc. } \\
\text { mM }\end{array}$ & $\begin{array}{c}\text { Time } \\
\text { days }\end{array}$ & $\begin{array}{c}\text { PCE conc. } \\
\text { mM }\end{array}$ & $\begin{array}{c}\text { Time } \\
\text { days }\end{array}$ & $\begin{array}{c}\text { PCE conc. } \\
\text { mM }\end{array}$ & $\begin{array}{c}\text { Time } \\
\text { days }\end{array}$ & $\begin{array}{c}\text { PCE conc. } \\
\text { mM }\end{array}$ \\
\hline 5.8 & 0.152 & 5.8 & 0.134 & 4.9 & 0.147 & 4.9 & 0.154 \\
5.8 & 0.144 & 5.8 & 0.136 & 4.9 & 0.160 & 4.9 & 0.120 \\
5.8 & 0.145 & 5.8 & 0.115 & 4.9 & 0.152 & 4.9 & 0.142 \\
\hline
\end{tabular}

\begin{tabular}{rrrrrrrr}
\hline \multicolumn{2}{c}{ Exp.135 } & \multicolumn{2}{c}{ Exp. 136 } & \multicolumn{2}{c}{ Exp.137 } & \multicolumn{2}{c}{ Exp. 138 } \\
$\begin{array}{r}\text { Time } \\
\text { days }\end{array}$ & $\begin{array}{c}\text { PCE conc. } \\
\text { mM }\end{array}$ & $\begin{array}{c}\text { Time } \\
\text { days }\end{array}$ & $\begin{array}{c}\text { PCE conc. } \\
\text { mM }\end{array}$ & $\begin{array}{c}\text { Time } \\
\text { days }\end{array}$ & $\begin{array}{c}\text { PCE conc. } \\
\text { mM }\end{array}$ & $\begin{array}{c}\text { Time } \\
\text { days }\end{array}$ & $\begin{array}{c}\text { PCE conc. } \\
\text { mM }\end{array}$ \\
\hline 4.9 & 0.144 & 4.9 & 0.138 & 4.9 & 0.118 & 4.9 & 0.129 \\
4.9 & 0.146 & 4.9 & 0.113 & 4.9 & 0.136 & 4.9 & 0.133 \\
4.9 & 0.160 & 4.9 & 0.147 & 4.9 & 0.157 & 4.9 & 0.129 \\
\hline
\end{tabular}


TABLE A-1 Continued

\begin{tabular}{rrrrrrrr}
\hline \multicolumn{2}{c}{ Exp.139 } & \multicolumn{2}{c}{ Exp. 140 } & \multicolumn{2}{c}{ Exp.141 } & \multicolumn{2}{c}{ Exp. 142 } \\
Time & $\begin{array}{c}\text { PCE conc. } \\
\text { days }\end{array}$ & $\begin{array}{c}\text { Time } \\
\text { days }\end{array}$ & $\begin{array}{c}\text { PCE conc. } \\
\text { mM }\end{array}$ & $\begin{array}{r}\text { Time } \\
\text { days }\end{array}$ & $\begin{array}{c}\text { PCE conc. } \\
\text { mM }\end{array}$ & $\begin{array}{r}\text { Time } \\
\text { days }\end{array}$ & $\begin{array}{c}\text { PCE conc. } \\
\text { mM }\end{array}$ \\
\hline 4.5 & 0.153 & 4.5 & 0.161 & 4.5 & 0.135 & 4.5 & 0.161 \\
4.5 & 0.145 & 4.5 & 0.158 & 4.5 & 0.138 & 4.5 & 0.165 \\
4.5 & 0.139 & 4.5 & 0.164 & 4.5 & 0.135 & 4.5 & 0.163 \\
\hline
\end{tabular}

\begin{tabular}{rrrr}
\hline \multicolumn{2}{c}{ Exp.143 } & \multicolumn{2}{c}{ Exp. 144 } \\
Time & $\begin{array}{c}\text { PCE conc. } \\
\text { days }\end{array}$ & $\begin{array}{r}\text { Time } \\
\text { days }\end{array}$ & $\begin{array}{c}\text { PCE conc. } \\
\text { mM }\end{array}$ \\
\hline 4.5 & 0.139 & 4.5 & 0.135 \\
4.5 & 0.133 & 4.5 & 0.150 \\
\hline
\end{tabular}

\begin{tabular}{rrrrrr}
\hline \multicolumn{2}{c}{ Exp.145 } & \multicolumn{2}{c}{ Exp. 146 } & \multicolumn{2}{c}{ Exp.147 } \\
Time & $\begin{array}{c}\text { PCE conc. } \\
\text { days }\end{array}$ & $\begin{array}{c}\text { Time } \\
\text { days }\end{array}$ & $\begin{array}{c}\text { PCE conc. } \\
\text { mM }\end{array}$ & $\begin{array}{r}\text { Time } \\
\text { days }\end{array}$ & $\begin{array}{c}\text { PCE conc. } \\
\text { mM }\end{array}$ \\
\hline 1.2 & 0.146 & 0.4 & 0.145 & 1.2 & 0.167 \\
1.2 & 0.146 & 0.4 & 0.142 & 1.2 & 0.174 \\
1.2 & 0.140 & 0.4 & 0.150 & 1.2 & 0.169 \\
2 & 0.128 & 0.5 & 0.0863 & 2 & 0.137 \\
2 & 0.127 & 0.5 & 0.0850 & 2 & 0.134 \\
2 & 0.128 & 0.5 & 0.0867 & 2 & 0.135 \\
2.9 & 0.106 & 0.8 & 0.0752 & 2.9 & 0.109 \\
2.9 & 0.115 & 0.8 & 0.0783 & 2.9 & 0.105 \\
2.9 & 0.100 & 0.8 & 0.0735 & 2.9 & 0.0986 \\
5 & 0.0963 & 1 & 0.0920 & 5 & 0.0559 \\
5 & 0.0852 & 1 & 0.0987 & 5 & 0.0505 \\
5 & 0.0856 & 1 & 0.0986 & 5 & 0.0506 \\
7.9 & 0.0595 & 3.8 & 0.0743 & 7.9 & 0.0190 \\
7.9 & 0.0686 & 3.8 & 0.0724 & 7.9 & 0.0178 \\
7.9 & 0.0553 & 3.8 & 0.0753 & 7.9 & 0.0186 \\
10 & 0.0366 & 6.9 & 0.0517 & 10 & 0.0063 \\
10 & 0.0436 & 6.9 & 0.0504 & 10 & 0.0064 \\
10 & 0.0388 & 6.9 & 0.0539 & 10 & 0.0071 \\
13.7 & 0.0206 & 10.9 & 0.0425 & 13.7 & 0.0052 \\
13.7 & 0.0206 & 10.9 & 0.0349 & 13.7 & 0.0049 \\
13.7 & 0.0236 & 10.9 & 0.0382 & 13.7 & 0.0054 \\
18.9 & 0.0141 & 16.3 & 0.0096 & 18.9 & 0.0027 \\
18.9 & 0.0108 & 16.3 & 0.0117 & 18.9 & 0.0035 \\
18.9 & 0.0128 & 16.3 & 0.0148 & 18.9 & 0.0028 \\
23.7 & 0.0040 & 20.4 & 0.0047 & 23.7 & 0.0009 \\
23.7 & 0.0029 & 20.4 & 0.0064 & 23.7 & 0.0012 \\
23.7 & 0.0031 & 20.4 & 0.0052 & 23.7 & 0.0011 \\
\hline & & & & &
\end{tabular}


TABLE A-1 Continued

\begin{tabular}{|c|c|c|c|c|c|}
\hline \multicolumn{2}{|c|}{ Exp.148 } & \multicolumn{2}{|c|}{ Exp. 149} & \multicolumn{2}{|c|}{ Exp. 150} \\
\hline $\begin{array}{l}\text { Time } \\
\text { days }\end{array}$ & $\begin{array}{c}\text { PCE conc. } \\
\text { mM }\end{array}$ & $\begin{array}{l}\text { Time } \\
\text { days }\end{array}$ & $\begin{array}{l}\text { PCE conc. } \\
\text { mM }\end{array}$ & $\begin{array}{l}\text { Time } \\
\text { days }\end{array}$ & $\begin{array}{c}\text { PCE conc. } \\
\mathrm{mM}\end{array}$ \\
\hline 0.96 & 0.196 & 0.96 & 0.1847 & 0.96 & 0.158 \\
\hline 0.96 & 0.197 & 0.96 & 0.1824 & 0.96 & 0.157 \\
\hline 0.96 & 0.189 & 0.96 & 0.1894 & 0.96 & 0.167 \\
\hline 1.8 & 0.181 & 1.8 & 0.1597 & 1.8 & 0.120 \\
\hline 1.8 & 0.164 & 1.8 & 0.1766 & 1.8 & 0.123 \\
\hline 1.8 & 0.182 & 1.8 & 0.1625 & 1.8 & 0.125 \\
\hline 2.8 & 0.151 & 2.8 & 0.1700 & 2.8 & 0.098 \\
\hline 2.8 & 0.167 & 2.8 & 0.1584 & 2.8 & 0.098 \\
\hline 2.8 & 0.151 & 2.8 & 0.1407 & 2.8 & 0.0993 \\
\hline 7.1 & 0.1244 & 7.1 & 0.1415 & 7.1 & 0.0772 \\
\hline 7.1 & 0.1138 & 7.1 & 0.1263 & 7.1 & 0.0706 \\
\hline 7.1 & 0.1356 & 7.1 & 0.1349 & 7.1 & 0.0673 \\
\hline 8.7 & 0.1028 & 8.7 & 0.0960 & 8.7 & 0.0472 \\
\hline 8.7 & 0.1006 & 8.7 & 0.0994 & 8.7 & 0.0460 \\
\hline 8.7 & 0.1007 & 8.7 & 0.0901 & 8.7 & 0.0455 \\
\hline 13.7 & 0.0780 & 13.7 & 0.0850 & 13.7 & 0.0354 \\
\hline 13.7 & 0.0829 & 13.7 & 0.0835 & 13.7 & 0.0366 \\
\hline 13.7 & 0.0876 & 13.7 & 0.0839 & 13.7 & 0.0365 \\
\hline 17.8 & 0.0392 & 17.8 & 0.0751 & 17.8 & 0.0299 \\
\hline 17.8 & 0.0385 & 17.8 & 0.0782 & 17.8 & 0.0260 \\
\hline 17.8 & 0.0333 & 17.8 & 0.0754 & 17.8 & 0.0320 \\
\hline 21.8 & 0.0329 & 21.8 & 0.0411 & 21.8 & 0.0194 \\
\hline 21.8 & 0.0276 & 21.8 & 0.0409 & 21.8 & 0.0212 \\
\hline 21.8 & 0.0355 & 21.8 & 0.0498 & 21.8 & 0.0173 \\
\hline 25.5 & 0.0195 & 25.5 & 0.0432 & 25.5 & 0.0150 \\
\hline 25.5 & 0.0209 & 25.5 & 0.0340 & 25.5 & 0.0188 \\
\hline 25.5 & 0.0235 & 25.5 & 0.0403 & 25.5 & 0.0187 \\
\hline 35.6 & 0.0099 & 35.6 & 0.0334 & 35.6 & 0.0094 \\
\hline 35.6 & 0.0103 & 35.6 & 0.0229 & 35.6 & 0.0098 \\
\hline 35.6 & 0.0109 & 35.6 & 0.0231 & 35.6 & 0.0086 \\
\hline
\end{tabular}


TABLE A-2 Changes in aqueous phase PCE concentration over time in the activity tests with the variation of $\mathrm{pH}$

\begin{tabular}{|c|c|c|c|c|c|c|c|}
\hline \multicolumn{2}{|c|}{ pH 10} & \multicolumn{2}{|c|}{$\mathrm{pH} 10.5$} & \multicolumn{2}{|c|}{ pH 11} & \multicolumn{2}{|c|}{ pH 11.5} \\
\hline $\begin{array}{l}\text { Time } \\
\text { days }\end{array}$ & $\begin{array}{l}\text { PCE conc. } \\
\text { mM }\end{array}$ & $\begin{array}{l}\text { Time } \\
\text { days }\end{array}$ & $\begin{array}{c}\text { PCE conc. } \\
\mathrm{mM}\end{array}$ & $\begin{array}{l}\text { Time } \\
\text { days }\end{array}$ & $\begin{array}{l}\text { PCE conc. } \\
\text { mM }\end{array}$ & $\begin{array}{l}\text { Time } \\
\text { days }\end{array}$ & $\begin{array}{l}\text { PCE conc. } \\
\text { mM }\end{array}$ \\
\hline 3 & 0.117 & 3 & 0.109 & 3 & 0.130 & 3 & 0.126 \\
\hline 3 & 0.133 & 3 & 0.126 & 3 & 0.109 & 3 & 0.123 \\
\hline 3 & 0.125 & 3 & 0.129 & 3 & 0.126 & 3 & 0.113 \\
\hline
\end{tabular}

\begin{tabular}{rrrrrrrr}
\hline \multicolumn{2}{c}{$\mathrm{pH} 12$} & \multicolumn{2}{c}{$\mathrm{pH} 12.5$} & \multicolumn{2}{c}{$\mathrm{pH} 13$} & \multicolumn{2}{c}{$\mathrm{pH} \mathrm{11.7}$} \\
$\begin{array}{r}\text { Time } \\
\text { days }\end{array}$ & $\begin{array}{c}\text { PCE conc. } \\
\mathrm{mM}\end{array}$ & $\begin{array}{c}\text { Time } \\
\text { days }\end{array}$ & $\begin{array}{c}\text { PCE conc. } \\
\mathrm{mM}\end{array}$ & $\begin{array}{r}\text { Time } \\
\text { days }\end{array}$ & $\begin{array}{c}\text { PCE conc. } \\
\mathrm{mM}\end{array}$ & $\begin{array}{c}\text { Time } \\
\text { days }\end{array}$ & $\begin{array}{c}\text { PCE conc. } \\
\mathrm{mM}\end{array}$ \\
\hline 3 & 0.141 & 3 & 0.144 & 3 & 0.139 & 3 & 0.134 \\
3 & 0.145 & 3 & 0.146 & 3 & 0.138 & 3 & 0.133 \\
3 & 0.142 & 3 & 0.140 & 3 & 0.147 & 3 & 0.137 \\
\hline
\end{tabular}




\section{APPENDIX B}

\section{COMPUTER PROGRAM (MATLAB) TO ESTIMATE PSEUDO FIRST-ORDER RATE CONSTANT FOR PCE DECHLORINATION}

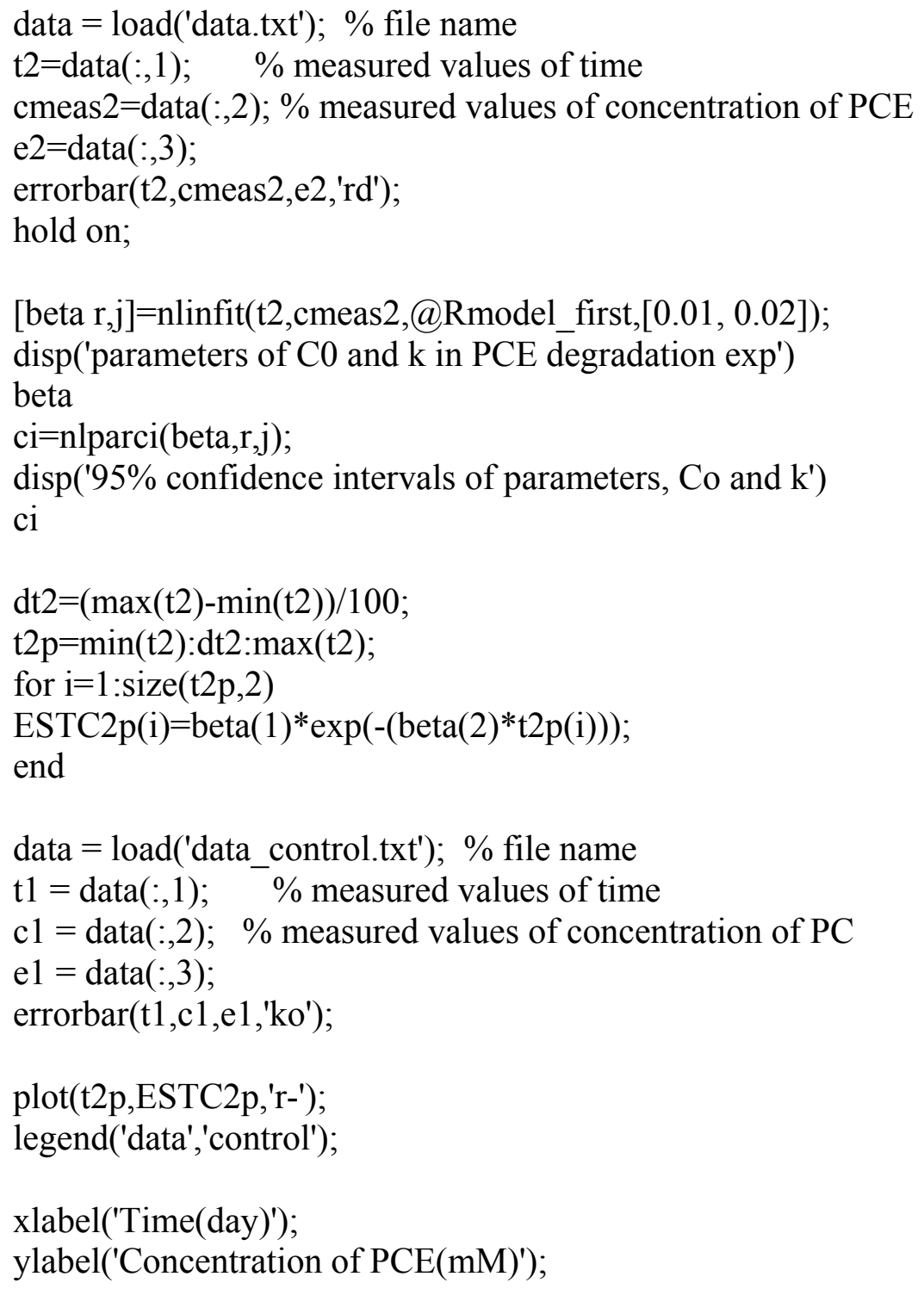




\section{APPENDIX C}

\section{COMPUTER PROGRAM (MATLAB) TO ESTIMATE SECOND-ORDER RATE CONSTANT FOR PCE DECHLORINATION}

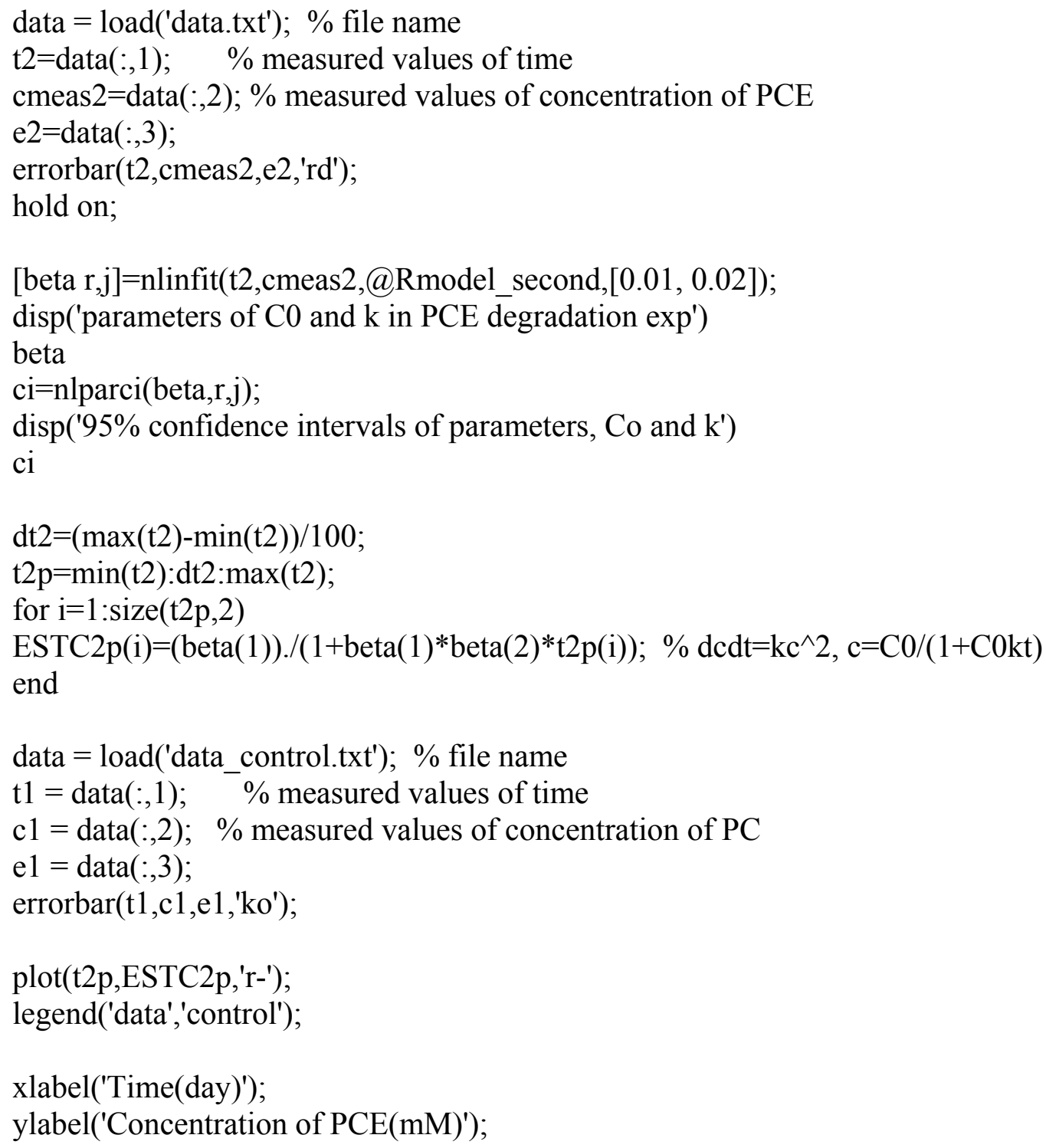




\section{VITA}

Sae Bom Ko was born in Inchon, Korea. She grew up in Seoul, Korea. She received a Batchelor of Science degree in chemistry at Dongguk University in February, 1993 and a Master of Science degree in civil engineering at Texas A\&M University in December, 2001. She started her Ph.D program at Texas A\&M University in 2002. Her research has been focused on remediation of soils contaminated with chlorinated organic compounds that are degraded by reductants, such as Fe(II). Her research interested includes chlorinated organic compounds transformation kinetics and their transformation mechanism by reductive dechlorination. Her permanent address is 482 Kaebong-2-dong Hyundae Apartment \#106-2201, Guro-Gu, Seoul, Korea, 152-755. 